\title{
Untersuchung des transkriptionellen Mechanismus der Igf2-Überexpression in Patched-assoziierten Tumoren
}

\author{
Dissertation \\ zur Erlangung des Doktorgrades \\ der Mathematisch-Naturwissenschaftlichen Fakultäten \\ der Georg-August-Universität zu Göttingen
}

vorgelegt von

Regine Bauer aus Meerane

Göttingen 2006 
D7

Referent:

Professor Dr. W. Engel

Korreferent:

Privatdozentin Dr. S. Hoyer-Fender

Tag der mündlichen Prüfung: 
Diese Arbeit wurde an der Georg-August-Universität, Institut für Humangenetik Direktor: Prof. Dr. Wolfgang Engel durchgeführt. 


\section{Ohne Begeisterung}

schlafen die besten Kräfte unseres Gemüts.

Es ist Zunder in uns, der Funken will.

Herder 


\section{Inhaltsverzeichnis}

1. Einleitung ...........................................................................................................5

1.1. Die Entstehung von Krebs ...................................................................................5

1.2. Der Sonic hedgehog-Signalweg und seine Bedeutung während der

Embryogenese und Tumorigenese ..................................................................... 7

1.2.1. Das Tumorsuppressorgen PTCH und seine Rolle in der Tumorentstehung.................... 9

1.2.2. Ein Tiermodell für $S h h / P t c h$-assoziierte Tumoren ....................................................... 10

1.2.2.1. Heterozygote Ptch-Mäuse entwickeln Rhabdomyosarkome (RMS).............................. 11

1.2.2.2. Igf2 und seine Rolle in der Tumorentstehung und Tumorwachstum .............................. 12

1.2.2.3. Überexpression des Igf2 in Ptch-assoziierten RMS.......................................................... 14

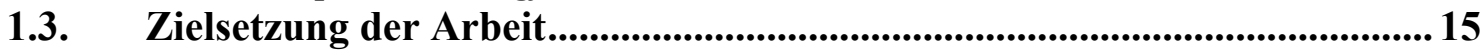

2. Material und Methoden ................................................................16

2.1. Material ..............................................................................................................16

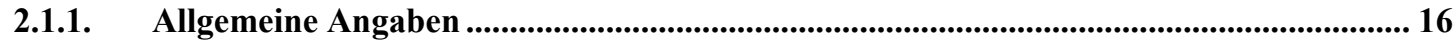

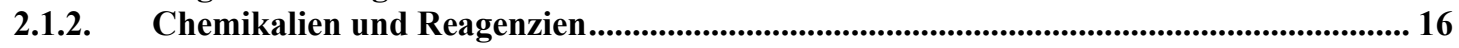

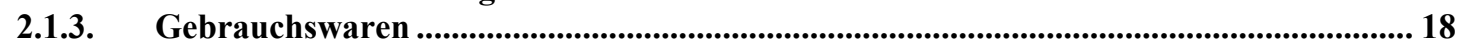

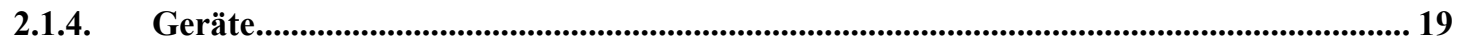

2.1.5. Gebrauchsfertige Reaktionssysteme......................................................................................... 22

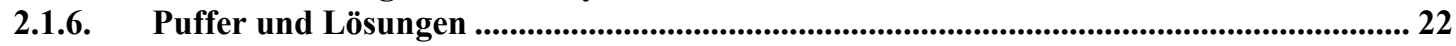

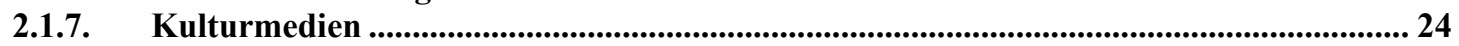

2.1.7.1. Flüssigmedien für Escherichia coli und Medienzusätze ................................................ 24

2.1.7.2. Flüssigmedien für eukaryotische Zellinien und Medienzusätze .................................... 26

2.1.8. Biologisches Material und Organismen .............................................................................26

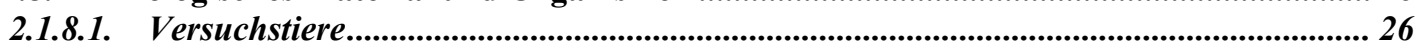

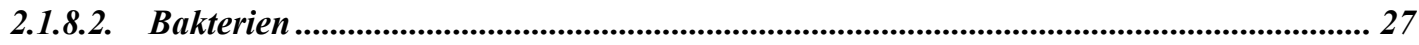

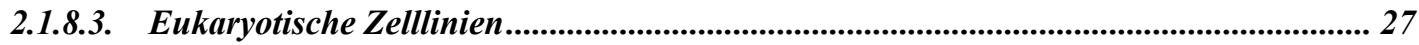

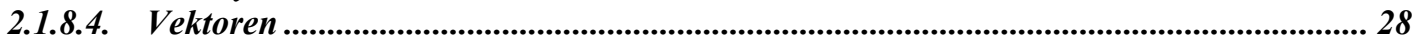

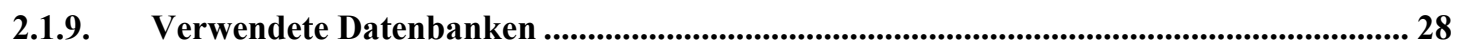

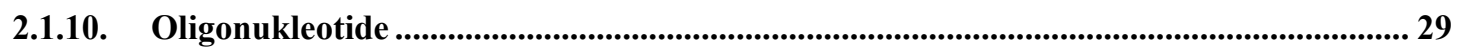

2.2. Methoden .................................................................................................... 35

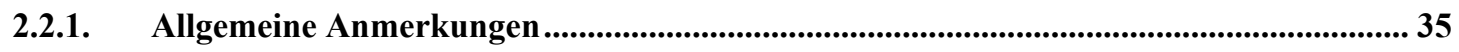

2.2.2. Präparative und analytische Arbeiten mit Nukleinsäuren .............................................. 36

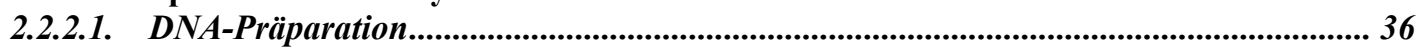

2.2.2.1.1. Minipräparation von Plasmid-DNA …................................................................ 36

2.2.2.1.2. Minipräparation von Cosmid-DNA ................................................................... 36

2.2.2.2. Konzentrationsbestimmung von Nukleinsäuren in Lösung .......................................... 37

2.2.2.3. DNA-Quantifizierung über PicoGreen ${ }^{\circledR}$-Reagent.......................................................... 37

2.2.2.4. Agarosegelelektrophorese ........................................................................................... 38

2.2.2.5. Isolierung von DNA-Fragmenten aus Agarosegelen PCI-und CI-Extraktion ................ 38

2.2.2.6. Phenol-Chloroform-Extraktion .................................................................................................... 38

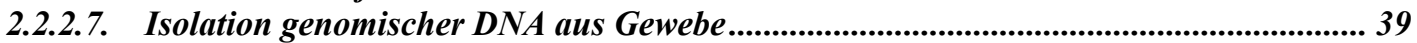

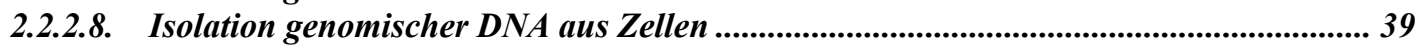

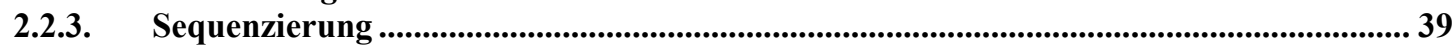

2.2.3.1. Aufreinigung der Sequenzierprodukte ...................................................................... 40

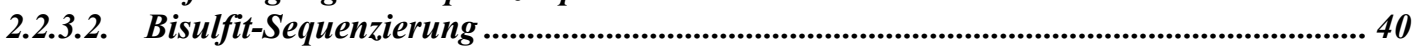

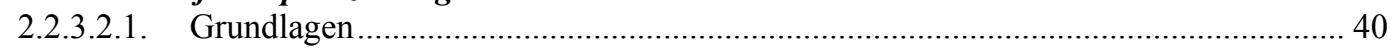

2.2.3.2.2. Computergestützte Analyse des Methylierungsstatus der zu untersuchenden DNA-

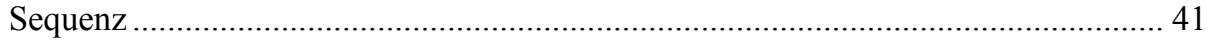

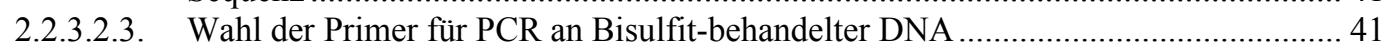

2.2.3.2.4. Auswahlkriterien der Oligonukleotide .............................................................. 42

2.2.3.2.5. Behandlung der DNA mit Bisulfit....................................................................... 42 
2.2.3.2.6. Aufreinigung der Bisulfit-behandelten DNA ...................................................... 43

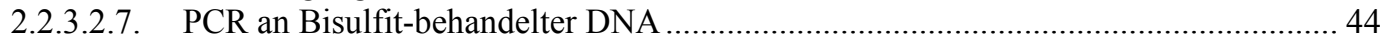

2.2.3.2.8. Sequenzierung von Bisulfit-behandelter DNA ...................................................... 45

2.2.4. Klonierung von DNA-Fragmenten ........................................................................ 46

2.2.4.1. Vektorpäparation und Dephosphorylierung von Vektor-DNA..................................... 46

2.2.4.2. Präparation von Restriktionsfragmenten ............................................................................. 46

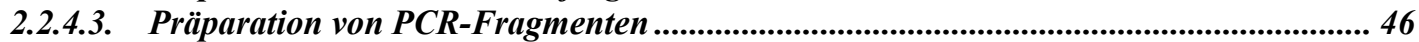

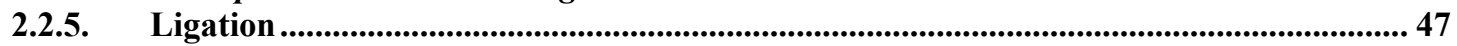

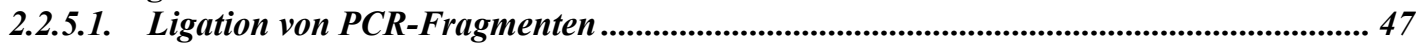

2.2.5.2. Ligation mit T4-DNA-Ligase .................................................................................... 47

2.2.5.3. Transformation von kompetenten E. coli-Zellen (nach Hanahan, 1983)...................... 47

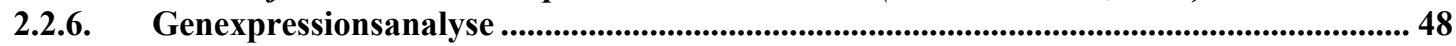

2.2.6.1. Gewebepräparation und Homogenisierung ............................................................. 48

2.2.6.2. RNA Isolierung aus Gewebe................................................................................. 48

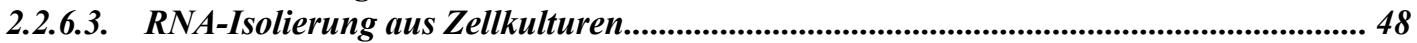

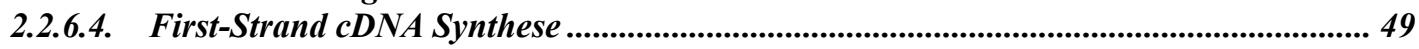

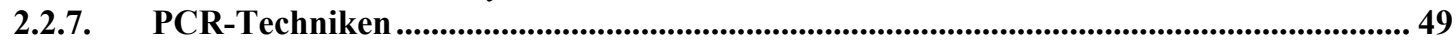

2.2.7.1. Quantitative real-time QRT-PCR ........................................................................50

2.2.7.1.1. Quantifizierung der endogenen Igf2-Expression über quantitative real-time QRT-PCR

2.2.7.1.2. Quantifizierung der $18 \mathrm{~S}$ rRNA als endogene Kontrolle über quantitative real-time

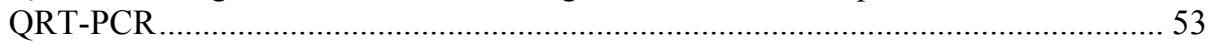

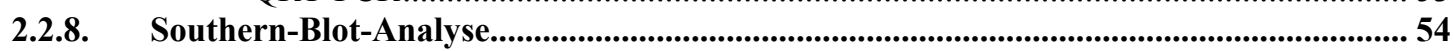

2.2.8.1. Vorbereitung der Proben und Gelelektrophorese ....................................................... 54

2.2.8.2. DNA-Transfer auf Nylon-Membranen.................................................................. 54

2.2.8.3. Herstellen radioaktiv markierter DNA-Sonden ........................................................... 55

2.2.8.4. Radioaktive Hybridisierung von Southern-Blots ......................................................... 55

2.2.8.5. Strippen der hybridisierten DNA-Nylon-Membranen .............................................56

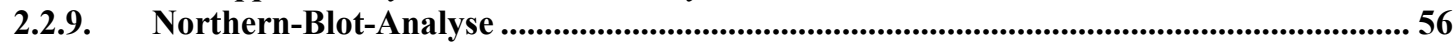

2.2.9.1. Denaturierende RNA-Gelelektrophorese .............................................................56

2.2.9.2. Probenvorbereitung und Elektrophorese ...................................................................56

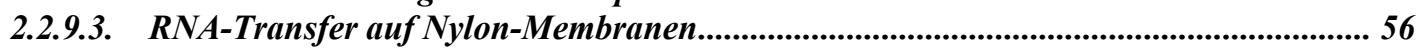

2.2.9.4. Radioaktive Hybridisierung von Northern-Blots ....................................................... 5 57

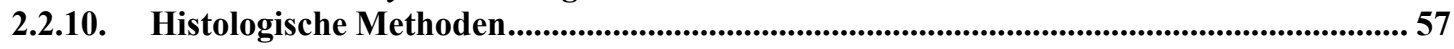

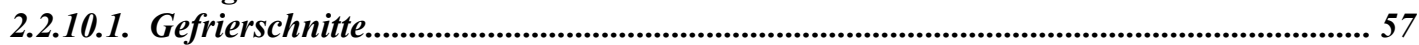

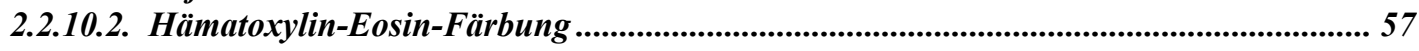

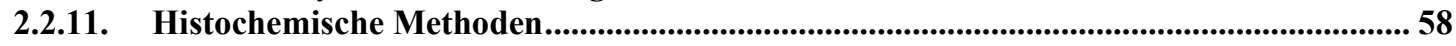

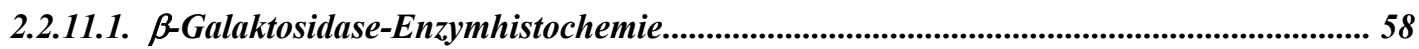

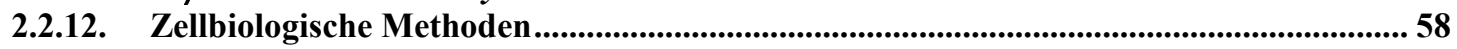

2.2.12.1. Zellkultur eukaryotischer Zellinien............................................................................58

2.2.12.2. Kryokonservierung und Revitalisierung von eukaryotischen Zelllinien......................... 58

2.2.12.3. Transiente Transfektionen eukaryotischer Zelllinien .................................................... 59

2.2.12.3.1. Transiente Transfektion von NIH/ 3T3- und C2C12-Zellen mit Roti ${ }^{\circledR}$-Fect-Reagenz

2.2.12.3.2. Transiente Transfektion von Cosmiden in NIH/ 3T3-Zellen mit TransFectin ${ }^{\mathrm{TM}}$ -

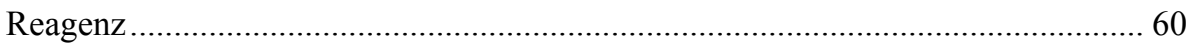

2.2.12.3.3. Transiente Transfektion von TP5014- und TP1588-Zellen mit Oligofectamin ${ }^{\mathrm{TM}}$.... 60

2.2.13. Reportergenanalysen ...........................................................................................................61 61

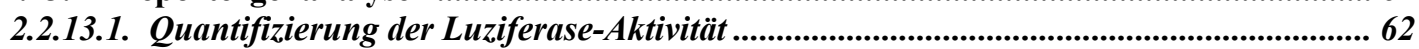

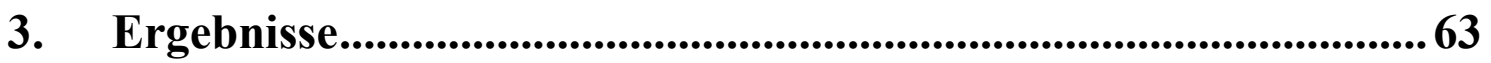

3.1. Untersuchung der Igf2-Transkripte in Ptch-assoziierten Tumoren ............ 63

3.1.1. Analyse der Igf2-Transkripte in RMS im Northern-Blot........................................... 64

3.1.2. Untersuchung der Aktivierung der vier Igf2-Promotoren in RMS mittels semiquantitativer RT-PCR.

3.1.2.1. Untersuchung der durch P1-, P2- und P3-regulierten Igf2-Spleißvarianten .................. 66 
3.1.2.2. Untersuchung der durch P0-regulierten Igf2-Spleißvarianten ........................................ 68

3.2. Untersuchung der endogenen Ig 2 -Expression in der RMS-Zelllinie TP5014 nach Behandlung mit 5-Aza-Cytidin ............................................... 70

3.3. Untersuchungen der Methylierungsveränderungen in den DMRs des Ig $\boldsymbol{f}$ Gens in Ptch-assoziierten Tumoren im Southern-Blot................................ 71

3.3.1. Untersuchung der Methylierung der DMR2-Region des Igf2-Gens................................... 72

3.3.2. Untersuchung der Methylierung der DMR0 und DMR1 des Igf2-Gens ........................... 77

3.3.2.1. Analyse der DMR0 im methylierungssensitiven Southern-Blot mit Hybridisierungssonde 1 ............................................................................................ 78

3.3.2.2. Analyse der DMR1 im methylierungssensitiven Southern-Blot mit Hybridisierungssonde 2 ..................................................................................................... 82

3.3.2.3. Analyse der DMR1 im methylierungssensitiven Southern-Blot mit Hybridisierungssonde 3 und 4 ....................................................................................... 84

3.3.2.4. Analyse der DMR1 im methylierungssensitiven Southern-Blot mit Hybridisierungssonde 5 .

3.4. Untersuchungen der Methylierung der H19-DMD-Region............................ 93

3.5. Untersuchung der Methylierung der Cytosine der DMRs über Bisulfit-

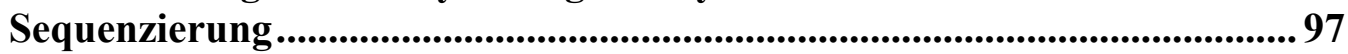

3.5.1. Bestimmung der Effizienz der Bisulfitbehandlung ............................................................. 98

3.5.2. Analyse der Methylierungsveränderungen der DMR2 mittels Bisulfit-Sequenzierung 98

3.5.2.1. Sequenzanalyse der DMR2 im Exon 6........................................................................ 98

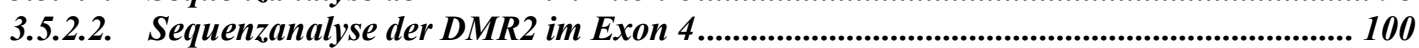

3.5.3. Analyse der Methylierungsveränderungen in der DMR1 über Bisulfit-Sequenzierung

3.5.3.1. Sequenzanalyse der DMR1 ...................................................................................... 102

3.6. Untersuchung des Einflußes von Gli-Transkriptions-faktoren auf die Igf2-

Expression.................................................................................................. 104

3.6.1. Identifikation von Gli-Bindungsstellen im Igf2-Lokus ............................................. 104

3.6.2. Untersuchung der Gli-Expression in RMS von heterozygoten Ptch-Mäusen und

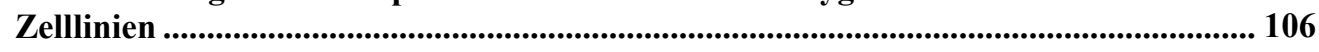

3.6.3. Untersuchung des Einflußes der Gli Transkriptionsfaktoren auf die endogene Expression vom Igf2 in Zellkultur mittels QRT-PCR Analyse................................... 107

3.6.3.1. QRT-PCR -Analyse der durch Gli1 und/oder Gli3-induzierten Igf2-Expression in C2C12-Zellen ................................................................................................................................. 108

3.6.3.2. QRT-PCR -Analyse der durch Gli1 und/ oder Gli3-induzierten Igf2-Expression in TP1588 und TP5014-Zellen.................................................................................................. 109

3.6.3.3. QRT-PCR -Analyse der durch Gli1 und/ oder Gli3-induzierten Igf2-Expression in NIH/ 3T3-Zellen.

3.6.3.4. QRT-PCR -Analyse der durch Gli2-induzierten Igf2-Expression in C2C12, TP-1588, TP-5014 und NIH/ 3T3-Zellen ................................................................................. 111

3.6.4. Analyse der Funktionalität der Gli-Bindungsstelle 4 des Igf2-Lokus im $\beta$-GalaktosidaseReporter-Assay...

3.6.5. Analyse der Funktionalität der Gli-Bindungsstelle 4 des Igf2-Lokus im LuziferaseReporter-Assay. 113

4. Diskussion.

4.1. Ein bisher nicht identifizierter Mechanismus bedingt die Überexpression des paternalen Igf2-Allels in Ptch-assoziierten RMS................................. 118

4.1.1. Aktivierung der IGF2/Igf2-Expression bei der Tumorentstehung .................................. 118

4.1.2. Die Rolle von IGF2/ Igf2 in Ptch-assoziierten Tumoren ................................................ 119

4.1.3. Die Überexpression des Igf2-Gens in Ptch-assoziierten Tumoren wird weder durch LOI des maternalen Allels, noch durch uniparentale Disomie, Polyploidie oder Genamplifikation hervorgerufen. 
4.2. Aktivität von drei Promotoren führt zu Igf2-Überexpression in Ptchassoziierten RMS

4.3. Die Igf2-Expression der RMS-Zelllinie TP5014 ist methylierungssensitiv 122

4.4. Methylierungssensitive Regionen im Igf2-Lokus zeigen aberrante

Methylierung in RMS.

4.4.1. Die H19-DMD von $I g f 2$ und $H 19$ weist keine Methylierungsveränderungen im RMS auf

Die DMR0 weist keine Methylierungsveränderungen im RMS auf

Die DMR1-Region weist signifikante Methylierungsveränderungen im RMS auf 125

4.4.4. Die DMR2-Region weist signifikante Methylierungsveränderungen im RMS auf ....... 127

4.5. Konsensus-Sequenzen im Igf2-Lokus weisen auf eine Gli-vermittelte

Transkription hin

4.5.1. Gli-Transkriptionsfaktoren und ihre Rolle als Mediatoren des Shh- Signalweges in der Tumorigenese

4.5.2. Der Igf2-Lokus enthält Gli-Konsensus-Sequenzen .............................................................. 131

4.6. Ptch-assoziierte RMS zeigen eine Überexpression von Gli1 und Gli3 ....... 131

4.7. Gli1/ Gli3-Kombination führt zu einem Anstieg der Expression des Igf2Gens in vitro

4.7.1. Igf2-Expression kann durch Ko-Expression von Gli1 und Gli3 in den Zelllinien C2C12, TP1588, TP5014 und NIH/ 3 T3 stimuliert werden

4.7.2. Ein 8.1 kb Fragment stromaufwärts des Igf2-Translationsstarts ist notwendig für die

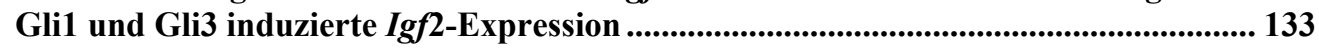

4.7.3. Induktion von Igf2 durch Gli1 und Gli3 wird nicht nur über die Gli-Bindungsstelle im Intron 3 vermittelt...

4.8. Verschiedene Mechanismen verdichten sich zu einem Modell der Igf2Überexpression in RMS

4.9. Zusammenfassung der Arbeit ................................................................... 137

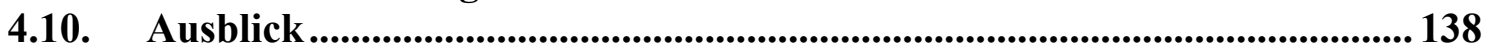

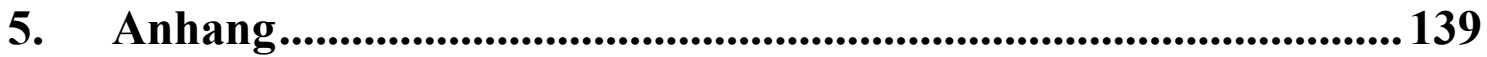

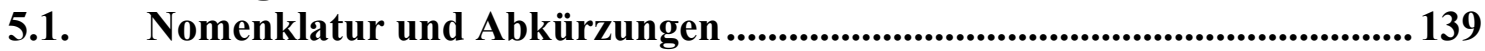

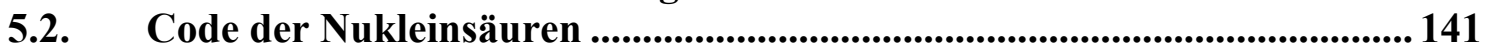

6. Literaturverzeichnis .....................................................................142

$\begin{array}{ll}\text { Danksagung } & 160\end{array}$

$\begin{array}{ll}\text { Lebenslauf } & 161\end{array}$ 


\section{Einleitung}

Im zweiten Jahrhundert nach Christus beschrieb Galenus, der römische Gelehrte und Leibarzt der Kaiser Commodus und Septimus Severus, die geschwollenen Venen eines äußeren Tumors. Durch die große Ähnlichkeit dieser Venenstruktur mit den Beinen von Krebstieren wurde Galenus zur Wahl des Begriffes „Krebs“ inspiriert. Seitdem werden alle bösartigen Gewebswucherungen als Krebs bezeichnet, bei denen das entartete Gewebe gesundes Gewebe infiltriert und Tochtergeschwüre (Metastasen) in entlegene Körperregionen entsendet.

\subsection{Die Entstehung von Krebs}

Jedes gesunde Gewebe verfügt über eine fein regulierte Balance zwischen Zellteilung und programmiertem Zelltod (Apoptose). Wird diese Balance gestört, kann das zur Entstehung von Krebs führen. Auch die Fähigkeit eines Gewebes, sich von Nachbargeweben abzugrenzen, geht in krebsartig verändertem Gewebe verloren.

Um einer solchen Entartung entgegen zu wirken, verfügen multizelluläre Organismen über ein breites Repertoire genetisch gesteuerter Mechanismen, welche das Gewebewachstum, den Gewebeabbau und die Gewebeintegrität regulieren. Viele dieser Mechanismen sind redundant angelegt, so daß selbst der Ausfall einzelner Mechanismus keine phänotypischen Auswirkungen hat. Erst der Ausfall mehrerer solcher Kontrollmechanismen, der oft sukzessiv, über einen langen Zeitraum und über mehrere Generationen von Zellen erfolgt, kann zur Ausbildung eines bösartigen Tumors führen. Es wird davon ausgegangen, daß mehr als sechs Einzelmutationen vorliegen müssen, bevor eine Zelle zur Krebszelle wird (Armitage und Doll, 1954). Die letzte Veränderung in dieser Kette von Ereignissen wirkt wie eine Art Initialzündung. Die Abkömmlinge der betroffenen Zelle können neue Eigenschaften ausbilden, darunter die Fähigkeit, aus dem Verband auszuscheren, sich in anderen Geweben anzusiedeln, unter Sauerstoffmangel $\mathrm{zu}$ überleben und eine eigene Blutversorgung aufzubauen. Sind Gene betroffen, die eigentlich die Apoptose auslösen müssten (z. B. Trp53), so werden die Zellen unsterblich. Erst durch solche Phänome gewinnt der Krebs seine tödliche Potenz (Übersichtsartikel in „Molekulare Humangenetik“, Strachan und Read, 1996).

Etwa 5000 der 25000 bekannten Gene des Menschen sind an der Konstanterhaltung des genetischen Kodes von einer Zellgeneration zur nächsten beteeiligt (www.wikipedia.de). Die durch diese Gene kodierten Proteine haben die Funktion, nach jeder Duplikation die korrekte 
Abfolge der Basenpaare in der DNA zu überprüfen und gegebenenfalls Reparaturvorgänge oder den programmierten Zelltod einzuleiten (Hanahan und Weinberg, 2000). Durch das Fehlschlagen dieser Reparaturmechanismen, das Überhandnehmen DNA-schädigender Mechanismen (z. B. UV-Strahlung, kanzerogene Chemikalien) und teils auch durch angeborene Gendefekte können Mutationen im Genom entstehen, welche die Transformation einer Zelle zur Krebszelle zur Folge haben (Tumorigenese).

Die Art und Weise, wie eine Genmutation zur Krebsentstehung beiträgt, kann sehr verschieden sein. So kann durch eine Mutation die Aktivität eines Proteins verloren gehen, welches normalerweise ein unkontrolliertes Zellwachstum verhindert (z. B. Ptch, Trp53, Ccdnk2a, Vhl; Tumorsuppressorgene). Andererseits können Mutationen aber auch zum Zugewinn von Genaktivität und einer Inbalance der Gendosis führen, die ebenfalls als eine Ursache der Krebsentstehung angesehen wird. Die daran beteiligten Gene werden als Onkogene bezeichnet (z. B. H-ras, jun, fos, N-myc, T-Antigen, Gli). Häufig führt die veränderte Aktivität der Tumorsuppressorgene und Onkogene zur aberranten Aktivierung oder Abschaltung von Signalwegen in der Zelle. Zum Beispiel zeigen Tumorzellen oft eine pathologische Aktivierung von Signalwegen, die unter physiologischen Bedingungen nur während der frühen Embryonalentwicklung aktiv sind. Eine mutationsbedingte Fehlregulation dieser Signalwege erlaubt es, den Tumorzellen unkontrolliert zu wachsen und der Zellzykluskontrolle zu entgehen (Macaluso et al., 2005).

Die aberrante Aktivierung oder Abschaltung von Signalwegen führt häufig zu veränderter Genexpression in den betroffenen Zellen. Dafür kann einerseits die veränderte Aktivität von Transkriptionsfaktoren verantwortlich sein. Oft kommt es aber auch zu Änderungen in der Chromatinstruktur bestimmter Genomabschnitte. Beispielsweise können Veränderungen im Methylierungszustand und im Grad der Histonazetylierung genregulatorischer Abschnitte zu einer veränderten Transkriptionsrate der betroffenen Gene führen (epigenetische Modifikationen, Reik und Dean, 2001b). Sowohl die veränderte Aktivität von Transkriptionsfaktoren, als auch die epigenetischen Veränderungen können in tumorigene Prozesse involviert sein. Auf einen Signalweg, dessen aberrante Aktivierung bei vielen Krebsarten von Bedeutung ist, soll im Folgenden eingegangen werden. 


\subsection{Der Sonic hedgehog-Signalweg und seine Bedeutung während der Embryogenese und Tumorigenese}

Eine essentielle Rolle in der Kontrolle der frühen Embryonalentwicklung nimmt ein Signalweg ein, an dem die Proteine Sonic hedgehog (Shh) ${ }^{1}$, Patched (Ptch) und Gli beteiligt sind (ShhSignalweg; Nüsslein-Volhard und Wieschaus 1980; Lee et al., 1992). Im Vertebratenembryo wird das Shh-Gen im Notochord, in der Grundplatte des Neuralrohrs, in der Zone polarisierender Aktivität der entstehenden Gliedmaßen und im Darm exprimiert (Oden et al., 1999, Mohler et al., 1992; Marigo et al., 1996c; Marigo et al., 1996d). Shh induziert eine gewebespezifische Zellproliferation und ist somit maßgeblich an der Entwicklung verschiedener Zelltypen und Organe, wie Gehirn, Knochen, Haut, Lunge und Gonaden beteiligt (Ruiz i Altaba et al., 2002a). In vielen dieser Gewebe wirkt das sezernierte Protein als Morphogen. So im ventralen Neuralrohr und der Extremität, wo ein Shh-Gradient nachgewiesen werden konnte und zur embryonalen Musterbildung beiträgt (Ho und Scott, 2002; Zeller, 2004). Genetische, biochemische und molekulare Analysen in Insekten und Vertebraten zeigen, daß die Transduktion des Shh-Signals von der Zellmembran bis zum Zellkern über 300 Millionen Jahre konserviert wurde (Ruiz i Altaba, 1999a).

Bei der Signaltransduktion bindet sezerniertes Shh-Protein zunächst an seinen membranständigen Rezeptor Patched (Ptch). Ptch inhibiert normalerweise seinen Ko-Rezeptor Smoothend (Smo), indem es einen Membrankomplex mit ihm ausbildet. Durch die Bindung von Shh an Ptch wird die reprimierende Wirkung auf Smo aufgehoben und eine komplexe Signalkaskade ausgelöst (Taipale et al., 2000; Tabata et al., 2001; Ho und Scott 2002; Abb. 1).

Das Tumorsuppressorgen Ptch kodiert ein Transmembranprotein, welches die Funktion eines negativen Regulators des Shh-Signals ausübt. Das Glycoprotein umfaßt zwölf hydrophobe amino- und carboxy-terminale Regionen und zwei hydrophile extrazelluläre Schleifen, die die Bindungsdomäne des sezernierten Shh-Liganden darstellen (Hooper und Scott et al., 1989; Marigo et al., 1996a). Ptch spielt eine duale Rolle in der Sequestration und Transduktion des Shh (Chen und Struhl, 1996). Im Falle einer Deletion durch Mutationen der zweiten sekundären Schleife des Ptch, die essentiell für die Bindung des Liganden Shh ist, geht die Interaktion zwischen Rezeptor und Ligand verloren. Die Repression von Smo durch Ptch wird davon aber nicht beeinflußt (Briscoe et al., 2001). Mutationen in Ptch, die zu einer Trunkierung des CTerminus führen, resultieren in der Inhibierung von Smo und einer Aktivierung des Signalweges, aber das Bindungspotential zum Liganden bleibt unbeeinträchtigt (Johnson et al., 2000).

\footnotetext{
${ }^{1}$ Shh: Sonic hedgehog nach dem Helden eines Videofilms und nach dem englischen Wort für Igel
} 
Mutationen sowohl in $P T C H$ als auch in $S H H$ führen beim Menschen zur Ausbildung von Holoprosenzephalie (Roessler et al., 1996; Nanni et al., 1999; Ming et al., 2002). Des Weiteren konnten Mutationen in $P T C H$ in einer großen Anzahl von Tumoren identifiziert werden. Hierzu gehören Basalzellepitheliome (Basaliom, semimaligner Tumor der Haut), Medulloblastome (Hirntumore), Meningeome (benigner Tumor von den Meningen des Gehirns und Rückenmarks), Rhabdomyosarkome (Weichteilsarkom), neuroektodermale Tumoren, Trichoepitheliome (benigner Tumor der Haarwurzelscheide) und Brustkarzinome (Cohen, 1999).

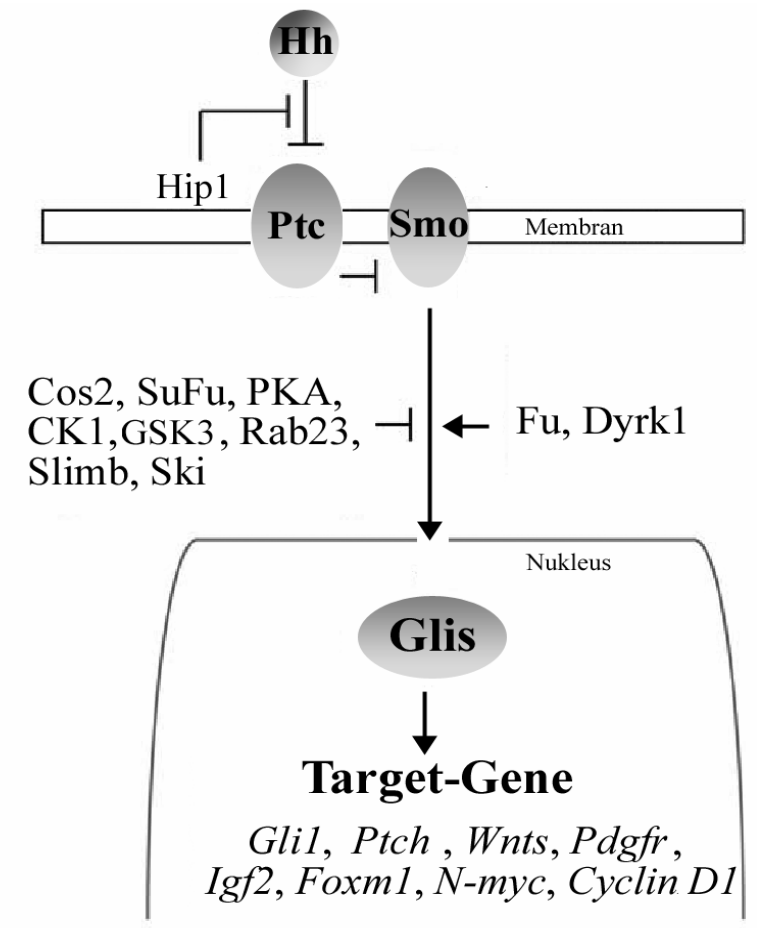

\begin{abstract}
Abb. 1: Schematische Darstellung des Shh-Signalweges in Vertebraten und involvierte Faktoren. Cholesterol-modifiziertes Shh wird oligomerisiert und sezerniert. Zielzellen mit dem membranständigen Rezeptor Ptch binden den Liganden Shh. Die Bindung kann durch Hip1 inhibiert werden. Smo-Repression durch Ptch wird aufgehoben und initialisiert eine komplexe Signalkette, in die Proteinkomplexe involviert sind. Repressoren des Shh-Signals sind: Cos2, SuFu, PKA, CK1, GSK3, Rab23, Slimb und Ski. Fu und Dyrk1 fungieren als Aktivatoren des ShhSignals. Mediatoren des Shh-Signals sind die Proto-Onkogene der GliFamilie. Sie kodieren für Zink-FingerTranskriptionsfaktoren und wirken im Nukleus auf die Expression von Zielgenen ein, wie Gli1, Ptch, Wnts, Pdgfra, Foxm1, N-myc, Cyclin D1 und $\operatorname{Igf} 2$.
\end{abstract}

Smo kodiert ein Transmembranprotein und übt die Funktion eines positiven Regulators des Shh-Signals in der Zelle aus. Das Protein umfaßt sieben hydrophobe transmembrane Domänen, eine extrazelluläre amino-terminale Region und eine intrazelluläre carboxy-terminale Domäne. Der Aufbau des Proteins zeigt Homologien zu G-Protein gekoppelten Rezeptoren und FrizzledProteinen, die Rezeptoren des Wnt-Liganden darstellen (Alcedo et al., 1996; van den Heuvel und Ingham, 1996).

Viele Faktoren sind in die Signalkaskade und die Modulation des Shh-Signals im Zytoplasma und im Kern involviert (siehe Abb. 1). Costal 2 (Cos2), Fused (Fu) und der Supressor von Fused $\mathrm{Su} \quad(\mathrm{Fu}) \quad(\mathrm{SuFu})$ regulieren die nukleäre Transkription und Aktivität der GliTranskriptionsfaktoren (Ruiz i Altaba, 1999b; Ho und Scott, 2002; Nybakken und Perrimon, 
2002). Ebenfalls im Signalweg involvierte Faktoren sind Rab23, Dyrk1, Protein Kinase A (PKA), Glykogen Synthase Kinase 3 (GSK3), Casein Kinase 1 (CK1), Slimb, SAP18, DCBP und Hip (Taipale et al., 2000; Tabata et al., 2001; Ho und Scott 2002; Chuang und McMahon et al., 1999; Eggenschwiler et al., 2001).

Das Segmentpolaritätsgen Cubitus interruptus (Ci), ein Zink-Finger-Gen in Drosophila, wurde als orthologes Gen der Gli-Gene in Vertebraten identifiziert (Übersichtsartikel in „Molecular Biology of the Cell“, Alberts et al., 2002). Die fünf-Zink-Finger-Proteine enthalten verschiedene Bindungsmotife wie z. B. Su (Fu)-Bindungsdomäne (SF), Zink-Finger-DNABindungsdomäne (ZF), nukleäres Lokalisierungssignal (NLS), nukleäres Export Signal (NES), Protein Kinase A (PKA) Phosphorylierungsregionen (P), Cos2 Bindungsdomänen (CORD), CREB Bindungsprotein-Domänen (CBP; Wang et al., 2000; Ko et al., 2002). Gli Zink-FingerTranskriptionsfaktoren stellen die direkten Übermittler der Aktivierung der Shh-Signalkaskade dar (Kinzler et al., 1987; Matsumoto et al., 1996). Die Aktivität der multifunktionalen ProtoOnkogene Gli ist gewebespezifisch reguliert. Dabei können sie sowohl als Aktivatoren als auch als Repressoren ihrer Zielgene wirken (Ruiz it Altaba et al., 1999b; Ohlmeyer et al., 1998; Sasaki et al., 1999; Bai et al., 2002). Auf Grund ihrer redundanten Wirkung wird vermutet, daß die Gli-Faktoren in Kombination gewebespezifisch miteinander interagieren (Ruiz i Altaba, 2002b; Ruiz i Altaba, 1999c; Marigo et al., 1996b). Als Zielgene des Shh-Signals wurden die Gene $W n t^{2}, B m p^{3}, P d g f \alpha^{4}, I g f 2^{5}$ und Ptch identifiziert (Cohen, 2003; Dai et al., 1999; Polakis, 2000; Hahn et al., 2000).

\subsubsection{Das Tumorsuppressorgen $P T C H$ und seine Rolle in der Tumorentstehung}

PTCH wird als ein Tumorsuppressorgen angesehen, da es einen inhibitorischen Effekt auf die Transkription von Genen ausübt, die an der Regulierung der Zellteilung beteiligt sind (Hahn et al., 1999). In der Gruppe der Tumorsuppressorgene werden die Gene zusammengefaßt, die durch die Unterdrückung der Zellteilung auch das Wachstum eines Tumors hemmen (TumorSuppression; Weinberg, 1991). Mutationen in einem Allel des Tumorsuppressorgens verhalten sich auf zellulärer Ebene rezessiv. Erst der Funktionsverlust beider Allele führt zu unkontrollierter Zellteilung und Tumorwachstum (Knudson, 1971; Stanbridge, 1990).

\footnotetext{
${ }^{2}$ Wnt: Wingless-/ Int-Gene

${ }^{3}$ Bmp: bone morphogenic proteins; engl.: morphogene Proteine des Knochens

${ }^{4}$ Pdgfa: platelet derived growth factor receptor $\alpha$

${ }^{5}$ Igf 2 : Insulin like growth factor 2
} 
Eine aberrante Aktivierung des SHH-Signalweges während des adulten Lebens führt zur Tumorentstehung. Eine derartige Beziehung zwischen SHH und der Entstehung von Krebs wurde erstmals in Patienten mit Basalzellnävus-Syndrom (auch Gorlin-Goltz-Syndrom; Gorlin et al., 1995; Hahn et al., 1996a; Hahn et al., 1996b; Johnson et al., 1996) gefunden, welches durch heterozygote Keimbahnmutationen eines PTCH-Allels ausgelöst wird. Die Patienten zeigen neben Entwicklungsdefekten (z. B. Polydactylie, Großwuchs, Keratozysten und Rippenabnormalitäten) auch eine Prädisposition zur Tumorenstehung. Tumoren, die bei diesen Patienten auftreten können, umfassen Basaliome, Medulloblastome, Fibrome (Bindegewebegeschwulst) und andere Tumoren wie bsw. Rhabdomyosarkome (Hahn et al., 1996a). Die Tumorentstehung bei diesen Patienten setzt somit voraus, daß das zweite, nichtmutierte $P T C H$-Allel auf somatischer Ebene ausfällt, was in einem sogenannten Verlust der Heterozygotie $(\mathrm{LOH})^{6}$ am $P T C H$-Lokus resultieren kann. Der Ausfall des zweiten $P T C H$-Allels kann durch Verlust, durch eine weitere Mutation, durch mitotische Rekombinationen, de novo Deletion, Non-Disjunktion (Cavenee et al., 1983) oder durch epigenetisch-bedingtes Abschalten dieses Allels hervorgerufen werden (Uhmann et al., 2005).

Interessanterweise konnten Mutationen in $P T C H$ auch in sporadischen Fällen von Basaliomen, Medulloblastomen und Rhabdomyosarkomen nachgewiesen werden (Gailani et al., 1996, Pietsch et al., 1997a, Pietsch et al., 1997b; Tostar et al., 2006). Ein LOH des PTCH-Lokus wurde in über $50 \%$ der sporadisch auftretenden Basaliome beschrieben, wogegen ein mutationsbedingter Ausfall beider Allele des $\mathrm{PTCH}$-Gens in $30 \%$ der PTCH-assoziierten Tumoren zu beobachten war (Gailani et al., 1996). Bei humanen Medulloblastomen werden PTCH-Mutationen mit dem desmoplastischen Subtyp in Verbindung gebracht, bei humanen Rhabdomyosarkomen mit dem embryonalen Subtyp (Wetmore et al., 2000).

\subsubsection{Ein Tiermodell für $S h h / P t c h$-assoziierte Tumoren}

Zur Untersuchung des Zusammenhanges zwischen Mutationen des PTCH-Gens und der Entstehung von $P T C H$-assoziierten Tumoren wurde ein Mausmodell etabliert. In dem von Hahn et al., 1998 beschriebenen Mausmodell wurden die Exone sechs und sieben, die für eine der beiden hydrophilen extrazellulären Schleifen des Rezeptorproteins kodieren, durch eine Neomyzinkassette ersetzt. Homozygote Ptch-Mutanten (Ptch $1^{\text {neo67 }} p^{\text {neo67 }}$ ) sterben in utero am Tag 9,5 der Embryonalentwicklung durch Fehldefekte des Neuralrohrs. Heterozygote Ptch-Tiere $\left(\mathrm{Ptch} 1^{\text {neo67 }} /^{+}\right)$entwickeln einen Phänotyp, der dem Krankheitsbild von Patienten mit GorlinGoltz-Syndrom ähnlich ist. Neben Entwicklungsdefekten, wie Polydaktylie, Zystenbildung und Rippenfehlbildung weisen die Tiere eine hohe Inzidenz für Medulloblastome (MB) und

\footnotetext{
${ }^{6}$ LOH: loss of heterozygosity; engl.: Verlust der Heterozygotie
} 
Rhabdomyosarkome (RMS) auf (Hahn et al., 1998). Unter UV-Bestrahlung entwickeln heterozygote Ptch-Tiere Basaliome (Hahn et al., 1998; Aszterbaum et al., 1999a; Aszterbaum et al., 1999b). Die Inzidenz und der Tumortyp werden dabei stark vom genetischen Hintergrund der Tiere beeinflußt (Hahn et al., 2004).

In den Tumoren des Tiermodells konnte ebenso wie in humanen PTCH-assoziierten Tumoren eine pathologische Aktivierung des Shh-Signalweges beobachtet werden, die sich durch eine erhöhte Expression von Ptch auf mRNA- sowie auf Proteinebene manifestiert. Ebenso konnte eine Gli1-Überexpression festgestellt werden, was auf eine Dysregulierung der ShhSignalkaskade und der Expression dieser Onkogene hinweist (Toftgard et al., 2000). Auf einen Tumortyp, den heterozygote Ptch-Tiere entwickeln, soll im Folgenden näher eingegangen werden.

\subsubsection{Heterozygote Ptch-Mäuse entwickeln Rhabdomyosarkome (RMS)}

Beim Menschen stellen Rhabdomyosarkome (RMS) eine Gruppe heterogener hochmaligner Tumoren mesenchymalen Ursprungs dar. Es kann davon ausgegangen werden, daß sich die Tumorzellen aus skeletalen Muskelvorläuferzellen entwickeln (Merlino und Helman, 1999). 250 neue Fälle werden jährlich in den USA diagnostiziert, wobei hauptsächlich Kinder von der Tumorerkrankung betroffen sind (Young et al., 1989). RMS steht somit als häufigstes Weichteilsarkom an dritter Stelle der Tumorerkrankungen bei Kindern, nach Neuroblastomen (vom sympathischen Nervengewebe ausgehender Tumor) und Wilms Tumoren (embryonaler maligner Nierentumor, Nephroblastom). RMS treten in den meisten Fällen sporadisch auf, sind jedoch häufig mit Syndromen assoziiert. Hierzu gehören neben dem Gorlin-Goltz-Syndrom auch die Neurofibromatosis generalisata, das Li-Fraumeni-Syndrom und das BeckwithWiedemann-Syndrom. Werden PTCH-Mutationen als ursächlich für RMS bei Gorlin-GoltzSyndrom angesehen, entstehen RMS bei Beckwith-Wiedemann-Syndrom auf Grund von Mutationen am Igf2-Lokus, durch Keimbahnmutation des Tumorsuppressorgens Trp53 bei Patienten mit Li-Fraumeni-Syndrom oder durch Mutationen in NF1 bei Patienten mit Neurofibromatosis generalisata (Dagher und Helman, 1999; Wexler und Garvin, 1997). Tiermodelle für die einzelnen Syndrome sind sehr gut geeignet, um die unterschiedlichen Mechanismen der Entstehung vom RMS zu untersuchen. So konnte in den Vorarbeiten zu dieser Arbeit zunächst gezeigt werden, daß RMS von heterozygoten Ptch-Mäusen sehr wahrscheinlich auf Grund epigenetischer Veränderungen entstehen (Uhmann et al., 2005). Des Weiteren wurde das Genexpressionsprofil von RMS aus heterozygoten Ptch-Tieren mit demjenigen von RMS aus heterozygoten $p 53$-Tieren verglichen (Kappler et al., 2004). RMS von heterozygoten Ptch-Tieren weisen einen höheren Differenzierungsgrad auf, der durch die Expression einer Anzahl von myogenen Markern (z. B. Tropomyosin und Actin) hervorgerufen 
wird. Zielgene des Shh-Signalweges, wie Foxf1, Gadd45a, Caveolin, Ptch und Igf2 sind in RMS aus heterozygoten Ptch-Mutanten ebenfalls höher exprimiert (Hahn et al., 2000; Kappler et al., 2003). Eine besondere Rolle in der Tumorgenese von RMS nimmt der Insulin like growth factor $\operatorname{Ig} 2$ ein.

\subsubsection{Igf 2 und seine Rolle in der Tumorentstehung und Tumorwachstum}

Igf2 wird während der frühen Embryonalentwicklung aktiviert und unterliegt einer gewebespezifischen Transkriptionskontrolle (Chiariotti et al., 1988; DeChiara et al., 1990; DeChiara et al., 1991; Rotwein und Hall, 1990). Als Mitogen wirkt Igf2 auf verschiedene Zelltypen, fördert die Differenzierung und das Wachstum von Muskelgewebe und verhindert die Apoptose (Pedone et al., 1994a; Pedone et al., 1994b; Pavelic et al., 2002). Auf Grund seiner anti-apoptotischen und wachstumsfördernden Wirkung kann überexprimiertem $I g f 2$ eine wichtige Rolle in der Tumorentstehung zugewiesen werden. Seit mehr als 20 Jahren ist bekannt, daß Igf2 häufig in Tumoren überexprimiert ist und an der Entstehung und dem Wachstum von Tumoren beteiligt ist (Reeve et al., 1985).

Igf2 gehört zu der Gruppe der geprägten Gene (imprinted genes) ${ }^{7}$, die sich durch eine monoallelische Expression entweder des paternalen oder des maternalen Allels auszeichnen. Im Falle des Igf2-Gens wird nur das paternale Allel, nicht aber das maternale Allel exprimiert (DeChiara et al., 1991; Szabo und Mann, 1995).

Das Imprinting wird über ein parentalspezifisches Methylierungsmuster gesteuert. Das festgelegte Methylierungsmuster bleibt während der Gametogenese bestehen, während im Gegensatz dazu nicht geprägte Bereiche des Genoms während der Zellteilung komplett demethyliert werden und im Blastozysten-Stadium einer de novo-Methylierung unterliegen (Jaenisch, 1997; Reik et al., 2001a). Dabei erfolgt eine Methylierung der Cytosine in CytosinGuanosin-Dinukleotiden (CpG Dinukleotide), welche im gesamten Genom verteilt sind (Robertson und Wolffe, 2000).

Funktionelle Unterschiede in der DNA-Methylierung sind meist auf sogenannte „CpG-Inseln“ beschränkt, in denen das Dinukleotid gehäuft vorkommt. Differentielle Methylierung solcher CpG-Inseln (DMRs) ${ }^{8}$ sind für die monoallelische Expression von entscheidender Bedeutung (Li et al., 1993; Sutcliffe et al., 1994 Ward et al., 1997, Sasaki et al., 1996). So können Veränderungen des Methylierungsmusters in den DMRs zu einer gestörten Prägung und genomischer Instabilität führen.

\footnotetext{
${ }^{7}$ Imprinting; engl.: Prägung eines Allels, welches zu der monoallelischen Expression des ungeprägten Allels führt

${ }^{8}$ DMR: differential methylated region; engl.: zwischen maternalem und paternalem Allel unterschiedliche Methylierung bestimmter DNA-Bereiche, die für die monoallelische Expression essentiell sind
} 
Die Prägung des maternalen IGF2/ Igf2 Allels wird durch einen komplizierten Mechanismus hervorgerufen, der auch das H19-Gen umfaßt. Beide Gene unterliegen einer reziproken Prägung, die zu einer Expression des paternalen Allels des Igf2-Gens und zur Expression des maternalen Allels des H19-Gens führt (Thorvaldsen et al., 1998; Ishihara et al., 2000).

Die Transkription beider Gene wird hierbei durch ein Set von gemeinsam benutzten EnhancerElementen $^{9}$ stromabwärts von $H 19$ und der differentiell methylierten Region H19-DMD stromaufwärts vom H19 kontrolliert. Die H19-DMD-Region beinhaltet Bindungsstellen für den „CCCTC-Bindungsfaktor“ (CTCF), welcher als ein Chromatin-Insulator wirkt (Kanduri et al., 2000a; Kanduri et al., 2000b; Szabo et al., 2000). Am maternal vererbten Chromosom bindet der CTCF an die unmethylierte H19-DMD und bewirkt auf diesem Chromosom eine Blockade der IGF2/ Igf2-Promotoren, so daß diese nicht mehr durch die stromabwärts vom H19 gelegenen Enhancer-Regionen stimuliert werden können. Dagegen ist die H19-DMD auf dem paternal vererbten Chromosom methyliert und inhibiert dadurch die Bindung von CTCF. Heute wird angenommen, daß dieser Verlust der CTCF-Bindung an die H19-DMD zu einer Aktivierung der paternalen IGF2/Igf2-Promotoren führt. Eine de novo Methylierung der H19DMD des maternalen Allels führt somit zu einer Inhibition der Bindung von CTCF. In Folge aktivieren die Enhancer die Promotoren sowohl des paternalen als auch des maternalen Igf2Allels. Letztere Mechanismus wird als „Loss of Imprinting“ LOI bezeichnet und wird bei vielen humanen Tumoren für die Überexpression von IGF2 verantwortlich gemacht (Cui et al., 2001; Nakagawa et al., 2001). Die H19-DMD ist auch als sogenanntes „Imprinting Center“ bekannt, da die differentielle Methylierung bereits in der Keimbahn festgelegt und somit vererbt wird (Bell und Felsenfeld, 2000; Lewis und Murrell, 2004).

Weiterhin existieren drei CpG-reiche, differentiell methylierte Regionen (DMR0, DMR1 und DMR2), die im Igf2-Lokus lokalisiert sind und während der Embryonalentwicklung reprogrammiert werden können (Li et al., 1993; Reik et al., 2001a). Im Gegensatz zum humanen $I G F 2$, sind die hierbei involvierten Mechanismen in der Maus besser untersucht und bekannt. Die differentielle Methylierung solcher DMRs ist für die monoallelische Expression des IGF2Gens während der Embryongenese von entscheidender Bedeutung (Sasaki et al., 1996; Ward et al., 1997; Moore et al., 1997, Sasaki et al., 1992; Feil et al., 1994).

Bei der Transkription des murinen paternalen Igf2-Allels spielen hierbei die DMR1 und DMR2 eine wichtige Rolle. Beide DMRs sind im paternal exprimierten Igf2-Allel bei der Maus methyliert. Die DMR1 liegt stromaufwärts des Promotors P1 und liegt im materalen Igf2-Allel im unmethylierten Zustand vor, der die Bindung an den methylierungssensitiven transkriptionellen Repressor GFC2 erlaubt (Constancia et al., 2000; Eden et al, 2001). Dieser

\footnotetext{
${ }^{9}$ Enhancer-Element; engl.: Verstärker-Element der Transkription eines Gens
} 
Repressor blockiert die Transkription des maternalen Igf2. Auf dem paternalen Chromosom dagegen liegt die DMR1 im methylierten Zustand vor und verhindert somit die Bindung des Repressors. Dies führt zur Expression des paternalen Igf2-Allels. Die Methylierung der paternalen DMR1 betrifft hierbei nicht alle CpG Inseln und kann gewebsspezifisch variieren (Feil et al, 1994, Eden et al., 2001).

Die DMR2 liegt innerhalb des kodierenden Bereichs von Igf2 in den Exonen 4-6. Eine unmethylierte DMR2, wie sie auf dem maternalen Igf2-Allel anzutreffen ist, verhindert die Igf2Expression. Methylierung der DMR2 dagegen führt zu vermehrten Expression des Igf2-Gens (Murrell et al, 2001). Dies konnte sowohl für das humane als auch das murine IGF2/Igf2-Gen gezeigt werden (Feil et al, 1994; Schneid et al., 1993).

Eine Überexpression des Igf2-Gens in Tumoren resultiert häufig aus einer veränderten Methylierung des maternalen Allels. Die Folge ist der Verlust der Prägung des maternalen Allels (LOI), welches zu einer biallelischer Expression führt (Beckwith-Wiedemann-Syndrom; Wilms Tumor, Sullivan et al., 1999; Falls et al., 1999). Eine Überexpression des Igf2-Gens kann ebenfalls durch uniparentale Disomie, was zu einer Duplikation des paternalen Allels führt, sowie durch Polyploidie und Genamplifikation hervorgerufen werden (Zatkova et al., 2004; Lamonerie et al., 1995; Slatter et al., 1994).

Die DMR0 umfaßt das Exon U1 und weist als einzige der DMRs eine allelische Differenzierung der Methylierung auf: im Embryo liegt das maternale „stillgelegte“ Allel in dem Bereich der DMR0 zum größten Teil methyliert vor. (Sasaki et al., 1992; Hu et al., 1997). In vielen Tumoren (z. B. in Patienten mit Beckwith-Wiedemann-Syndrom und in Wilms Tumoren) konnte im maternalen IGF2 Allel eine Relaxierung in der Methylierung in einem Bereich von $2 \mathrm{~kb}$ stromaufwärts des Promotorkomplexes des humanen IGF2-Gens nachgewiesen werden. Diese Hypomethylierung führt zu einem Verlust der Prägung (LOI), was eine erhöhte IGF2Expression zur Folge hat (Ogawa et al., 1993; Randhawa et al., 1998).

\subsubsection{3. Überexpression des $\operatorname{Ig} f 2$ in Ptch-assoziierten RMS}

Die wachstumsfördernde Rolle des Igf2 im RMS spiegelt sich auch in Tumoren heterozygoter Ptch-Mutanten wider. Im Mausmodell ist Igf2 ein notwendiger Faktor für die Tumorgenese und das Wachstum von RMS (Hahn et al., 2000). Mäuse aus einer Kreuzung von heterozygoten Ptch-Mutanten zeigten auf einem Igf2-Null Hintergrund eine signifikant niedrigere Inzidenz an RMS. Daher wurde postuliert, daß Igf2 nicht nur ein Zielgen des Shh-Signalweges darstellt, sondern auch eine essentielle Funktion bei der Ptch-assoziierten Tumorentstehung und im Tumorwachstum einnimmt.

In RMS der heterozygoten Ptch-Mutanten wird Igf2 bis zu 1000 fach mehr als im normalen Muskel exprimiert. Ein LOI, sowie uniparentale Disomie, Polyploidie und Genamplifikation 
konnten als Ursache der Überexpression des Igf2-Gens ausgeschlossen werden (Hahn et al., 2000). So kann davon ausgegangen werden, daß in heterozygoten Ptch-Mutanten das paternale Allel aberrant überexprimiert wird.

\subsection{Zielsetzung der Arbeit}

In die Tumorentstehung und Tumorprogression sind multiple molekulare Veränderungen involviert. Hierzu gehören die Deregulation von Signalkaskaden und Veränderungen von DNAMethylierungsmustern. Modifikationen, die zu Hyper- und Hypomethylierungen von Promotorsequenzen oder regulatorischen Elementen führen, beeinflussen die Genexpression und sind oft mit genomischer und chromosomaler Instabilität gekoppelt (Feinberg et al., 2002; Robertson, 2001; Momparler und Bovenzi, 2000). Zu den zahlreichen Fragen, die sich zum Verständnis der Tumorentstehung und der Progression von RMS in heterozygoten PtchMutanten stellen, gehört die Untersuchung der Mechanismen, die zu einer paternalen Überexpression des mitogenen Wachstumsfaktors Igf2 führen. Dies stellte die Zielsetzung der vorliegenden Arbeit dar.

Zunächst sollten die Promotoraktivitäten des Igf2-Gens untersucht werden, um eine Aussage über die Regulierung und Aktivierung der verschiedenen I $g f 2$-Transkripte zu treffen.

Ein Schwerpunkt der Arbeit war ferner die Analyse der Methylierung am Igf2-Lokus in Ptchassoziierten RMS. Im Vergleich zum Normalgewebe (Skelettmuskel) sollten im RMS mit Hilfe von methylierungssensitiver Southern-Blot-Technik eventuell auftretende Methylierungsveränderungen in den differentiell methylierten Regionen (DMRs) des Igf2Lokus identifiziert werden. Aberrante Methylierungen sollten mit Hilfe einer BisulfitSequenzierung näher charakterisiert und auf ihre Signifikanz hin untersucht werden.

Ein weiteres Ziel der Arbeit stellte die Untersuchung von transkriptionellen Mechanismen dar, die an einer Überexpression des Igf2-Gens in Ptch-assoziierten Tumoren beteiligt sein können. Igf2 ist ein Zielgen des im RMS abnormal aktivierten Shh-Signalweges. Mediatoren dieses Signals sind die Proto-Onkogene der Gli-Familie, die entscheidend als Aktivatoren auf die Expression von Zielgene des Shh-Signalweges einwirken. Im Rahmen der vorliegenden Arbeit konnten durch bioinformatische Recherchen Gli-Konsensussequenzen im Igf2-Lokus nachgewiesen werden. Diese sollten auf ihre Funktionalität hin überprüft werden. Hierzu wurden Zellkulturexperimenten durchgeführt, bei denen der Einfluss der GliTranskriptionsfaktoren auf die Expression des Igf2-Gens mittels quantitativer real-time QRTPCR, Luziferase- und $\beta$-Galaktosidase-Reporter Experimenten untersucht wurde. 


\section{Material und Methoden}

\subsection{Material}

\subsubsection{Allgemeine Angaben}

Im weiteren Text sind Prozentangaben für Feststoffe als Masseprozent, für Flüssigkeiten und Gase als Volumenprozent zu verstehen. Lösungen wurden in Wasser angesetzt oder im entsprechenden Lösungsmittel. Verwendetes Wasser wurde im Ionenaustauscher (MilliQ System) entmineralisiert.

\subsubsection{Chemikalien und Reagenzien}

Agarose

Ammoniumazetat

Ampizillin

$\beta$-Mercaptoethanol

Chloroform

Cresol

Cryoblock (Einbettfüssigkeit)

dNTPs

radioaktiv markiertes $\left[\alpha^{32} \mathrm{P}\right]$-dCTP

DNA-Längenstandards

DTT

Dimethylsulfoxid (DMSO)

Eosin

Ethanol, vergällt

Ethidiumbromid

FKS (Fetales Kälber-Serum)

Glykogen

Hämatoxylin

Horse Serum Donor Herd

Hybridisierungslösung

Kanamyzin
PeqLab, Erlangen

Sigma, Steinheim

ICN, Aurora, USA

Sigma, Deisenhofen

Carl Roth GmbH, Karlsruhe

Sigma, Steinheim

Medite, Burgdorf

PeqLab, Erlangen

Amersham Biosciences, Braunschweig

MBI Fermentas, St. Leon-Rot

Invitrogen, Karlsruhe

Merck, Darmstadt

Sigma, Steinheim

GeReSo mbH, Einbeck

Eurobio, Fisher Scientific GmbH, Heiligenfeld

Gibco/ BRL, Karlsruhe

Roche, Mannheim

Sigma, Steinheim

Gibco/ BRL, Karlsruhe

Amersham Biosciences, Braunschweig

Sigma, Steinheim 
Lachsspermien-DNA

Magenta Polymerase

MOPS-EDTA-Natriumazetat-Puffer

Natriumazetat

Natriumzitrat

Natriumbisulfit (Sodium bisulfite)

Oligofectamin ${ }^{\mathrm{TM}}$ Reagent

Oligonukleotide (Primer)

PBS

Pertex (Eindeckelflüssigkeit)

Penizillin/ Streptomyzin

Proofreading Expand Polymerase

Proteinase K

Phenol

PicoGreen ${ }^{\circledR}$-Reagent

Random Hexamere

Restriktionsenzyme

Reverse Transkriptase (Superskript II)

RNA-Ladepuffer

RNA-Längenstandards

RNase $\mathrm{H}$

RNaseZap

Roti $^{\circledR}$-Fect

Sukrose

Taq-DNA-Polymerase

TransFectin ${ }^{\mathrm{TM}}$ Lipid Reagent

Trizol

Trypsin TryPLE ${ }^{\mathrm{TM}}$ Express

T4 DNA-Ligase

Wasser destilliert

Wasser (RNase-/ DNase-frei)
Stratagene, La Jolla, USA

Stratagene, La Jolla, USA

Sigma, Deisenhofen

Sigma, Steinheim

Sigma, Steinheim

Sigma, Steinheim

Invitrogen, Karlsruhe

Carl Roth GmbH, Karlsruhe

QIAGEN GmbH, Operon, Hilden

Gibco/ BRL, Karlsruhe

Medite, Burgdorf

PAN $^{\mathrm{TM}}$, Biotech $\mathrm{GmbH}$, Aidenbach

Roche, Mannheim

Carl Roth + Co, Karlsruhe

Gibco/ BRL, Karlsruhe

Invitrogen, Karlsruhe

Roche, Mannheim

Invitrogen, Karlsruhe

Stratagene, La Jolla, USA

New England Biolabs, Frankfurt

Invitrogen, Karlsruhe

Sigma, Steinheim

MBI Fermentas, St. Leon-Rot

Roche, Mannheim

Ambion, Huntingdon, Cambridgeshire, UK

Carl Roth $\mathrm{GmbH}+\mathrm{Co}$, Karlsruhe

Sigma, Deisenhofen

Amersham Pharmacia Biotech, Braunschweig

BIO-RAD Laboratories, Hercules, CA, USA

Invitrogen, Karlsruhe,

MRC Center, Inc., USA

Gibco $^{\mathrm{TM}}$ Invitrogen Corporation, Dänemark

Invitrogen, Karlsruhe

Ampuwa Fresenius AG, Bad Homburg

Gibco/ BRL, Karlsruhe 
Xgal

Zellkulturmedien
Carl Roth $\mathrm{GmbH}+\mathrm{Co}$, Karlsruhe

Gibco/ BRL, Karlsruhe

$\mathrm{PAN}^{\mathrm{TM}}$, Biotech $\mathrm{GmbH}$, Aidenbach

Alle hier nicht aufgeführten Chemikalien wurde von der Firma Carl Roth + Co GmbH, Karlsruhe, bezogen.

\subsubsection{Gebrauchswaren}

1,5 ml Reaktionsgefäße

$2 \mathrm{ml}$ Reaktionsgefäße

$14 \mathrm{ml}$ Röhrchen

$15 \mathrm{ml}$ Schraubröhrchen

$50 \mathrm{ml}$ Röhrchen

6 Well Tissue Culture Plate

(6-Loch-Platte)

96 Well Assay Plate costar ${ }^{\circledR}$

(96-Loch-Platte)

Blotpapier

Deckgläser

Dispensionspipetten

Combitips plus $0,2 \mathrm{ml} ; 5 \mathrm{ml}$

ABsolute $^{\text {TM }}$ QPCR Seal

(Folien für TaqMan-Platten)

Glaswaren

Kryoröhrchen 1,8 ml

MicroSpinTM G-50 Colums

Millipore-Säulchen (Ultrafree MC)

Millipore-MAHV N45-Platte

Nylonmembran (Hybond-XL)

Petrischalen (Nunclon ${ }^{\mathrm{TM}}$ )

Petrischalen

PCR-Reaktionsgefäße und Deckel
Ochs GmbH, Bovenden/ Lengern

Sarstedt AG \& Co, Nürmbrecht

Sarstedt AG \& Co, Nürmbrecht

Nunc GmbH \& Co KG, Wiesbaden

Sarstedt AG \& Co, Nümbrecht

Sarstedt, Newton, USA

Corning Incorporated, Corning, USA

Heinemann Labortechnik GmbH, Schwäbisch

Gmünd

Menzel GmbH \& Co KG, Braunschweig

Eppendorf, Hamburg

Abgene House, Surrey, UK

Schott AG, Mainz

Nunc GmbH \& Co KG, Wiesbaden

Amersham Biosciences, Freiburg

Millipore Cooperations, Bendford

Millipore Cooperations, Bendford

Amersham Biosciences Europe $\mathrm{GmbH}$,

Freiburg

Nunc, Neerijse, Belgien

Sarstedt AG \& Co., Nümbrecht

Sarstedt AG \& Co., Nümbrecht 
ThermaFast 96, non-skirted

(Domed cap strips, natural)

Röntgenfilm Hyperfilm ${ }^{\mathrm{TM}} \mathrm{MP}$

Zellkulturflaschen CELLSTAR ${ }^{\circledR}$
Abgene House, Surrey, UK

Amersham Pharmacia Biotech, Braunschweig

Greiner Bio-one GmbH, Frickenhausen

Alle hier nicht aufgeführten Gebrauchswaren wurden von den Firmen Schütt und Krannich, Göttingen, und Sarstedt, Nümbrecht, bezogen.

\subsubsection{Geräte}

$-80{ }^{\circ} \mathrm{C}$-Gefrierschrank

(Ultra low temperature freezer MDF-U71V)

Agarosegelelektrophorese-Kammern

(Consort Power Supply E835 Peqlab)

Crosslinker CL-1

Digitale Photokamera, PowerShot G2

Einkanal Pipetten

$0,5 \mu 1-10 \mu 1$

$20 \mu 1-200 \mu 1$

$100 \mu 1-1000 \mu 1$

Fluorometer (Tecan Ultra)

Gasbrenner (Gasprofi 2 scs)

Heizblöcke, Thermomixer

(ThermoStat plus)

Homogenisator

Inkubatoren (Baureihe 6000,
Sanyo Electric Co., Ltd., Japan

Biotechnologie GmbH, Erlangen

Herolab GmbH, Wiesloch

Canon Inc., Japan

Eppendorf AG, Hamburg

Tecan Deutschland GmbH, Crailsheim

WLD-TEC GmbH, Göttingen

Eppendorf AG, Hamburg

ART-moderne Labortechnik e. K., Müllheim

Kendro Laboratory Products GmbH, Hanau 
BBD 6220 Sorvall; Heraeus)

Hybridizer HB-1000,

Inkubator (INCUBATOR SHAKER, Innova $^{\mathrm{TM}} 4000$, Bakterien)

Inverses Mikroskop (Axiovert 25)

Kryostat (Model CM 1900-1-1)

Luminometer (MPL-3 2 Injektoren)

Microwelle Inverter System Inside,

Dimension4

MilliQ-Anlage

Multifunctional Microplate Reader

(Fluoreszenz Intensity)

PCR-Gerät (Robocycler

Gradient 96 Combo)

PCR-Gerät (PrimusHT,

Primus-HT control,

Primus-HT manager)

pH-Meter

Photometer, Thermodrucker

Pipettierhilfe
UVP Laboratory Products, Upland CA, USA

New Brunswick Scientific

Carl Zeiss Jena GmbH, Jena

Leica Microsystems Vertrieb GmbH, Bensheim

Berthold Detection Systems GmbH,

Pforzheim

Panasonic, Hamburg

MembranPure GmbH, Bodenheim

TECAN Deutschland GmbH, Grailsheim

Stratagene, Amsterdam, Niederlande

MWG AG Biotech, Ebersberg

WTW Ges. mbH, Wien

Eppendorf AG, Hamburg

Brand GmbH \& Co. KG, Wertheim 
Quarz-Küvette

Schüttler UNIMAX 1010

Sequencer, (3130xl Genetic Analyzer

ABI PRISM)

Sterilbank (Euroflow Klasse IIA)

Stromquellen

TaqMan ABI PRISM,

7900HT Sequence Detection System

Thermalcycler Mastercycler epgradients

(PCR-Gerät)

Turboblotter

(Rapid Downward Transfer Systems)

UV-Dokumentation (digital

monochrome printer P91D)

UV-Transilluminator

Vortexer

Waagen BP 310P, BP 2100

Wasserbad (Schüttelwasserbad 1083)

Zählkammer, Neubauer

Tiefe: $0,100 \mathrm{~mm}$,

$0,0025 \mathrm{~mm}^{2}$
Hellma, Mühlheim

Heidolph Instruments $\mathrm{GmbH}+\mathrm{Co} \mathrm{KG}$, Schwabach

Applied Biosystems, Darmstadt

Clean Air Techniek bv, Woerden

Peqlab Biotechnologie GmbH, Erlangen

Applied Biosystems, Darmstadt

Eppendorf AG, Hamburg

Schleicher \& Schuell GmbH, Dasel

Mitsubishi, Ratingen

Intas, Göttingen

Scientific Industries, Inc., Bohemia

Satorius AG, Göttingen

GFL mBH, Burgwedel

Assistent Germany 
Zentrifugen ( Biofuge pico, Kendro Laboratory Products GmbH, Hanau

Biofuge fresco, Biofuge primo,

Multifuge 3L-R Heraeus)

\subsubsection{Gebrauchsfertige Reaktionssysteme}

Soweit nicht anders erwähnt, wurde bei der Verwendung von gebrauchsfertigen Reaktionssystemen nach den Angaben des Herstellers gearbeitet.

BigDye Terminator Cycle

Dual-Luciferase ${ }^{\circledR}$ Reporter Assay System

Eukaryotic $18 \mathrm{~S}$ rRNA MGB

Expand Long Template PCR System

qPCRTMCore Kit

(No AmpErase ${ }^{\circledR} \mathrm{UNG}$ )

pGEM $^{\circledR}$-T Easy Vector System I

Oligotex $^{\circledR}$ mRNA Kit

Primer-It ${ }^{\circledR}$ RmT Random Primer Labeling Kit

QIAGEN $^{\circledR}$ Large-Construct Kit

QIAGEN $^{\circledR}$ Plasmid Midi Kit

QIAqick ${ }^{\circledR}$ Gel Extraktion Kit

TA Cloning ${ }^{\circledR}$ Kit Dual Promotor

TaqMan ${ }^{\circledR}$ Universal PCR Master Mix
Applied Biosystems, Weiterstadt

Promega GmbH, Mannheim

Applied Biosystems, Darmstadt

Roche Diagnostics GmbH, Mannheim

EUROGENTEC, Liège, Belgien

Promega, Mannheim

Qiagen GmbH, Hilden

Stratagene, La Jolla, USA

Qiagen GmbH, Hilden

Qiagen GmbH, Hilden

Qiagen $\mathrm{GmbH}$, Hilden

Invitrogen, Karlsruhe

Applied Biosystems, Darmstadt

\subsubsection{Puffer und Lösungen}

Lösungen und Puffer für den routinemässigen Gebrauch wurden nach Sambrook et al., 1989 angesetzt. Die benötigten Chemikalien wurden den Erfordernissen gemäss in bidestilliertem oder DEPC-behandeltem Wasser gelöst und nach Bedarf autoklaviert $\left(121{ }^{\circ} \mathrm{C}, 20 \mathrm{~min}\right)$ oder sterilfiltriert.

\section{PBS (10 x):}

$150 \mathrm{mM} \mathrm{NaCl}$

$500 \mathrm{mM} \mathrm{K}_{2} \mathrm{HPO}_{4}$

$500 \mathrm{mM} \mathrm{KH}_{2} \mathrm{PO}_{4}$

$\mathrm{pH} 7,2$

\section{TE-Puffer:}

$1 \mathrm{M}$ Tris- $\mathrm{Cl} \mathrm{pH} \mathrm{7,4}$

500 mM EDTA pH 8,0 


\section{TBE-Puffer (1 x):}

$89 \mathrm{mM}$ Tris-Borat

$89 \mathrm{mM}$ Borsäure

2 mM EDTA pH 8,0

Resuspensionspuffer (pH 8,0):

$50 \mathrm{mM}$ Tris

$10 \mathrm{mM}$ EDTA

$0,1 \%$ RNase A

Neutralisationspuffer (pH 5,5):

3 M Kaliumazetat

Puffer 2:

$0,2 \mathrm{~N} \mathrm{NaOH}$

$1 \%$ SDS

\section{Cresol-Ladepuffer (10 x):}

$0,1 \%(\mathrm{w} / \mathrm{v})$ Cresol

$100 \%(w / v)$ Sucrose

ad. $10 \mathrm{ml}$ Ampuwa

$\mathrm{pH} 7,0$

\section{SSC (20 x):}

$3 \mathrm{M} \mathrm{NaCl}$

0,3 M Natriumzitrat

$\mathrm{pH} 7,0$

Waschpuffer II (high stringency buffer):

0,2x SSC (10 ml 20x SSC/ 11)

$0,1 \% \operatorname{SDS}(10 \% \mathrm{w} / \mathrm{v})$

Depurinierungspuffer:

$0,25 \mathrm{~N} \mathrm{HCl}$

\section{STE-Puffer:}

$1 \mathrm{M}$ Tris-Cl pH 8,0

$5 \mathrm{M} \mathrm{NaCl}$

$1 \% \operatorname{SDS}(10 \% \mathrm{w} / \mathrm{v})$

\section{Lysepuffer:}

$200 \mathrm{mM} \mathrm{NaOH}$

$1 \%$ SDS

\section{Puffer 1:}

$50 \mathrm{mM}$ Glucose

20 mM Tris- $\mathrm{HCl}$; $\mathrm{pH} 8,0$

10 mM EDTA; pH 8,0

\section{Puffer 3:}

3 M K-Azetat; pH 4,8

\section{MOPS-Puffer (10 x):}

0,2 M 3-(N-Morpholino)propansulfonsäure

$50 \mathrm{mM}$ Natriumazetat

10 mM EDTA

Waschpuffer I (low stringency buffer):

2x SSC (100 ml 20x SSC/ 11)

$0,1 \% \operatorname{SDS}(10 \% \mathrm{w} / \mathrm{v})$

\section{TAE-Puffer $(50 \mathrm{x})$ :}

$2 \mathrm{M}$ Tris-Azetat

50 mM EDTA pH 8,3

Denaturierungspuffer:

$1,5 \mathrm{M} \mathrm{NaCl}$

$0,5 \mathrm{M} \mathrm{NaOH}$ 


\section{Neutralisierungspuffer:}

$0,5 \mathrm{M}$ Tris-Cl

$1,5 \mathrm{M} \mathrm{NaCl}$

$\mathrm{pH} 7,0$

0,5 M EDTA $\mathrm{pH} 8,0$

\section{Strippingpuffer:}

$0,05 \% \operatorname{SDS}(10 \% \mathrm{w} / \mathrm{v})$

\section{Transferpuffer:}

$20 \times \mathrm{SSC}$

\section{Hämatoxylin-Lösung:}

$0,1 \%(w / v)$ Hämatoxylin

$0,02 \%(\mathrm{w} / \mathrm{v}) \mathrm{NaIO}_{3}$ (Natriumiodat)

$5 \%$ (w/v) $\mathrm{CCL}_{3}-\mathrm{CH}(\mathrm{OH})_{2}$ (Chloralhydrat)

$5 \%(\mathrm{w} / \mathrm{v}) \mathrm{NH}_{4} \mathrm{KSO}_{4}$

(Ammoniumkaliumsulfat)

$0,1 \%(w / v)$ Citrat

lacZ-Puffer:
$1 \mathrm{M} \mathrm{MgCl}_{2}$
$1 \%$ Na-desoxycholat
$10 \%$ NP-40/ 1x PBS
ad. $50 \mathrm{ml} 1 \mathrm{x}$ PBS

lacZ-Färbelösung:

$250 \mathrm{mM} \mathrm{K}_{3} \mathrm{Fe}(\mathrm{CN})_{6}$

$250 \mathrm{mM} \mathrm{K}_{4} \mathrm{Fe}(\mathrm{CN})_{6}$

$4 \%$ Xgal

ad. $10 \mathrm{ml}$ LacZ-Puffer

\subsubsection{Kulturmedien}

\subsubsection{Flüssigmedien für Escherichia coli und Medienzusätze}

Sofern nicht anders vermerkt, wurden sowohl die Flüssigmedien als auch die Medien mit Agarzusatz $20 \mathrm{~min}$ bei $121{ }^{\circ} \mathrm{C}$ autoklaviert. Für das Giessen der Agarplatten wurden pro Petrischale ca. $20 \mathrm{ml}$ der auf $55^{\circ} \mathrm{C}$ abgekühlten Flüssigkeit benötigt. Die Lösung wurde mit dem entsprechenden Selektionsantibiotikum und nach Bedarf mit IPTG $(0,1 \mathrm{mM})$ und Xgal (2\%) versetzt und in Kulturschalen gegossen. Die ausgehärteten und abgeflammten Agarplatten konnten ebenso wie die Flüssigmedien für einen Monat bei $4-8{ }^{\circ} \mathrm{C}$ gelagert werden. 
Tabelle 1: Flüssigmedien für Bakterien

\begin{tabular}{|c|c|c|}
\hline Luria Bertani (LB) -Medium & $\begin{array}{l}\text { Pepton aus Casein (tryptisch verdaut) } \\
\text { (a) }\end{array}$ & $10 \mathrm{~g}$ \\
\hline \multirow[t]{3}{*}{ (Typ Lennox) } & Hefeextrakt & $5 \mathrm{~g}$ \\
\hline & $\mathrm{NaCl}$ & $10 \mathrm{~g}$ \\
\hline & $\mathrm{H}_{2} \mathrm{O}$ & ad. 11 \\
\hline NZY+ -Medium für Cosmid- & Siehe LB - Medium & \\
\hline Konstrukte (Bakterienstamm & Einstellen auf pH 7,5 mit $10 \mathrm{M} \mathrm{NaOH-Lösung}$ & \\
\hline \multirow[t]{4}{*}{ ED8767) } & Zugabe nach Autoklavieren: & \\
\hline & $\mathrm{MgCl}_{2}$ & $12,5 \mathrm{ml}(1 \mathrm{M})$ \\
\hline & $\mathrm{MgSO}_{4}$ & $12,5 \mathrm{ml}(1 \mathrm{M})$ \\
\hline & Glucose steril filtriert & $20 \mathrm{ml}(2 \mathrm{M})$ \\
\hline \multirow[t]{8}{*}{ S.O.C.-Medium } & Pepton aus Casein (tryptisch verdaut) & $20 \mathrm{~g}$ \\
\hline & Hefeextrakt & $5 \mathrm{~g}$ \\
\hline & $\mathrm{NaCl}$ & $0,5 \mathrm{~g}$ \\
\hline & $\mathrm{KCl}$ & $10 \mathrm{ml}(250 \mathrm{mM})$ \\
\hline & $\mathrm{MgCl}_{2}$ & $5 \mathrm{ml}(2 \mathrm{M})$ \\
\hline & $\mathrm{H}_{2} \mathrm{O}$ & ad. 11 \\
\hline & Zugabe nach Autoklavieren: & \\
\hline & Glucose steril filtriert & $20 \mathrm{ml}(1 \mathrm{M})$ \\
\hline
\end{tabular}

Tabelle 2: Selektivböden zur Anzucht von Bakterien

\begin{tabular}{lll}
\hline \hline LB-Agarplatten & Pepton aus Casein (tryptisch verdaut) & $10 \mathrm{~g}$ \\
Hefeextrakt & $5 \mathrm{~g}$ \\
$\mathrm{NaCl}$ & $10 \mathrm{~g}$ \\
$\mathrm{Agar}$ & $15 \mathrm{~g}$ \\
& $\mathrm{H}_{2} \mathrm{O}$ & ad. 11 \\
Zugabe nach Autoklavieren: & \\
Glucose steril filtriert & $20 \mathrm{ml}(1 \mathrm{M})$ \\
\hline \hline
\end{tabular}

Tabelle 3: Antibiotikakonzentrationen und -zusätze für Selektivböden und Flüssigmedien von Bakterien

\begin{tabular}{llll}
\hline \hline Antibiotikum/Zusätze & Stammlösung & Endkonzentration & Agarplatten \\
\hline Ampizillin & $100 \mathrm{mg} / \mathrm{ml} \mathrm{H}_{2} \mathrm{O}$ & $100 \mu \mathrm{g} / \mathrm{ml}$ & $100 \mu \mathrm{g} / \mathrm{ml}$ \\
Kanamyzin & $10 \mathrm{mg} / \mathrm{ml} \mathrm{H}_{2} \mathrm{O}$ & $50 \mu \mathrm{g} / \mathrm{ml}$ & $50 \mu \mathrm{g} / \mathrm{ml}$ \\
IPTG & $100 \mathrm{mM}$ & - & $0,1 \mathrm{mM}$ \\
Xgal & $40 \mathrm{mg} / \mathrm{ml} \mathrm{DMSO}$ & $2 \%$ & $40 \mu \mathrm{g} / \mathrm{ml}$ \\
\hline
\end{tabular}


Die aufgeführten Antibiotika-Stammlösungen wurden sterilfiltriert, in 1,5 ml Eppendorfgefäßen aliquotiert und bei $-20{ }^{\circ} \mathrm{C}$ bzw. bei $4-8{ }^{\circ} \mathrm{C}$ (Kanamyzin) aufbewahrt.

\subsubsection{Flüssigmedien für eukaryotische Zelllinien und Medienzusätze}

Die Medien für die Kultivierung eukaryotischer Zellinien wurden von den Firmen PAN $^{\mathrm{TM}}$, Biotech GmbH, Aidenbach und Gibco/ BRL, Karlsruhe bezogen.

Tabelle 4: Flüssigmedien für eukaryotische Zelllinien

\begin{tabular}{|c|c|c|}
\hline Zelllinie & "Kulturmedium & Zusätze \\
\hline NIH/ $3 T 3$ & $\begin{array}{l}\text { DMEM Dulbeco`s modified Eagle`s } \\
\text { Medium }\end{array}$ & $\begin{array}{l}\text { FKS } 10 \%(\mathrm{v} / \mathrm{v}) \\
\text { Penizillin } 1 \% \\
\text { Streptomyzin } 1 \%\end{array}$ \\
\hline $\mathrm{C2C12}$ & $\begin{array}{l}\text { DMEM Dulbeco`s modified Eagle`s } \\
\text { Medium }\end{array}$ & $\begin{array}{l}\text { FKS } 20 \%(v / v) \\
\text { Penizillin } 1 \% \\
\text { Streptomyzin } 1 \%\end{array}$ \\
\hline TP1588 & $\begin{array}{l}\text { RPMI } 1640 \text { ( } 25 \mathrm{mM} \text { HEPES, } 2 \mathrm{mM} \\
\text { L-Glutamin) }\end{array}$ & $\begin{array}{l}\text { FKS } 10 \%(v / v) \\
\text { Penizillin } 1 \% \\
\text { Streptomyzin } 1 \%\end{array}$ \\
\hline TP5014 & $\begin{array}{l}\text { RPMI } 1640 \text { ( } 25 \mathrm{mM} \text { HEPES, } 2 \mathrm{mM} \\
\text { L-Glutamin) }\end{array}$ & $\begin{array}{l}\text { FKS } 10 \%(v / v) \\
\text { Penizillin } 1 \% \\
\text { Streptomyzin } 1 \%\end{array}$ \\
\hline
\end{tabular}

Tabelle 5: Zusätze von Antibiotika in Kulturmedien eukaryotischer Zelllinien

\begin{tabular}{lll}
\hline \hline Antibiotikum & Stammlösung & Endkonzentration \\
& & \\
\hline Penizillin & $10000 \mathrm{IE} / \mathrm{ml}$ & $100 \mathrm{IE} / \mathrm{ml}$ \\
Streptomyzin & $10 \mathrm{mg} / \mathrm{ml}$ & $100 \mu \mathrm{g} / \mathrm{ml}$ \\
\hline \hline
\end{tabular}

\subsubsection{Biologisches Material und Organismen}

\subsubsection{Versuchstiere}

Tumor- und Organgewebe wurden aus heterozygoten Ptch $^{\text {neo67/+ }}$-Mäusen gewonnen, die auf einem CD1-Hintergrund gezüchtet wurden (Hahn et al., 1998). Die Tiere wurden in der tierexperimentellen Einrichtung der Humangenetik der Universität Göttingen unter konstanten Bedingungen (Temperatur $18-21^{\circ} \mathrm{C}$, Luftfeuchtigkeit $55-66 \%$ ) mit abwechselnden Hell- und 
Dunkelperioden von jeweils $12 \mathrm{~h}$ gehalten. Sie erhielten Standardfutter (ssniff Spezialdiäten $\mathrm{GmbH}$, Soest) und Wasser ad libitum.

\subsubsection{Bakterien}

Der chemisch-kompetente recA-Bakterienstamm Escherichia coli DH5 $\alpha^{\mathrm{TM}}$ (Hanahan, 1983; Invitrogen, Karlsruhe) wurde in den Transformations-Versuchen zur Vermehrung der Vektoren bzw. der rekombinanten DNA verwendet.

\subsubsection{Eukaryotische Zelllinien}

Für die in der vorliegenden Arbeit durchgeführten Transfektionsexperimente wurden die in Tabelle 6 aufgeführten Zelllinien verwendet.

Tabelle 6: Eukaryotische Zelllinien

\begin{tabular}{|c|c|c|}
\hline ATCC-Nummer & Bezeichnung & Charakterisierung \\
\hline $\begin{array}{l}\text { CRL-1658, LGC Promochem, } \\
\text { Wesel, } \\
\text { American Type Culture Collection, } \\
\text { VA, USA }\end{array}$ & NIH/ 3T3 & Murine, adhärente Fibroblastenzellen \\
\hline $\begin{array}{l}\text { CRL-1772, LGC Promochem, } \\
\text { Wesel, } \\
\text { American Type Culture Collection, } \\
\text { VA, USA }\end{array}$ & $\mathrm{C} 2 \mathrm{C} 12$ & Murine, adhärente Myoblastenzellen \\
\hline $\begin{array}{l}\text { Bereitgestellt von Dr. Torsten } \\
\text { Pietsch (isolierte Zelllinien aus } \\
\text { RMS-Tumoren von Ptch } \\
\text { Mäusen) }\end{array}$ & TP1588 & $\begin{array}{l}\text { Rhabdomyosarkomzellen aus heterozygoten } \\
\text { Ptch-Mäusen }\end{array}$ \\
\hline $\begin{array}{l}\text { Bereitgestellt von Dr. Torsten } \\
\text { Pietsch (isolierte Zelllinien aus } \\
\text { RMS-Tumoren von Ptch } \\
\text { Mäusen) }\end{array}$ & TP5014 & $\begin{array}{l}\text { Rhabdomyosarkomzellen aus heterozygoten } \\
\text { Ptch-Mäusen }\end{array}$ \\
\hline
\end{tabular}




\subsubsection{Vektoren}

Die in dieser Arbeit benutzen Plasmide und Sequenzierprimer sind in Tabelle 7 aufgeführt.

Tabelle 7: Vektoren und ihre Sequenzierprimer

\begin{tabular}{|c|c|c|c|}
\hline Vektor & $\begin{array}{l}\text { Vorwärts-Primer } \\
\left(5^{\prime} \rightarrow 3^{\prime}\right)\end{array}$ & $\begin{array}{l}\text { Rückwärts-Primer } \\
\left(5^{\prime} \rightarrow 3^{\prime}\right)\end{array}$ & Firma \\
\hline \multirow[t]{3}{*}{ pGEM $^{\circledR}$-T Easy } & Sp6new & T7new & Promega, Mannheim \\
\hline & TTAGGTGACACTATAG & AATACGACTCACTATA & \\
\hline & AATACTCAAGC & GGGCGAATGG & \\
\hline \multirow[t]{3}{*}{$\mathbf{p C R}^{\circledR} \mathbf{I I}$} & Sp6 & $\mathbf{T 7}$ & Invitrogen, Karlsruhe \\
\hline & ATTTAGGTGACACTAT & ATTATGCTGAGTGATA & \\
\hline & AG & TCCC & \\
\hline \multirow[t]{3}{*}{$\mathrm{pCR}^{\circledR} 3.1$} & BGH R pCR3.1 & T7 F pCR3.1 & Invitrogen, Karlsruhe \\
\hline & TAGAAGGCACAGTCGA & TAATACGACTCACTAT & \\
\hline & GG & AGGG & \\
\hline pEGFP-N1 & - & - & $\begin{array}{l}\text { CLONTECH Laboratories, } \\
\text { Inc., CA, USA }\end{array}$ \\
\hline \multirow[t]{3}{*}{ pBluescript II SK+/- } & $\mathbf{T 3}$ & T7 long & Stratagene, La Jolla, USA \\
\hline & ААТТАAСССТСАСТА & GCGCATTATGCTGAG & \\
\hline & AAGGG & TGATATCCCCGCTTA & \\
\hline pCDNA3.1/ & BGH & T7 & Invitrogen, Karlsruhe \\
\hline \multirow[t]{2}{*}{$\mathrm{His}^{\odot} \mathrm{A}, \mathrm{B}, \mathrm{C}$} & CCTCGACTGTGCCTTC & TAATACGACTCACTAT & \\
\hline & $\mathrm{TA}$ & AGGG & \\
\hline
\end{tabular}

\subsubsection{Verwendete Datenbanken}

Die in der vorliegenden Arbeit verwendeten Gen-Sequenzen für Primerdesign, Sequenz- und Promotoranalysen wurden aus verschiedenen Datenbanken extrahiert und sind in Tabelle 8 aufgeführt. 
Tabelle 8: Gen-Datenbanken und Zugriffsnummern

\begin{tabular}{ll}
\hline \hline Gen & Accession-Nummer der Sequenzen \\
\hline Gli1 & NM_010296 (NCBI-Datenbank) \\
Gli2 & XM_136212 (NCBI-Datenbank) \\
Gli3 & NM_008130 (NCBI-Datenbank) \\
$\boldsymbol{I g} \boldsymbol{f} 2$ & U71085 (NCBI-Datenbank) \\
$\boldsymbol{P t c h}$ & ENSMUST00000021921 (Ensembl-Datenbank) \\
$\boldsymbol{G a p d h}$ & M32599 (NCBI-Datenbank) \\
$\boldsymbol{H P R T}$ & ENSMUST00000026723 (Ensembl-Datenbank) \\
$\boldsymbol{H 1 9}$ & AF049091 (NCBI-Datenbank) \\
\hline \hline
\end{tabular}

\subsubsection{Oligonukleotide}

Alle in dieser Arbeit verwendeten Oligonukleotide wurden von den Firmen Carl Roth GmbH + Co. (Karlsruhe) und QIAGEN GmbH, Operon (Hilden) als Lyophilisat bezogen und mit autoklaviertem Aqua bidest. auf $100 \mu \mathrm{M}$ eingestellt. Die Stocks wurden bei $-20{ }^{\circ} \mathrm{C}$ gelagert. Gebrauchsfertige Primerlösungen für die PCR wurden mit autoklaviertem Aqua bidest. auf $10 \mu \mathrm{M}$ verdünnt.

Die Sequenzabschnitte aller verwendeten Primer und Sonden sind in $5^{`} \rightarrow 3^{`}$-Richtung auf dem Plus-Strang dargestellt.

Tabelle 9: Igf2 Primer für den TaqMan-Assay

\begin{tabular}{lllll}
\hline \hline Gen & Vorwärtsprimer $\left(\mathbf{5}^{`} \rightarrow \mathbf{3}^{\prime}\right)$ & Rückwärtsprimer $\left(\mathbf{5}^{`} \rightarrow \mathbf{3}^{\prime}\right)$ & $\begin{array}{l}\mathbf{T}_{\mathbf{A}}{ }^{\mathbf{1 0}} \\
\text { in }^{\mathbf{0}}\end{array}$ & $\begin{array}{l}\mathbf{L}_{\mathbf{P}}{ }^{\mathbf{1 1}} \\
\text { in bp }\end{array}$ \\
\hline $\boldsymbol{I g f 2}$ & mIgf2 F1 TaqMan & mIgf2 R1 TaqMan & 60 & 87 \\
& $\begin{array}{l}\text { TGTGCTGCATCGCTGCTT } \\
\text { AC }\end{array}$ & CGGTCCAACAGACAAACTGA & \\
& & & \\
\hline \hline
\end{tabular}

Tabelle 10: TaqMan-Sonde für Igf2

\begin{tabular}{lllll}
\hline \hline Name & Sequenz $\left(\mathbf{5}^{`} \rightarrow \mathbf{3}^{\prime}\right)$ & $\mathbf{5}^{`}$-Labeling & $\mathbf{3}^{`}$-Labeling & Firma \\
\hline mIgf2 TaqMan Exon 4 & CCCGGAGACTCTGTGCGGA & FAM & TAMRA & ABI \\
& GG & & & \\
\hline \hline
\end{tabular}

\footnotetext{
${ }^{10} \mathrm{~T}_{\mathrm{A}}$ beschreibt die Annealingtemperatur in ${ }^{\circ} \mathrm{C}$ der Oligonukleotide für die PCR

${ }^{11} \mathrm{~L}_{\mathrm{P}}$ beschreibt die Länge des zu amplifizierenden PCR-Fragment in Basenpaaren (bp)
} 
Tabelle 11: 18S rRNA-Primer für den TaqMan-Assay

\begin{tabular}{|c|c|c|c|c|}
\hline Name & $\begin{array}{l}\text { Vorwärts-Primer } \\
\left(5^{`} \rightarrow 3^{\prime}\right)\end{array}$ & $\begin{array}{l}\text { Rückwärts-Primer } \\
\left(5^{`} \rightarrow 3^{\prime}\right)\end{array}$ & $\begin{array}{l}\mathbf{T}_{\mathrm{A}} \\
\text { in } \mathrm{C}^{\circ}\end{array}$ & $\begin{array}{l}\mathbf{L}_{\mathbf{P}} \\
\text { in bp }\end{array}$ \\
\hline \multirow[t]{2}{*}{ 18S rRNA } & $\underline{18 \mathrm{~S}-\mathrm{fwd}}$ & $\underline{18 \mathrm{~S}-\mathrm{rev} 2}$ & 60 & 500 \\
\hline & CGCAAATTACCCACTCCCG & TTCCAATTACAGGGCCTCGAA & & \\
\hline
\end{tabular}

Tabelle 12: Oligonukleotide für semi-quantitative PCRs

\begin{tabular}{|c|c|c|c|c|}
\hline Gen & $\begin{array}{l}\text { Vorwärts-Primer } \\
\left(5^{\prime} \rightarrow 3^{`}\right)\end{array}$ & $\begin{array}{l}\text { Rückwärts-Primer } \\
\left(5^{\prime} \rightarrow 3^{\prime}\right)\end{array}$ & $\begin{array}{l}\mathrm{T}_{\mathrm{A}} \\
\text { in } \mathrm{C}^{\circ}\end{array}$ & $\begin{array}{l}\mathbf{L}_{\mathbf{P}} \\
\text { in bp }\end{array}$ \\
\hline \multirow[t]{2}{*}{ Gli1 } & TGCACCAAGCGCTACACAGATCC & AGCTGATGCAGCTGATCCAGCCCT & 60 & 420 \\
\hline & $\mathrm{CA}$ & A & & \\
\hline Gli2 & CGGGATATTGATGTCTCCTC & AGTGGTCAGATAGTGCACTG & 58 & 320 \\
\hline \multirow[t]{2}{*}{ Gli3 } & GAAGGAACAACCCTAGTCAAGGA & AAAGCCTTGTTGCAGCCCTCAT & 55 & 400 \\
\hline & GGA & & & \\
\hline $\operatorname{Ig} f 2$ & ACCACAACCCAGAGCACCCCCTG & GTAAGGAGCGATGCAGCACAAGGC & 55 & 244 \\
\hline \multirow[t]{2}{*}{ (U1-Exon) } & $\mathrm{CT}$ & GAAGGC & & \\
\hline & (U1) & $(\mathrm{E} 4)$ & & \\
\hline $\operatorname{Ig} f 2$ & AGCTGAGGCCTCTGCCACCAAGG & GTAAGGAGCGATGCAGCACAAGGC & 59 & 316 \\
\hline \multirow[t]{2}{*}{ (U2-Exon) } & $\mathrm{C}$ & GAAGGC & & \\
\hline & (U2) & $(\mathrm{E} 4)$ & & \\
\hline $\operatorname{Ig} f^{2}$ & ACTGGGCATTGCCCCCAGTTTC & GTAAGGAGCGATGCAGCACAAGGC & 55 & 283 \\
\hline \multirow[t]{5}{*}{ (Exon1) } & $(\mathrm{E} 1)$ & GAAGGC & & \\
\hline & & $(\mathrm{E} 4)$ & & \\
\hline & & $\begin{array}{l}\text { TGGCACAGTATGTCTCCAGGA } \\
\text { (E5) }\end{array}$ & 55 & 467 \\
\hline & & TTGCTGGACATCTCCGAAGAG & 55 & 655 \\
\hline & & $(\mathrm{E} 6)$ & & \\
\hline $\operatorname{Ig} f^{2}$ & CGTCGCACATTCGGCCTCTGCG & GTAAGGAGCGATGCAGCACAAGGC & 55 & 208 \\
\hline \multirow[t]{6}{*}{ (Exon2) } & $\mathrm{CT}$ & GAAGGC & & \\
\hline & $(\mathrm{E} 2)$ & $(\mathrm{E} 4)$ & & \\
\hline & & TGGCACAGTATGTCTCCAGGA & & \\
\hline & & $(\mathrm{E} 5)$ & 57 & 392 \\
\hline & & TTGCTGGACATCTCCGAAGAG & & \\
\hline & & $(\mathrm{E} 6)$ & 55 & 616 \\
\hline $\operatorname{Ig} f 2$ & TСTTCATCCTCTTCCAGCCCCAG & GTAAGGAGCGATGCAGCACAAGGC & 55 & 110 \\
\hline \multirow[t]{3}{*}{ (Exon3) } & CG & GAAGGC & & \\
\hline & (E3) & $(\mathrm{E} 4)$ & & \\
\hline & & TGGCACAGTATGTCTCCAGGA & & \\
\hline
\end{tabular}




\begin{tabular}{llllc}
\hline \hline & & $(\mathrm{E} 5)$ & 55 & 294 \\
& & TTGCTGGACATCTCCGAAGAG & & 518 \\
$\boldsymbol{I g f 2}$ & TGTGCTGCATCGCTGCTTAC & TGGCACAGTATGTCTCCAGGA & 55 & 187 \\
$($ Exon4) & $(\mathrm{E} 4)$ & $(\mathrm{E} 5)$ & & \\
& & TTGCTGGACATCTCCGAAGAG & 55 & 425 \\
& & $(\mathrm{E} 6)$ & & \\
$\boldsymbol{G a p d h}$ & ATCTTCTTGTGCAGTGCCAG & ATGGCATGGAACTGTGGTCAT & 58 & 576 \\
$\boldsymbol{H P R T}$ & GCTGGTGAAAAGACCTCT & CACAGGACTAGAACACCTGC & 55 & 250 \\
\hline \hline
\end{tabular}

Tabelle 13: Oligonukleotide zur Herstellung von Hybridisierungssonden für den Northern-Blot

\begin{tabular}{llllc}
\hline \hline Gen & Vorwärts-Primer & Rückwärts-Primer & $\mathbf{T}_{\mathbf{A}}$ & $\mathbf{L}_{\mathbf{P}}$ \\
& $(\mathbf{5} \boldsymbol{\rightarrow} \mathbf{3})$ & $(\mathbf{5} \rightarrow \mathbf{3})$ & in $\mathbf{C}^{\circ}$ & in $\mathbf{~ b p ~}$ \\
\hline $\boldsymbol{I g f 2}$ & GACGACTTCCCCAGATACCCCGT & TTGCTGGACATCTCCGAAGAG & 55 & 227 \\
$($ Exon6) & G & & & \\
Gapdh & GTCATCAACGGGAAGCCCAT & GTCATACCAGGAAATGAGCT & 55 & 743 \\
\hline \hline
\end{tabular}

Die Igf2- und $m$ Gapdh-PCR-Produkte wurden aus genomischer Mausschwanz-DNA von CD1Wildtypen amplifiziert. Das Igf2-PCR-Produkt wurde in pGEM $^{\circledR}$-T Easy und das $m G a p d h$ Fragment in $\mathrm{pCR}^{\circledR} \mathrm{II}$ TA subkloniert. Zur Herstellung der Hybridisierungssonden wurden die klonierten Fragmente aus den Plasmiden über einen EcoRI-Verdau isoliert und aufgereinigt. 
Tabelle 14: Oligonukleotide zur Generierung von PCR Produkten für Hybridisierungssonden für den Southern-Blot

\begin{tabular}{|c|c|c|c|c|}
\hline Fragment & $\begin{array}{l}\text { Vorwärts-Primer } \\
\left(5^{`} \rightarrow 3^{`}\right)\end{array}$ & $\begin{array}{l}\text { Rückwärts-Primer } \\
\left(5^{\prime} \rightarrow 3^{\prime}\right)\end{array}$ & $\begin{array}{l}\mathbf{T}_{\mathrm{A}} \\
\text { in } \mathrm{C}^{\circ}\end{array}$ & $\begin{array}{l}L_{P} \\
\text { in bp }\end{array}$ \\
\hline Igf2-DMR0 & AGGTCAGATGACTGATGACAG & CTGCACCTTCACTCATACACA & 55 & 885 \\
\hline \multirow[t]{2}{*}{$\operatorname{Ig} f 2$-DMR1/ 1} & CTCCGTGTTCCCTGTGCACAG & GGAGAGGGGTCAGCAGGGAAG & 55 & 2434 \\
\hline & GCAGGAATT & GCCAGTGTC & & \\
\hline $\operatorname{Ig} 2$-DMR1/ 2 & TTCACTGGTCAGGTACTGGG & TGCATGCATGGGGTCTATTG & 55 & 879 \\
\hline \multirow[t]{2}{*}{ Igf $2-D M R 1 / 3$} & ATGCTCCTTACTCCCAACAAA & TCGTCCCTAGCTCAGTTTTG & 55 & 945 \\
\hline & $\mathrm{T}$ & & & \\
\hline $\operatorname{Ig} 2$-DMR1/ 4 & AACTGAGCTAGGGACGAG & GATACCACTGTTATGCGCA & 57 & 3018 \\
\hline \multirow[t]{2}{*}{ Igf2-DMR2 } & GACGTGTCTACCTCTCAGGCC & TCTCCTTGGGTTCTTTCACC & 60 & 1209 \\
\hline & GTACTT & & & \\
\hline \multirow[t]{2}{*}{ H19 5 } & ACTGAGAGGGCCATAGTGTGA & CGGGCTTTTTTCTAACTGGAG & & 4808 \\
\hline & & $\mathrm{T}$ & & \\
\hline Atractin & AGTGGGAACTCCCATGAGA & АCCTGGAACAGACTCTCTT & 55 & 677 \\
\hline $\begin{array}{l}\text { Hadhsc (L-3- } \\
\text { hydroxyacyl- }\end{array}$ & TGCATTGCATGTCTCAGTAGC & AGTGAGACACTGAGACAGTC & 57 & 302 \\
\hline Coenzym) & & & & \\
\hline
\end{tabular}

Tabelle 15: Klonierung der PCR-Produkte aus Tabelle 14 und entsprechender Restriktionsverdau zur Wiedergewinnung des klonierten Fragments

\begin{tabular}{|c|c|c|c|}
\hline Sonde & Klonierung von & $\begin{array}{l}\text { Restriktionsverdau des } \\
\text { Plasmids mit }\end{array}$ & $\begin{array}{l}\text { Größe des eluierten } \\
\text { Fragments in bp zur } \\
\text { radioaktiven Markierung }\end{array}$ \\
\hline $\begin{array}{l}\text { Sonde } 1 \\
\end{array}$ & $\begin{array}{l}\text { Igf2-DMR0 Fragment in } \\
\text { pGEM }^{\circledR} \text {-T Easy }\end{array}$ & NotI & 835 \\
\hline Sonde 2 & $\begin{array}{l}\text { Igf2-DMR1/ } 1 \text { Fragment in } \\
\text { pCR }^{\circledR} \mathrm{II}\end{array}$ & EcoRI-BamHI & 2200 \\
\hline Sonde 3 & $\begin{array}{l}\text { Igf2-DMR1/ } 2 \text { Fragment in } \\
\text { pCR }^{\circledR} \mathrm{II}\end{array}$ & EcoRI-XbaI & 720 \\
\hline Sonde 4 & $\begin{array}{l}\text { Igf2-DMR1/ } 3 \text { Fragment in } \\
\text { pCR }^{\circledR} \mathrm{II}\end{array}$ & HindIII-SmaI & 888 \\
\hline Sonde 5 & $\begin{array}{l}\text { Igf2-DMR1/ } 4 \text { Fragment in } \\
\text { pGEM }^{\circledR} \text {-T Easy }\end{array}$ & BamHI & 2600 \\
\hline Sonde 6 & Igf2-DMR2 Fragment in $\mathrm{pCR}^{\circledR} \mathrm{II}$ & BamHI-KpnI & 877 \\
\hline Subsonde 7 & $H 195^{\prime}$ Fragment in $\mathrm{pCR}^{\circledR} \mathrm{II}$ & SacI & 3850 \\
\hline Sonde 8 & H19-DMD (EcoRI/ BamHI & EcoRI-BamHI & 2017 \\
\hline
\end{tabular}


Fragment aus Sonde 7 in EcoRI-

BamHI Schnittstellen von

$\mathrm{pCR}^{\circledR} \mathrm{II}$

Sonde 9 Atractin Fragment in pCR ${ }^{\circledR} \mathrm{II} \quad$ EcoRI

586 (Hybridisierung von

1440 bp BamHI-verdauter

DNA)

Sonde $10 \quad$ Hadhsc Fragment in pCR ${ }^{\circledR}$ II $\quad$ EcoRI 302 (Hybridisierung von 850 bp EcoRI-verdauter DNA)

Tabelle 16: LacZ-Primer

\begin{tabular}{|c|c|c|c|c|}
\hline Gen & $\begin{array}{l}\text { Vorwärts-Primer } \\
\left(5^{`} \rightarrow 3^{\prime}\right)\end{array}$ & $\begin{array}{l}\text { Rückwärts-Primer } \\
\left(5^{\prime} \rightarrow 3^{\prime}\right)\end{array}$ & $\begin{array}{l}\mathbf{T}_{\mathrm{A}} \\
\text { in } \mathrm{C}^{\circ}\end{array}$ & $\begin{array}{l}\mathbf{L}_{\mathbf{P}} \\
\text { in bp }\end{array}$ \\
\hline \multirow[t]{3}{*}{ LacZ } & $\underline{\text { LacZ F1 }}$ & $\underline{\mathrm{LacZ} \text { R4 }}$ & 58 & 560 \\
\hline & AGGCTGCCCTCTGAGTTTGACC & TGATGAGCAGAGGCTTGCC & & \\
\hline & $\mathrm{TC}$ & ATTGA & & \\
\hline
\end{tabular}

Tabelle 17: Oligonukleotide für die Klonierung und die Klonierungsstrategie von Gli1 in den Expressionsvektor pCR3.1

\begin{tabular}{lllll}
\hline \hline Gen & Vorwärts-Primer & Rückwärts-Primer & $\mathbf{T}_{\mathbf{A}}$ & $\mathbf{L}_{\mathbf{P}}$ \\
& $\left(\mathbf{5}^{\prime} \rightarrow \mathbf{3}^{\prime}\right)$ & $\left(\mathbf{5}^{\prime} \rightarrow \mathbf{3}^{\prime}\right)$ & in $\mathbf{C}^{\circ}$ & in $\mathbf{b p}$ \\
\hline Gli1 & mGli1 NheI-ov-F & $\underline{\text { mGli1 KpnI-ov-R3 }}$ & 57 & 413 \\
& ACGGCTAGCGAATGTTCAATCC & GAAGGCTCATGGTACCAAT & & \\
& AAT & GGAGAGATGG & & \\
& &
\end{tabular}

Anmerkung: Die in der Sequenz hervorgehobenen bp stellen die Erkennungssequenz des jeweiligen Restriktionsenzymes dar.

Zur Herstellung von mGli1-pCR3.1 wurde zunächst ein 3,1 kb-KpnI-NotI-Fragment von mGli1-pCDNA3.1/ myc-His B (Sasaki et al., 1999) in pCR3.1 kloniert. Dann wurde aus mGli1pCDNA3.1 ein 400 bp-Fragment mit NheI-KpnI-Überhang-Primern über PCR amplifiziert (mit den Primern mGli1 NheI-ov-F/ mGli1 KpnI-ov-R3, Tab. 17). Dieses Fragment wurde mit NheIKpnI verdaut und in NheI-KpnI-geschnittenes mGli1-pCR3.1-Plasmid kloniert. Im Gegensatz zu mGli1-pCDNA3.1 enthält das neue Plasmid keinen His-/ Myc-Tag und wurde in die Transfektionsversuche eingesetzt. 
Tabelle 18: Sequenzierungsprimer für Gli1

\begin{tabular}{lll}
\hline \hline Name & Sequenz $\left(\mathbf{5}^{\prime} \rightarrow \mathbf{3}^{\prime}\right)$ & Firma \\
\hline Gli1-SeqFStart & AGGAACTTCGCCTCCTATG & QIAGEN GmbH, Operon, Hilden \\
Gli1-Seq-0 & GAGAAGCAACACAAGTGCA & QIAGEN GmbH, Operon, Hilden \\
Gli1-FR & GTACAGCGAGAGTTAATAAAGCC & QIAGEN GmbH, Operon, Hilden \\
Gli1-Seq-1 & AAGAGAGCAGACTGACTGTGC & QIAGEN GmbH, Operon, Hilden \\
Gli1-Seq-2 & AGCAGCAGCTCCAGCAGCAT & QIAGEN GmbH, Operon, Hilden \\
Gli1-Seq-3 & TCAAGAGCCTGGGATGTGTCCA & QIAGEN GmbH, Operon, Hilden \\
Gli1-Seq-4 & AGAAAACTGGGGTGATTCC & QIAGEN GmbH, Operon, Hilden \\
Gli1-Seq-5 & AGCTCAAAGCTCAGCTGGTGTGTA & QIAGEN GmbH, Operon, Hilden \\
Gli1-Seq-6 & ATACCAACCCCAGCTGTGGCCAT & QIAGEN GmbH, Operon, Hilden \\
\hline \hline
\end{tabular}

Tabelle 19: Oligonukleotide für die Klonierung und die Strategie der Klonierung von Gli3 in den Expressionsvektor pCR3.1

\begin{tabular}{|c|c|c|c|c|}
\hline Gen & $\begin{array}{l}\text { Vorwärts-Primer } \\
\left(5^{\prime} \rightarrow 3^{\prime}\right)\end{array}$ & $\begin{array}{l}\text { Rückwärts-Primer } \\
\left(5^{\prime} \rightarrow 3^{\prime}\right)\end{array}$ & $\begin{array}{l}\mathbf{T}_{\mathrm{A}} \\
\text { in } \mathrm{C}^{\circ}\end{array}$ & $\begin{array}{l}\mathrm{L}_{\mathbf{P}} \\
\text { in bp }\end{array}$ \\
\hline Gli3 & mGli3 NheI-ov-F & $\underline{\text { mGli3 HindIII-R }}$ & 55 & 1120 \\
\hline \multirow[t]{2}{*}{ N-Terminus } & СTAGCTAGCATGGAGGCCCAGG & GGAGCCTAAGCTTTGCTGTC & & \\
\hline & $\mathrm{CC}$ & GGGCTT & & \\
\hline Gli3 & mGli3 HindIII-F & mGli3 NotI-ov-R & 55 & 3700 \\
\hline \multirow[t]{2}{*}{ C-Terminus } & AGCCGACAGCAAAGCTTAGGCT & ATCCCAAGGCGGCCGCAAGT & & \\
\hline & CCGCA & CATTTCAGT & & \\
\hline
\end{tabular}

Anmerkung: Die in der Sequenz hervorgehobenen bp stellen die Erkennungssequenz des jeweiligen Restriktionsenzymes dar.

Zur Herstellung von mGli3-pCR3.1 wurde zunächst ein 1,12 kb-Fragment mit NheI- und HindIII-Überhang-Primern (mGli3 NheI-ov-F und mGli3 HindIII-R, Tab. 19) aus embryonaler cDNA amplifiziert. Das entsprechende Fragement, welches den N-terminalen Teil von mGli3 umfaßt, wurde mit NheI und HindIII verdaut und in die NheI- und HindIII-Schnittstellen vom pCR3.1-Vektor (Gli3-5'-pCR3.1) kloniert. Das C-terminale Ende von mGli3 wurde mit den Primern mGli3-HindIII-F und mGli3 NotI-ov-R aus derselben cDNA amplifiziert, mit HindIII und NotI verdaut und in die HindIII-NotI-Schnittstelle des Gli3-5'-pCR3.1-Plasmids kloniert. mGli3-pCR3.1 wurde in die Transfektionsversuche eingesetzt. 
Tabelle 20: Sequenzierungsprimer für Gli3

\begin{tabular}{lll}
\hline \hline Name & Sequenz $(\mathbf{5} \boldsymbol{\rightarrow} \mathbf{3})$ & Firma \\
\hline mGli3F1 & ATCTAGTAGCCCGACGTATCCAGA & QIAGEN GmbH, Operon, Hilden \\
mGli3F2 & GAAGGAAAACCCTAGTCAAGGAG & QIAGEN GmbH, Operon, Hilden \\
mGli3R1 & TGACAGTGGCGATATTGACAGTGT & QIAGEN GmbH, Operon, Hilden \\
mGli3R2 & AAAGCCTTGTTGCAGCCCTCAT & QIAGEN GmbH, Operon, Hilden \\
mGli3Ex2f1 & CTGAGGAGGAAGAAGCT & QIAGEN GmbH, Operon, Hilden \\
mGli3Ex5f1 & ATCTAGTAGCCCGACGTA & QIAGEN GmbH, Operon, Hilden \\
mGli3Ex7f1 & CACTGTCAATATCGCCAC & QIAGEN GmbH, Operon, Hilden \\
mGli3Ex10f1 & GAAGGAACAACCCTAGT & QIAGEN GmbH, Operon, Hilden \\
mGli3Ex13f1 & AAATCCCCTGGCTGCACCA & QIAGEN GmbH, Operon, Hilden \\
mGli3Ex14f1 & CAATCATGGACTCGACCA & QIAGEN GmbH, Operon, Hilden \\
\hline \hline
\end{tabular}

Tabelle 21: Molekulargewichtstandards

\begin{tabular}{lll}
\hline \hline Name & Charakterisierung & Firma \\
\hline DNA-Längenstandard & GeneRuler ${ }^{\mathrm{TM}} 1 \mathrm{~kb}$ DNA Ladder MBI Fermentas, Vilnius, Littauen \\
& $(0,5 \mathrm{mg} \mathrm{DNA} / \mathrm{ml})$ \\
& GeneRuler ${ }^{\mathrm{TM}} \quad 100 \quad \mathrm{bp} \quad$ DNA MBI Fermentas, Vilnius, Littauen \\
DNA-Längenstandard & Ladder $(0,5 \mathrm{mg} \mathrm{DNA} / \mathrm{ml})$ \\
& GeneRuler ${ }^{\mathrm{TM}} 50 \mathrm{bp}$ DNA Ladder MBI Fermentas, Vilnius, Littauen \\
DNA-Längenstandard & $(0,5 \mathrm{mg} \mathrm{DNA} / \mathrm{ml})$ \\
& $\mathrm{RNA}$ Ladder, High Range $(0,5$ MBI Fermentas, Vilnius, Littauen \\
RNA-Längenstandard & $\mu \mathrm{g} / \mu \mathrm{l})$ \\
\hline \hline
\end{tabular}

\subsection{Methoden}

\subsubsection{Allgemeine Anmerkungen}

Sofern nicht anders ausgewiesen, wurden alle Versuche bei Raumtemperatur (RT) ausgeführt. Zentrifugationsschritte von Lösungen mit kleinem Volumen $(<2 \mathrm{ml})$ erfolgten in 1,5 ml - oder $2 \mathrm{ml}$ - Reaktionsgefäßen in Tischzentrifugen (Heraeus) bei $13000 \mathrm{U} / \mathrm{min}$. Für große Volumina wurden $15 \mathrm{ml}$ - und $50 \mathrm{ml}$ - Gefäße in die Multifuge 3L-R-Zentrifuge (Heraeus) bei bis zu $6000 \mathrm{U} / \mathrm{min}$ eingesetzt. 


\subsubsection{Präparative und analytische Arbeiten mit Nukleinsäuren}

\subsubsection{DNA-Präparation}

Das Plasmid enthaltende Bakterien wurden auf Selektiv-Agarböden ausgestrichen und über Nacht bei $37^{\circ} \mathrm{C}$ inkubiert. Zur Vorkultur wurden Einzelkolonien in $5 \mathrm{ml}$ LB-Medium inokuliert und $6-8 \mathrm{~h}$ bei $37^{\circ} \mathrm{C}$ schüttelnd (140 U/ min) inkubiert. Es folgten das Animpfen von $100 \mathrm{ml}$ LB-Medium mit $500 \mu \mathrm{l}$ Vorkultur und Inkubation unter Schütteln über Nacht bei $37{ }^{\circ} \mathrm{C}$. Zur Präparation von Plasmid-DNA wurde das QIAGEN ${ }^{\circledR}$ Plasmid Midi Kit verwendet. Dabei wurde nach Angaben des Herstellers verfahren. Die gewonnene Plasmid-DNA wurde in $100 \mu 1 \mathrm{TE}-$ Puffer ( $\mathrm{pH} 7,5)$ oder in autoklaviertem Wasser gelöst.

\subsection{Minipräparation von Plasmid-DNA}

Die Isolierung geringer Mengen Plasmid-DNA diente analytischen Zwecken (Restriktionsverdau, Sequenzierung) und wurde in modifizierter Form der alkalischen Lyse (Birnboim und Doly, 1979) unterzogen. Von der Minikultur wurden 1,5 $\mathrm{ml}$ für $1 \mathrm{~min}$ bei $13000 \mathrm{U} / \mathrm{min}$ zentrifugiert. Das Pellet wurde in $100 \mu 1$ Resuspensionspuffer aufgenommen, 5 min mit $200 \mu \mathrm{l}$ alkalischem Lysepuffer und anschließend für 5 min mit schwach saurem Neutralisationspuffer inkubiert. Das Proteinpräzipitat wurde $10 \mathrm{~min}$ bei $13000 \mathrm{U} / \mathrm{min}$ sedimentiert. Der Überstand wurde in ein neues Reaktionsgefäß (1,5 ml Eppendorfgefäß) überführt, mit 2,5 Volumenanteilen absoluten Ethanols $(1 \mathrm{ml})$ versetzt und nach Invertieren $20 \mathrm{~min}$ bei $-20^{\circ} \mathrm{C}$ gefällt. Die Lösung wurde $20 \mathrm{~min}$ bei $4{ }^{\circ} \mathrm{C}$ und $13000 \mathrm{U} / \mathrm{min}$ zentrifugiert. Das erhaltene DNA-Pellet wurde mit $70 \%$ Ethanol gewaschen, für 5 min bei $4{ }^{\circ} \mathrm{C}$ und $13000 \mathrm{U} / \mathrm{min}$ zentrifugiert und getrocknet. Die Plasmid-DNA wurde in $20 \mu \mathrm{l}$ Aqua bidest. aufgenommen und bei $-20^{\circ} \mathrm{C}$ gelagert.

\subsection{Minipräparation von Cosmid-DNA}

Das Cosmid enthaltende Bakterien wurden auf Selektiv-Agarböden (Ampizillin oder Kanamyzin) ausgestrichen und über Nacht bei $37{ }^{\circ} \mathrm{C}$ inkubiert. Zur Vorkultur wurden Einzelkolonien in $2 \mathrm{ml} \mathrm{NZY+} \mathrm{-} \mathrm{Medium,} \mathrm{versetzt} \mathrm{mit} \mathrm{der} \mathrm{doppelten} \mathrm{Konzentration} \mathrm{des}$ Antibiotikums (Ampizillin: $200 \mu \mathrm{g} / \mathrm{ml}$, Kanamyzin: $100 \mu \mathrm{g} / \mathrm{ml}$ ), inokuliert und über Nacht bei $37{ }^{\circ} \mathrm{C}$ schüttelnd (300 U/ min) inkubiert. Von der Bakteriensuspension wurden $1,5 \mathrm{ml}$ in ein Eppendorfgefäß überführt und für $30 \mathrm{~s}$ bei $13000 \mathrm{U} / \mathrm{min}$ abzentrifugiert. Das Pellet wurde in $100 \mu 1$ vorgekühltem Puffer 1 durch Pipettieren resuspendiert und für 5 min auf Eis inkubiert. Dann wurden $200 \mu$ Puffer 2 zugegeben und durch vorsichtiges Invertierten gemischt. Nach einer kurzen Inkubation auf Eis wurden $150 \mu 1$ Puffer 3 zugegeben und ebenfalls durch Invertieren gemischt. Das Proteinpräzipitat wurde bei $13000 \mathrm{U} / \mathrm{min}$ für 10 min sedimentiert. 
Der in ein neues Eppendorfgefäß überführte Überstand wurde mit $1 \mathrm{ml}$ absolutem Ethanol vermischt. Nach einer Präzipitation der DNA von $30 \mathrm{~min}$ bei $-20^{\circ} \mathrm{C}$ wurde die DNA bei 13000 $\mathrm{U} / \mathrm{min}\left(4{ }^{\circ} \mathrm{C}\right)$ für 15 min sedimentiert. Das Pellet wurde mit $70 \%$ Ethanol gewaschen, getrocknet und in $20 \mu 1$ Tris-EDTA-Puffer ( $\mathrm{pH} 8,0)$ aufgenommen.

In die sich anschließende Restriktions-Analyse des Cosmides wurden $5 \mu 1$ der gelösten DNA eingesetzt. Zur Gewinnung gösserer Mengen an Cosmid-DNA wurde das QIAGEN ${ }^{\circledR}$ LargeConstruct Kit angewendet. Für die Aufreinigung der Cosmid-DNA wurde dabei nach den Angaben des Herstellers gearbeitet. ${ }^{12}$

\subsubsection{Konzentrationsbestimmung von Nukleinsäuren in Lösung}

Die photometrische Konzentrationsbestimmung der Nukleinsäuren wurde in einem Spektrophotometer (Eppendorf) vorgenommen. Dazu wurde die DNA- bzw. RNA-Lösung 1:100 in Wasser verdünnt und die optische Dichte bei $260 \mathrm{~nm}\left(\mathrm{OD}_{260}\right)$ ermittelt. Eine $\mathrm{OD}_{260}$ von 1 entspricht einer RNA-Konzentration von $40 \mu \mathrm{g} / \mathrm{ml}$ bzw. einer DNA-Konzentration von 50 $\mu \mathrm{g} / \mathrm{ml}$. Auf Grundlage dieser Definitionen wurden die Konzentrationen der jeweiligen Nukleinsäure errechnet. Die Quotienten $\mathrm{OD}_{260 / 280}$ und $\mathrm{OD}_{260 / 230}$ stellen ein Maß für die Proteinbzw. Salzkontamination dar und sollten zwischen 1.8 und 2.0 betragen.

Geringe DNA-Konzentrationen wurden im Agarosegel durch den Vergleich der Fluoreszenzintensitäten der unbekannten Probe mit einer in der Konzentration bekannten DNAProbe abgeschätzt.

\subsubsection{DNA-Quantifizierung über PicoGreen ${ }^{\circledR}$-Reagent}

Diese Methode der Quantifizierung doppelsträngiger DNA basiert auf der Detektion der Fluoreszenz (485/ $535 \mathrm{~nm}$ ) interkalierten PicoGreens zwischen beiden Strängen der DNA. Die hohe Sensitivität der Methode ermöglichte eine Quantifizierung von sehr geringen DNAMengen (bis zu $50 \mathrm{pg} / \mu \mathrm{l}$ ) und fand Anwendung bei der Bestimmung von Konzentrationen genomischer DNA für Southern-Blots und der Messung von Cosmiden, die für die Transfektionsexperimente benötigt wurden.

Zunächst wurden $5 \mu \mathrm{l}$ der zu bestimmenden DNA (20 ng/ $\mu$ l) mit $200 \mu 1$ frisch angesetzter PicoGreen DNA Quantification Reagent ${ }^{\circledR}$-Lösung (MoBiTec P-7589 gelöst in TE-Puffer) in die entsprechende Anzahl an zu vermessenden Proben in eine Corning ${ }^{\circledR}$ Microtest 96-Well Assay Platte pipettiert. Als Standard wurden je $5 \mu$ l humane genomische DNA (10 ng/ $\mu$, vom

\footnotetext{
${ }^{12}$ Die oft geringe DNA-Ausbeute, bedingt durch sehr langsames Wachstum großer Plasmide ( $\left.>20 \mathrm{~kb}\right)$, konnte durch Zugabe der doppelten bis dreifachen Menge des Selektiv-Antibiotikums erhöht werden. Des Weiteren war darauf zu achten, daß die DNA einer 500 ml-Bakterienkultur über nur eine Säule aufgereinigt wurde.
} 
Hersteller gestellt) in mehreren Verdünnungsstufen verwendet. Nach einer Inkubation von 30 min bei RT erfolgte die Messung der Fluoreszenz in Doubletten in einem Tecan Ultra microplates reader. Die Fluoreszenz der zu messenden Proben wurde auf die parallel mitgeführte Eichreihe abgeglichen. Dies ermöglichte eine exakte Bestimmung der DNAKonzentrationen.

\subsubsection{Agarosegelelektrophorese}

Bei analytischen und präparativen Anwendungen wurden DNA-Fragmente im Agarosegel (0,7 3 \%) nach ihrer Größe aufgetrennt. Dabei wurde einfach konzentrierter TBE-Puffer sowohl für das Gel als auch für den Laufpuffer verwendet. Die DNA-Proben wurden auf $200 \mathrm{ng} / \mathrm{x} \mu \mathrm{l}$ verdünnt und mit dem Ladepuffer aufgetragen. Die Detektion der DNA-Banden wurde durch die Zugabe von $0,1 \mathrm{mg} / \mathrm{ml}$ Ethidiumbromid ermöglicht und erfolgte unter UV-Licht $(\lambda=258$ $\mathrm{nm}$ ), die Dokumentation mittels Fotografie.

\subsubsection{Isolierung von DNA-Fragmenten aus Agarosegelen PCI-und CI-Extraktion}

Diese Methode wurde eingesetzt, um DNA-Fragmente weiteren Experimenten (z.B. für Klonierungen) zugänglich zu machen. Hierbei kam das QIAquick ${ }^{\circledR}$ Gel Extraktion Kit zum Einsatz.

Die entsprechende DNA-Bande wurde nach einer gelelektrophoretischen Auftrennung in einem Agarosegel auf einem Transilluminator unter langwelligem UV-Licht mit einem sterilen Skalpell herausgeschnitten und wie folgt weiter behandelt:

Zur in Agarose eingebetteten DNA-Bande wurde eine hochmolare Lösung des chaotropen Salzes Natriumperchlorat $\left(\mathrm{NaClO}_{4}\right)$ zugegeben, die die Agarose bei $50{ }^{\circ} \mathrm{C}$ innerhalb von $10 \mathrm{~min}$ irreversibel auflöste. Diese Lösung wurde zur Adsorption der DNA auf eine Anionenaustauschsilikat-Säule gegeben und die DNA nach dem Waschen mit einem weiteren Puffer bei $\mathrm{pH} 8,5$ eluiert.

\subsubsection{Phenol-Chloroform-Extraktion}

Diese Methode wurde haupsächlich zur Extraktion von genomischer DNA aus Gewebe der Maus angewendet. Extraktionen mit PCI (Phenol-Chloroform-Isoamylalkohol) und CI (Chloroform-Isoamylalkohol) dienten zur Entfernung von Proteinrückständen aus DNAhaltigen Lösungen. Die DNA-Lösung wurde in einem äquivalenten Volumen des PCIGemisches (vol/ vol/ vol=24/24/ 1) bzw. der CI-Mischung (vol/ vol=24/1) versetzt und $30 \mathrm{~s}$ kräftig geschüttelt. Die Phasen wurden durch Zentrifugation (13000 U/ min, 5 min) getrennt. Die wässrige Phase wurde abgenommen und die DNA durch Ethanolfällung gewonnen. 


\subsubsection{Isolation genomischer DNA aus Gewebe}

Gewebe von Tumoren und Mausorganen wurden über Nacht bei $55^{\circ} \mathrm{C}$ in $500 \mu$ 1 Proteinase KLysepuffer verdaut (STE-Puffer + Proteinase K, $10 \mathrm{mg} / \mathrm{ml}$ ). Gewebereste wurden durch Zentrifugation abgetrennt und der Überstand mit PCI extrahiert. Die genomische DNA wurde mit 2,5 Volumenanteilen absolutem Ethanol gefällt, in $70 \%$ Ethanol gewaschen, getrocknet und in autoklaviertem Aqua bidest. bei $60^{\circ} \mathrm{C}$ für 10 min gelöst.

\subsubsection{Isolation genomischer DNA aus Zellen}

Transfizierte Zellen wurden mit 1 x PBS gewaschen und mit $500 \mu$ Proteinase K-Lysepuffer pro 6-Loch-Platte versetzt. Mit einem Zellschaber wurden die Zellen abgelöst, in ein geeignetes Reaktionsgefäß überführt und bei $55^{\circ} \mathrm{C}$ über Nacht verdaut. Die genomische DNA wurde mit 2,5 Volumananteilen absolutem Ethanol gefällt, mit $70 \%$ Ethanol gewaschen, getrocknet und in autoklaviertem Aqua bidest. aufgenommen.

\subsubsection{Sequenzierung}

Zur Sequenzierung wurde das Verfahren der kontrollierten Unterbrechung der DNA-Synthese nach Sanger et al., 1977 eingesetzt. Die Bestimmung der Nukleotidsequenzen wurde auf einem DNA-Sequencer (ABI PRISM-3100 Genetic Analyzer, Universitätsklinikum Göttingen, Abtlg. Phamakologie und Toxikologie) mit dem Standard-Leseweitenprogramm von 700 bp durchgeführt. Die Auswertung der Sequenzdateien erfolgte mit den PCR-Software-Programmen Sequencher ${ }^{\mathrm{TM}}$ Version 4.05 (Gene Code, Corporation) und ClustalW (EBI).

Im Reaktionsansatz wurden $400 \mathrm{ng}-1 \mu \mathrm{g}$ DNA, 10 pmol Primer, 3 \% DMSO und 1,8 4 1 Big Dye Terminator Cycle Sequencing Kit-Lösung zugegeben. Die Reaktion fand in einem Gesamtvolumen von $10 \mu \mathrm{l}$ statt. Das Cycle Sequencing-Programm wurde in einem Thermoblock (Thermalcycler Mastercycler epgradients) durchgeführt.

\begin{tabular}{|c|c|c|}
\hline Sequenzierungs-PCR: & $94^{\circ} \mathrm{C}$ & $2 \mathrm{~min}$ \\
\hline & $96^{\circ} \mathrm{C}$ & $15 \mathrm{~s}$ \\
\hline & $56,5^{\circ} \mathrm{C}$ & $15 \mathrm{~s}$ \\
\hline & $60^{\circ} \mathrm{C}$ & $4 \min$ \\
\hline & $72{ }^{\circ} \mathrm{C}$ & $7 \mathrm{~min}$ \\
\hline & $20^{\circ} \mathrm{C}$ & HOLD \\
\hline
\end{tabular}




\subsubsection{Aufreinigung der Sequenzierprodukte}

Nach der Reaktion wurden die Sequenzierprodukte mit Sephadex G50 aufgereinigt. Dabei wurde das Sephadex-Pulver in die entsprechende Anzahl an Löchern einer Millipore-MAHV N45-Platte gestrichen und mit je $300 \mu 1$ autoklaviertem Wasser aufgefüllt. Nach einer Quellzeit von $3 \mathrm{~h}$ wurde das Wasser bei $1800 \mathrm{U} / \mathrm{min}$ für 5 min abzentrifugiert und erneut mit $150 \mu \mathrm{l}$ Wasser gewaschen. Die Quellung erfolgte nun für $15 \mathrm{~min}$, danach wurde erneut zentrifugiert. Der Ansatz der Sequenzier-Produkte wurde auf ein Gesamtvolumen von $50 \mu 1$ aufgefüllt und in die vorbereiteten Sephadex-Säulen überführt. Es folgte ein weiterer Zentrifugationsschritt, wobei die nun aufgereinigten Sequenzier-Produkte in einer 96-Lochplatte aufgefangen wurden. Die Proben konnten bei $-20^{\circ} \mathrm{C}$ über einen längeren Zeitraum gelagert werden.

\subsubsection{Bisulfit-Sequenzierung}

\subsection{Grundlagen}

Die Methylierung der DNA am Cytosin stellt neben der Azetylierung von Histonen eine der häufigsten epigenetischen Modifikation der DNA dar und ist ein wichtiger Regulationsmechanismus der Genexpression während der frühen Embryonalentwicklung in Säugetieren.

Die Methode der selektiven Basen-Konversion der Einzelstrang-DNA durch BisulfitBehandlung erlaubt es, Methylierungen des Cytosins zu detektieren. Genutzt wird dabei die Eigenschaft des Natriumbisulfits, effizient Cytosin-Reste in Uracil zu verwandeln, während das 5-Methyl-Cytosin unverändert bleibt (Hayatsu et al., 1970; Wang et al., 1980). Bei der anschließenden Amplifikation mittels einer Polymerase-Kettenreaktion werden alle UracilReste als Thymine gelesen, während die 5-Methyl-Cytosine weiterhin als Cytosine erkannt werden. Durch eine direkte Sequenzierung der PCR-Produkte oder der subklonierten PCRFragmente kann somit der Methylierungsstatus jedes einzelnen Cytosins festgestellt werden, wie in Abbildung 2 dargestellt ist. 


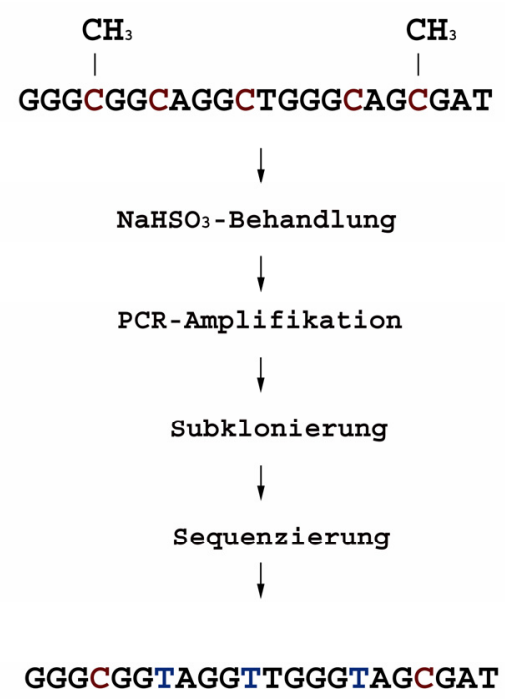

Abb. 2: Schematische Darstellung der Bisulfit-Sequenzierung. Cytosine werden zu Uracil umgewandelt und in der anschließenden PCR als Thymine gelesen. 5-Methyl-Cytosine hingegen werden weiterhin als Cytosine erkannt.

\subsection{Computergestützte Analyse des Methylierungsstatus der zu untersuchenden DNA-Sequenz}

Mit Hilfe eines Microsoft ${ }^{\circledR}$ Word $^{\mathrm{TM}}$ Macro-gestützten Computerprogrammes (Singal et al., 2001) war es möglich, an der genomischen DNA-Sequenz Methylierungen zu simulieren, wie sie durch Bisulfit-Behandlung erreicht werden. Diese theoretische Konvertierung der zu untersuchenden Sequenz stellte die Grundlage für die Auswahl der Primerpaare dar.

\subsection{Wahl der Primer für PCR an Bisulfit-behandelter DNA}

Die Auswahl von Oligonukleotiden für die Amplifikation von Bisulfit-behandelter DNA unterscheidet sich in einigen zentralen Punkten von der Primerwahl für eine herkömmliche PCR. Es ist zu beachten, daß durch die Bisulfit-Behandlung einer doppelsträngigen DNASequenz die Komplementarität verloren geht, wie in Abbildung 3 dargestellt ist. Dadurch müssen die Primer-Sequenzen für die anschließende PCR entweder separat für den Plus-Strang oder für den Minus-Strang ausgewählt werden. Während der PCR wird ein entsprechender neuer Gegenstrang synthetisiert, der nicht mit dem Gegenstrang vor der Bisulfit-Behandlung identisch ist. 


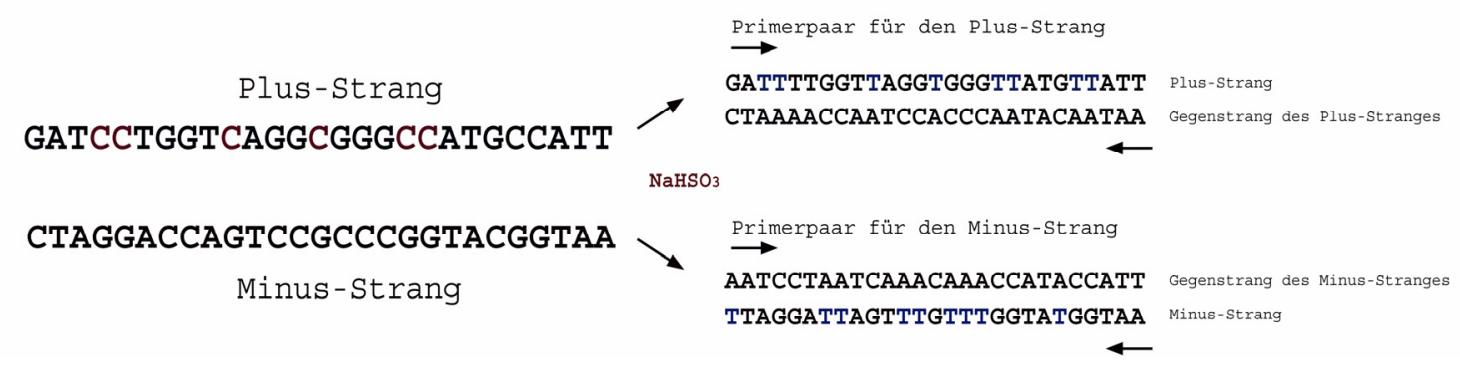

Abb. 3: Prinzip der Primerwahl für den Plus-Strang oder den Minus-Strang für eine PCR an Bisulfitbehandelter DNA.

\subsection{Auswahlkriterien der Oligonukleotide}

- Endständige Basen der Primer sollten ein Cytosin (C) oder ein Guanin (G) enthalten, um die Bindung des Primers zu festigen.

- Es sollten keine CG-Basenabfolgen enthalten sein, wenn der Methylierungsstatus nicht bekannt ist. Denn dort kann nach Bisulfit-Behandlung das Cytosin entweder als Cytosin (C; methyliert) oder als Thymin ( $\mathrm{T}$, unmethyliert) gelesen werden und entsprechend in der reversen Seqeunz als Guanin (G) oder Adenin (A).

- Es sollten Thymine, die aus Cytosinen konvertiert wurden, in der Sequenz enthalten sein, um eine Spezifität für Bisulfit-behandelte DNA zu gewährleisten.

- Die Anlagerungstemperatur der Primer sollte, wenn möglich, über $55{ }^{\circ} \mathrm{C}$ liegen und bei einem Primerpaar möglichst gleich sein.

- Es sollten keine internen komplementären Sequenzen oder Komplementarität zwischen den Primern vorhanden sein.

- Die Länge der Primer sollte zwischen 30 und 35 Nukleotiden liegen, um eine adäquate Hybridisierung der A/ T-reichen Bisulfit-behandelten DNA zu gewährleisten.

\subsection{Behandlung der DNA mit Bisulfit}

Zunächst wurde eine bisulfithaltige Inkubationslösung vorbereitet. Dazu wurden 3,1 M 12 x $\mathrm{NaHSO}_{3}$ × $3 \mathrm{Na}_{2} \mathrm{SO}_{3}(4,25 \mathrm{~g})$ und $7,5 \mathrm{ml}$ Aqua bidest. in ein verschließbares $14 \mathrm{ml}$ Reaktionsröhrchen gegeben. Da gelöstes Bisulfit leicht durch Sauerstoff oxidiert wird, wurde die verbleibende Luft im Röhrchen durch $\mathrm{N}_{2}$ ausgetauscht. Die Lösung wurde anschließend bei RT durch Schwenken (kein Schütteln) gelöst. Um oxidative Prozesse durch nicht vollständig entfernten Sauerstoff $\mathrm{zu}$ verhindern, wurde die Bisulfit-Lösung mit $450 \mu 150 \mathrm{mM}$ frisch angesetzter Hydrochinonlösung versetzt. Dieses $a, b$-ungesättigte Di-Keton wird durch Oxidation in $p$-Benzochinon überführt und wirkt somit als Inhibitor der Bisulfit-Oxidation. 
Durch Zugabe von $500 \mu \mathrm{l}$ frisch angesetzter $10 \mathrm{M} \mathrm{NaOH-Lösung} \mathrm{wurde} \mathrm{die} \mathrm{Bisulfit-Lösung}$ anschließend auf pH 5,0 justiert. Durch Zugabe von Aqua bidest. wurde die Lösung schließlich auf ein Endvolumen von $10 \mathrm{ml}$ gebracht.

Die Bisulfit-Behandlung wurde wie folgt vorgenommen: $2 \mu \mathrm{g}$ genomische DNA wurden in einem Volumen von 30-50 $\mu 1$ mit 3,3-5,5 $\mu 13 \mathrm{M} \mathrm{NaOH-Lösung} \mathrm{versetzt} \mathrm{(Endkonzentration} \mathrm{0,3}$ M) und 15 min bei $37{ }^{\circ} \mathrm{C}$ denaturiert. Es folgte ein Hitzeschock bei $99{ }^{\circ} \mathrm{C}$ für 2 min mit anschließendem Abkühlen in Eiswasser. Die so vorbehandelte DNA wurde dann mit $500 \mu 1$ der bisulfithaltigen Inkubationslösung gemischt, und $16-20 \mathrm{~h}$ bei $50{ }^{\circ} \mathrm{C}$ im Inkubator (im Dunkeln) inkubiert.

In Abbildung 4 ist der chemische Ablauf der Bisulfit-induzierten hydrolytischen Deaminierung von Cytosin zu Uracil schematisch beschrieben.

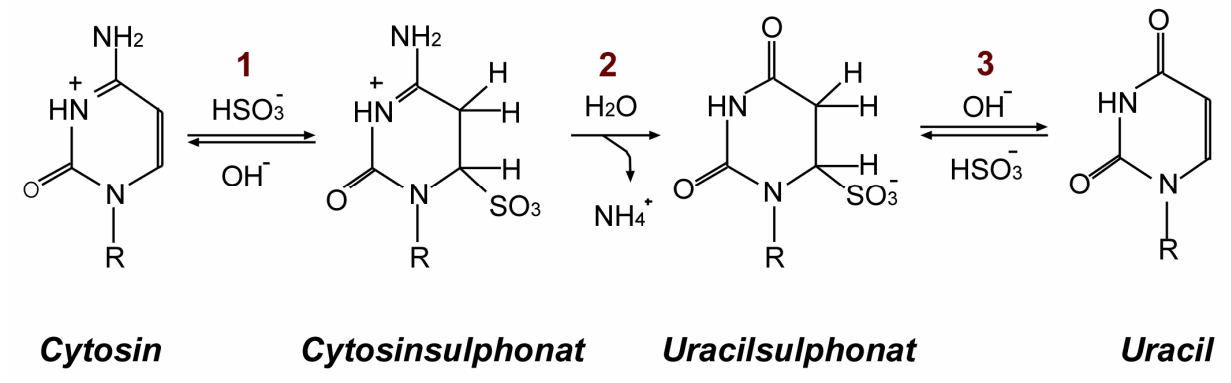

\begin{abstract}
Abb. 4: Schematische Darstellung der chemischen Umwandlung der Bisulfit-induzierten Deaminierung des Cytosins zu Uracil: Die relativ langsame Reaktion der DNA mit Natrium-Bisulfit ist hochgradig Einzelstrangspezifisch und wird bei niedrigem $\mathrm{pH}-$ Wert katalysiert. Dabei wird das Cytosin-Bisulfit-Addukt unter Abspaltung der $\mathrm{NH}_{2}$-Gruppe zum Uracil-SO $\mathrm{SO}_{3}$-Derivat deaminiert. Bei der anschließenden Alkali-Behandlung wird dieses Zwischenprodukt zu Uracil desulphoniert. 1: Sulphonierung, 2: Hydrolytische Deaminierung, 3: AlkaliDesulphonierung (bearbeitet nach Shapiro et al., 1973).
\end{abstract}

\title{
2.2.3.2.6. $\quad$ Aufreinigung der Bisulfit-behandelten DNA
}

$350 \mu 1$ der Bisulfit-behandelten DNA wurden auf Millipore-Säulchen (amicon Ultrafree MCSäulchen, Millipore) gegeben und bei $8000 \mathrm{U} / \min$ und $4{ }^{\circ} \mathrm{C}$ für 12 min abzentrifugiert. Der Durchfluss wurde verworfen und das Säulchen nochmals abzentrifugiert. Die DNA wurde in drei Waschschritten zunächst mit $350 \mu \mathrm{l}$ Aqua bidest., dann mit $350 \mu 1$ 0,1 M NaOH-Lösung und im letzten Waschschritt erneut mit $350 \mu \mathrm{l}$ Aqua bidest bei $8000 \mathrm{U} / \mathrm{min}$ für $12 \mathrm{~min}$ gewaschen. Zur Eluierung der DNA wurden $50 \mu$ A Aqua bidest. auf die Säule gegeben, nach mehrmaligem Spülen mit der Pipette abgezogen und in ein neues Reaktionsgefäß überführt. Nach der Denaturierung in $55 \mu$ einer $0,1 \mathrm{M} \mathrm{NaOH}$-Lösung für 15 min bei $37^{\circ} \mathrm{C}$ wurde die Lösung mit $55 \mu \mathrm{l} 6 \mathrm{M}$ Ammoniumazetat, $2 \mu \mathrm{l}$ Glykogen $(10 \mu \mathrm{g} / \mu \mathrm{l})$ und $350 \mu 199 \%$ Ethanol versetzt. Die Fällung der DNA fand bei $-20^{\circ} \mathrm{C}$ für ca. 30 min statt. Im Anschluß wurde die DNA für $20 \mathrm{~min}$ bei $13000 \mathrm{U} / \mathrm{min}$ und $4{ }^{\circ} \mathrm{C}$ sedimentiert. Das Pellet wurde in $300 \mu 170 \%$ 
Ethanol gewaschen, getrocknet und in 20-30 $\mu 1$ Aqua bidest gelöst. Gelagert wurde die DNA bei $-20^{\circ} \mathrm{C}$.

\subsubsection{7. $\quad P C R$ an Bisulfit-behandelter DNA}

Um eine für die Subklonierung ausreichende Menge Amplifikationsprodukt zu erzielen, wurde für jede der zu untersuchenden Regionen des Igf2-Genes ein innerhalb des ersten Primerpaares liegendes zweites Oligonukleotid-Primerpaar entworfen, mit dem eine "nested PCR" durchgeführt wurde. Für die PCR wurde das Expand Long Template PCR System von Roche Diagnostics verwendet. Die Nukleotidsequenzen sind in den Tabelle 22 und 23 aufgeführt.

Tabelle 22: Amplifikationsprimer für die Klonierung der Bisulfit-behandelte DNA (designed am modifizierten Vorwärtsstrang)

\begin{tabular}{|c|c|c|c|}
\hline Region & $\begin{array}{l}\text { Vorwärts-Primer } \\
\left(5^{`} \rightarrow 3^{`}\right)\end{array}$ & $\begin{array}{l}\text { Rückwärts-Primer } \\
\left(5^{`} \rightarrow 3^{`}\right)\end{array}$ & $\begin{array}{l}\mathbf{T}_{\mathrm{A}} \\
\text { in } \mathbf{C}\end{array}$ \\
\hline DMR1 H1 & $\begin{array}{l}\text { GCGGAATTCCGTTTATTTAGATT } \\
\text { TAGGAT }\end{array}$ & $\begin{array}{l}\text { GCCTACCTACCTTACATACATAAA } \\
\text { ATCG }\end{array}$ & 57 \\
\hline DMR2 H2 & $\begin{array}{l}\text { TGTTATAATATGGAAATTAGGTT } \\
\text { TAGTG }\end{array}$ & $\begin{array}{l}\text { СТTААСАТССАСАТTТААТTTТАС } \\
\text { TTT }\end{array}$ & 55 \\
\hline DMR2 H3-H4 & $\begin{array}{l}\text { TTGTTTGGTTTATATTTTTATTA } \\
\text { TATTTTT }\end{array}$ & $\begin{array}{l}\text { ТАТТTСАСТААТААТТАСТАААСА } \\
\text { ТСТСС }\end{array}$ & 53 \\
\hline
\end{tabular}

Alle PCR-Reaktionen wurden mit $3 \%$ DMSO versetzt. Dabei wurden die PCR-Schritte Denaturierung $\left(95{ }^{\circ} \mathrm{C} ; 30 \mathrm{~s}\right)$, Annealing (variable Temperatur s. Tabelle $\left.22 ; 1,30 \mathrm{~min}\right)$ und Extension $\left(68^{\circ} \mathrm{C} ; 3,30 \mathrm{~min}\right)$ $30 \mathrm{x}$ wiederholt.

Tabelle 23: „Nested“-Amplifikationsprimer für die Klonierung der Bisulfit-behandelten DNA des modifizierten Vorwärtsstranges

\begin{tabular}{|c|c|c|c|c|c|}
\hline Region & $\begin{array}{l}\text { Vorwärts-Primer } \\
\left(5^{`} \rightarrow 3^{\prime}\right)\end{array}$ & $\begin{array}{l}\text { Rückwärts-Primer } \\
\left(5^{`} \rightarrow 3^{\prime}\right)\end{array}$ & $\begin{array}{l}\mathbf{T}_{\mathrm{A}} \\
\text { in } \mathrm{C}^{\circ}\end{array}$ & $\begin{array}{l}\mathbf{L}_{\mathbf{P}} \\
\text { in bp }\end{array}$ & $\begin{array}{l}\text { Kloniert } \\
\text { in }\end{array}$ \\
\hline \multirow[t]{2}{*}{ DMR1 H1 } & GCGGAATTCCGGTGTGGG & CGCGGATCCGCACTAAAC & 62 & 596 & pGEM $^{\circledR}-$ \\
\hline & TTGTG & TTTAАСССТАТ & & & T Easy \\
\hline \multirow[t]{2}{*}{ DMR2 H1 } & CCGGAATTCCTTTTTGTA & CGCGGATCCCACTAATAA & 57 & 795 & pGEM $^{\circledR}-$ \\
\hline & GGGTGATTTAGT & TTACTAAАСАT & & & T Easy \\
\hline \multirow[t]{3}{*}{ DMR2 H4 } & CGCGGATCCGCGTGTGGT & CGCGGATCCGCGTTAAAA & 55 & 635 & pGEM $^{\circledR}-$ \\
\hline & TAAGTTGTAATTG & АСТАТСАААСТТАТААСТ & & & T Easy \\
\hline & & TTTAАААТТАС & & & \\
\hline
\end{tabular}

Alle PCR-Reaktionen wurden mit $3 \%$ DMSO versetzt. Dabei wurden die PCR-Schritte der Denaturierung $\left(95^{\circ} \mathrm{C} ; 30 \mathrm{~s}\right)$, Annealing (variable Temperatur s. Tabelle 23; 1,30 min) und Extension (68 $\left.{ }^{\circ} \mathrm{C} ; 4 \mathrm{~min}\right) 35 \mathrm{x}$ wiederholt. 


\subsection{Sequenzierung von Bisulfit-behandelter DNA}

Im Anschluß an die Amplifikation der Bisulfit-behandelten DNA wurden die Fragmente im Agarosegel aufgetrennt und eluiert. Zur Überprüfung der Quantität der DNA für die nachfolgende Klonierung wurden $2 \mu$ Eluat erneut in einem Agarosegel aufgetrennt. Die Klonierung erfolgte in den TA-Klonierungs-Vektor pGEM ${ }^{\circledR}-\mathrm{T}$ Easy. Nach der anschließenden Ligation und Transformation wurden von jeder Agar- Platte 24 weiße Klone selektiert und die DNA aufgereinigt. Nach einem Restriktionsendonuklease-Verdau mit EcoRI wurden die das entsprechende Fragment enthaltenden positiven Klone verifiziert. Die Sequenzierung erfolgte im Universitäts-Klinikum Göttingen, Abteilung Toxikologie und Pharmakologie. Für die Sequenzreaktion wurden folgende Sequenzierprimer benutzt:

Tabelle 24: Ausgewählte Sequenzierprimer der Bisulfit-behandelten DNA-Klone

\begin{tabular}{ll}
\hline Primername & Sequenz $\mathbf{( 5} \boldsymbol{\rightarrow} \mathbf{3})$ \\
\hline Sp6new & TTAGGTGACACTATAGAATACTCAAGC \\
pGEM-R & TGAGCGGATAACAATTTCACACA \\
T7new & AATACGACTCACTATAGGGCGAATGG \\
\hline \hline
\end{tabular}

Als Kontrolle für das Alignment und die Untersuchung der Subklone der Bisulfit-behandelten DNA wurden die entsprechenden Sequenzabschnitte aus Bisulfit-unbehandelter DNA von CD1 Wildtyptieren amplifiziert und subkloniert. In Tabelle 25 sind die Oligonukleotide und die PCRKonditionen dieser DNA-Bereiche aufgeführt.

Die Sequenzen aus Bisulfit-unbehandelter DNA diente als Kontrollsequenz der Basanabfolge in CD1 Mäusen und wurde im Macro-gestützten Computerprogramm einer hypothetischen Methylierung unterzogen. Diese konvertierten DNA-Sequenzen wurden zusammen mit den Sequenzen der Bisulfit-behandelten DNAs im Alignment ausgewertet.

Tabelle 25 Amplifikationsprimer für die Klonierung ausgewählter Regionen der DNA, die über die BisulfitBehandlung analysiert wurden.

\begin{tabular}{|c|c|c|c|c|c|}
\hline Region & $\begin{array}{l}\text { Vorwärts-Primer } \\
\left(5^{\prime} \rightarrow 3^{\prime}\right)\end{array}$ & $\begin{array}{l}\text { Rückwärts-Primer } \\
\left(5^{`} \rightarrow 3^{\prime}\right)\end{array}$ & $\begin{array}{l}\mathbf{T}_{\mathrm{A}} \\
\text { in } \mathrm{C}^{\circ}\end{array}$ & $\begin{array}{l}\mathbf{L}_{\mathbf{P}} \\
\text { in bp }\end{array}$ & $\begin{array}{l}\text { Kloniert } \\
\text { in }\end{array}$ \\
\hline \multirow[t]{2}{*}{ DMR1 H5-H9 } & ATGCTCCTTACTCCCAACAA & TCGTCCCATGCTCAGTTT & 60 & 963 & pGEM $^{\circledR}-\mathrm{T}$ \\
\hline & AT & TG & & & Easy \\
\hline \multirow[t]{2}{*}{ DMR2 H2 } & GATGTCATAGCATGGAAACC & CTGGCTGAGACTTGACAT & 58 & 745 & pGEM $^{\circledR}-\mathrm{T}$ \\
\hline & AGG & CCACAT & & & Easy \\
\hline \multirow[t]{2}{*}{ DMR2 H3-H4 } & СТСАСАСТTСТАССАСАТG & TTGCTGGACATCTCCGAA & 55 & 807 & pGEM $^{\circledR}-\mathrm{T}$ \\
\hline & & GAG & & & Easy \\
\hline
\end{tabular}




\subsubsection{Klonierung von DNA-Fragmenten}

\subsubsection{Vektorpäparation und Dephosphorylierung von Vektor-DNA}

2-5 $\mu \mathrm{g}$ der Vektor-DNA wurde für $2 \mathrm{~h}$ mit einem Überschuß des entsprechenden Restriktionsenzymes (3-5 U/ $\mu$ g DNA) unter optimalen Puffer- und Temperaturkonditionen inkubiert.

Die Dephosphorylierung von Vektor-DNA wurde direkt im Anschluß an den Restriktionsverdau durchgeführt. Das linearisierte Plasmid wurde für 30 min bei $37{ }^{\circ} \mathrm{C}$ in CIAP-Puffer der Behandlung mit alkalischer Phosphatase aus dem Kälberdarm (CIAP, 2U/ $\mu$ l, Fermentas) unterzogen. Das CIAP-Enzym (Calf Intestinal Alkaline Phosphatase) katalysiert die Entfernung der 5' -Phosphatgruppe von DNA, RNA sowie Ribo- und Desoxyribonukleosidtriphosphaten, wodurch eine Religation von Vektor-DNA nach erfolgreichem Restriktionsverdau verhindert wird. Die Reaktion wurde durch eine 10-minütige Inkubation bei $65^{\circ} \mathrm{C}$ gestoppt. Durch die sich anschließende Gelelektrophorese und Elution wurde das linearisierte und dephosphorylierte Plasmid aufgereinigt. Die DNA wurde PCI-extrahiert, mit Ethanol gefällt und in $10 \mu 1$ Aqua bidest. oder TE-Puffer resuspendiert. Bei Vektoren, die mit zwei verschiedenen Restriktionsenzymen hydrolysiert wurden, entfiel die CIAP-Behandlung.

\subsubsection{Präparation von Restriktionsfragmenten}

$\mathrm{Zu}$ klonierende DNA-Fragmente (Inserts) wurden durch Restriktionsverdau aus bereits vorhandenen Plasmiden ausgeschnitten. Das DNA-Fragment wurde durch Gelelektrophorese und Elution aus dem Gel aufgereinigt. Es folgten Fällung mit Ethanol und Resuspension in $10 \mu$ l Aqua bidest.

\subsubsection{Präparation von PCR-Fragmenten}

Eine große Anzahl klonierter Fragmente wurden durch die Polymerase-Ketten-Reaktion (PCR) aus genomischer DNA oder cDNA amplifiziert. Die PCR-Produkte wurden durch Gelelektrophorese und Elution aus dem Gel aufgereinigt, mit Ethanol gefällt und in einem geeigneten Volumen Wasser aufgenommen. In die Vektoren pGEM ${ }^{\circledR}-\mathrm{T}$ Easy oder pCR ${ }^{\circledR} \mathrm{II}$ konnten die PCR-Fragmente auf Grund ihres A-Überhanges direkt kloniert werden.

Sollten PCR-Produkte als Restriktionsfragmente kloniert werden, so wurden in der PCR Oligonukleotide verwendet, die entsprechende Überhänge mit den Erkennungssequenzen der Restriktionsenzyme enthielten. 


\subsubsection{Ligation}

\subsubsection{Ligation von PCR-Fragmenten}

Die von Invitrogen patentierte Methode erlaubt die direkte Ligation von gereinigten PCRProdukten in diverse Klonierungs- und Expressionsvektoren mit einer wesentlich höheren Ligationseffizienz als die klassische Ligation mit der T4-Ligase. TA-Vektorlösungen enthalten den linearisierten Vektor mit 3' -T-Überhängen, die sich komplementär zu den von der TaqDNA-Polymerasen erzeugten 5' -A-Überhängen verhalten.

Die Konzentration des zu klonierenden PCR-Fragmentes (2 $\mu$ l Eluat) wurde im Agarosegel abgeschätzt. Für die Ligationsreaktion nach Herstellerprotokoll wurden PCR-Produkt und Vektorlösung in einem Gesamtvolumen von $20 \mu 1$ gemischt und über Nacht bei $4{ }^{\circ} \mathrm{C}$ inkubiert. Das Ligationsprodukt wurde direkt in den Transformation-Reaktionsansatz eingesetzt.

\subsubsection{Ligation mit T4-DNA-Ligase}

Enzymatisch gespaltene und aufgereinigte DNA-Fragmente konnten direkt in die komplementären Restriktionsschnittstellen des nach Bedarf dephosphorylierten Vektors ligiert werden. Dafür wurde ein Verhältnis von DNA zu Vektor von $3: 1$ angestrebt und in einem $20 \mu$ l-Reaktionansatz mit $2 \mu 1$ Ligasepuffer $(10 \mathrm{x})$ und $1 \mu \mathrm{l}$ T4-DNA-Ligase $(5 \mathrm{U} / \mu \mathrm{l})$ vermischt. Der Ansatz wurde über Nacht bei $4{ }^{\circ} \mathrm{C}$ inkubiert und konnte direkt zur Transformation eingesetzt werden.

\subsubsection{Transformation von kompetenten E. coli-Zellen (nach Hanahan, 1983)}

$50 \mu 1$ kompetente (entsprechend für die Transformation vorbehandelte Bakterienzellen) E. coliZellen des Stammes DH5 $\alpha$ wurden auf Eis aufgetaut und mit dem Ligationsansatz (20 $\mu 1)$ oder 10-50 ng Plasmid-DNA versetzt. Im Anschluß an eine Inkubation von 20 min auf Eis erfolgte ein Hitzeschock für $45 \mathrm{~s}$ bei $42{ }^{\circ} \mathrm{C}$. Die Bakterien wurden für $5 \mathrm{~min}$ auf Eis abgekühlt und mit S.O.C.-Medium $(250 \mu 1$ für eine Transformation eines Ligationsansatzes, $500 \mu 1$ für eine Transformation von Plasmid-DNA) vermischt. Die Vermehrung der transformierten Bakterien erfolgte für $55 \mathrm{~min}$ bei $37{ }^{\circ} \mathrm{C}$ auf dem Schüttler (1200 U/ min). Abhängig von ihrer Antibiotikaresistenz wurden die transformierten Bakterienzellen $(150 \mu 1$ eines transformierten Ligationsansatzes, $20 \mu 1$ einer Plasmid-DNA-Transformation) auf die entsprechenden SelektivAgarböden ausgestrichen. Die entstandenen Kolonien wurden mittels einer Minipräparation und nachfolgendem Restriktionsverdau analysiert und gegebenenfalls sequenziert. 


\subsubsection{Genexpressionsanalyse}

\subsubsection{Gewebepräparation und Homogenisierung}

Die RNA-Lösungen wurden mit DEPC $(0,1 \%)$ bei RT über Nacht behandelt und autoklaviert. Alle Arbeitsschritte erfolgten unter RNase-freien Bedingungen.

Gewebe aus veschiedenen Organen der Maus und des Tumors wurden präpariert und bis zur weiteren Verwendung bei $-80{ }^{\circ} \mathrm{C}$ eingefroren. Die Gesamt-RNA wurde über die TRIzolMethode isoliert. Dazu wurde das Gewebe unverzüglich mit einem sterilen Skalpell zerteilt und mit Hilfe eines Homogenisators in TRIzol-Reagent homogenisiert. Die Integrität der RNA wurde im nativen Agarosegel überprüft und die Konzentration wurde in einem Spektrophotometer bestimmt.

\subsubsection{RNA Isolierung aus Gewebe}

Für die RNA-Isolierung aus Geweben wurde mit der Trizol-Methode gearbeitet. Trizol, ein Gemisch aus Phenol und Guanidiniumisothiozyanat, ist ein RNA-stabilisierendes Reagent, welches Zellbestandteile, DNA und Proteine zersetzt. Die durch das Phenol denaturierten Proteine werden als hydrophober Anteil in die organische Phase überführt, lagern sich in der Phasengrenze an, aggregieren und werden wasserunlöslich. Dagegen bleibt der hydrophile Anteil, die RNA, wasserlöslich und kann gefällt werden.

Nach der Homogenisierung der Gewebe in $2 \mathrm{ml}$ TRIzol-Reagent und einer Inkubation auf Eis für 5 min wurden $400 \mu$ l Chloroform zugegeben und für $15 \mathrm{~s}$ kräftig geschüttelt. Nach einer Inkubation bei RT für 3 min fand die Phasentrennung bei $3000 \mathrm{U} / \mathrm{min}$ für maximal $30 \mathrm{~min}$ bei $4{ }^{\circ} \mathrm{C}$ statt. Die wässrige Phase wurde in ein $2 \mathrm{ml}$ Reaktionsgefäß überführt und mit einem Volumenanteil Isopropanol für die RNA-Präzipitation versetzt. Nach einer Inkubation von 30 min bei $-20{ }^{\circ} \mathrm{C}$ wurde die RNA durch Zentrifugation bei $12000 \mathrm{U} / \mathrm{min}$ und $4{ }^{\circ} \mathrm{C}$ für $30 \mathrm{~min}$ sedimentiert. Das RNA-Pellet wurde mit $70 \%$ Ethanol gewaschen, getrocknet und in 100-200 $\mu 1$ RNAse-freiem Wasser aufgenommen, auf Eis gelöst und bei $-80^{\circ} \mathrm{C}$ eingefroren.

\subsubsection{RNA-Isolierung aus Zellkulturen}

Es wurde die RNA aus $1 \times 10^{3}-5 \times 10^{4}$ transfizierten Zellen isoliert. Die kultivierten Zellen wurden mit 1 x PBS gewaschen und in $500 \mu 1$ TRIzol-Reagent pro Loch der 6-Loch-Platte für 5 min inkubiert. Das Zelllysat wurde mit einer Pipette abgenommen und in sterile $2 \mathrm{ml}$ Reaktionsgefäße überführt. Da die Transfektionsexperimente in Doubletten durchgeführt wurden, konnten je zwei Zelllysate von gleich transfizierten Löchern der 6-Loch-Platte gepoolt werden. Nach Inkubation auf Eis und Zugabe von $200 \mu$ Chloroform/ ml Zelllysat wurde wie im vorherigen Kapitel "RNA-Isolierung aus Gewebe" verfahren. 


\subsubsection{First-Strand cDNA Synthese}

Bei dieser Variante der cDNA-Synthese dient die instabile mRNA als initiale PCR-Matrize und muss zunächst mittels einer reversen Transkription (RT) in eine stabile Form der copy oder complementary DNA (cDNA) übersetzt werden.

Für die Synthese wurden $2 \mu \mathrm{g}$ gelöste RNA mit RNAse-freiem Wasser auf ein Volumen von $7 \mu 1$ gebracht und mit $5 \mu 1$ Hexameren $(50 \mathrm{ng} / \mu 1)$ vermischt. Die Anlagerung der Hexamere fand bei $70{ }^{\circ} \mathrm{C}$ für $10 \mathrm{~min}$ statt. Nach kurzem Abzentrifugieren wurden $7 \mu 1$ eines Mastermixes (4 $\mu 15 \times 1^{\text {st }}$ strand Puffer; $2 \mu 1$ 0,1 M DTT und $1 \mu 10 \mathrm{mM}$ dNTPs) zugegeben und bei RT für 10 min inkubiert. Der Reaktionsansatz wurde anschließend für $2 \mathrm{~min}$ auf das Temperaturoptimum der Reversen Transkriptase (Moloney Murine Leukämia-Virus RT) von $42{ }^{\circ} \mathrm{C}$ gebracht und nach Zugabe von $1 \mu \mathrm{l}$ Enzym (200 U/ $\left.\mu \mathrm{l}\right)$ und vorsichtigem Mischen fand die Synthese innerhalb von 55 min statt. Nach einem kurzen Abzentrifugieren und der Inaktivierung des Enzymes bei $70{ }^{\circ} \mathrm{C}$ für 15 min wurden $1 \mu 1$ RNAse $\mathrm{H}(1 \mathrm{U} / \mu 1)$ dem cDNAGemisch zugesetzt. Diese Endoribonuklease degradiert den RNA-Strang von RNA-DNAHybriden in einer Reaktionszeit von 20 min bei $37{ }^{\circ} \mathrm{C}$. Die Lagerung der cDNA erfolgte bei $-20^{\circ} \mathrm{C}$.

Bei der Umschreibung von RNA in cDNA wird davon ausgegangen, daß die Reverse Transkriptase eine Effizienz von mindestens $50 \%$ erreicht. Bei $2 \mu \mathrm{g}$ in die Synthese eingesetzter RNA könnten somit mindestens $1 \mu \mathrm{g}$ cDNA/ $20 \mu$ l Reaktionsansatz erwartet werden.

\subsubsection{PCR-Techniken}

Mit der Methode der Polymerase-Kettenreaktion (PCR) werden DNA-Matrizen (Templates) sequenzspezifisch amplifiziert. Dazu wird die DNA durch Hitze zunächst denaturiert. Im zweiten Schritt, der Anlagerungsreaktion, hybridisieren anschließend die Oligonukleotidprimer mit ihrem komplementären DNA-Strang (Anlagerung), worauf im dritten Schritt die DNAPolymerase eine DNA-Neusynthese (Verlängerung) zwischen diesen Primern in 5' $\rightarrow$ 3'-Richtung vornimmt. Der Zyklus aus Denaturierung, Anlagerung und Verlängerung wird 20-35 x wiederholt, wobei die neu synthetisierten Tochterstränge im nächsten Zyklus selbst als DNA-Matrizen fungieren.

Schon ab dem dritten Zyklus entstehen DNA-Doppelstränge, deren Länge dem Abstand zwischen den Primern entspricht. Mit jedem Zyklus erhöht sich der Anteil dieser DNAAbschnitte mit der Zielsequenz auf etwa das Doppelte, so daß theoretisch nach $n$ Zyklen eine Anzahl von maximal $2^{n}$ DNA-Molekülen dieser Länge im Reaktionsansatz enthalten ist. Dies entspricht einer logarithmischen Vervielfältigung der DNA-Zielsequenz. 
Alle PCR-Produkte wurden im Anschluß an die Reaktion elektrophoretisch auf einem DNAAgarosegel analysiert.

\subsubsection{Quantitative real-time QRT-PCR}

Diese Methode erlaubt es, den Verlauf einer PCR-Reaktion zu verfolgen und das gebildete Produkt relativ zu einem Standard zu quantifizieren. Nach Holland et al., 1991 und Livak et al., 1995 werden neben den üblichen Oligonukleotid-Primern für die Amplifikation ein beidseitig markiertes Oligonukleotid (TaqMan-Sonde) für die Detektion des gebildeten Produkts benötigt. Diese Markierung besteht aus dem nicht fluoreszierenden 3' -gebundenen Quencher TAMRA (Minor Groove Binder, MGB, ABI) und dem fluoreszierenden 5' -gebundenen 6-CarboxyFluorescein (FAM, ABI), das als Reporter fungiert (Abb. 5).

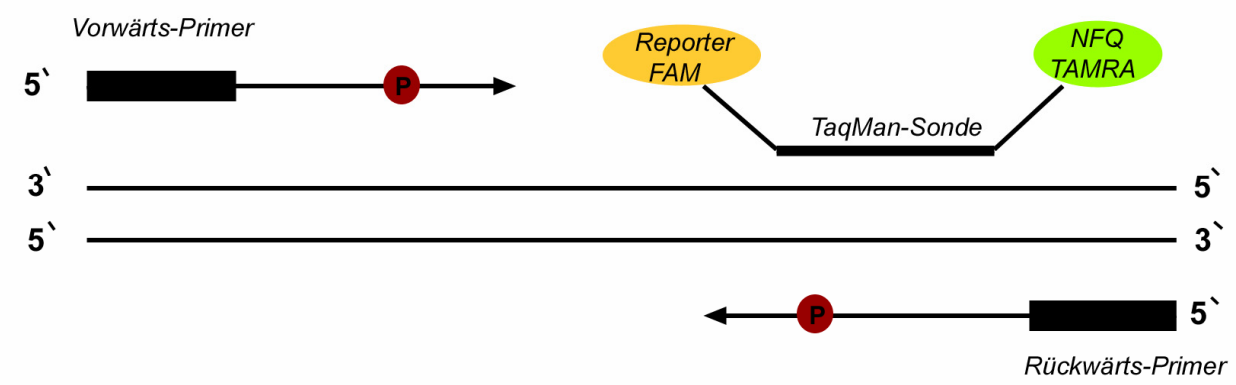

Abb. 5: Anlagerung der Primer und der TaqMan-Sonde während der PCR. Die TaqMan-Sonde kann je nach Syntheserichtung entweder mit dem Plus-Strang $\left(5^{\prime} \rightarrow 3^{\prime}\right)$ oder mit dem komplementären cDNA-Strang (3' $\rightarrow$ 5') hybridisieren. Solange die Sonde intakt ist, wird durch den nicht-fluoreszierenden Quencher (NFQ, TAMRA) die Fluoreszenzstrahlung des Reporters (FAM) unterdrückt. Der Quencher verankert die Sonde in der kleinen Furche der DNA und erlaubt eine spezifische Anlagerung trotz geringer Sondenlänge (ca. 13-17 bp). P: DNA-Polymerase.

Durch die 5' $\rightarrow$ 3'-Exonukleaseaktivität der Taq-DNA-Polymerase wird im Verlauf der DNASynthese die an die cDNA gebundene Sonde abgespalten. Dadurch wird der Reporter in zunehmendem Maß freigesetzt und entfernt sich räumlich vom Quencher. Während der PCRReaktion werden die freien Reportermoleküle durch regelmäßige Fluoreszenzeinstrahlung angeregt und geben ihrerseits Fluoreszenzstrahlung ab (Abb. 6). 


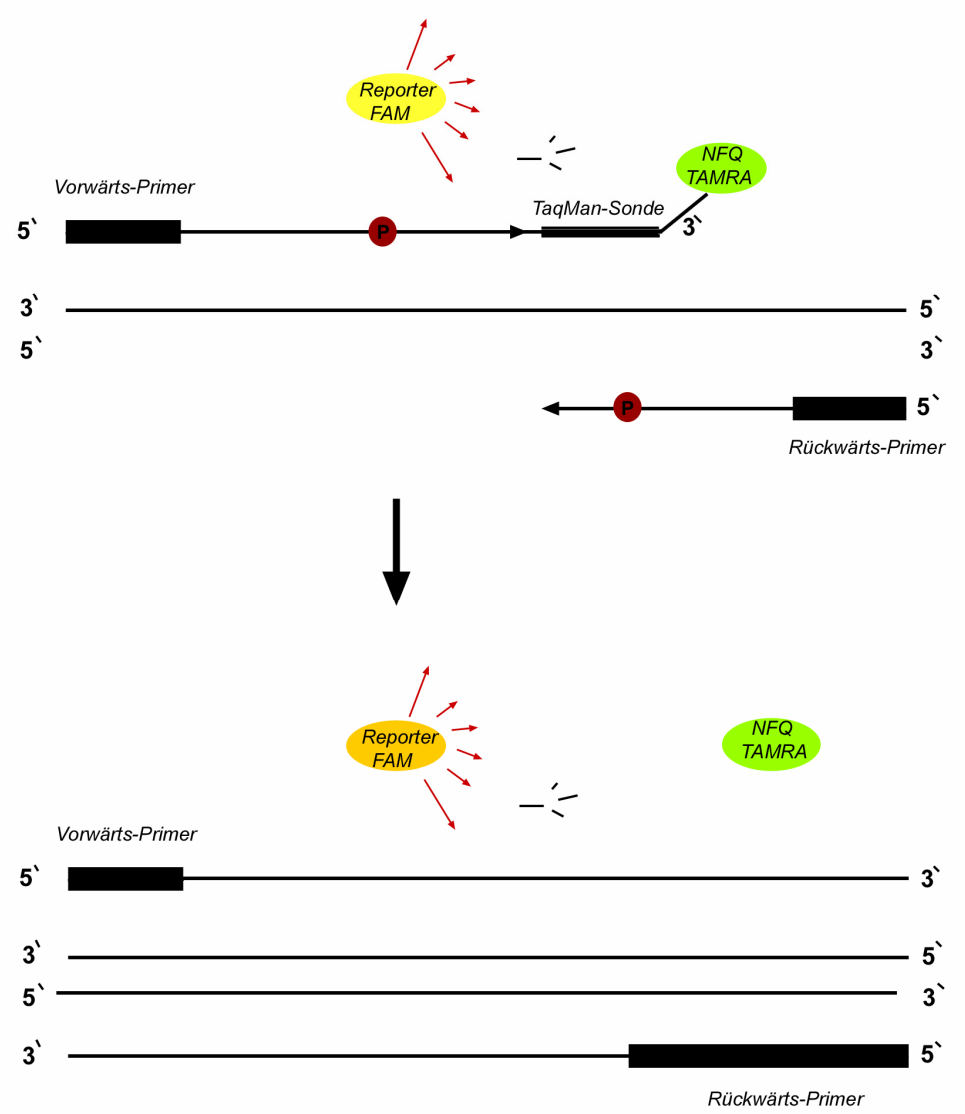

Abb. 6: Abspaltung der TaqMan-Sonde und cDNA-Synthese. Die 5' $\rightarrow$ 3'-Exonukleaseaktivität der Taq-DNAPolymerase führt zur Abspaltung der Sonde und Freisetzung des Reporters (FAM), der in räumlicher Entfernung vom Quencher (NFQ, TAMRA) bei Anregung Fluoreszenzstrahlung abgibt. Nur tatsächlich angelagerte Sondenmoleküle werden durch die Exonukleaseaktivität gespalten (mit freundlicher Genehmigung von Dr. Frauke Petry).

Der Anstieg des Fluoreszenzsignals korreliert in der exponentiellen Phase der PCR direkt mit der Zunahme des PCR-Produktes. Mittels der SDS 2.1 Software (ABI) läßt sich die Zykluszahl bestimmen, bei der sich das Fluoreszenzsignal gerade deutlich vom Reaktionshintergrund abhebt. Führt man parallel zur eigentlichen Messung die gleiche Reaktion mit bekannten cDNA-Matrizenmengen durch (z. B. mit Referenzplasmiden), erhält man eine Standardkurve mit $\mathrm{C}_{\mathrm{T}}$-Werten und relativen Werten, die einen Rückschluß auf die Produktmengen zulassen. Eine relative Quantifizierung ermöglicht somit den Vergleich verschiedener Expressionen der eingesetzten cDNAs.

In dieser Arbeit wurde die Methode der quantitativen real-time PCR genutzt, um auf mRNAEbene den Anstieg des endogenen Igf2-Genes in stimulierten Zellen zu bestimmen. Zur Erstellung einer Standardkurve wurde cDNA aus Rhabdomyosarkomen in verschiedenen Verdünnungen verwendet, da in diesen Tumoren $\operatorname{Ig} f 2$ überexprimiert wird. 
Da Unterschiede im cDNA-Gehalt verschiedener Proben das Ergebnis verfälschen können, wurde eine endogene Kontrolle (18S rRNA) verwendet, um diese Unterschiede ausgleichen zu können.

\subsection{Quantifizierung der endogenen Igf2-Expression über quantitative real-time QRT-PCR}

Zur Erstellung der Standardkurven wurde cDNA von RMS in mindestens fünf Vedünnungsstufen verwendet, wobei von einer Ausgangskonzentration von $10 \mathrm{ng} / \mu 1$ gestartet wurde. Die cDNA wurde in 1: 5 Verdünnungenschritten mit Aqua bidest. verdünnt. Die Standardkurven wurden zur Bestimmung der relativen Quantifizierung unbekannter cDNA, die aus transfizierten Zellen gewonnen wurde, eingesetzt.

Die zu quantifizierende cDNA aus den Zellkulturexperimenten wurde $1: 5$ verdünnt und jeweils $100 \mathrm{ng}(10 \mu \mathrm{l})$ der cDNA wurden im TaqMan vermessen ${ }^{13}$.

Die lyophilisierte Igf2-Sonde wurde in $600 \mu \mathrm{l}$ Puffer ( $1 \mathrm{mM}$ Tris-HCl; $0,01 \mathrm{mM}$ EDTA) aufgenommen und somit auf eine Konzentration von $10 \mu \mathrm{g} / \mu \mathrm{l}(10 \mu \mathrm{M})$ gebracht. Aliquots zu je $50 \mu 1$ wurden in Aluminiumfolie bei $-20{ }^{\circ} \mathrm{C}$ gelagert.

\author{
Mastermix (Igf2): \\ Puffer (10x) \\ $\mathrm{MgCl}_{2}(50 \mathrm{mM})$ \\ dNTPs $(2,5 \mathrm{mM})$ \\ fwd. Primer $(10 \mu \mathrm{M})$ \\ rev. Primer $(10 \mu \mathrm{M})$ \\ Igf2-Sonde $(10 \mu \mathrm{M})$ \\ Hot Gold Star Polymerase $(5 \mathrm{U} / \mu \mathrm{l})$ \\ $\mathrm{H}_{2} \mathrm{O}$ \\ Probe
}

PCR-Programm:

$10 \min 95^{\circ} \mathrm{C}$

$\left.\begin{array}{ll}15 \mathrm{~s} & 95^{\circ} \mathrm{C} \\ 60 \mathrm{~s} & 60^{\circ} \mathrm{C}\end{array}\right\} \quad 40$ Zyklen

\begin{tabular}{|c|c|}
\hline $\begin{array}{l}\text { 96-Platte } \\
\text { einfach konzentriert }\end{array}$ & $\begin{array}{l}\text { 384-Platte } \\
\text { einfach konzentriert }\end{array}$ \\
\hline $5 \mathrm{mM}$ & $2,5 \mathrm{mM}$ \\
\hline $200 \mu \mathrm{M}$ & $100 \mu \mathrm{M}$ \\
\hline $300 \mathrm{nM}$ & $150 \mathrm{nM}$ \\
\hline $300 \mathrm{nM}$ & $150 \mathrm{nM}$ \\
\hline $200 \mathrm{nM}$ & $100 \mathrm{nM}$ \\
\hline $0,025 \mathrm{U}$ & $0,025 \mathrm{U}$ \\
\hline ad. $20 \mu \mathrm{l}$ & ad. $10 \mu \mathrm{l}$ \\
\hline $10 \mu \mathrm{l}$ & $10 \mu \mathrm{l}$ \\
\hline
\end{tabular}




\subsection{Quantifizierung der $18 S \mathrm{rRNA}$ als endogene Kontrolle über quantitative real- time QRT-PCR}

Zur Erstellung der Standardkurve für die endogene Kontrolle wurde ein Plasmid der 18S rRNAcDNA (bereitgestellt von Dr. Frauke Petry) verwendet. Das murine Haushaltsgene wurde in mindestens fünf Vedünnungsstufen verwendet, wobei von einer Ausgangskonzentration von 100 pg/ $\mu 1$ gestartet wurde. Das Plasmid wurde jeweils $1: 5$ mit Aqua bidest. verdünnt. Da man eine konstante Kopienzahl der Haushaltsgene innerhalb verschiedener cDNA-Proben voraussetzt, kann die Expression von Haushaltsgenen zur Normalisierung verwendet werden.

Die zu quantifizierenden cDNAs der transfizierten Zellen wurden auf $1 \mathrm{pg} / \mu \mathrm{l}$ verdünnt, wobei $10 \mu 1$ der cDNA vermessen wurden.

\section{Mastermix (18S rRNA, ABI):}

Puffer (10x)

$\mathrm{MgCl}_{2}(50 \mathrm{mM})$

dNTPs $(2,5 \mathrm{mM})$

Reaktionsmix (Primer, Sonde VIC-MGB-gelabelt)

Hot Gold Star Polymerase $(5 \mathrm{U} / \mu \mathrm{l})$

$\mathrm{H}_{2} \mathrm{O}$

Probe

\section{PCR-Programm:}

$10 \min 95^{\circ} \mathrm{C}$

$15 \mathrm{~s} \quad 95^{\circ} \mathrm{C}$

$\left.60 \mathrm{~s} \quad 60^{\circ} \mathrm{C}\right\}$

40 Zyklen

\section{6-Platte}

einfach konzentriert

$5 \mathrm{mM}$

$300 \mathrm{nM}$

$1,5 \mu l$

$0,025 \mathrm{U}$

ad. $20 \mu 1$

$10 \mu 1$

\section{Mastermix (18S rRNA, Qiagen):}

Reaktionsmix QuantiTect (SYBR Green, 2x)

fwd. Primer $(10 \mu \mathrm{M})$

rev. Primer $(10 \mu \mathrm{M})$

$\mathrm{H}_{2} \mathrm{O}$

Probe

\section{PCR-Programm:}

$2 \min 50^{\circ} \mathrm{C}$

$15 \min 95^{\circ} \mathrm{C}$

$\left.\begin{array}{ll}15 \mathrm{~s} & 95^{\circ} \mathrm{C} \\ 30 \mathrm{~s} & 60^{\circ} \mathrm{C} \\ 30 \mathrm{~s} & 72^{\circ} \mathrm{C}\end{array}\right\}$

Aus den Werten der Messungen von Igf2 und 18S rRNA wurde der Quotient gebildet, die Standardabweichung errechnet und grafisch dargestellt. Alle Messungen wurden in Doubletten durchgeführt und jedes Ergebnis wurde in einem zweiten unabhängig durchgeführten Experiment verifiziert.

\section{4-Platte}

einfach konzentriert

$300 \mathrm{nM}$

$300 \mathrm{nM}$

ad. $10 \mu \mathrm{l}$

$10 \mu \mathrm{l}$ 


\subsubsection{Southern Blot-Analyse}

\subsubsection{Vorbereitung der Proben und Gelelektrophorese}

Die aus dem Tumor und Normalgeweben isolierte genomische DNA wurde zunächst einem qualitativen Test unterzogen. Dabei wurden $1 \mu \mathrm{g}$ der DNA auf ein $1 \%$ Agarosegel geladen und auf eventuelle Degradierung hin untersucht. Dann wurden $15 \mu \mathrm{g}$ der getesteten genomischen DNA über Nacht mit den methylierungssensitiven Enzymen HpaII und MspI hydrolytisch gespalten. Die mit Cresol-Ladepuffer versetzten und geschnittenen DNAs wurden auf ein maximales Endvolumen von $80 \mu$ gebracht und auf ein 1 x TAE 0,8 \%iges Agarosegel aufgetragen. Die Auftrennung der Fragmente nach ihrer Größe erfolgte über Nacht bei $50 \mathrm{~V}$ im 1 x TAE-Elektrophoresepuffer. Nach der photographischen Dokumentation unter UV-Licht wurde der Transfer nach der neutralen SSC-Methode vorbereitet.

\subsubsection{DNA-Transfer auf Nylon-Membranen}

Der Transfer von genomischer DNA aus dem Agarosegel auf eine Nylon-Membran (Southern Blotting) erfolgte in Anlehnung an eine von Ed Southern, 1975 beschriebenen, auf Kapillarkräften beruhenden Methode.

Zunächst wurden die DNA-Fragmente depuriniert. Dazu wurde das Gel im Depurinierungspuffer 30 min vorsichtig geschüttelt. Während der Inkubationszeit erfolgte ein Farbumschlag des Ladepuffers von rot nach gelb. Es folgten die Denaturierung der DNAFragmente durch vorsichtiges Schütteln des Gels im Denaturierungspuffer und die Neutralisierung im Neutralisierungspuffer für je $30 \mathrm{~min}$. Im Anschluß wurde das Gel im Transferpuffer für 10 min geschüttelt. Zwischen den jeweiligen Waschschritten wurde das Gel mit Aqua bidest. vorsichtig gewaschen. Die verwendete Nylon-Membran wurde vor dem Transfer mit dem Transferpuffer benetzt und ebenso wie die Filterpapiere in $20 \mathrm{x}$ SSC äquilibriert. Der Blotaufbau erfolgte nach dem Prinzip wie in Sambroock et al., 1989 beschrieben.

Die Transferzeit im Turbo-Blotter-System (Schleicher \& Schuell) erfolgte über Nacht im Transferpuffer. Im Anschluß an den Transfer wurde die Nylon-Membran mit $250 \mathrm{~mJ} / 50 \mathrm{~s}$ UVLicht bestrahlt und bei $80{ }^{\circ} \mathrm{C}$ für $2 \mathrm{~h}$ gebacken, um die DNA-Fragmente stabil auf die Membranoberfläche zu fixieren. Die Vollständigkeit des Transfers wurde durch Betrachtung des Gels und der Membran auf dem UV-Durchlichttisch überprüft und fotografisch dokumentiert. 


\subsubsection{Herstellen radioaktiv markierter DNA-Sonden}

Zur radioaktiven Markierung von Oligonukleotiden wurde das Primer-It ${ }^{\circledR}$ RmT Random Primer Labeling Kit von Stratagene verwendet. Dieses System basiert auf der Anlagerung von Random-Primern an multiple Seiten des denaturierten DNA-Templates. Die Magenta DNAPolymerase erkennt die Primer-Template-Komplexe und synthetisiert einen neuen DNA-Strang, wobei das radoaktiv markierte Monophosphat $\left[\alpha^{32} \mathrm{P}\right]-\mathrm{dCTP}$ an die freie $\mathrm{OH}-\mathrm{Gruppe}$ der vorangehenden Base gebunden und somit in die DNA inkorporiert wird. Die so radioaktiv markierte DNA wurde als Hybridisierungssonde für Southern- und Northern-Blots eingesetzt.

50-100 ng DNA wurden dem Primer-Reaktionsmix zugegeben, auf ein Endvolumen von $42 \mu 1$ mit Aqua. Bidest. aufgefüllt und bei $99^{\circ} \mathrm{C}$ für 5 min denaturiert. Nach dem Abkühlen auf $4{ }^{\circ} \mathrm{C}$ wurden $50 \mu \mathrm{Ci}\left[\alpha^{32} \mathrm{P}\right]$-dCTP zugegeben und unter Zuhilfenahme des Primer-It ${ }^{\circledR}$ RmT Random Primer Labeling Kits fand die radioaktive Markierung für 20 min bei $37{ }^{\circ} \mathrm{C}$ statt. Nichtinkorporierte Nukleotide wurden durch Gelfiltration an G50-Säulen (Amersham) entfernt.

\subsubsection{Radioaktive Hybridisierung von Southern-Blots}

Zur Absättigung freier Bindungsstellen wurde die in 2 x SSC-Lösung (ㅁtandard $\underline{\text { Saline }}$ Citrate Buffer) befeuchtete Membran in einem Hybridisierungsgefäß (Glasflasche) bei $65{ }^{\circ} \mathrm{C}$ im Hybridisierungsofen mit $5 \mathrm{ml}$ Rapid-hyb-Buffer (Amersham) und $100 \mu 1$ denaturierten, auf Eis abgekühlten, Lachsspermien (10 mg/ ml, Stratagene) vorhybridisiert. Die Vorhybridisierung erfolgte für 1-2 Stunden, danach wurde die Lösung erneuert und mit der radioaktiv markierten, denaturierten und aufgereinigten DNA-Sonde versetzt. Es wurden $>50 \mathrm{ng}$ des radioaktiv markierten Sondenmaterials in $5 \mathrm{ml}$ Hybridsierungslösung eingesetzt. Dabei wurden für die Hybridisierung jeweils zwei Sondenansätze vorbereitet, da die Nylon-Membranen für SouthernBlot-Hybridisierungen größere Oberflächen als die für Northern-Blot Hybridisierungen aufwiesen. Die Hybridisierung erfolgte unter Rotation über Nacht bei $65^{\circ} \mathrm{C}$.

Nach Beendigung der Hybridisierung wurde die Hybridisierungslösung verworfen und die Membran zur Entfernung unspezifisch gebundener Oligonukleotide unter abnehmender Ionenkonzentration des Waschpuffers I (low stringency buffer) zweimal für 30 min und einmal für $30 \mathrm{~min}$ mit dem Waschpuffer II (high stringency buffer) gewaschen. Nach dem letzten Waschschritt wurden die radioaktiven Zerfälle/ Flächeneinheit $\left(\mathrm{Bq} / \mathrm{cm}^{2}\right)$ mit einem Flächenzähler (LB122, Berthold) gemessen. Nach dem Erreichen einer konstanten Aktivität von 1-5 Bq/ $\mathrm{cm}^{2}$ wurde die Waschprozedur abgebrochen. Die leicht angetrocknete Membran wurde in Klarsichtfolie eingeschweißt und in einer Bleikassette zusammen mit einem Röntgenfilm für $4 \mathrm{~h}$ bei $-80{ }^{\circ} \mathrm{C}$ exponiert. Die Auswertung der radioaktiven Signale erfolgte in einem Entwicklerautomaten (AGFATEX Curix 60, AGFA). 


\subsubsection{Strippen der hybridisierten DNA-Nylon-Membranen}

Durch die Behandlung einer hybridisierten Nylon-Membran mit dem Stripping-Puffer wurde die komplementär gebundene Hybridisierungssonde von der Membran gewaschen und ermöglichte eine nochmalige Hybridisierung der Membran mit einer zweiten Sonde. Dazu wurde die hybridisierte Nylon-Membran für 1-2 h im aufgekochten Stripping-Puffer inkubiert.

\subsubsection{Northern Blot-Analyse}

Die Arbeiten zur Northern Blot-Analyse wurden unter RNase-freien Bedingungen durchgeführt. Die Lösungen wurden mit DEPC-Wasser behandelt und autoklaviert.

\subsubsection{Denaturierende RNA-Gelelektrophorese}

In einem autoklavierten Gefäß wurden 1,5 g Agarose (Agarose Electrophoresis Grade ultra pure, Invitrogen) in $108 \mathrm{ml}$ Wasser durch Aufkochen vollständig gelöst. Nach einer Abkühlungsphase wurden $15 \mathrm{ml} 10$ x MOPS-Puffer und $27 \mathrm{ml} 37 \%$ Formaldehyd zugesetzt. Nach Schwenken und Abkühlen wurde das Gel $(14$ x 11 x $0.7 \mathrm{~cm})$ nach Einsetzen der Kämme luftblasenfrei gegossen. Die Gelkammer und Kämme waren zuvor zur Inaktivierung der RNasen mit RNaseZAP inkubiert worden.

\subsubsection{Probenvorbereitung und Elektrophorese}

Zunächst wurden $10 \mu \mathrm{g}$ der auf Eis aufgetauten RNA mit $10 \mu \mathrm{l} 3 \mathrm{M}$ Na-Azetat und $250 \mu 1$ absolutem Ethanol gefällt. Das gewonnene Pellet wurde in $6 \mu 1$ Wasser aufgenommen und mit $14 \mu 1$ Ladepuffer gemischt. Anschließend wurden die Ansätze, einschließlich des RNAMarkers, bei $65{ }^{\circ} \mathrm{C}$ für 10 min denaturiert, auf Eis abgekühlt, kurz zentrifugiert und auf das Gel aufgetragen.

Die elektrophoretische Auftrennung erfolgte bei einer konstanten Stromstärke von 40-45 V unter Umwälzung des Elektrophoresepuffers (1 x MOPS-Puffer). Im Anschluß wurde die gleichmäßige Beladung der Bahnen mittels UV-Durchlicht überprüft und fotografisch dokumentiert. Das in die RNA interkalierende Ethidiumbromid des Ladepuffers ermöglicht es, die rRNA-Banden unter UV-Licht sichtbar zu machen. Die 18S rRNA- und 28S rRNA-Banden (1,9 kb bzw. 4,7 kb in der Maus) dienten als interner Molekulargewichtsstandard.

\subsubsection{RNA-Transfer auf Nylon-Membranen}

Der Transfer von RNA aus dem Agarosegel auf eine Nylon-Membran (Northern Blotting) erfolgte in Anlehnung an eine 1975 von Ed Southern beschriebenen, auf Kapillarkräften beruhenden Methode.

Die verwendete Nylon-Membran wurde vor dem Transfer mit sterilem Aqua bidest. benetzt und wie die Filterpapiere in 10 x SSC äquilibriert. Der Blotaufbau erfolgte nach dem Prinzip wie in 
Sambroock et al., 1989 beschrieben. Die Transferzeit im Turbo-Blotter-System (Schleicher \& Schuell) erfolgte für 24-36 h im 10 x SSC Transferpuffer. Im Anschluß an den Transfer wurde die Nylon-Membran mit $250 \mathrm{~mJ} / 50 \mathrm{~s} \mathrm{UV}$-Licht bestrahlt und bei $80^{\circ} \mathrm{C}$ für $2 \mathrm{~h}$ inkubiert, um die RNA stabil auf die Membran zu fixieren. Die Vollständigkeit des Transfers wurde durch Betrachtung des Gels und der Membran auf dem UV-Durchlichttisch überprüft und fotografisch dokumentiert.

\subsubsection{Radioaktive Hybridisierung von Northern-Blots}

Die radioaktive Hybridisierung von RNA an Northern Blots erfolgte nach dem wie oben "Radioaktive Hybridisierung von DNA an Southern-Blots" beschriebenen Protokoll. Dabei wurde für die Hybridisierung nur ein Sondenansatz vorbereitet, da die Nylon-Membranen für Northern-Blot-Hybridisierungen kleinere Oberflächen als die für Southern-BlotHybridisierungen aufwiesen.

\subsubsection{Histologische Methoden}

\subsubsection{Gefrierschnitte}

Das Einbetten von tiefgefrorenen Geweben und Tumoren erfolgte im Einbettmedium (Cryoblock, Medite) auf Trockeneis. Im Anschluß wurden 3-5 $\mu \mathrm{m}$ dicke Gefrierschnitte am Kryostaten (Leica Instruments, Model CM 1900-1-1) angefertigt und auf beschichtete Objektträger (SuperFrost) aufgeschmolzen. Die Schnitte wurden bei RT für 30 min getrocknet und bei $4-8{ }^{\circ} \mathrm{C}$ gelagert.

\subsubsection{Hämatoxylin-Eosin-Färbung}

Durch diese Färbemethode werden Moleküle, die im sauren pH-Bereich liegen, durch Hämatoxylin angefärbt. So weisen die Zellkerne eine blaue Färbung auf. Das Zytoplasma hingegegen wird durch die Eosin-Lösung rot angefärbt.

Die Gefrierschnitte wurden für 3 min in Hämatoxylin-Lösung inkubiert und unter fließendem Leitungswasser gebläut. Nach einer Inkubation für $15 \mathrm{~s}$ in Eosin-Lösung $(1: 3$ Verdünnung der Stocklösung durch Zugabe von $80 \%$ Ethanol und $0,5 \%$ Eisessigsäure) wurden die Gefrierschnitte mit Aqua bidest. gespült. Die Präparate wurden in einer aufsteigenden Ethanolreihe (70\%, $96 \%$ und $99 \%)$ dehydriert und nach kurzem Schwenken in Xylol dauerhaft in Pertex eingedeckelt. Das Trocknen der nun gefärbten und fixierten Schnitte erfolgte für 10-15 min bei $55{ }^{\circ} \mathrm{C}$. Die Auswertung und Bilddokumentation wurde am Mikroskop (Axiovert 25, Carl Zeiss Jena GmbH, Jena) durchgeführt. 


\subsubsection{Histochemische Methoden}

\subsubsection{1. $\quad \beta$-Galaktosidase-Enzymhistochemie}

Diese Nachweismethode wurde für Zelllinien angewendet, die mit lacZ-enthaltenden Cosmiden transfiziert wurden. Der Nachweis des lacZ-Genes erfolgte durch eine Xgal-Behandlung. Diese farblose Substanz ist mit einer chromophoren Gruppe $\beta$-1-4-glykosidisch an Galactose gebunden. Nach der Hydrolyse von Xgal durch das $\beta$-Galaktosidase-Enzym erfolgt eine Blaufärbung.

Die transfizierten Zellen wurden mit 1 x PBS/ 4 \% PFA versetzt und 15 min auf Eis inkubiert. Es folgten drei Waschschritte mit 1 x PBS. Die Inkubation der Zellen erfolgte auf Eis für jeweils 20 min. Nach einer Fixierung der Zellen mit 1 x PBS/ 0,2 \% Glutaraldehyd und einer einmaligen Inkubation für 10 min auf Eis wurden die fixierten Zellen dreimal je 5 min mit dem lacZ-Puffer gewaschen. Die Inkubation der Zellen mit der lacZ-Färbelösung erfolgte über Nacht bei $30^{\circ} \mathrm{C}$ im Dunkeln.

Die Konservierung der blau gefärbten und dreimal à 20 min mit 1 x PBS gewaschenen Zellen erfolgte zunächst in $15 \%, 30 \%$ und $50 \%$ Glyzerol jeweils über Nacht. Die Zellen konnten über einen längeren Zeitraum in $80 \%$ Glyzerol bei $4-8{ }^{\circ} \mathrm{C}$ gelagert werden.

\subsubsection{Zellbiologische Methoden}

\subsubsection{Zellkultur eukaryotischer Zelllinien}

Bis zu einer Konfluenz von $90 \%$ wurden die Zellen bei $37{ }^{\circ} \mathrm{C}$ und einer Begasung von $5 \% \mathrm{CO}_{2}$ in einer gesättigten Atmosphäre in Gewebekulturschalen (Nunc ${ }^{\mathrm{TM}}$ Danmark, Durchmesser $9 \mathrm{~cm}$ ) oder -flaschen (Greiner bio-one Cellstar ${ }^{\circledR}$ Kulturflaschen $250 \mathrm{ml}, 75 \mathrm{~cm}^{2}$ ) im entsprechenden Kulturmedium kultiviert. In Abhängigkeit von der Proliferationsrate wurden die Zellen ein- bis zweimal pro Woche verdünnt. Dazu wurde das Kulturmedium abgesaugt, die Zellen mit 1 x PBS gewaschen und mit $3 \mathrm{ml}$ Trypsin/ EDTA inkubiert, solange bis sich die Zellen vom Boden der Zellkulturgefäßes gelöst hatten. Die Zellsuspension wurde mit $3 \mathrm{ml}$ frischem Kulturmedium versetzt und in entsprechender Verdünnung (1:50) in neue Kulturgefäße ausgesät.

\subsubsection{Kryokonservierung und Revitalisierung von eukaryotischen Zelllinien}

Zur Langzeitlagerung der Zellstocks in flüssigem Stickstoff wurde das Zellpellet (Zentrifugation $300 \mathrm{U} / \mathrm{min}$ für $5 \mathrm{~min}$ ) im entsprechenden Kulturmedium mit $10 \%$ FKS und $10 \%$ DMSO aufgenommen. Die Zellsuspension wurde in je $1 \mathrm{ml}$ Aliquots für 2-3 $\mathrm{h}$ bei 
zunächst $-20{ }^{\circ} \mathrm{C}$ eingefroren. Nach einer 1-2-tägigen Lagerung bei $-80{ }^{\circ} \mathrm{C}$ wurden die Zellen in flüssigen Stickstoff überführt.

Zur Revitalisierung wurden die Zellen schnell aufgetaut, in auf $37{ }^{\circ} \mathrm{C}$ vorgewärmtes Kulturmedium überführt und über Nacht inkubiert. Nach $24 \mathrm{~h}$ wurde die Zellen in $1 \mathrm{x}$ PBS gewaschen und mit neuem Kulturmedium versetzt.

\subsubsection{Transiente Transfektionen eukaryotischer Zelllinien}

Durch das Einbringen fremder Plasmid-DNA in eukaryotische Zellen können gezielt die Eigenschaften der Zellen, insbesondere ihr Expressionsmuster manipuliert werden. Da die Fremd-DNA schnell wieder eliminiert wird, wird von einer transienten Transfektion gesprochen.

In der vorliegenden Arbeit erfolgte die Transfektion eukaryotischer Zellen zum Nachweis der Stimulierung der endogenen Igf2-Expression, der Stimulation von LuziferaseReporterplasmiden sowie zum histochemischen Nachweis der $\beta$-Galaktosidaseaktivität von lacZ-Cosmiden. Dabei wurden die Transfektionen in Abhängigkeit von der Zelllinie und der Größe der Plasmide mit Hilfe von drei unterschiedlichen Transfektionsreagenzien durchgeführt.

\subsection{Transiente Transfektion von NIH/ 3T3- und C2C12-Zellen mit Roti ${ }^{\circledR}$-Fect- Reagenz}

Die in DMEM-Medium (10\% FKS, $1 \%$ Penizillin/ Streptomyzin) kultivierten Zellen wurden trypsiniert und in 6-Loch-Platten (Sarstedt; Durchmesser 3,5 cm) am Vortag des Transfektionsexperimentes ausgesät. Durch Auszählen der Zellen in der Neubauer-Zählkammer wurde die Zelldichte ermittelt. Dabei entsprachen 100-150 $\mu 1$ der Zellsuspension ca. 5-6 x 10² Zellen/ Loch. Somit konnte innerhalb von 24 h eine Zelldichte von $60-70 \%$ erreicht werden, welche ein Optimum für das Transfektionsexperiment darstellte. Die Transfektion wurde nach dem Protokoll des Herstellers durchgeführt.

Das verwendete Transfektionsreagenz Roti $^{\circledR}$-Fect ist ein polykationisches Lipid und bildet mit der Plasmid-DNA auf Grund der entgegengesetzten Ladungen einen Komplex. Für die Transfektion wurden $1 \mu \mathrm{g}$ Plasmid-DNA und $2 \mu \mathrm{l}$ des Reagenz in einem Volumen von $100 \mu \mathrm{l}$ DMEM (ohne Zusätze) zur Komplexierung eingesetzt. Die Komplexierung fand bei RT für $1 \mathrm{~h}$ statt. Die zu transfizierenden Zellen wurden mit 1 x PBS gewaschen und mit dem Kulturmedium (ohne Antibiotikazusatz) ebenfalls $1 \mathrm{~h}$ im Inkubator inkubiert. Nach $1 \mathrm{~h}$ wurde der DNA-Lipid-Komplex vorsichtig in das Medium der Zellen getropft. Durch den Kontakt der Liposomen mit der Zellmembran wurde die Plasmid-DNA in die Zelle durch eine nichtspezifische Endozytose aufgenommen. Nach einer Transfektionszeit von $2 \mathrm{~h}$ wurde die Transfektionslösung abgenommen. Die Zellen wurden mit 1 x PBS gewaschen und mit neuem 
Kulturmedium versetzt. Nach $48 \mathrm{~h}$ wurde die RNA der transfizierten Zellen mit Hilfe der TRIzol-Methode isoliert und stand für weitere Analysen (cDNA-Synthese, semi-quantitative PCR; QRT-PCR) zur Verfügung.

Zum Nachweis der Transfektionseffizienz wurde ein EGFP-N1-Plasmid kotransfiziert. Die grün-fluoreszierenden Zellen wurden unter dem Mikroskop ausgezählt und die Transfektionseffizienz ermittelt.

\subsection{Transiente Transfektion von Cosmiden in NIH/3T3-Zellen mit TransFectin TM_ Reagenz}

Für die Transfektionsexperimente von NIH/ 3T3-Zellen mit lacZ-Cosmiden wurde mit dem TransFectin ${ }^{\mathrm{TM}}$-Lipid-Reagenz von Bio-Rad nach Angaben des Herstellers gearbeitet. TransFectin ${ }^{\mathrm{TM}}$-Lipid-Reagenz setzt sich aus einer kationischen Komponente und einem KoLipid (1,2-Dioleoyl-sn-Glycerol-3-Phosphoethanolamin) zusammen und eignet sich besonders gut zur Transfektion großer Plasmid-DNA.

Zur Komplexierung wurden $2 \mu \mathrm{g}$ PicoGreen ${ }^{\circledR}$-vermessener Cosmid-DNA und $4 \mu \mathrm{l}$ des Transfektionsreagenz in einem Volumen von $100 \mu \mathrm{l}$ serum- und antibiotikafreiem Kulturmedium verwendet. Nach 20 min Komplexierung bei RT wurde die KomplexierungsLösung auf die mit 1 x PBS gewaschenen und mit Kulturmedium (ohne Antibiotikazusatz) versetzten Zellen getropft. Nach $6 \mathrm{~h}$ Transfektionszeit wurden die Zellen mit 1 x PBS gewaschen und mit $2 \mathrm{ml}$ frischem Kulturmedium versetzt. Zum Nachweis der Transfektionseffizienz wurde der pCMV- $\beta-$ Gal-Vektor (bereitgestellt von Dr. Peter Burfeind) kotransfiziert. Nach 48 h wurde der enzymhistochemische $\beta$-Galaktosidase-Nachweis durchgeführt.

\subsection{Transiente Transfektion von TP5014- und TP1588-Zellen mit Oligofectamin ${ }^{T M}$} Die beiden RMS-Zelllinien wurden in RPMI-1640-Medium (10 \% FKS, 1 \% Penizillin/ Streptomyzin) bis zu einer Zelldichte von 60-70 \% kultiviert. Nach der Trypsinierung und der Ausaat der Zellen in 6-Loch-Platten erfolgte nach $24 \mathrm{~h}$ die Transfektion. Auf Grund der schnellen Proliferation wurden $50 \mu \mathrm{l}\left(5-6 \times 10^{2}\right.$ Zellen)/ Loch ausgesät. Die Transfektion erfolgte nach den Angaben des Herstellers Invitrogen.

Es wurden $1 \quad \mu \mathrm{g}$ Plasmid-DNA und $5 \quad \mu \mathrm{l}$ des Transfektionsreagenzes in den Komplexierungsansatz eingesetzt. Die Komplexierung erfolgte für $30 \min$ bei RT in $100 \mu \mathrm{l}$ serum- und antibiotikafreien RPMI-1640-Medium. Nach einer Transfektionszeit von $4 \mathrm{~h}$ wurden die Zellen gewaschen und mit frischem Kulturmedium versetzt. Zum Nachweis der Transfektionseffizienz wurde ein EGFP-N1-Plasmid kotransfiziert. Die grün-fluoreszierenden Zellen wurden unter dem Mikroskop ausgezählt und die Transfektionseffizienz ermittelt. 
Nach $48 \mathrm{~h}$ wurde die RNA der Zellen nach der Trizol-Methode isoliert und stand weiteren Analysen zur Verfügung.

\subsubsection{Reportergenanalysen}

Für die Analyse der Promotordeletionskonstrukte des Igf2-Genes nach Gli-Kotransfektion wurde das Dual-Luciferase ${ }^{\circledR}$ Reporter Assay System von Promega eingesetzt. Dabei wurden verschieden große Deletionskonstrukte des Igf2-Genes verwendet, die in einen Vektor kloniert wurden, in dem das Luziferase-Gen aus Photinus pyralis (Firefly) als Reportergen fungierte. Die Quantifizierung der Luziferase-Aktivität, die im Luminometer über eine chemolumineszente Reaktion nachgewiesen werden konnte, ermöglichte es, Rückschlüsse auf die Aktivierung des Promotorkonstruktes zu ziehen. Zur Standardisierung der Reportergenwerte und zur Eliminierung von Schwankungen, die durch ungleiche Zellzahlen oder Transfektionseffizienzen hervorgerufen werden können, wurde ein zweites Reportergen aus Renilla reniformis kotransfiziert (Abb. 7). Die Vektorexpression stand unter Kontrolle eines TK-Promotors. Alle Experimente wurden in Doubletten angesetzt, um statistische Schwankungen mitteln zu können.
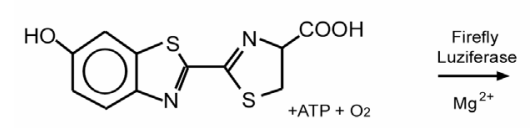

$\mathrm{Mg}^{2+}$

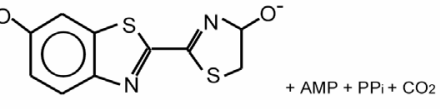

+ Licht
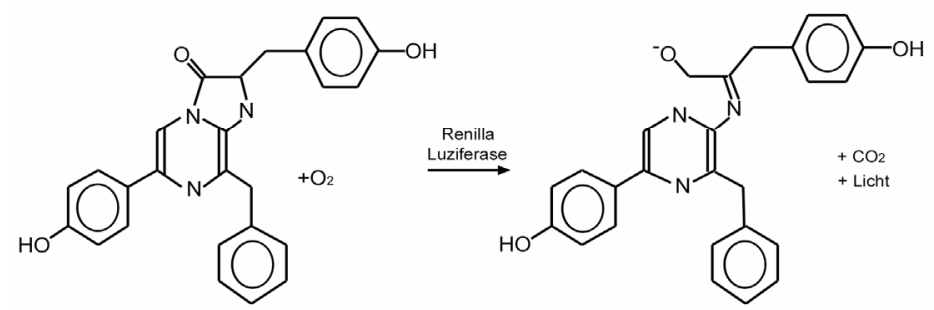

Abb. 7: Darstellung der biolumineszenten Reaktionen von Photinus pyralis (Firefly) und Renilla reniformis: Die Firefly-Luziferase katalysiert die Oxidation des Luziferins zum Oxyluziferin. Dabei wird ATP/ $\mathrm{Mg}^{2+}$ als Kosubstrat benötigt. Das bei dieser Reaktion emittierte Licht wird durch eine Luminometer gemessen. 


\subsubsection{Quantifizierung der Luziferase-Aktivität}

Die Transfektionsexperimente wurden unter Zugabe von $2 \mu$ des Transfektionsreagenz Roti ${ }^{\circledR}$ Fect, $1 \mu \mathrm{g}$ Expressionsplasmid-DNA der Transkriptionsfaktoren, sowie $1 \mu \mathrm{g}$ der ReportergenVektoren und $10 \mathrm{ng}$ des Renilla-DNA-Plasmides durchgeführt. Nach $48 \mathrm{~h}$ wurden die Zellen mit je $500 \mu 11$ x Passiv-Lysispuffer/ Loch der 6-Loch-Platte lysiert. Das Zell-Lysat wurde bei RT für $30 \mathrm{~s}$ abzentrifugiert, in ein neues Reaktionsgefäß überführt und bis zur Messung bei $-80{ }^{\circ} \mathrm{C}$ gelagert.

Zur Messung der Luziferase-Aktivität wurden $20 \mu \mathrm{l}$ des Zell-Lysates in eine 96-Loch-Platte gegeben. In einem Luminometer (Luminometer MPL-3 2 Injektoren, Berthold Detection Systems) wurden die Lysate zunächst mit $100 \mu$ LarII-Reagent (gestellt vom Hersteller) inkubiert. Nach $5 \mathrm{~s}$ Verzögerung, die der Durchmischung von Puffer und Lysat dienten, wurde für $20 \mathrm{~s}$ die Lichtemission gemessen, die die Firefly-Luziferase in einer chemolumineszenten Reaktion bei der Umwandlung zu Oxyluziferin erzeugte. Anschließend wurden $100 \mu 1$ Stop\&Glo ${ }^{\circledR}$-Reagent (gestellt vom Hersteller) eingespritzt. Nach einer Verzögerung von $5 \mathrm{~s}$ fand für $20 \mathrm{~s}$ die Messung der Biolumineszenz der Renilla-Aktivität statt.

Für die Auswertung wurde aus den gemessenen Werten der Luziferaseaktivität von Firefly und Renilla ein Quotient gebildet. Die aus den zwei verschiedenen Transfektionsansätzen pro Probe erhaltenen Quotienten wurden gemittelt, die Standardabweichung errechnet und im Anschluß erfolgte die grafische Auswertung. 


\section{Ergebnisse}

\subsection{Untersuchung der Igf 2 -Transkripte in Ptch-assoziierten Tumoren}

In der vorliegenden Arbeit wurde der regulatorische Mechanismus untersucht, der zu einer Überexpression des mitogenen Wachstumsfaktors Igf2 in Ptch-assoziierten Tumoren führt. Die Struktur des Igf2-Gens läßt auf eine komplexe Transkriptionseinheit schließen (Rietveld et al., 1997). Das murine Igf2-Gen besteht aus acht Exonen, wobei die fünf ersten Exone, U1, U2, E1, E2 und E3 alternativ in das Exon 4 gespleißt werden können. Exone E1 und E2 werden von unterschiedlichen, nicht überlappenden 5 ' -untranslatierten Regionen kodiert. Die Expression des E1 enthaltenden Transkripts (im Weiteren als Transkript T1 bezeichnet) wird vom Promotor P1 reguliert. Obwohl die Existenz von T1 durch RT-PCR gesichert wurde (Hu et al., 1995), ist die Größe der T1-mRNA nicht bekannt. Die Expression des E2 enthaltenden Transkripts T2 wird vom Promotor P2 reguliert. Das Transkript T2 hat eine Größe von 4,8 kb (Murell et al., 2001). Der Promotor P3 reguliert die Expression der alternativen T3 Transkripte, welche eine Größe von 3,6 kb, 2,1 kb, 1,8 kb und 1,3 kb aufweisen (Sun et al., 1997; Murell et al., 2001). Allen Transkripten gemeinsam ist das Spleißen von E3 in Exon 4 (Li et al., 1993). Die unterschiedliche Größe der Transkripte beruht auf unterschiedlichen Längen der 3' - und 5' -untranslatierten Regionen (van Dijk et al., 1991; Sussenbach et al., 1991; Rotwein und Hall, 1990). Die beiden weiter stromaufwärts vom Igf2 lokalisierte Exone U1 und U2 unterliegen der Kontrolle des Promotors P0. Bisher konnte nur ein Transkript nachgewiesen werden, bei dem U1 in U2 und dann in Exon 4 gespleißt wird. Das entsprechende Transkript von 5,0 kb (Moore et al., 1997), wird im Weiteren als Transkript T0 bezeichnet.

Die Expression der Transkripte T0, T1, T2 und T3 unterliegt einer gewebe- und entwicklungsspezifischen Kontrolle (Moore et al., 1997). So konnten die Transkripte T1, T2 und T3 im Embryo und der neonatalen Leber nachgewiesen werden. Die Expression des Transkriptes T0 unterliegt einer plazentaspezifischen Kontrolle und konnte nur in Trophoblastenzellen nachgewiesen werden (DeChiara et al., 1991; Moore et al., 1997; Constancia et al., 2002).

Die Exone 4, 5 und 6 kodieren das 67 Aminosäuren (AS) umfassende Vorläuferprotein und sind in allen oben beschriebenen Transkripten enthalten (Rotwein, 1991). Der Translationsstart des 
Igf2-Vorläuferproteins liegt hierbei im Exon 4 (Sasaki et al., 1996). Der schematische Aufbau des $I g f$-Lokus und das Spleißen der alternativen ersten fünf Exone sind in Abb. 8 dargestellt.

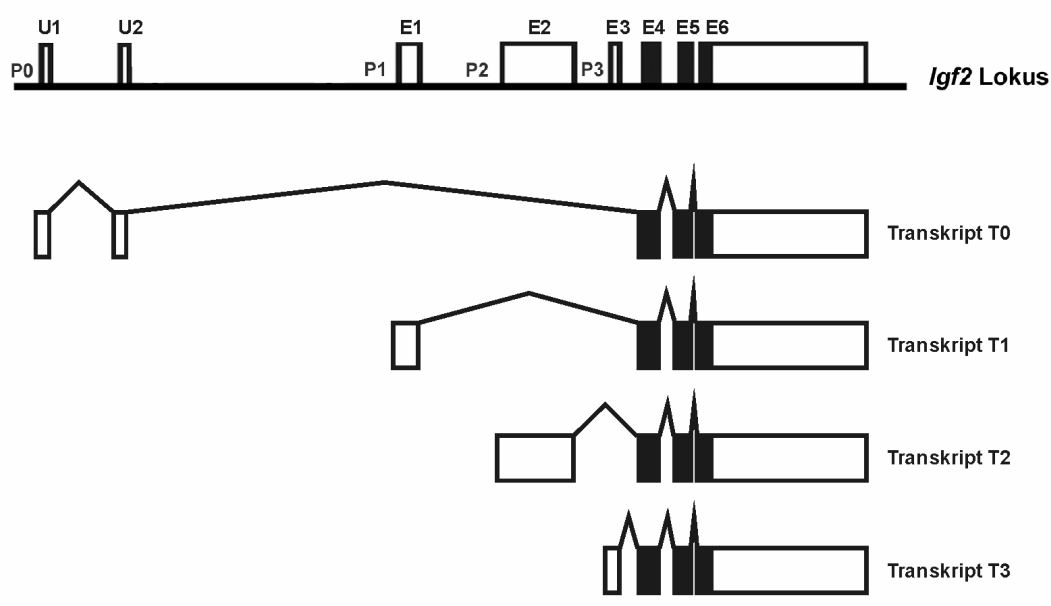

\begin{abstract}
Abb. 8: Schematische Darstellung des murinen Igf2-Lokus und seiner vier Spleißvarianten. Der Igf2-Lokus umfaßt acht Exone (U1, U2 und E1-E6), wobei nur die Exone 4, 5 und 6 für das Vorläuferprotein kodieren (gefüllte Rechtecke). Die Exone U1, U2 und E1-3 (offene Rechtecke) kodieren für unterschiedlich lange 5 ` -untranslatierte Trankripte und unterliegen der Kontrolle der gewebespezifischen Promotoren P0, P1, P2 und P3. An das Exon 6 schließt sich eine $3 \mathrm{~kb}$ umfassende 3' -untranslatierte Region an, die mit einer Polyadenylierungsregion endet (offenes Rechteck). Die vier Spleißvarianten des $I g f 2$-Gens sind untereinander angeordnet. Die Orientierung der Promotoren und Exone ist von $5^{`} \rightarrow 3^{`}$-Richtung dargestellt.
\end{abstract}

\title{
3.1.1. Analyse der Igf2-Transkripte in RMS im Northern-Blot
}

Zur Analyse der Expression der verschiedenen Igf2-Transkripte wurde ein Northern-Blot durchgeführt. Hierfür wurde die mRNA aus dem Rhabdomyosarkom (RMS) von heterozygoten Ptch-Mäusen auf CD1-Hintergrund und dem entsprechenden normalen Skelettmuskel (SM) herangezogen (Abb. 9). Der Skelettmuskel diente hierbei als Referenz, da davon auszugehen ist, daß sich Rhabdomyosarkome aus Muskelvorläuferzellen entwickeln (Merlino und Helmann, 1997). Als Positivkontrolle für den Nachweis der Transkripte T1, T2 und T3 wurde embryonale mRNA aus 12,5 Tage alten CD1 Mausembryonen (Wildtyp) mitgeführt. Für den Nachweis des Transkriptes T0 wurde mRNA der Plazenta (isoliert am Tag E 18,5 aus CD1 Wildtyp Mäusen) herangezogen. 


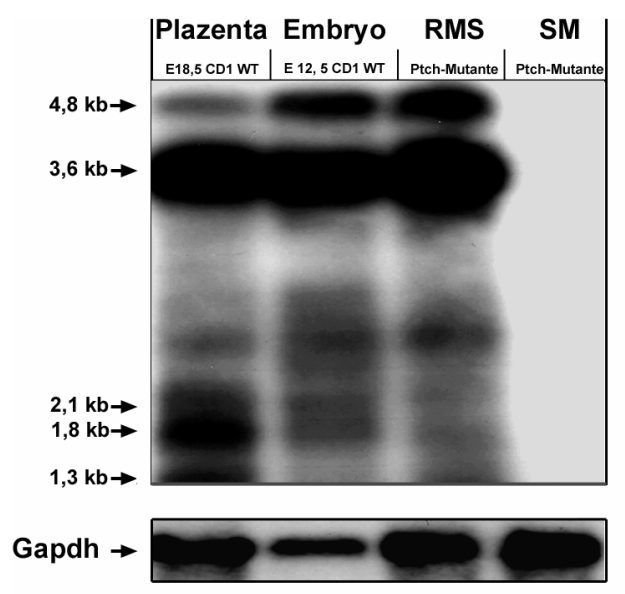

Abb. 9: Northern-Blot-Hybridisierung mit einer 227 bp-Igf2Sonde (siehe Tabelle 13) aus Exon 6. Alle von P3 regulierten Transkripte (T3-Transkripte: $3,6 \mathrm{~kb}, 2,1 \mathrm{~kb}, 1,8 \mathrm{~kb}$ und 1,3 kb) konnten in der Plazenta nachgewiesen werden. Dagegen waren im RMS das 3,6 kb T3-Transkript stark, und die 2,1 kb, 1,8 kb und $1,3 \mathrm{~kb}$ Transkripte schwach exprimiert. Das T2-Transkript $(4,8$ kb) konnte sowohl im Tumor als auch im Embryo und der Plazenta nachgewiesen werden. Keines der beschriebenen Igf2Transkripte konnte im normalen Skelettmuskel (SM) beobachtet werden. Als Ladekontrolle wurde eine 743 bp-Gapdh-Sonde mitgeführt.

Im RMS war ein Transkript der Länge 4,8 kb detektierbar. Dieses Signal repräsentiert das T2Transkript. Auf Grund der engen Zusammenlagerung der Größen des T0-Transkripts (5,0 kb) und des T2-Transkripts $(4,8 \mathrm{~kb})$ könnte es aber auch das T0-Transkript darstellen. Weiterhin konnten im RMS alle alternativen T3-Transkripte $(3,6 \mathrm{~kb}, 2,1 \mathrm{~kb}, 1,8 \mathrm{~kb}$ und 1,3 kb) nachgewiesen werden. Im Referenzgewebe, dem Skelettmuskel, wurde dagegen keines dieser Transkripte exprimiert.

Auf Grund der starken Expression der Transkripte T2, T0 und T3 konnte die Schlußfolgerung gezogen werden, daß im Tumor die Promotoren P2/ P0 und P3 aberrant reaktiviert sind. Auf Grund der nicht bekannten Größe der murinen T1-mRNA war es nicht möglich, eine entsprechende Zuordnung im Blot zu treffen.

\subsubsection{Untersuchung der Aktivierung der vier Igf2-Promotoren in RMS mittels semi-quantitativer RT-PCR}

Durch die Untersuchung der Expression der Igf2-Transkripte im Northern-Blot konnte eine Aussage über die Aktivierung des Promotors P3 im Tumor getroffen werden. Es war aber nicht möglich, eine Aussage über a) die Regulation der Promotoren P0, P1, sowie P2 zu formulieren und b) eine eindeutige Aussage über die Stärke der Promotoraktivierung im RMS zu treffen. Des Weiteren war nicht auszuschließen, daß bisher noch nicht untersuchte Promotoren und Spleißformen in den Ptch-assoziierten Tumoren in die Kontrolle der Transkription des Igf2Gens involviert sind. Unter diesen Aspekten wurden in den folgenden semi-quantitativen RTPCRs die verschiedenen Igf2-Transkripte und möglicherweise auftretende, neue Spleißformen untersucht. 


\subsubsection{Untersuchung der durch P1-, P2- und P3-regulierten Ig 2 -Spleißvarianten}

Für die im Folgenden beschriebene Analyse der Igf2-Spleißvarianten wurde die RNA aus vier RMS heterozygoter Ptch-Mäuse isoliert und in cDNA umgeschrieben. Die Tumoren wurden mittels einer HE-Färbung und eines pathologischen Gutachtens als RMS verifiziert. Die cDNA des normalen Skelettmuskel (SM) der Tumortiere diente als Referenz. Zum Nachweis der Transkripte T0, T1, und T2 wurden sowohl die entsprechenden cDNAs aus Plazenta $(\mathrm{E} 18,5)$ und aus Leber (P1) ${ }^{14}$ vom Wildtypen mitgeführt (Abb. 10).

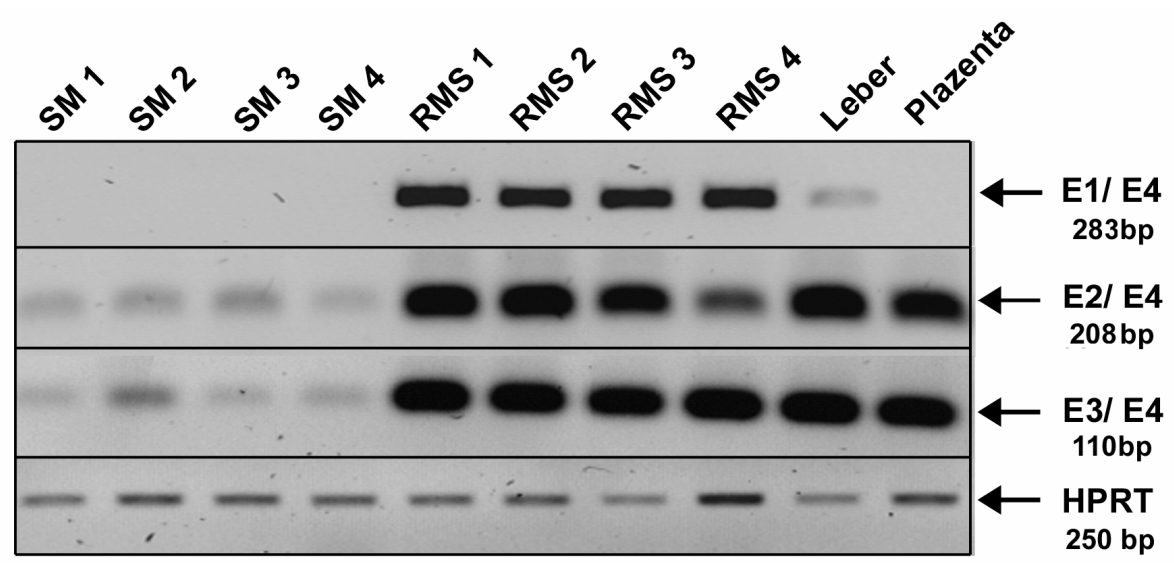

Abb. 10: Untersuchung der Igf2-Expression in RMS von heterozygoten Ptch-Mäusen durch RT-PCR mit den Primerkombinationen E1/ E4, E2/ E4 und E3/ E4: In allen untersuchten RMS sind im Vergleich zur Refenerenz alle drei Spleißvarianten E1/ E4, E2/ E4 und E3/ E4 überexprimiert. Als interne Kontrolle der semi-quantitativen Analyse wurde eine PCR für das Haushaltsgen HPRT (250 bp) mitgeführt.

Durch die Primerkombination E1/ E4 wird das Spleißen von Exon 1 in Exon 4 detektiert. Das entstehende Fragment ist somit repräsentativ für das Transkript T1 und die Aktivität des Promotors P1. Die Primerkombination E2/ E4 detektiert das Spleißen von Exon 2 in Exon 4 und ist somit repräsentativ für das Transkript T2 und die Aktivität des Promotors P2. Die Primerkombination E3/ E4 detektiert das Spleißen von Exon 3 in Exon 4 und ist somit repräsentativ für die T3-Transkripte und die Aktivität des Promotors P3. Alle drei Fragmente hatten die erwartete Größe und ließen sich in den vier Tumoren sehr stark amplifizieren, im Gegensatz zum Referenzgewebe SM.

Die Ergebnisse zeigen eine Überexpression der Transkripte T1, T2 und T3 in RMS. Diese Beobachtung läßt die Schlußfolgerung zu, daß alle drei Promotoren P1, P2 und P3 in RMS aberrant aktiviert sind. Nichtsdestotrotz konnte bis zum jetzigen Zeitpunkt nicht ausgeschlossen werden, daß weitere unbekannte Transkripte oder Promotoren existieren, die durch die bisherigen Experimente nicht erfaßt werden konnten. Derartige mRNA-Spezies könnten z. B. durch Spleißen der ersten drei 5' -untranslatierten Exone in die Exone 5 und 6 entstehen. Um

$\overline{{ }^{14} \mathrm{P} n \text { : postnatales Lebensalter mit } \mathrm{n}}=$ Tage nach der Geburt, $\mathrm{P} 0=$ Tag der Geburt 
dies zu untersuchen, wurden zwei weitere semi-quantitative RT-PCRs durchgeführt. Dabei wurden drei verschiedene Vorwärtsprimer für die Exone 1, 2 und 3 gewählt, wobei der entsprechende Rückwärtsprimer im Exon 5 bzw. im Exon 6 lag. Die Ergebnisse dieser RTPCRs sind in den Abbildungen 11 und 12 dargestellt.

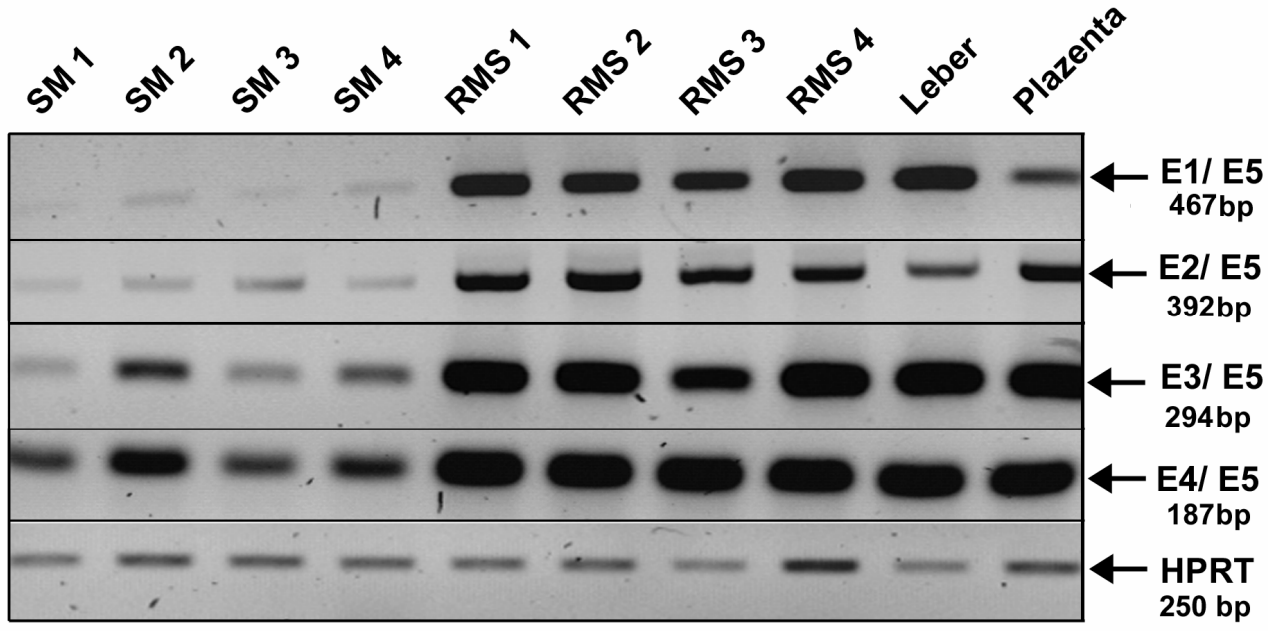

Abb. 11: Untersuchung der Igf2-Expression in RMS von heterozygoten Ptch-Mäusen durch RT-PCR mit den Primerkombinationen E1/ E5, E2/ E5, E3/ E5 und E4/ E6: In allen untersuchten RMS sind im Vergleich zur jeweiligen Referenz die Spleißformen E1/ E5, E2/ E5 und E3/ E5 überexprimiert. Neue Spleißvarianten wurden nicht detektiert. Als interne Kontrolle der semi-quantitativen Analyse wurde eine PCR für das Haushaltsgen HPRT (250 bp) mitgeführt.

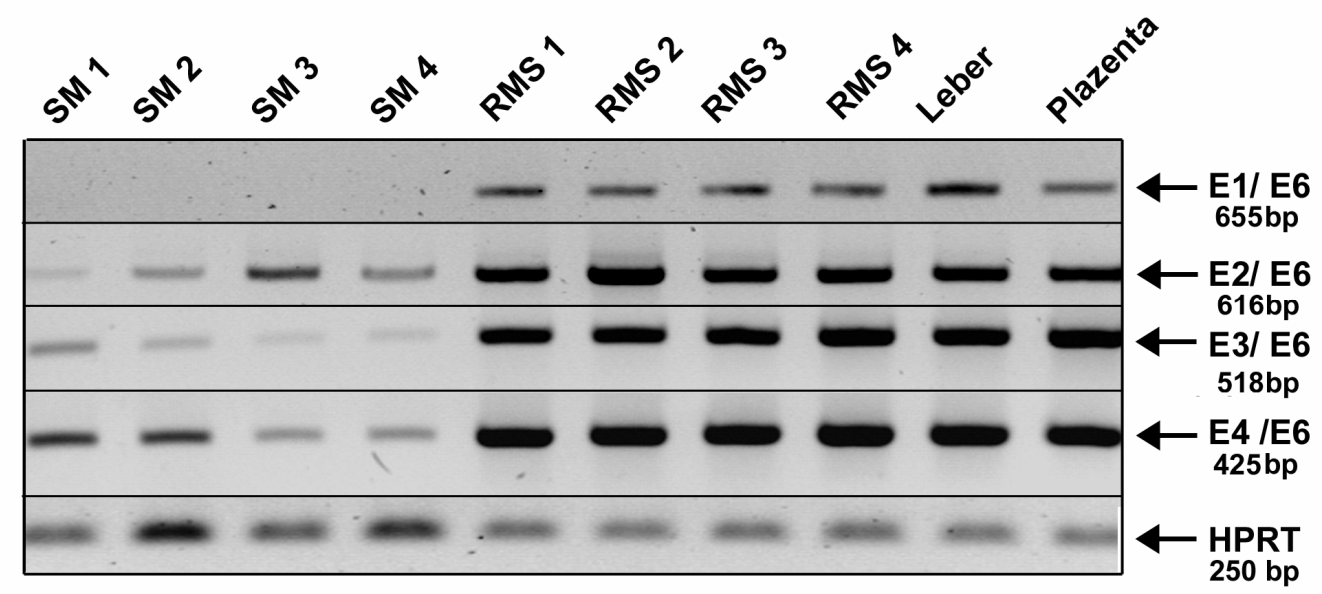

Abb. 12: Untersuchung der Igf2-Expression in RMS von heterozygoten Ptch-Mäusen durch RT-PCR mit den Primerkombinationen E1/ E6, E2/ E6, E3/ E6 und E4/ E6: In allen untersuchten RMS sind im Vergleich zur jeweiligen Referenz die Spleißformen E1/ E6, E2/ E6, E3/ E6 und E4/ E6 überexprimiert. Neue Spleißvarianten wurden nicht detektiert. Als interne Kontrolle der semi-quantitativen Analyse wurde eine PCR für das Haushaltsgen HPRT (250 bp) mitgeführt.

Auf Grund der Fragmentgrößen dieser RT-PCRs (Abb. 11, Abb. 12) kann angenommen werden, daß keine weiteren Spleißformen, ausgehend von den Exonen 1, 2 und 3 in das Exon 5 
(Abb. 11) oder Exon 6 (Abb. 12), weder im Tumorgewebe noch im Referenzgewebe vorliegen. So entsprachen die Fragmentgrößen den berechneten Basenabfolgen der publizierten Igf2cDNA (Hu et al., 1996), für die bisher ebenfalls kein Spleißen der alternativen ersten Exone in Exon 5 oder Exon 6 beschrieben worden ist.

Das starke Amplifikat in den Tumoren mit der Primerkombination E3/ E5 (Abb. 11) könnte darauf beruhen, daß diese Primerkombination a) vier alternative Transkripte detektiert, die durch den Promotor P3 reguliert werden oder b) sehr effizient amplifiziert. Da im Northern-Blot vier alternative T3-Transkripte im Tumor $(3,6 \mathrm{~kb}, 2,1 \mathrm{~kb}, 1,8 \mathrm{~kb}$ und 1,3 kb) nachgewiesen werden konnten (vergleiche Abb. 8), wird die erste Möglichkeit in Betracht gezogen. Dasselbe sollte für die Primerkombination E3/ E6 zutreffen, die ebenfalls vier alternative T3-Transkripte detektieren sollte. Jedoch unterschied sich die Stärke des entstehenden Fragmentes nicht wesentlich von denjenigen der Primerkombinationen E1/ E6 oder E2/ E6 (Abb. 12). Hier mag tatsächlich die schlechte Effizienz der Amplifikation eine Rolle spielen. Die hohe Intensität der Fragmente mit den Primerkombinationen E4/ E5 (Abb. 11) oder E4/ E6 (Abb. 12) resultiert aus der Amplifikation aller Transkripte, die alle das Exon 4, 5 und 6 beinhalten.

Es wurden keine weiteren Spleißvarianten zwischen den Exonen 4 und 5 sowie den Exonen 4 und 6 detektiert. Schließlich verifiziert diese PCR, daß alle Transkripte in den Tumoren gegenüber dem normalen Muskel überexprimiert sind.

\subsubsection{Untersuchung der durch P0-regulierten Ig 2 -Spleißvarianten}

Schließlich bestand auch die Möglichkeit, daß im Tumor der Promotor P0 aktiviert wird. Ein von P0 reguliertes Transkript wurde in Trophoblastenzellen der Plazenta beschrieben (Constancia et al., 2002). Im Folgenden wurde die Expression des Transkriptes T0 in Ptchassoziierten RMS über eine semi-quantitative RT-PCR untersucht. Dafür wurden Vorwärtsprimer gewählt, die in den Exonen U1 und U2 binden und ein Rückwärtsprimer, der im Exon 4 liegt (Abb. 13). 


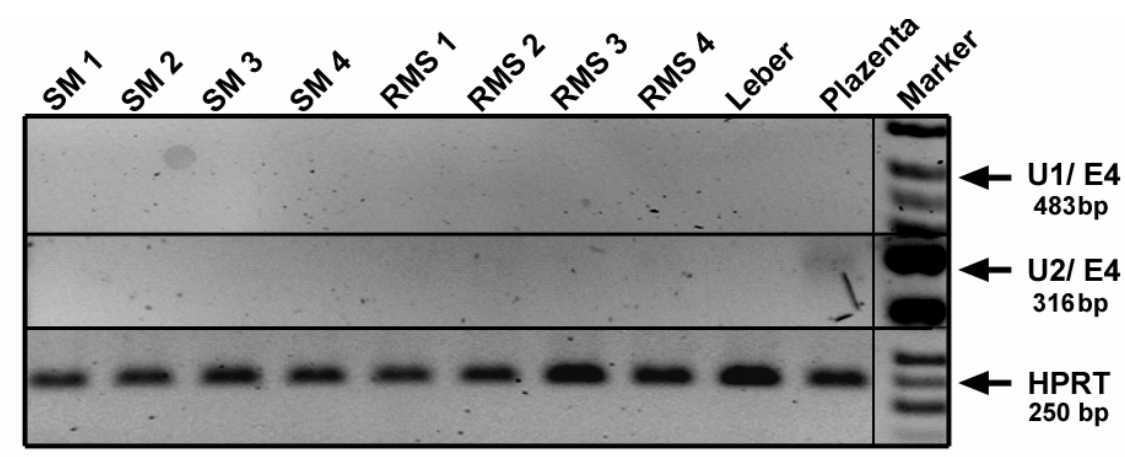

Abb. 13: Untersuchung der Igf2-Expression in RMS von heterozygoten Ptch-Mäusen durch RT-PCR mit der Primerkombination U1/ E4 und U2/ E4: Es konnte weder ein Amplifikat U1/ E4 noch U1/ U2/ E4 in den RMS noch in den SM detektiert werden. In der Plazenta wurde die Spleißform U2/ E4 nachgewiesen. Als interne Kontrolle der semi-quantitativen Analyse wurde eine PCR für das Haushaltsgen HPRT (250 bp) mitgeführt.

Das in der Literatur beschriebene Transkript T0 ensteht durch Spleißen von U1 in U2 und darauffolgend in Exon 4. Durch die Amplifikation der cDNA mit der Primerkombination U1/ E4 wurde ein Fragment der Größe von 483 bp und mit der Primerkombination U2/ E4 eines von 316 bp erwartet. Wie der Abbildung 13 zu entnehmen ist, sind solche Fragmente im Tumor und im SM nicht detektierbar. Ein Fragment der Größe von 483 bp konnte auch im Kontrollgewebe der Plazenta nicht amplifiziert werden, obwohl ein Transkript P0 in diesem Gewebe beschrieben wurde (Constancia et al., 2002). Jedoch konnte mit der Primerkombination U2/ E4 ein Fragment der Größe 316 bp in der cDNA der Plazenta detektiert werden.

Diese Ergebnisse zeigen zunächst, daß die Effizienz der Amplifiaktion mit der Primerkombiantion U1/ E4 unzureichend ist. Auf Grund des entstandenen Amplifikates mit der Primerkombination U2/ E4 in der Positivkontrolle, nicht aber in Tumoren (oder SM), kann die Aussage getroffen werden, daß der Promotor P0 im Tumor nicht aktiviert wird.

Des Weiteren konnte auch kein direktes Spleißen von U1 in Exon 4 (Abb. 13) in den untersuchten Geweben detektiert werden. Eine solche Variante hätte zu einem Fragment der Größe von 244 bp geführt.

Zusammenfassend kann gesagt werden, daß im RMS die Igf2 Promotoren P1, P2 und P3 aktiviert werden, nicht jedoch der Promotor P0. Die Aktivierung der Promotoren führt zu einer Überexpression aller bekannten Igf2-Transkripte, die durch diese Promotoren reguliert werden können. Die Aktivierung resultiert jedoch nicht in der Expression aberranter Igf2-Transkripte. 


\subsection{Untersuchung der endogenen Igf2-Expression in der RMS-Zelllinie TP5014 nach Behandlung mit 5-Aza- Cytidin}

Im Folgenden wurde der Effekt des Demethylierungsreagenz 5-Aza-Cytidin auf die endogene Expression des Igf2-Gens in vivo untersucht. Dafür wurden eine Fibroblasten-Zelllinie (NIH/ 3T3) und eine RMS-Zelllinie TP5014 mit $10 \mu \mathrm{M}$ 5-Aza-Cytidin behandelt. Die Wahl der Molarität von $10 \mu \mathrm{M}$ stützte sich hierbei auf Vorexperimente der AG Olaf Witt aus dem Universitäts-Klinikum Göttingen. Das Cytidinanalogon 5-Aza-Cytidin wird in der Zelle phosphoryliert und kann nach Reduktion anstelle von Cytidin in die DNA eingebaut werden. Dadurch wird sowohl die DNA-Synthese als auch die DNA-Methylierung behindert (Cihak et al., 1974; Johnes und Taylor, 1980).

$48 \mathrm{~h}$ nach Zugabe von 5-Aza-Cytidin wurde die RNA aus den behandelten Zellen isoliert. Nach anschließender cDNA-Synthese wurde die endogene Igf2-Expression quantifiziert. Dafür wurde die Methode der quantitativen real-time PCR angewendet, die es ermöglicht, das im Verlauf der PCR gebildete Produkt relativ zu einem Standard zu quantifizieren. Zur Erstellung einer Standardkurve wurde cDNA aus Rhabdomyosarkomen in verschiedenen Verdünnungen verwendet, da in diesen Tumoren Igf2 überexprimiert ist. Eine endogene Kontrolle (18S rRNA) zur Normaliserung der Ergebnisse wurde verwendet, da Unterschiede im cDNA-Gehalt verschiedener Proben das Ergebnis verfälschen können. Dies erlaubt eine relative Quantifizierung des vermessenen Transkripts und somit den Vergleich verschiedener Proben untereinander (siehe 2.2.7.1.1.). Aus den Werten der Messungen von Igf 2 und $18 \mathrm{~S}$ rRNA wurde der Quotient gebildet, die Standardabweichung errechnet und grafisch dargestellt (Abb. 14).

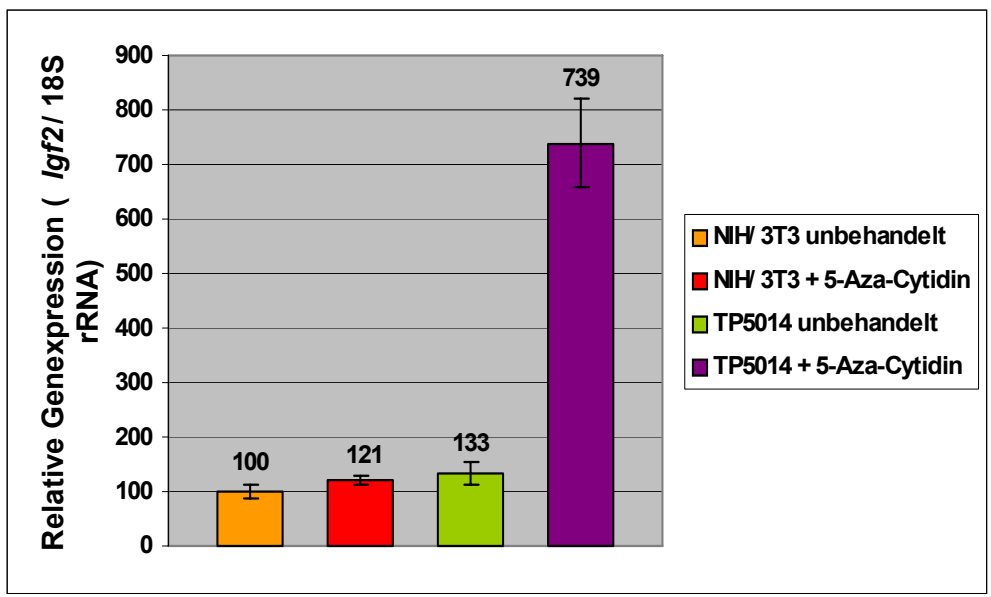

Abb. 14: Analyse der Ig $f$ Expression der mit 5-AzaCytidin-behandelten NIH/ 3T3und TP5014- Zelllinien im TaqMan-Assay. Grafische Darstellung der berechneten relativen Genexpressionen des Igf2-Gens nach 5-Aza-CytidinBehandlung $(10 \mu \mathrm{M})$. Die stärkste Stimulierung der endogenen Igf2Expression wurde in der Tumorzellinie TP5014 nachgewiesen. Die über jedem Balken angegebene Zahl gibt den Mittelwert der endogenen Expression des Igf2-Gens an. Standardabweichungen sind durch Balken dargestellt. 
Eine Stimulierung der endogenen Igf2-Expression konnte in 5-Aza-Cytidin-behandelten Tumorzellen, nicht aber in Fibroblastenzellen festgestellt werden. Dies läßt die Schlußfolgerung $\mathrm{zu}, \mathrm{da} ß$ in Tumorzellen eine DNA-Demethylierung entweder direkt die Igf2-Expression verstärkt oder daß Faktoren, die die Transkription des Igf2-Gens regulieren, methylierungssensitiv sind.

\subsection{Untersuchungen der Methylierungsveränderungen in den DMRs des Igf2-Gens in Ptch-assoziierten Tumoren im Southern-Blot}

Im Fokus dieser Analysen standen drei Regionen des Igf2-Lokus, die im Folgenden als DMR0, DMR1 und DMR2 bezeichnet werden (Moore et al., 1997; Ward et al., 1996; Sasaki et al., 1992; Brandeis et al., 1993; Feil et al., 1994). In Feil et al., 1994 und Sasaki et al., 1992 wurden in der DMR1 und DMR2 eine differentielle Methylierung zwischen dem paternalen und maternalen Allel des Igf2-Gens im Embryo beschrieben. In beiden differentiell methylierten Regionen liegt eine Methylierung des paternalen Allels vor. Für die DMR1 ist bekannt, daß die Methylierung des paternalen Allels die Bindung des Transkriptionsrepressor GCF2 verhindert und dadurch die Igf2-Expression stimuliert (Constancia et al., 2000; Eden et al., 2001). Dagegen ist eine Methylierung der DMR2 für die Expression des paternalen Igf2 Allels notwendig (Murell et al., 2001). Die Methylierung des maternalen Allels in der DMR0 wird in das Silencing ${ }^{15}$ des maternalen Igf2 Allels involviert (Moore et al., 1997). In allen drei DMRs konnte ein veränderter Methylierungstatus bei Wilms-Tumoren (Cui et al., 2001) und kolorektalen Tumoren (Nakagawa et al., 2001) nachgewiesen werden.

In der vorliegenden Arbeit wurden diese drei Regionen in RMS von heterozygoten PtchMäusen mittels methylierungssensitiver Southern-Blot-Technik untersucht. Die DMR0 und DMR1 liegen in den Promotorbereichen P0 und P1, wogegen die DMR2 im kodierenden Bereich des $I g f 2-G e n s$ lokalisiert ist. Die Methylierungsanalyse erfolgte mit Hilfe von sechs Hybridisierungssonden (Abb. 15), wobei eine Sonde (Sonde 1) für die DMR0, vier Sonden (Sonden 2-5) für die DMR1 und eine Sonde (Sonde 6) für die DMR2 verwendet wurden. In Abbildung 15 sind die Lokalisierungen der Hybridisierungssonden aufgeführt.

\footnotetext{
${ }^{15}$ Silencing, engl.: Schweigen, Stille; Stilllegung, Inhibierung eines Allels, welches somit nicht transkribiert wird.
} 


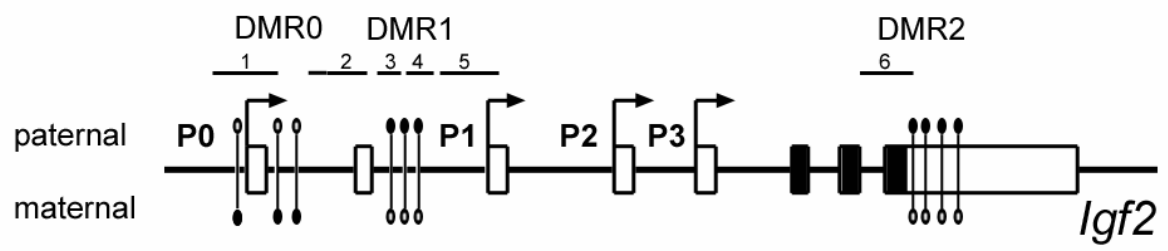

\begin{abstract}
Abb. 15: Darstellung der DMR0, DMR1 und DMR2 im Igf2-Lokus. Bekannte Unterschiede in der Methylierung zwischen dem maternalen und paternalen Allel während der Embryonalentwicklung treten in drei distinkten Bereichen des Igf2-Lokus auf (methylierter Bereich: gefüllter Kreis, unmethylierter Bereich: leerer Kreis): Die Exone U1, U2 und E1-3 sind mit offenen Rechtecken und die Exone 4-6 mit gefüllten Rechtecken dargestellt. Die Promotoren P0-P3 aktivieren verschiedene Transkripte, dabei gibt die Pfeilrichtung den Transkriptionsstart an. Die im Southern-Blot verwendeten Sonden sind von 1-6 nummeriert.
\end{abstract}

In den methylierungssensitiven Southern-Blots wurde genomische DNA aus Tumoren (RMS), den entsprechenden Skelettmuskeln (SM) und der Niere oder der Lunge heterozygoter PtchMäuse sowie aus dem Muskelgewebe von CD1 Wildtyp-Mäusen analysiert. Hierbei repräsentiert das Muskelgewebe das Referenzgewebe des Tumors. Lungen- oder Nierengewebe wurden als weitere Kontrollen gewählt.

\title{
3.3.1. Untersuchung der Methylierung der DMR2-Region des Igf2-Gens
}

Im Folgenden wurde zunächst die den kodierenden Bereich des Igf2-Gens umfassende DMR2 auf Methylierungsveränderungen im Tumor untersucht. Die verwendete Hybridisierungssonde 6 wurde in Feil et al., 1994 erstmalig zum Nachweis einer gewebespezifischen Methylierung des paternalen Allels im Embryo verwendet (Abb. 15 und Abb. 16).

In den methylierungssensitiven Southern-Blots für die DMR2 wurde genomische DNA aus zehn Tumoren (RMS), den Skelettmuskeln (SM) und der Lunge heterozygoter Ptch-Mäuse sowie aus dem Muskelgewebe von CD1 Wildtyp-Mäusen analysiert.

Die isolierte DNA wurde mit den Restriktionsendonukleasen BamHI-HpaII und BamHI-MspI enzymatisch gespalten. Der MspI-Verdau diente hierbei in mehrerer Hinsicht als Kontrolle. Das Restriktionsenzym spaltet die DNA-Erkennungssequenz 5`'CCGG- 3`unabhängig vom Grad der Methylierung. Durch diesen Verdau kann sichergestellt werden, daß die DNA vollständig geschnitten wurde (die Anzahl der Fragmente, die durch die jeweilige Sonde hybridisiert werden kann, ist vorherbestimmbar). Zudem erlaubt der Vergleich zum methylierungssensitiven Verdau schließlich die Identifikation von Methylierungsunterschieden in der von der Sonde hybridisierten DNA-Sequenz. 


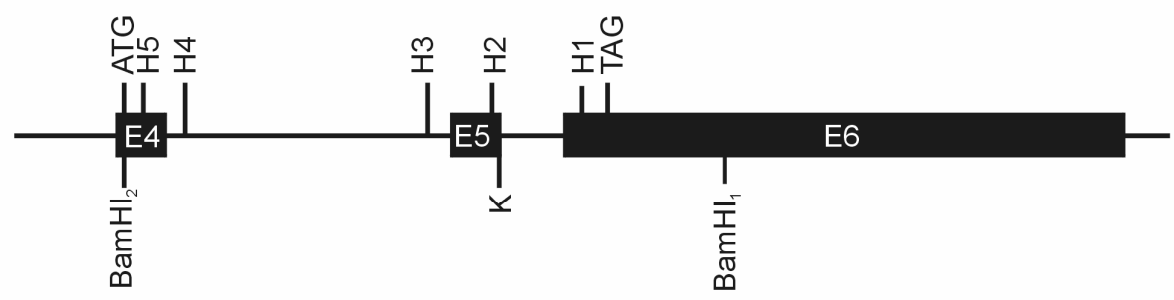

DMR2 Sonde 6

Abb. 16: Schematische Darstellung der DMR2 des Igf2-Lokus mit entsprechenden BamHI- und HpaIISchnittstellen sowie der Lokalisierung der Sonde 6: Die Exone 4, 5 und 6 umfassen die kodierende Sequenz des Igf2-Gens (gefüllte Rechtecke). Im Exon 4 liegt der Translationsstart (ATG), im Exon 6 liegt das Stoppkodon (TGA). Die 877 bp große Sonde (entspricht dem BamHI $1-K p n I-F r a g m e n t)$ hybridisiert ein $2481 \mathrm{~kb}$ umfassendes BamHIFragment, in dem fünf methylierungssensitive HpaII-Schnittstellen (H1-H5) lokalisiert sind. K: KpnI

Abhängig vom Methylierungsstatus der HpaII-Schnittstellen innerhalb der BamHI-Sequenz entsteht eine Anzahl an theoretisch möglichen Fragmenten, die in Abbildung 17 dargestellt sind.

Die Sonde 6 umspannt einen DNA-Bereich, der eine methylierungssensitive HpaII-Schnittstelle (H1) enthält. Daher dürfen nach vollständigem Verdau der DNA mit MspI-BamHI nur zwei Fragmente (DMR2-F1 und DMR2-F7) entstehen (Abb. 17).

Abhängig vom Methylierungsstatus der HpaII-Schnittstellen (im Folgenden auch als „H“ bezeichnet) können weitere Fragmente entstehen. Im Fall einer kompletten Methylierung von H1 und einer vollständig unmethylierten H2 Schnittstelle wäre nur das Fragment DMR2-F2 von der Sonde detektierbar. Ein Fragment DMR2-F3 kann erst detektiert werden, wenn eine Methylierung der Schnittstellen H1 und H2 vorliegt. So erklären sich alle weiteren Fragmente, die in der Abbildung 17 dargestellt sind. Bedingt durch die Lokalisation der Sonde 6, könnten bei partieller Methylierung der fünf HpaII-Schnittstellen somit insgesamt 11 Fragmente entstehen (siehe Abb. 17). Würde eine vollständige Methylierung aller HpaII-Schnittstellen vorliegen, kann durch die Sonde 6 nur ein BamHI-Fragment der Größe 2481 bp detektiert werden. Würde gar keine Methylierung der HpaII-Schnittstellen vorliegen, könnten wie beim MspI-Verdau nur das Fragment DMR2-F1 und -F7 detektiert werden. 


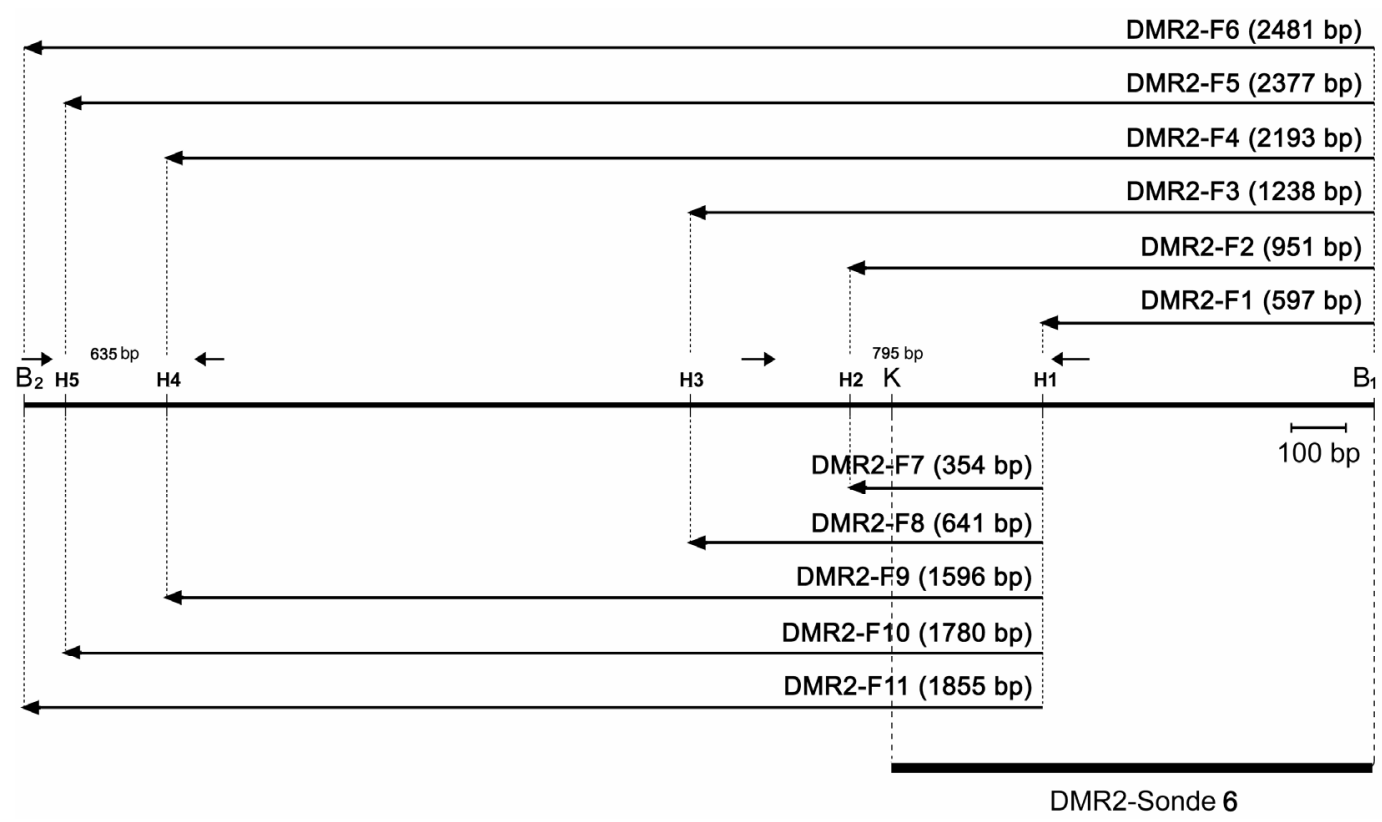

Abb. 17: Darstellung aller theoretisch möglichen Fragmente von BamHI-HpaII geschnittener genomischer DNA, die durch die Hybridisierung mit Sonde 6 detektierbar sind. Das 2481 bp BamHI-Fragment umfaßt fünf methylierungssensitive HpaII-Schnittstellen (H1-H5). Dabei liegt H1 in der von der Sonde 6 hybridisierten DNASequenz. Die Pfeile repräsentieren die Lokalisation der Primer, die für die Amplifikation der 795 bp und 635 bp Fragmente benutzt wurden. Über die Bisulfit-Sequenzierung wurden die CpGs innerhalb der beiden Fragmente in ihrer Methylierung näher untersucht (näheres siehe Kapitel 3.5.2.1. und 3.5.2.2.). KpnI: K, BamHI: B.

Ein repräsentativer Southern-Blot, der an der verdauten DNA aus RMS und SM durchgeführt wurde, ist in Abbildung 18 gezeigt. Nicht dargestellt ist in der Abbildung der Kontrollverdau mit dem Enzym BamHI. Dabei hybridisiert die Sonde ein Fragment der Größe von 2481 bp (siehe Abb. 17, Fragment DMR2-F6), was zur Kontrolle der Hybridisierung und der Zuordung der Fragmente des Blotes diente. Dieses Fragment läßt sich jedoch nicht vom Fragment DMR2F5 mit der Größe 2377 bp unterscheiden.

Zur Überprüfung der in den Verdau eingesetzten DNA-Mengen wurde eine zweite Hybridisierung mit der Atractin-Sonde (Sonde 9, siehe Tab. 14) durchgeführt. Dabei wurde die Atractin-Sonde so ausgewählt, daß sie keine HpaII-Schnittstellen umfaßt, sondern nur ein BamHI-Fragment von 1440 bp hybridisiert. Es konnte somit ausgeschlossen werden, daß der ausgewählte DNA-Bereich einer Methylierung unterlag. 


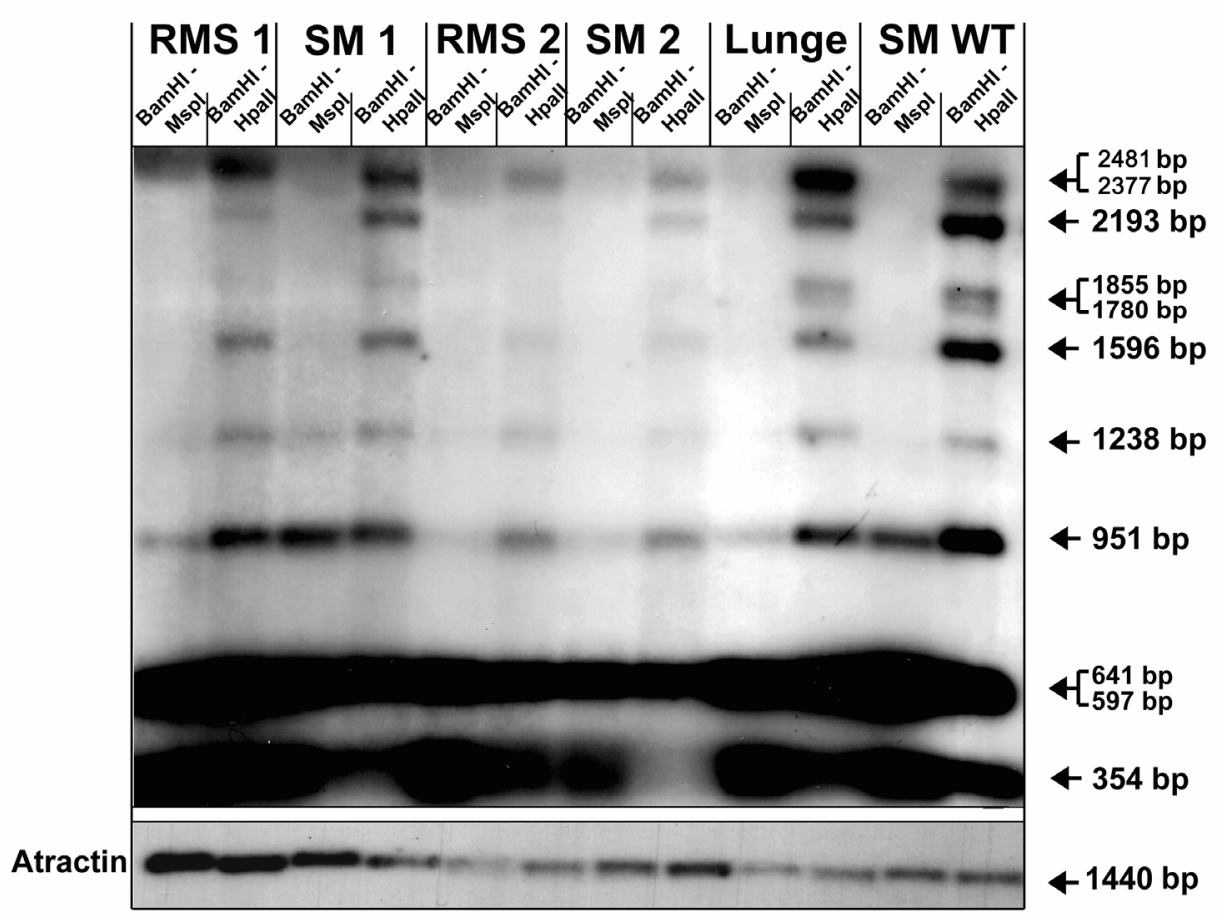

Abb. 18: Untersuchung der Methylierungsunterschiede der DMR2 zwischen Tumor- und Normalgewebe im methylierungssensitiven Southern-Blot (Sonde 6, KpnI- BamHI, siehe Abb. 15 und 16). Die DNA jedes Gewebes wurde entweder im Doppelverdau BamHI-MspI oder BamHI-HpaII geschnitten und in einem 0,8\%igen Agarosegel aufgetrennt. Mit der 677 bp Atractin- Sonde (Sonde 9, Tabelle 14) wurde eine zweite Hybridisierung zur Überprüfung der in den Verdau eingesetzten DNA-Mengen durchgeführt. Die Größe der hybridisierten Fragmente ist in Basenpaaren (bp) angegeben. Der Methylierungsstatus der Schnittstellen, der die Entstehung der hybridisierten Fragmente erklärt, ist im Text dargestellt.

Im Folgenden wurden die Intensitätsunterschiede der Fragmente ausgewertet, die im SouthernBlot durch die Hybridisierung mit der Sonde 6 detektiert wurden (Tab. 26). Dabei kann eine hohe Intensität durch eine Hypomethylierung der in die Entstehung des Fragmentes involvierten HpaII-Schnittstellen erklärt werden. Eine Methylierung einer HpaII-Schnittstelle führt dagegen $\mathrm{zu}$ einem Bandenverlust. 
Tabelle 26: Auswertung der Intensitäten von HpaII-geschnittenen Fragmenten der DMR2: Die mit einem hochgestellten Buchstaben markierten Fragmente können auf Grund ähnlicher Größen im Blot nicht aufgetrennt werden, wobei jeder Buchstabe verschiedene, eng zusammenliegende Fragmente repräsentiert. Markierte Fragmente in der Tabelle weisen einen Intensitätsunterschied zwischen RMS und Muskel auf, was durch eine veränderte Methylierung der involvierten Schnittstelle zu erklären ist. Ptch $^{+/-}=$heterozygote Ptch-Mäuse; H=HpaII-Schnittstelle

\begin{tabular}{|c|c|c|c|c|c|}
\hline Fragment & & Intensität & & & \\
\hline Fragmentgröße & Schnittstellen & $\begin{array}{l}\text { RMS } \\
\text { Ptch }^{+/-}\end{array}$ & $\begin{array}{l}\text { Skelettmuskel } \\
\mathrm{Ptch}^{+/-}\end{array}$ & $\begin{array}{l}\text { Lunge } \\
\text { Ptch }^{+/-}\end{array}$ & $\begin{array}{l}\text { Skelettmuskel } \\
\text { Wildtyp }\end{array}$ \\
\hline $\begin{array}{l}\text { DMR2-F1 } \\
597 \mathrm{bp}^{\mathrm{a}}\end{array}$ & $\mathrm{BamHI}_{1}-\mathrm{H}_{1}$ & $+++++^{\mathrm{a}}$ & $++++^{a}$ & $+++++^{\mathrm{a}}$ & $+++++^{a}$ \\
\hline $\begin{array}{l}\text { DMR2-F2 } \\
951 \mathrm{bp}\end{array}$ & $\mathrm{BamHI}_{1}-\mathrm{H}_{2}$ & +++ & +++ & +++ & ++++ \\
\hline $\begin{array}{l}\text { DMR2-F3 } \\
1238 \mathrm{bp}\end{array}$ & $\mathrm{BamHI}_{1}-\mathrm{H}_{3}$ & ++ & ++ & ++ & ++ \\
\hline $\begin{array}{l}\text { DMR2-F4 } \\
2193 \text { bp }\end{array}$ & $\mathrm{BamHI}_{1}-\mathrm{H}_{4}$ & + & +++ & +++ & ++++ \\
\hline $\begin{array}{l}\text { DMR2-F5 } \\
2377 \mathrm{bp}^{\mathrm{b}}\end{array}$ & $\mathrm{BamHI}_{1}-\mathrm{H}_{5}$ & $++^{\mathrm{b}}$ & $++^{\mathrm{b}}$ & $++++^{b}$ & $+++^{b}$ \\
\hline $\begin{array}{l}\text { DMR2-F6 } \\
2481 \mathrm{bp}^{\mathrm{b}}\end{array}$ & $\mathrm{BamHI}_{1}-\mathrm{BamHI}_{2}$ & $++^{\mathrm{b}}$ & $++^{\mathrm{b}}$ & $++++^{\mathrm{b}}$ & $+++^{\mathrm{b}}$ \\
\hline $\begin{array}{l}\text { DMR2-F7 } \\
354 \text { bp }\end{array}$ & $\mathbf{H}_{1}-\mathbf{H}_{2}$ & ++++ & ++ & +++ & ++++ \\
\hline $\begin{array}{l}\text { DMR2-F8 } \\
641 \mathrm{bp}^{\mathrm{a}}\end{array}$ & $\mathrm{H}_{1}-\mathrm{H}_{3}$ & $+++++^{a}$ & $++++^{\mathrm{a}}$ & $+++++^{\mathrm{a}}$ & $+++++^{a}$ \\
\hline $\begin{array}{l}\text { DMR2-F9 } \\
1596 \text { bp }\end{array}$ & $\mathrm{H}_{1}-\mathrm{H}_{4}$ & +++ & +++ & +++ & ++++ \\
\hline $\begin{array}{l}\text { DMR2-F10 } \\
1780 \mathrm{bp}^{\mathrm{c}}\end{array}$ & $\mathrm{H}_{1}-\mathrm{H}_{5}$ & $(+)^{c}$ & $+^{\mathrm{c}}$ & $++^{c}$ & $++^{c}$ \\
\hline $\begin{array}{l}\text { DMR2-F11 } \\
1855 \mathrm{bp}^{\mathrm{c}}\end{array}$ & $\mathrm{H}_{1}-\mathrm{BamHI}_{2}$ & $(+)^{\mathrm{c}}$ & $+^{\mathrm{c}}$ & $++^{\mathrm{c}}$ & $++^{\mathrm{c}}$ \\
\hline
\end{tabular}

Obwohl auf Grund der Konzentrationsbestimmungen mittels Photometer und Fluoreszenzmessung über die Picogreen-Methode (siehe 2.2.2.3.) von gleichen Mengen genomischer DNA der unterschiedlichen Gewebe ausgegangen wurde (nicht gezeigt), ergab die Hybridisierung des Blots mit der Atractin Sonde Unterschiede in den Intensitäten des von dieser Sonde hybridisierten 1440 bp-Fragmentes.

Eine Aussage über potentielle Methylierungsveränderungen zwischen Tumor und Referenz war trotz des unterschiedlichen DNA Gehalts der einzelnen Proben dennoch möglich. So wurde im ersten Tumor-Muskel-Paar (RMS1/ SM1) eine größere DNA-Menge in der RMS-Probe im Vergleich zum Muskel eingesetzt, während im zweiten untersuchten Paar (RMS2/ SM2) weniger DNA des RMS und mehr DNA des Muskels zum Einsatz kam. Trotzdem sind in 
beiden untersuchten Tumor-Muskel-Paaren gleiche Intensitätsunterschiede in einigen der Fragmente zu verzeichnen (Abb. 18, Tab. 26).

Der Nachweis der großen Fragmente DMR2-F5 (2377 bp) und DMR2-F9 (1596 bp) weist auf eine Methylierung der Schnittstellen H1, H2 und H3 hin. Eine vollständige Methylierung dieser Schnittstellen konnte jedoch ausgeschlossen werden, da auch die Fragmente DMR2-F2 (951 bp), DMR2-F3 (1238 bp), DMR2-F4 (2193 bp) sowie die Fragmente DMR2-F7 (354 bp) und DMR2-F8 (641 bp) detektiert wurden.

Den wichtigsten Befund dieses Southern-Blots stellt der Unterschied in den Bandenintensitäten des Fragmentes DMR2-F7 (354 bp) dar, welcher auf einen differentiellen Methylierungsstatus der Schnittstellen H1 und H2 zwischen RMS und Muskel hinweist. Auf Grund der hohen Intensität des Fragmentes DMR2-F7 kann von einer Hypomethylierung dieser Schnittstellen im RMS ausgegangen werden. Einen weiteren Intensitätsunterschied wies das Fragment DMR2-F4 (2193 bp) auf. Die schwache Intensität dieses Fragmentes zeigt eine Hypermethylierung der Schnittstellen H4 im RMS an. DNA-Bereiche, in denen Unterschiede im Methylierungsmuster zwischen RMS und Referenz festzustellen waren, wurden im Weiteren einer BisulfitSequenzierung unterzogen (siehe Abb. 32 und 33, Kapitel 3.5.2.1. und 3.5.2.2.).

Der Nachweis eines Fragmentes DMR2-F2 (951 bp) im Kontrollverdau mit MspI (siehe Abb. 18) ist durch einen partiellen Verdau zu erklären.

\subsubsection{Untersuchung der Methylierung der DMR0 und DMR1 des Igf2- Gens}

Im Folgenden wurden die Methylierungsveränderungen in der DMR0 und DMR1 untersucht. In Abbildung 19 ist die Lage der eingesetzten Hybridisierungssonden 1-5 angezeigt.

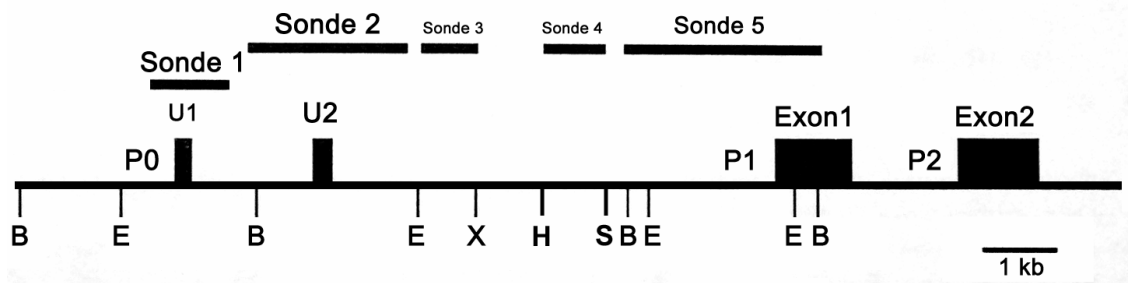

Abb. 19: Schematische Darstellung der DMR0 und DMR1 des Igf2-Lokus mit entsprechenden BamHI- und HpaII-Schnittstellen sowie der Lage der Sonden 1-5. P0-P2 bezeichnet drei Promotoren vom Igf2. Die alternativen Exone U1, U2, E1 und E2 des Igf2-Gens sind als offene Rechtecke eingezeichnet. B: BamHI, E: EcoRI; X: XbaI; H: HindIII; S: SmaI (bearbeitet nach Feil et al., 1994). 


\subsubsection{Analyse der DMR0 im methylierungssensitiven Southern-Blot mit Hybridisierungssonde 1}

Besonderes Interesse galt der Analyse des Methylierungsmusters der DMR0-Region in Ptchassoziierten Tumoren. Diese das Exon U1 umfassende Region (Abb. 15 und 19) weist als einzige der DMRs eine allelische Differenzierung der Methylierung auf, das heißt, daß im Embryo das maternale „stillgelegte“ Allel in dem Bereich der DMR0 zum größten Teil methyliert vorliegt (Sasaki et al., 1992; Hu et al., 1997). In vielen Tumoren (z. B. in Patienten mit Beckwith-Wiedemann-Syndrom und in Wilms Tumoren) konnte im maternalen Igf2-Allel eine Relaxierung der Methylierung nachgewiesen werden. Diese Hypomethylierung führt zu einem Verlust der Prägung (LOI), was eine erhöhte Igf2-Expression zur Folge hat (Ogawa et al., 1993; Randhawa et al., 1998). Obwohl Arbeiten aus unserer Arbeitsgruppe keinen LOI am Igf2Lokus in RMS heterozygoter Ptch-Mäuse gezeigt haben (Hahn et al., 2000), wurde diese Region einer detaillierteren Analyse mittels methylierungssensitiver Southern-Blot-Technik unterzogen (Abb. 21).

Die Sonde 1 (835 bp, Tab. 15) hybridisiert ein 3345 bp-umfassendes BamHI-Fragment. Innerhalb dieser Sequenz sind neun HpaII-Schnittstellen lokalisiert (Abb. 20). Durch den Doppelverdau der genomischen DNA mit BamHI und HpaII kann über diese Schnittstellen eine Aussage über den Methylierungsstatus getroffen werden.

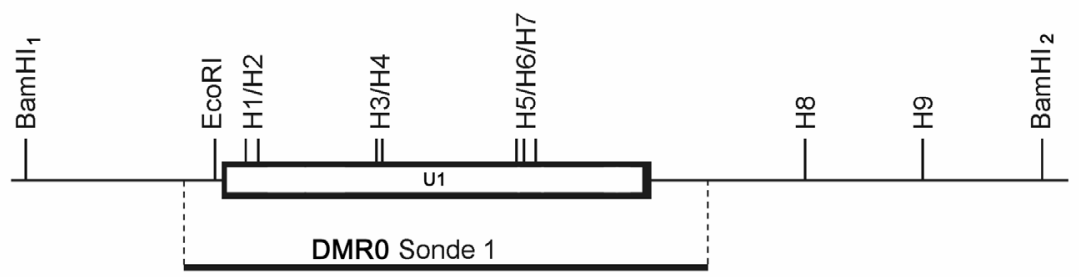

Abb. 20: Schematische Darstellung der DMR0-Region des Igf2-Lokus: Die DMR0 umfaßt den Bereich des Exons U1 (offenes Rechteck). Die 835 bp Sonde 1 hybridisiert ein 3345-umfassendes BamHI-Fragment, in dem neun methylierungssensitive HpaIISchnittstellen (H1-H9) lokalisiert sind. Dabei liegen sieben Schnittstellen in dem Bereich der DMR0-Sonde. 
Für diese Region wurden vier RMS heterozygoter Ptch-Mäuse mittels methylierungssensitiver Southern-Blot-Technik untersucht. Ein repräsentativer Blot ist in Abbildung 21 dargestellt.

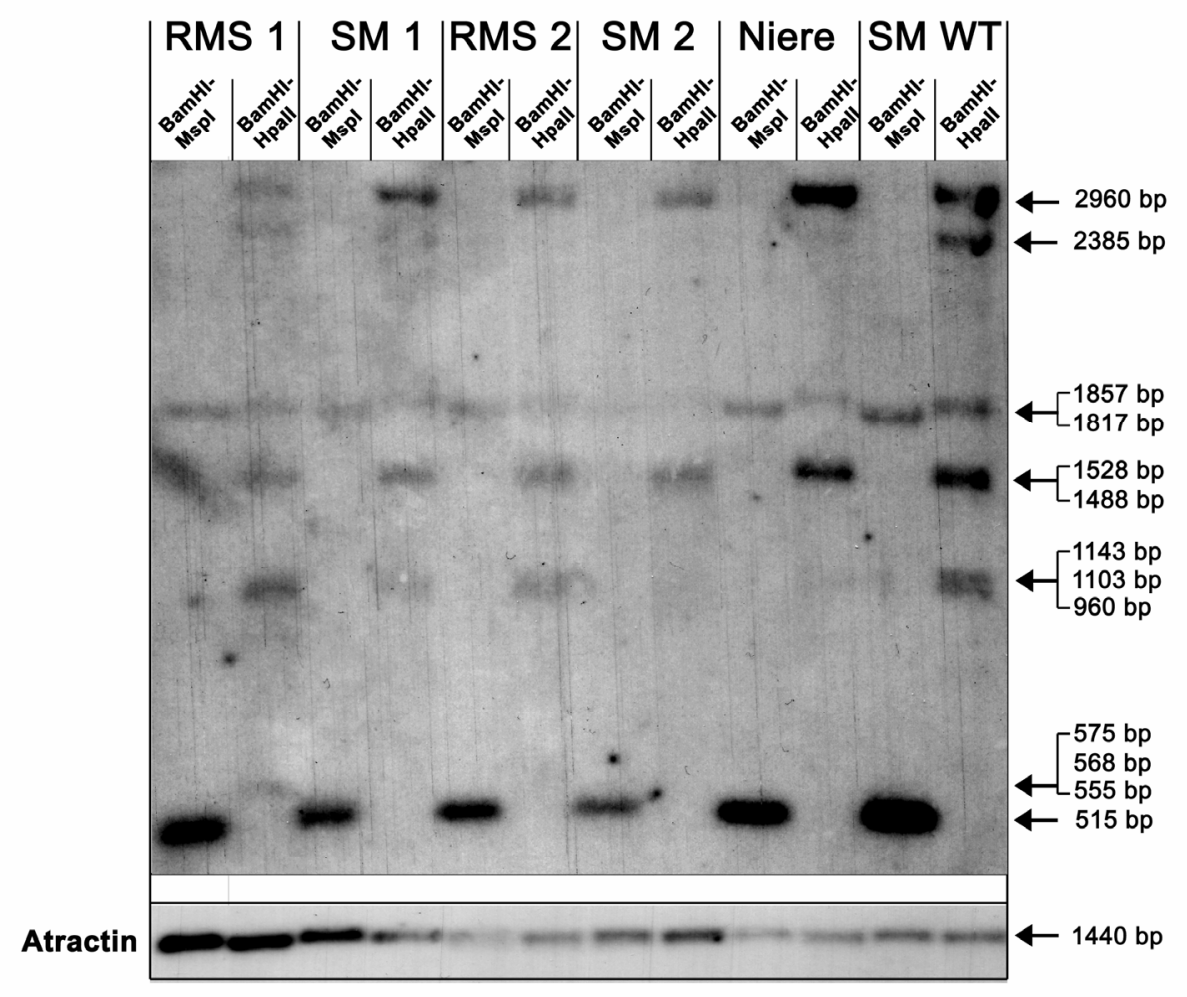

Abb. 21: Untersuchung der Methylierungsunterschiede in der DMR0 zwischen Tumor und normalem Muskelgewebe über die methylierungssensitive Southern-Blot-Technik mittels der Sonde 1: Die DNA aus jedem Gewebe wurde im Doppelverdau BamHI-MspI und BamHI-HpaII geschnitten und in einem 0,8\% igen Agarosegel aufgetrennt. Zur Normalisierung der eingesetzten DNA-Konzentrationen wurde die 677 bp-AtractinSonde 9 verwendet (siehe Tabellen 14 und 15), welche ein 1440 bp großes BamHI-Fragment hybridisiert.

Auf Grund der Auswertung der Intensitäten der detektierten Fragmente im Southern-Blot wurde versucht, Unterschiede in der Methylierung zwischen Tumor und der Referenz festzustellen.

Die Unterschiede in den Intensitäten des 1440 bp-Fragmentes, welches durch die Hybridisierungssonde Atractin (Sonde 9) detektiert wird, erklären sich aus unterschiedlichen in den Verdau eingesetzten DNA-Mengen. Eine Untersuchung der Methylierungsveränderungen zwischen Tumor und Referenz war dennoch möglich. So wurde im ersten Tumor-Muskel-Paar (RMS1/ SM1) eine größere DNA-Menge in der RMS-Probe im Vergleich zum Muskel eingesetzt, während im zweiten untersuchten Paar (RMS2/ SM2) weniger Tumor-DNA und mehr Muskel-DNA zum Einsatz kam. Trotzdem sind in beiden untersuchten Tumor-MuskelPaaren gleichlautende Unterschiede in den methylierungsabhängig auftretenden Fragmenten zu verzeichnen (Abb. 21). 
In Tabelle 27 sind nur die für die Interpretation der Ergebnisse wichtigen Fragmente aufgelistet. Hierzu gehören alle durch die Sonde 1 hybridisierten Fragmente. Insgesamt wären zweiundfünfzig verschiedene Fragmente möglich gewesen, wenn jede der untersuchten HpaIISchnittstellen partiell methyliert gewesen wäre. Die Berechnung der Fragmentgrößen erfolgte äquivalent zur Berechnung der Fragmentgrößen der DMR2 (siehe 3.3.1). Auf ein entsprechendes Schema für die DMR0 wurde jedoch an dieser Stelle verzichtet.

Tabelle 27: Auswertung des der Intensitäten von BamHI/ HpaII-geschnittenen Fragmenten der DMR0: Die mit einem hochgestellten Buchstaben markierten Fragmente können auf Grund ähnlicher Größen im Blot nicht aufgetrennt werden, wobei jeder Buchstabe verschiedene, eng zusammenliegende Fragmente repräsentiert. Sehr kleine Fragmente, die durch die Sonde nicht detektiert wurden, sind unter „nicht nachweisbar“ aufgeführt, da sie beim Auftrennen der Fragmente bei der Elekrophorese verloren gegangen sind. Markierte Fragmente in der Tabelle weisen einen Intensitätsunzerschied zwischen RMS und Muskel auf, was durch eine veränderte Methylierung der involvierten Schnittstelle zu erklären ist. $(+)$ : Aussage nur begrenzt möglich. Ptch $^{+/}=$heterozygotePtch-Mäuse; $\mathrm{H}=$ HpaII-Schnittstelle.

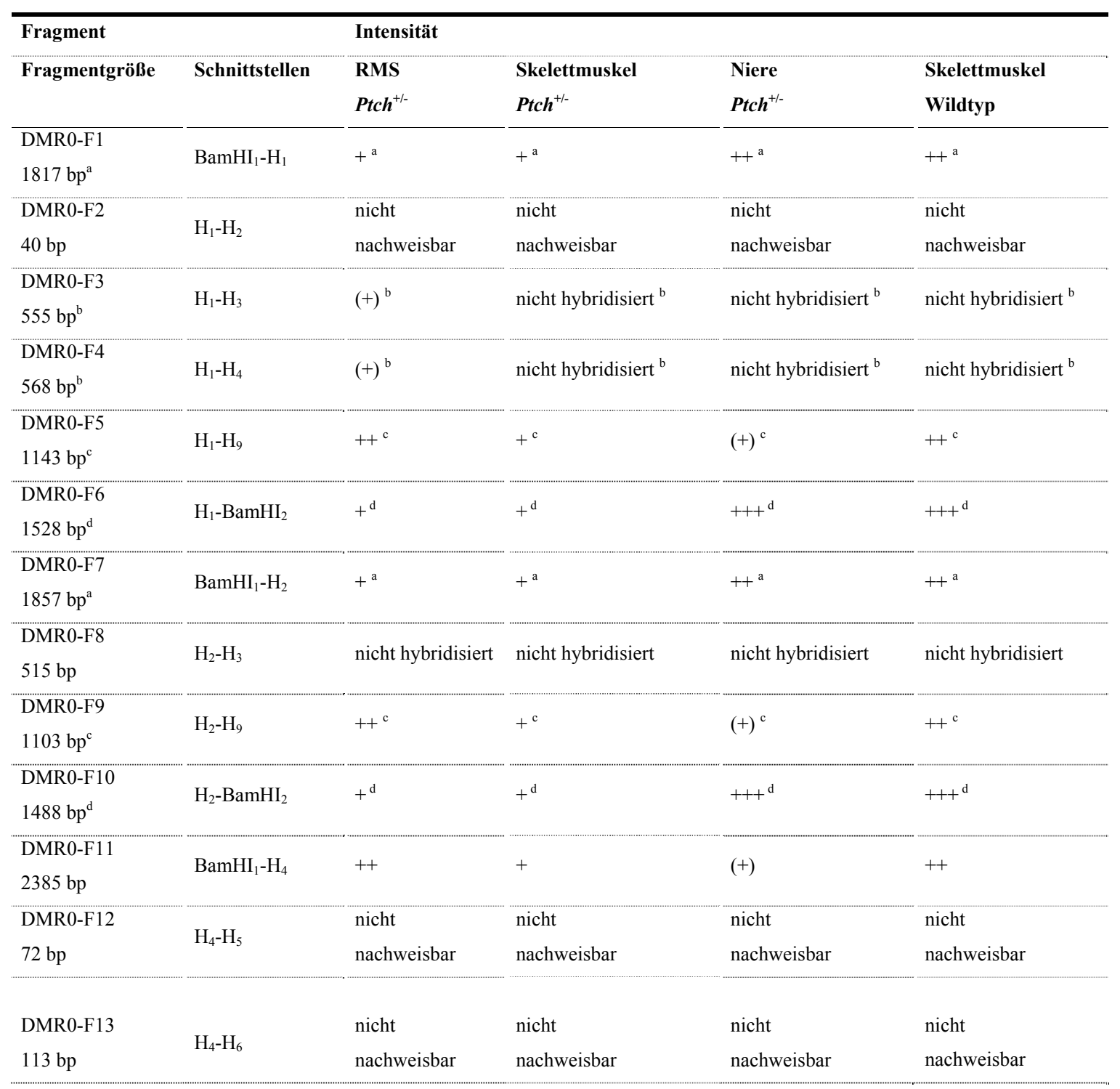




\begin{tabular}{|c|c|c|c|c|c|}
\hline $\begin{array}{l}\text { DMR0-F14 } \\
135 \mathrm{bp}\end{array}$ & $\mathrm{H}_{4}-\mathrm{H}_{7}$ & $\begin{array}{l}\text { nicht } \\
\text { nachweisbar }\end{array}$ & $\begin{array}{l}\text { nicht } \\
\text { nachweisbar }\end{array}$ & $\begin{array}{l}\text { nicht } \\
\text { nachweisbar }\end{array}$ & $\begin{array}{l}\text { nicht } \\
\text { nachweisbar }\end{array}$ \\
\hline $\begin{array}{l}\text { DMR0-F15 } \\
318 \mathrm{bp}\end{array}$ & $\mathrm{H}_{4}-\mathrm{H}_{8}$ & nicht hybridisiert & nicht hybridisiert & nicht hybridisiert & nicht hybridisiert \\
\hline $\begin{array}{l}\text { DMR0-F16 } \\
575 \mathrm{bp}^{\mathrm{b}}\end{array}$ & $\mathrm{H}_{4}-\mathrm{H}_{9}$ & $(+)^{\mathrm{b}}$ & nicht hybridisiert $^{\mathrm{b}}$ & nicht hybridisiert $^{\mathrm{b}}$ & nicht hybridisiert ${ }^{b}$ \\
\hline $\begin{array}{l}\text { DMR0-F17 } \\
960 \text { bp }\end{array}$ & $\mathrm{H}_{4}-\mathrm{BamHI}_{2}$ & ++ & + & $(+)$ & ++ \\
\hline $\begin{array}{l}\text { DMR0-F18 } \\
22 \mathrm{bp}\end{array}$ & $\mathrm{H}_{6}-\mathrm{H}_{7}$ & $\begin{array}{l}\text { nicht } \\
\text { nachweisbar }\end{array}$ & $\begin{array}{l}\text { nicht } \\
\text { nachweisbar }\end{array}$ & $\begin{array}{l}\text { nicht } \\
\text { nachweisbar }\end{array}$ & $\begin{array}{l}\text { nicht } \\
\text { nachweisbar }\end{array}$ \\
\hline $\begin{array}{l}\text { DMR0-F21 } \\
13 \mathrm{bp}\end{array}$ & $\mathrm{H}_{3}-\mathrm{H}_{4}$ & $\begin{array}{l}\text { nicht } \\
\text { nachweisbar }\end{array}$ & $\begin{array}{l}\text { nicht } \\
\text { nachweisbar }\end{array}$ & nicht nachweisbar & $\begin{array}{l}\text { nicht } \\
\text { nachweisbar }\end{array}$ \\
\hline $\begin{array}{l}\text { DMR0-F22 } \\
41 \mathrm{bp}\end{array}$ & $\mathrm{H}_{5}-\mathrm{H}_{6}$ & $\begin{array}{l}\text { nicht } \\
\text { nachweisbar }\end{array}$ & $\begin{array}{l}\text { nicht } \\
\text { nachweisbar }\end{array}$ & nicht nachweisbar & $\begin{array}{l}\text { nicht } \\
\text { nachweisbar }\end{array}$ \\
\hline $\begin{array}{l}\text { DMR0-F23 } \\
183 \mathrm{bp}\end{array}$ & $\mathrm{H}_{7}-\mathrm{H}_{8}$ & $\begin{array}{l}\text { nicht } \\
\text { nachweisbar }\end{array}$ & $\begin{array}{l}\text { nicht } \\
\text { nachweisbar }\end{array}$ & nicht nachweisbar & $\begin{array}{l}\text { nicht } \\
\text { nachweisbar }\end{array}$ \\
\hline
\end{tabular}

Im vorliegenden Southern-Blot konnte im methylierungssensitiven Verdau kein Fragment DMR0-F20 nachgewiesen werden, welches durch eine vollständige Methylierung aller HpaIISchnittstellen entstanden wäre. Das Fragment DMR0-F1 (1857 bp) und DMR0-F8 (515 bp) konnten nur an mit BamHI-MspI geschnittener DNA nachgewiesen werden. Alle anderen Fragmente, die bei diesem Verdau von der Sonde hätte detektiert werden müssen (DMR0-F2, F12, F18, F21, F23 und F23; siehe Tabelle 27), waren auf Grund Ihrer geringen Größe aus dem Gel gelaufen. Im BamHI-HpaII Verdau konnten keine Fragmente detektierte werden, die an den Schnittstellen H3, H5-H8 geschnitten worden wären. Dies kann durch die Methylierung dieser Schnittstellen erklärt werden.

Im Blot konnten nur Fragmente detektiert werden, die an den Schnittstellen BamH1 $1_{1}, \mathrm{H} 1, \mathrm{H} 2$, H4, H9 oder BamH1 2 verdaut worden waren. Zusätzlich zu H1/ H2, H2/ H4 oder H4/ H9 Fragmenten traten jedoch auch H1/ H4, H1/ H9 sowie H2/ H9 Fragmente auf. Hierdurch kann die Aussage getroffen werden, das die H1, H2, H4 und H9 Schnittstellen nur partiell verdaut wurden und daher im partiell methylierten Zustand vorliegen.

Starke Methylierungsunterschiede zwischen RMS und SM waren durch dieses Experiment nicht erkennbar. Jedoch sollen zwei leichte Unterschiede im untersuchten RMS1/ SM1 festgehalten werden. Das Fragment DMR0-F19 (2960 bp) ensteht aus dem Verdau der Schnittstellen BamHI $_{1}$ und H9. Intensitätsunterschiede im Blot zwischen Tumor und Muskel könnten auf eine 
Methylierung der H9-Schnittstelle im RMS hindeuten. Weitere Unterschiede in den Intensitäten ergaben sich aus einer wahrscheinlichen Hypomethylierung der H4-Schnittstelle im RMS. Dies würde demzufolge auch die Unterschiede in den Intensitäten der Fragmente DMR0-F4 (568 bp) und DMR0-F17 (960 bp) erklären, die im RMS1 gegenüber SM1 zu beobachten waren (siehe Abb. 21).

Da diese Unterschiede jedoch nur in einem der untersuchten vier RMS/ SM Paare nachgewiesen werden konnten, wurde diese Region keiner Bisulfit-Sequenzierung unterzogen.

\subsubsection{Analyse der DMR1 im methylierungssensitiven Southern-Blot mit Hybridisierungssonde 2}

Die DMR1-Region befindet sich $2 \mathrm{~kb}$ upstream von der Promotorregion P1 des Igf2-Gens und wurde mit Hilfe von vier Hybridisierungssonden (Sonde 2-5, Abb. 19, Feil et al, 1994) systematisch auf ihre Methylierung untersucht.

Da die Überexpression von Igf2 in Ptch-assoziierten RMS durch eine verstärkte Expression des paternalen Igf2 Allels zustande kommt, stellte diese Region eine potentielle Kandidatenregion für Methylierungsunterschiede zwischen RMS und SM dar (Hahn et al., 2000). Es ist bekannt, daß im Falle einer Methylierung des paternalen Allels keine Interaktionen in cis zwischen methylierungssensitiven Repressor-Proteinen und der DNA stattfinden können (Eden et al., 2001). Es ist daher möglich, daß dieser Bereich im RMS gegenüber dem entsprechenden SM verstärkt methyliert sein könnte.

Für die Untersuchung dieser Region wurde die DNA aus RMS und SM mit EcoRI-MspI und EcoRI-HpaII verdaut. Die eingesetzte Sonde 2 (Tab. 14 und 15, Abb. 19) hybridisiert ein 3776 bp umfassendes EcoRI-Fragment. Innerhalb der Sequenz sind elf HpaII-Schnittstellen lokalisiert, die sich teilweise mit denen der DMR0 überlagern (Abb. 22).

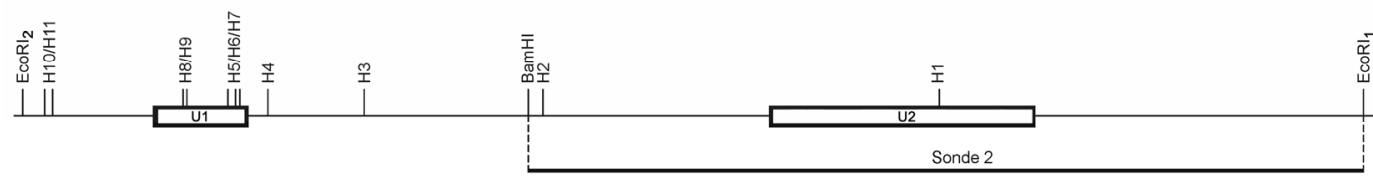

Abb. 22. Schematische Darstellung des Bereiches der DMR1 des Igf2-Gens, der durch die Sonde 2 hybridisiert wird. Die Sonde $2(2200$ bp EcoRI-BamHI) hybridisiert ein 3776 bp EcoRI-Fragment, welches elf methylierungssensitive HpaII-Schnittstellen (H1-H11) umfaßt. Zwei Schnittestellen H1 und H2 liegen in dem DNA Bereich, der von der Sonde 2 hybridisiert wird. Die Exone U1 und U2 sind als offene Rechtecke dargestellt.

Eine Untersuchung der Methylierung wurde an acht RMS und dem korrespondierenden Muskelgewebe aus $P t c h^{\text {neo67/+ }}$-Mäusen durchgeführt. Ein repräsentativer methylierungssensitiver Southern-Blot ist in der Abbildung 23 gezeigt. 


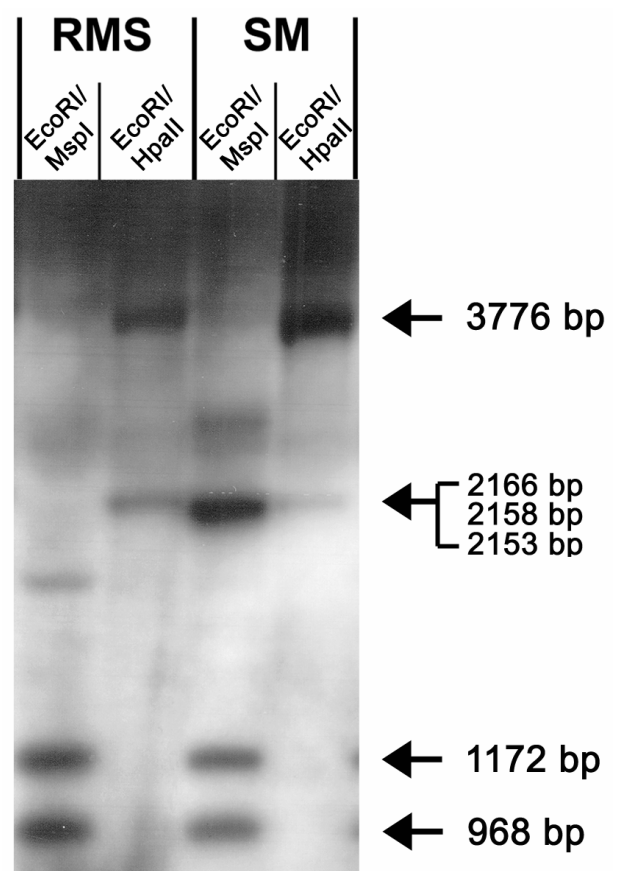

Abb. 23: Untersuchung der Methylierungsunterschiede in der DMR1 zwischen Tumor und normalem Muskelgewebe über die methylierungssensitive Southern-Blot-Technik mittels der Sonde 2: Die DNA aus Gewebe wurde im Doppelverdau EcoRI-MspI und EcoRI-HpaII hydrolytisch gespalten und in einem $0,8 \%$ igen Agarosegel aufgetrennt.

Die Signale der Fragmente, die im Southern-Blot durch die Hybridisierung mit der Sonde 2 detektiert wurden, wurden in Tabelle 28 ausgewertet.

Tabelle 28: Auswertung der Intensitäten von EcoRI-HpaII-geschnittenen Fragmenten der DMR1 nach Hybridisierung mit Sonde 2: Die mit einem hochgestellten Buchstaben (a) markierten Fragmente können auf Grund ähnlicher Größen im Blot nicht aufgetrennt werden. Ptch $^{+/}=$heterozygotePtch-Mäuse; H=HpaII-Schnittstellen

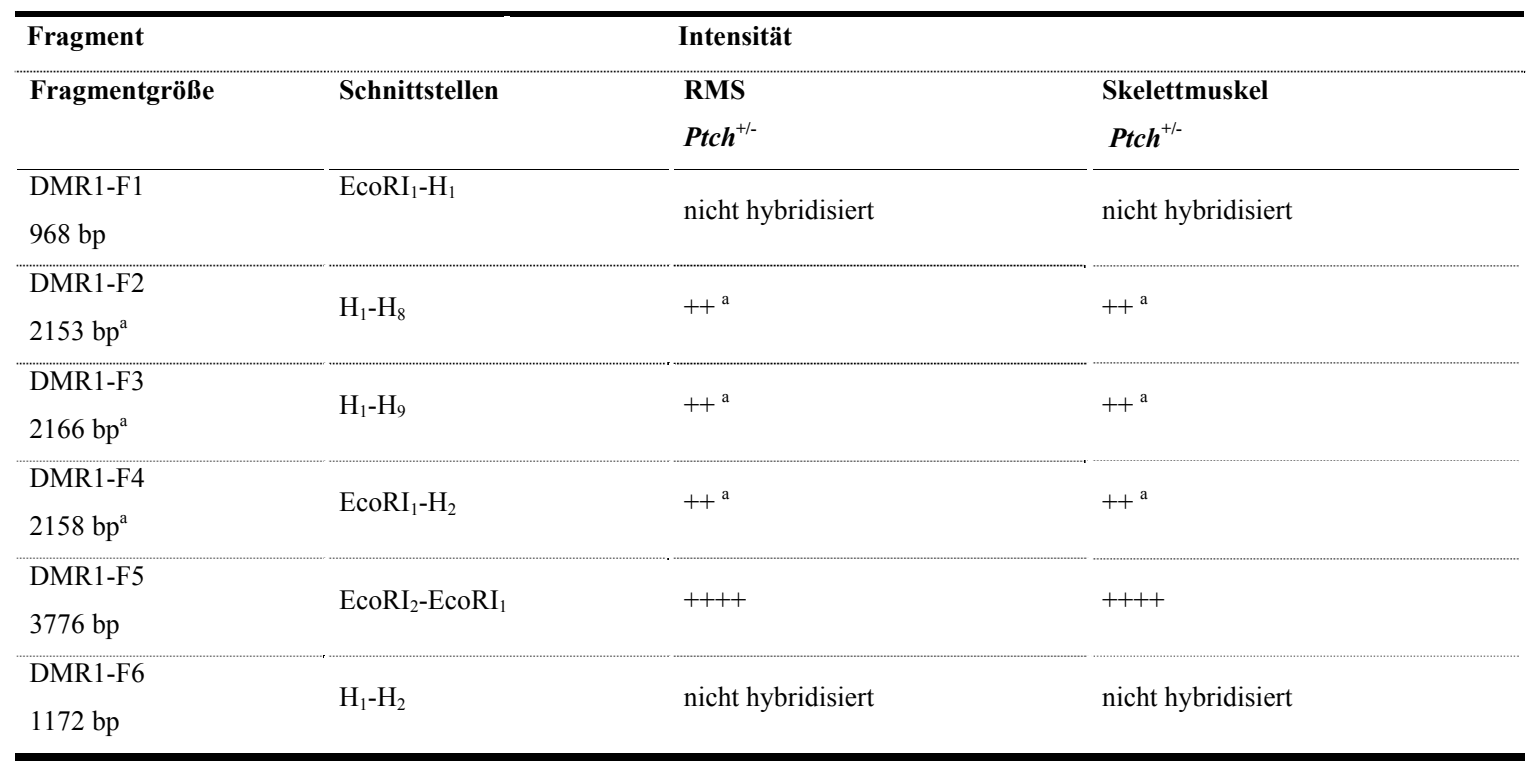


Dieser Blot zeigt zunächst keine Unterschiede in den Intensitäten der detektierten Fragmente zwischen RMS und SM nach EcoRI-HpaII-Verdau der DNA auf. Die starke Hybridisierung des Fragmentes DMR1-F5 (3776 bp) im RMS und Referenz weist darauf hin, daß bei allen HpaIISchnittstellen Methylierungen vorliegen müssen. Eindeutig ist eine Methylierung der HpaIISchnittstellen H1 und H2 zu erkennen, denn das entsprechende Fragment DMR1-F1 (968 bp) oder DMR1-F6 (1172 bp) konnte weder im RMS noch im SM detektiert werden. Beide Fragmente sind im nichtmethylierungssensitiven Kontrollverdau mit EcoRI-MspI im Blot (siehe Abb. 23; Tabelle 28) detektierbar.

Der Nachweis des Fragmentes von ca. 2150 bp mit geringer Intensität im Blot ist sehr schwer zu interpretieren. Es könnte durch einen EcoR1 1 / H2-, einen H1/ H9- oder einen H1/ H8-Verdau zustande kommen. Dadurch könnte nun die Schlußfolgerung gezogen werden, daß die Schnittstellen H1 und/ oder H2 sowie H8 oder H9 nicht vollständig methyliert sind. Hierdurch müssten jedoch auch H1/ H2 und H8/ H9 Fragmente entstehen, die aber nicht detektiert werden konnten. Des Weiteren konnten keine weiteren Fragmente im Southern-Blot detektiert werden. Da keine auffälligen Unterschiede im Methylierungsgrad von RMS und SM gefunden wurden, wurde diese Region nicht für die anschließende genauere Untersuchung mittels BisulfitSequenzierung ausgewählt.

\subsubsection{Analyse der DMR1 im methylierungssensitiven Southern-Blot mit Hybridisierungssonde 3 und 4}

Die Sonden 3 und 4 hybridisieren ein 3000 bp umfassendes EcoRI-Fragment. Innerhalb des DNA-Bereiches sind vierzehn HpaII-Schnittstellen lokalisiert. Durch den zusätzlichen Verdau der genomischen DNA mit HpaII kann sowohl über den Methylierungsstatus der Schnittstellen H1 (durch Sonde 3) als auch über H5-H10 (durch Sonde 4) eine Aussage getroffen werden (Abb 24).

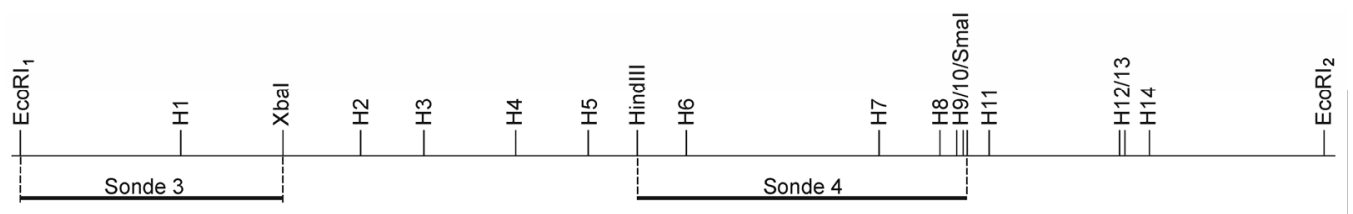

Abb. 24: Schematische Darstellung des Bereiches der DMR1 des Igf2-Gens, der durch die Sonden 3 und 4 hybridisiert wird. Die Sonde 3 (720 bp EcoRI-XbaI) und Sonde 4 (880 bp HindIII-SmaI) hybridisieren ein 3000 bp EcoRI-Fragment, welches vierzehn HpaII-Schnittstellen (H1-H14) umfaßt. 
Zur Analyse der Methylierung der DMR1-Region, die von der Sonde 3 hybridisiert wird, wurde genomische DNA aus zwölf Tumoren (RMS) und den entsprechenden Skelettmuskeln (SM) heterozygoter Ptch-Mäuse herangezogen. Weitere Kontrollen stellten die genomische DNA der Niere heterozygoter Ptch-Mäuse und des Muskels aus CD1 Wildtyp-Mäusen dar.

Ein für die DMR1 repräsentativer Southern-Blot ist in Abbildung 25 gezeigt. Zum Nachweis der in den Verdau eingesetzten DNA-Mengen wurde eine zweite Hybridisierung des Blots mit der Hadhsc-Sonde (Sonde 10, Tab. 14 und 15; Hadhsc: L-3-hydroxy-acyl-Coenzym) durchgeführt. Die Hadhsc-Sonde wurde so ausgewählt, daß sie keine HpaII-Schnittstellen umfaßt, sondern nur ein EcoRI-Fragment von 850 bp hybridisiert und in einem Intron liegt. Somit konnte ausgeschlossen werden, daß die Stärke des Hybridisierungssignals, welches ein Maß für die in den Verdau eingesetzten DNA-Menge darstellt, durch eine mögliche DNAMethylierung der im Fragment involvierten Schnittstellen beeinflußt wurde.

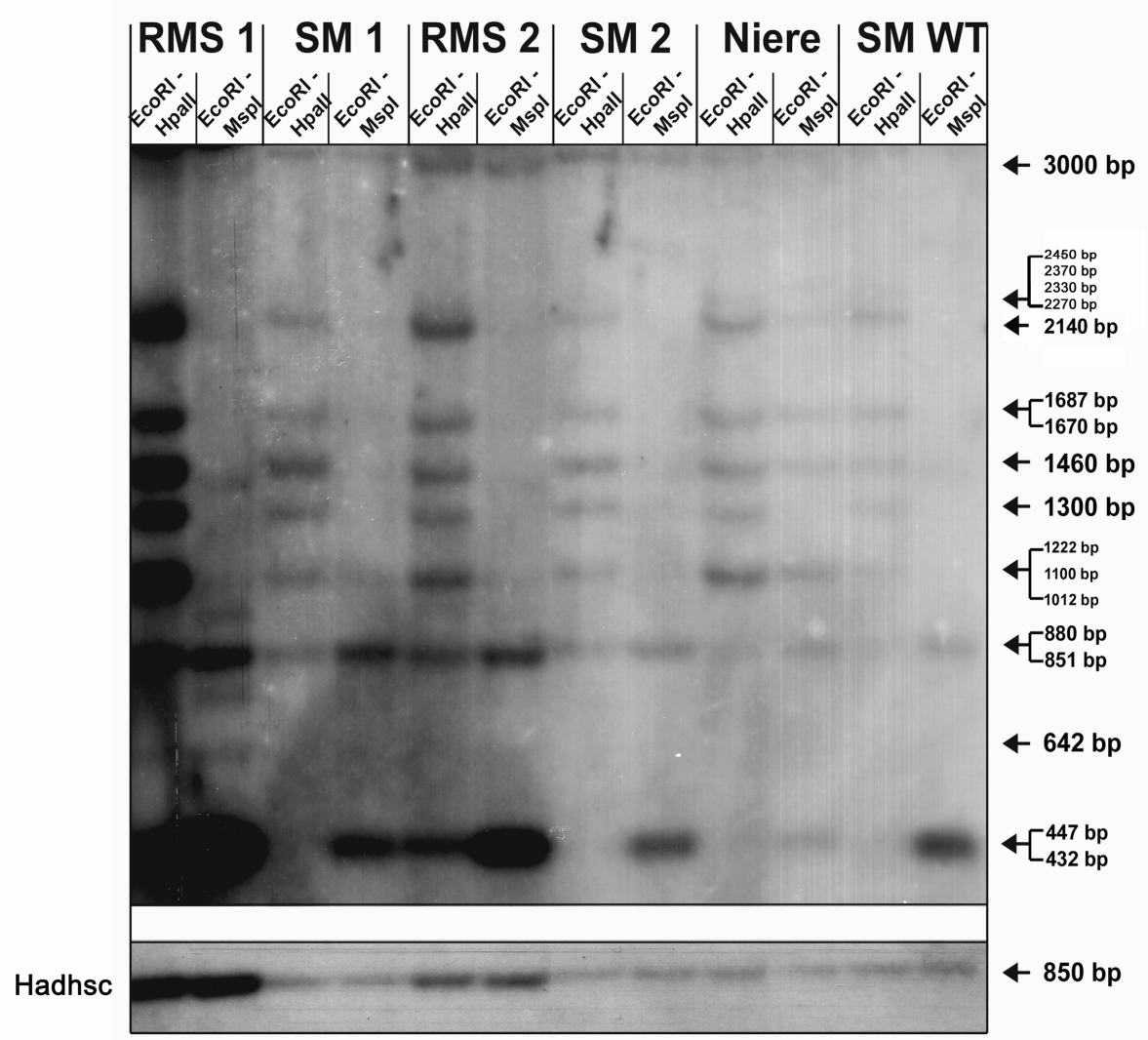

Abb. 25: Untersuchung der Methylierungsunterschiede in der DMR1 zwischen Tumor und normalem Muskelgewebe über die methylierungssensitive Southern-Blot-Technik mittels der Sonde 3: Die DNA aus den Geweben wurde im Doppelverdau EcoRI-MspI und EcoRI-HpaII hydrolytisch gespalten und in einem 0,8 \% igen Agarosegel aufgetrennt. Als Ladekontrolle für die eingesetzten DNA-Mengen wurde eine 302 bp Hadhsc-Sonde verwendet, welche ein $850 \mathrm{bp}$ EcoRI-Fragment hybridisiert. Wie bei der Atractin-Sonde für den BamHIDoppelverdau mit MspI und HpaII war von besonderem Interesse, daß innerhalb des von der Sonde zu detektierenden EcoRI-Fragmentes keine HpaII-Schnittstellen lokalisiert waren. 
Die Auswertung des Southern-Blots erwies sich als schwierig, da unterschiedliche in den Verdau eingesetzte DNA-Mengen nachgewiesen wurden (siehe Hadhsc-Hybridisierung). Dies erschwerte die Auswertung von Intensitätsunterschieden zwischen Tumor und Referenz. Trotzdem wurden die Intensitätsunterschiede der Fragmente ausgewertet. In Tabelle 29 sind nur die für die Interpretation der Ergebnisse wichtigen Fragmente aufgeführt. Insgesamt wäre der Nachweis von siebenundzwanzig verschiedenen Fragmenten möglich gewesen, wenn jede der untersuchten HpaII-Schnittstellen partiell methyliert gewesen wäre.

Tabelle 29: Auswertung der Intensitäten von EcoRI-HpaII-geschnittenen Fragmenten der DMR1 mit Sonde 3: Die mit einem hochgestellten Buchstaben markierten Fragmente können auf Grund ähnlicher Größen im Blot nicht aufgetrennt werden, wobei jeder Buchstabe verschiedene, eng zusammenliegende Fragmente repräsentiert. Hervorgehobene Fragmente weisen zwischen RMS und Referenz unterschiedliche Intensitäten auf. (+): Aussage nur begrenzt möglich. Ptch $^{+-}=$heterozygote Ptch-Mäuse; H=HpaII-Schnittstelle.

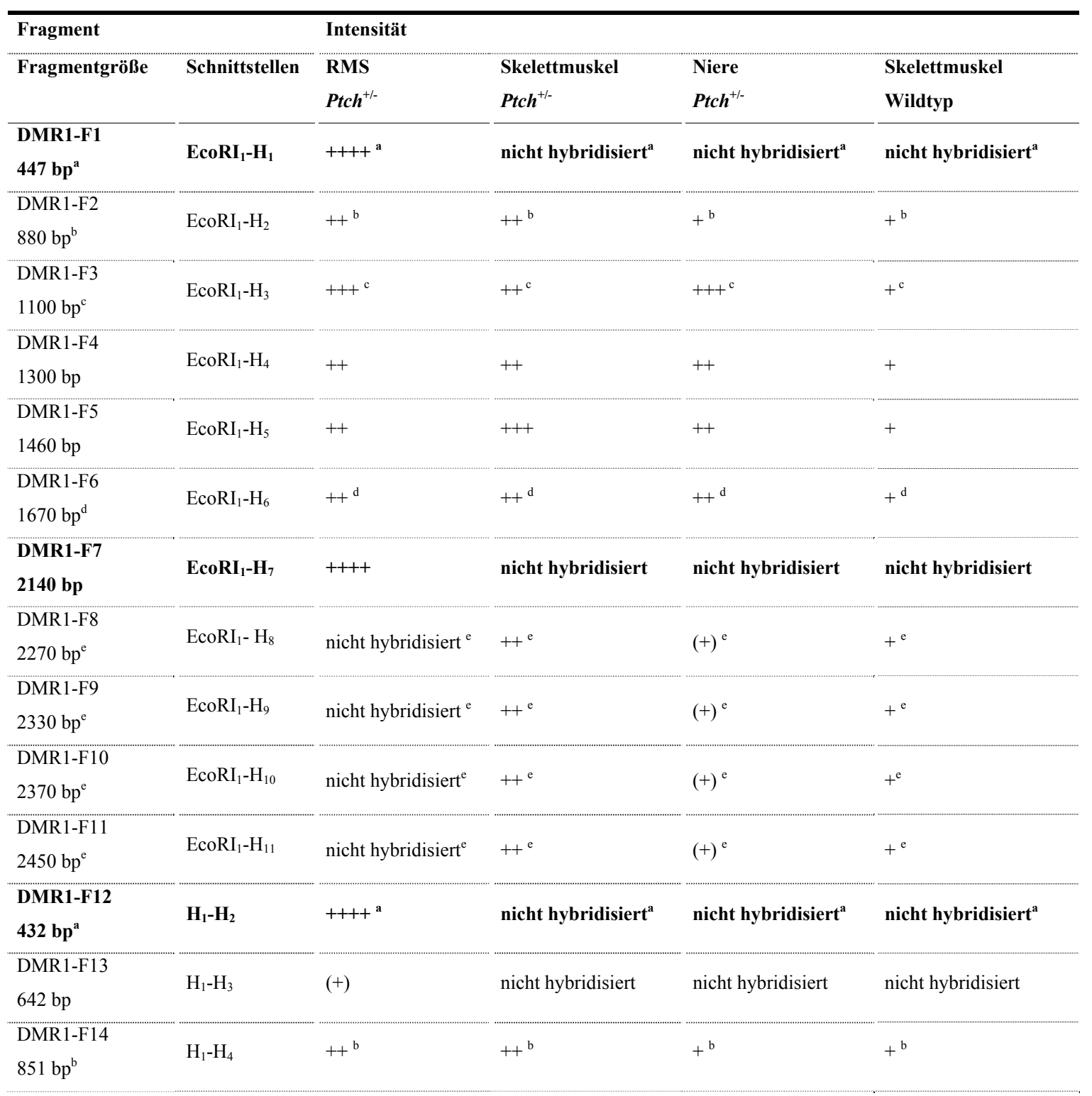




\begin{tabular}{|c|c|c|c|c|c|}
\hline $\begin{array}{l}\text { DMR1-F15 } \\
1012 \mathrm{bp}^{\mathrm{c}}\end{array}$ & $\mathrm{H}_{1}-\mathrm{H}_{5}$ & $+++^{c}$ & $++^{\mathrm{c}}$ & $+++^{\mathrm{c}}$ & $+^{\mathrm{c}}$ \\
\hline $\begin{array}{l}\text { DMR1-F16 } \\
1222 \mathrm{bp}^{\mathrm{c}}\end{array}$ & $\mathrm{H}_{1}-\mathrm{H}_{6}$ & $+++^{c}$ & $++^{\mathrm{c}}$ & $+++^{\mathrm{c}}$ & + \\
\hline $\begin{array}{l}\text { DMR1-F17 } \\
1687 \mathrm{bp}^{\mathrm{d}}\end{array}$ & $\mathrm{H}_{1}-\mathrm{H}_{7}$ & $+{ }^{d}$ & $+{ }^{d}$ & $+{ }^{\mathrm{d}}$ & $+{ }^{\mathrm{d}}$ \\
\hline $\begin{array}{l}\text { DMR1-F18 } \\
1827 \mathrm{bp}\end{array}$ & $\mathrm{H}_{1}-\mathrm{H}_{8}$ & nicht hybridisiert & nicht hybridisiert & nicht hybridisiert & nicht hybridisiert \\
\hline $\begin{array}{l}\text { DMR1-F19 } \\
3000 \mathrm{bp}\end{array}$ & $\mathrm{EcoRI}_{1}-\mathrm{EcoRI}_{2}$ & ++ & + & $(+)$ & nicht hybridisiert \\
\hline
\end{tabular}

Durch die Sonde 3 wird eine DNA-Sequenz hybridisiert, die eine methylierungssensitive HpaIISchnittstelle H1 enthält. Alle Fragmente, die sich durch den Verdau dieser Schnittstelle ergeben, sind in Abbildung 26 dargestellt. Die durch diese Schnittstelle entstehenden Fragmente DMR1F1 (447 bp) und DMR1-F12 (432 bp) unterscheiden sich in ihrer Größe in 15 bp und sind deshalb im Blot nicht aufzutrennnen. Im Kontrollverdau mit EcoRI-MspI sollten nur diese beiden Fragmente von der Sonde detektiert werden. Wie in Abbildung 25 gezeigt ist, wurde aber noch ein weiteres Fragement H1/ H3 (642 bp) detektiert, welches daher auf einen partiellen MspI-Verdau der DNA hinweist.

Nichtsdestotrotz lassen sich Unterschiede im Hybridisierungssignal zwischen Tumor und Muskel erkennen: Im Muskelgewebe konnten im methylierungssensitiven Verdau die Fragmente DMR1-F1 (447 bp) oder DMR1-F12 (432 bp) nur sehr schwach detektiert werden. Dies bedeutet, daß im Muskelgewebe eine Methylierung der Schnittstellen H1 und H2 vorliegen muß. Daher sollten keine weiteren Fragmente ausgegehend von diesen beiden Schnittstellen entstehen können. Jedoch wurde ein Fragment im Southern-Blot detektiert, welches entweder das DMR1-F2 (880 bp) oder das DMR1-F12 (851 bp) Fragment repräsentieren kann. Das Fragment DMR1-F2 entsteht durch einen Verdau an den Schnittstellen EcoRI $/$ H2; das Fragment DMR1-F12 entsteht durch einen Verdau an den H1/ H4 Schnittstellen. Dies läßt die Schlußfolgerung zu, daß die H1- und H2-Schnittstellen im Muskel nicht vollständig methyliert vorliegen.

Im Tumor dagegen wurde ein starkes Hybridisierungssignal eines Fragmentes der Größe 447 bp bzw. 432 bp detektiert. Dies bedeutet, daß im Tumor keine oder aber nur eine unvollständige Methylierung der Schnittstellen H1 und/ oder H2 vorliegt. Durch die ähnlichen Größen der Fragmente, war die weitere Analyse problematisch. Jedoch konnte noch festgestellt werden, daß der Tumor im Gegensatz zum Muskel ein stärkeres Hybridisierungssignal des 2140 bp großen DMR1-F7 Fragmentes zeigte, was auf eine verminderte Methylierung der H7 Schnittstelle hinwies. 
Abhängig vom Methylierungsstatus der HpaII-Schnittstellen innerhalb der EcoRI-Sequenz entsteht eine Anzahl an theoretisch möglichen Fragmenten, die in Abbildung 26 dargestellt sind

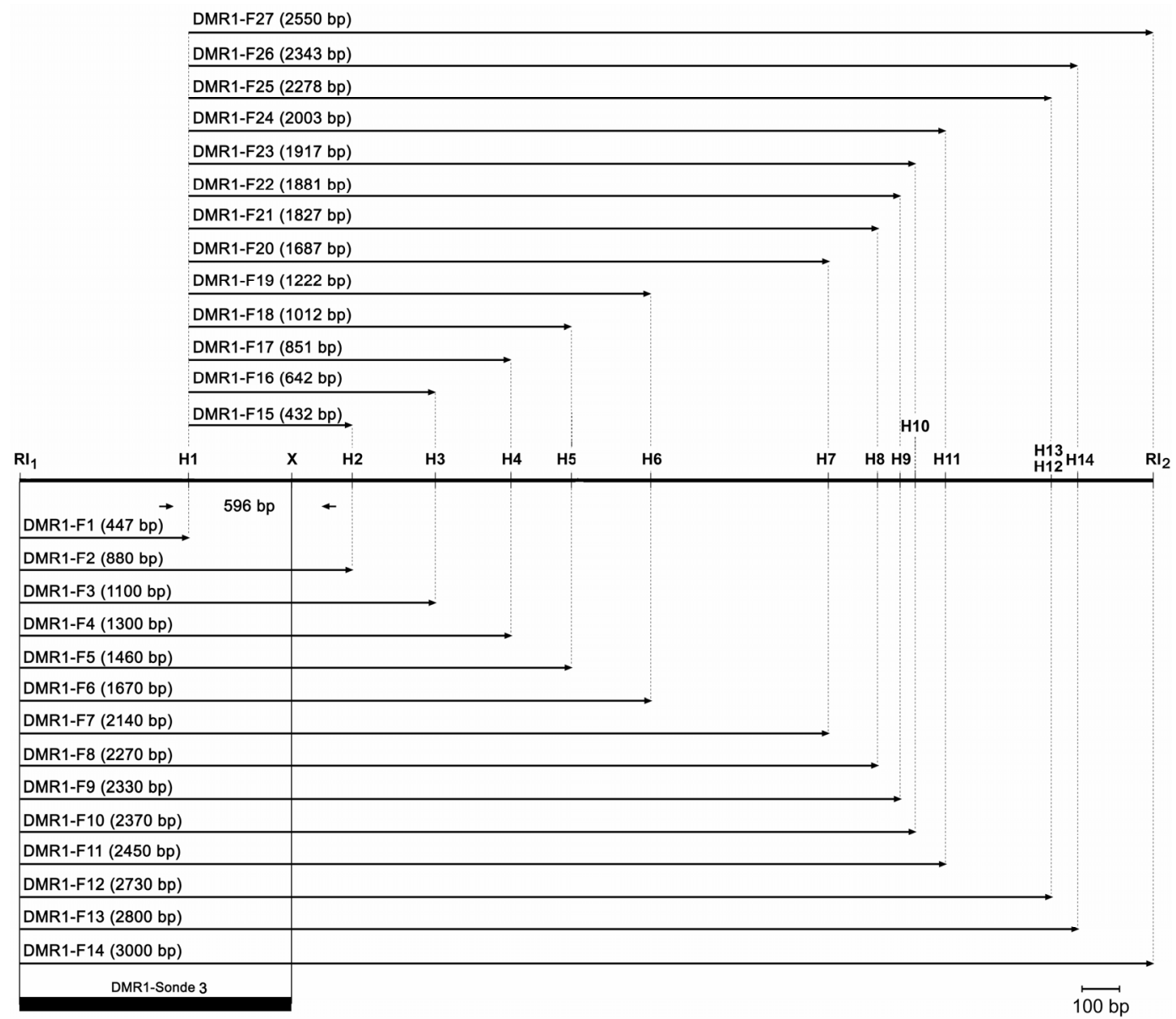

Abb. 26: Darstellung aller theoretisch möglichen Fragmente von EcoRI/ HpaII geschnittener genomischer DNA, die durch die Hybridisierung mit der DMR1-Sonde 3 detektierbar sind. Das 3000 bp EcoRI-Fragment umfaßt vierzehn methylierungssensitive Schnittstellen (H1-H14). Dabei liegt H1 in der von der Sonde 3 (RI: EcoRI; X: XbaI) hybridisierten DNA-Sequenz. Eine mit Pfeilen eingegrenzte Region von 596 bp wurden über die BisulfitSequenzierung in ihrer Methylierung näher untersucht.

Der Einsatz der Hybridisierungssonde 4 (siehe Abb. 24) sollte die Charakterisierung des Methylierungstatus der Schnittstellen H3 und H7 ermöglichen. Obwohl das mit dieser Sonde erzielte Resultat nur eingeschränkt interpretierbar war, konnte der zuvor detektierte Unterschied in der Methylierung der Schnittstelle H7 zwischen SM und Tumor bestätigt werden. Ein repräsentativer Southern-Blot des DMR1-Bereiches, der durch die Sonde 4 detektiert wird, ist in der folgenden Abbildung gezeigt (Abb. 27). 


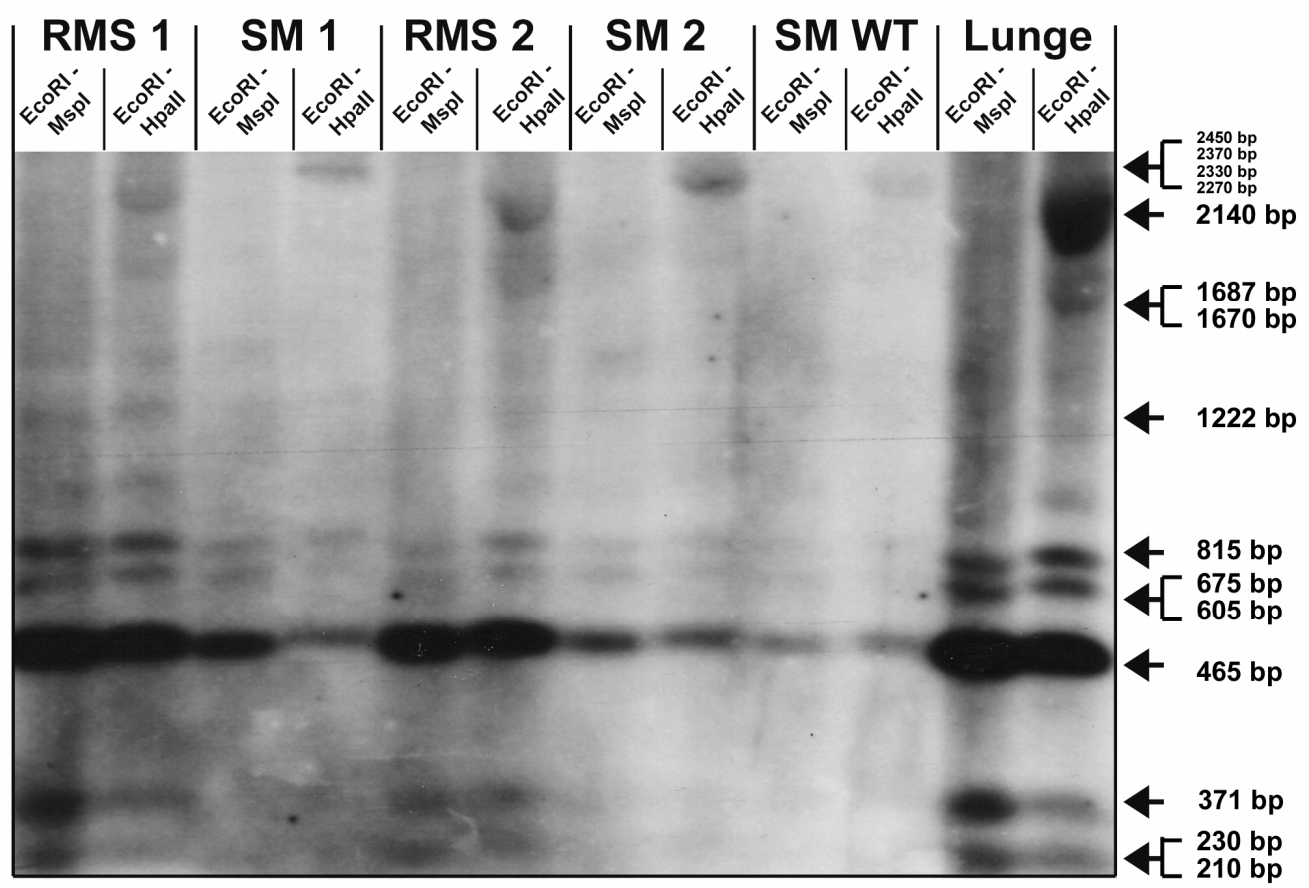

Abb. 27: Untersuchung der Methylierungsunterschiede in der DMR1 zwischen Tumor und normalem Muskelgewebe über die methylierungssensitive Southern-Blot-Technik mittels der Sonde 4: Die DNA aus jedem Gewebe wurde im Doppelverdau EcoRI-MspI und EcoRI-HpaII hydrolytisch gespalten und in einem $0,8 \%$ igen Agarosegel aufgetrennt.

Im Southern-Blot zeigt sich ein deutlicher Unterschied im Hybridisierungssignal des 465 bp großen Fragmentes zwischen RMS und Referenz (siehe Tab. 29 und 30). Dieses Fragment entsteht durch den Verdau der DNA an den Schnittstellen H6 und H7. Die höhere Intensität dieses Fragments im Tumor wies daher auf eine verminderte Methylierung der beiden Schnittstellen in diesem Gewebe hin. Dies wird auch durch das 2140 bp große Fragment deutlich, daß durch die Spaltung der DNA an den Schnittstellen EcoR1 1 / H7 zustande kommt und dem Fragment DMR1-F7 in Tabelle 29 entspricht. Auch das 230 bp große Fragment im RMS weist auf eine fehlende Methylierung der Schnittstelle H7 hin (siehe Tab. 30).

Ein Hybridisierungssignal von Fragmenten, die durch den Verdau der DNA an den Schnittstellen EcoR1 1 / H8, EcoR1 1 / H9, EcoR $1_{1} / \mathrm{H} 10$ oder EcoR $1_{1} /$ H1 1 entstehen (im Bereich von 2270 bp-2450 bp), konnte im RMS nicht beobachtet werden. Dies kann in einer Methylierung der involvierten Schnittstellen begründet sein. Im Muskel dagegen trat ein starkes Signal in dieser Größe auf (Southern-Blot, Abb. 27). Eine definitive Aussage über den Methylierungszustand der vier potentiell involvierten Schnittstellen konnte aber nicht getroffen werden. Grund dafür sind die ähnlichen Größen der aus diesen Schnittstellen entstehenden Fragmente, die keine Auftrennung im Blot ermöglichten. 
Tabelle 30: Auswertung der Intensitäten von EcoRI/ HpaII-geschnittenen Fragmenten der DMR1, die von der Sonde 4 detektiert werden: Die mit einem hochgestellten Buchstaben markierten Fragmente können auf Grund ähnlicher Größen im Blot nicht aufgetrennt werden, wobei jeder Buchstabe verschiedene, eng zusammenliegende Fragmente repräsentiert. Auf eine Namengebung der Fragmente wurde verzichtet, da die entsprechenden Fragmente auch schon in Tabelle 29 aufgeführt sind. (+): Aussage nur begrenzt möglich. Ptch ${ }^{+/-}=$heterozygote Ptch-Mäuse ; $\mathrm{H}=$ HpaII-Schnittstelle.

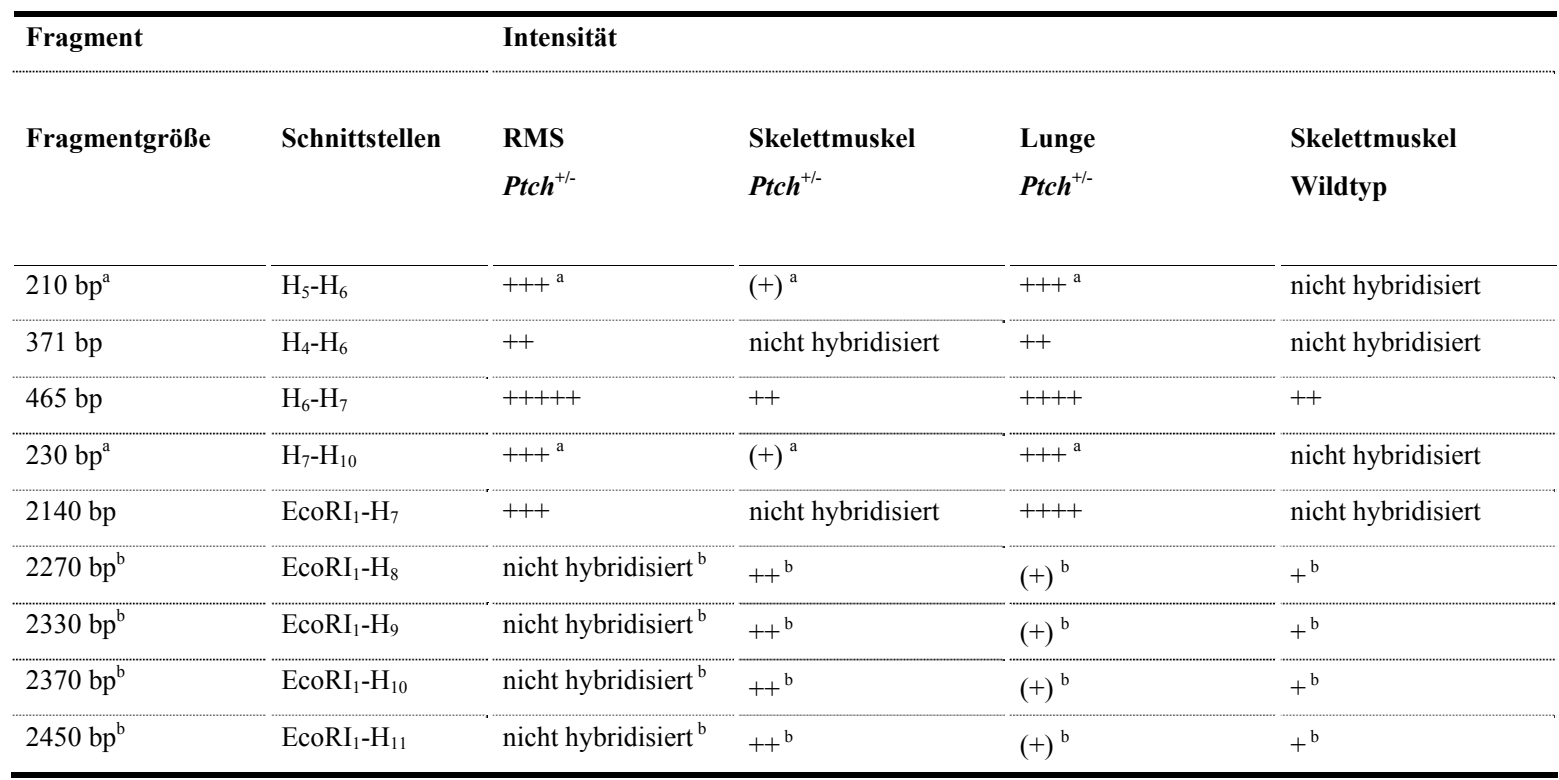

Aus den Analysen der Southern-Blots (Abb. 25 und 27) kann angenommen werden, daß im RMS gegenüber dem normalen Muskel eine Hypomethylierung an den Schnittstellen H1 und/ oder $\mathrm{H} 2$ und $\mathrm{H} 7$ vorliegt.

Für die weitere Untersuchung der Methylierung wurde ein Bereich für die BisulfitSequenzierung ausgewählt, der die Schnittstelle H1 umfaßt (siehe Abb. 34 und Kapitel 3.5.3.1.1.).

\subsubsection{Analyse der DMR1 im methylierungssensitiven Southern-Blot mit Hybridisierungssonde 5}

Unter Anwendung der 2600 bp BamHI-Hybridisierungssonde 5 konnte der stromaufwärts vom Promotor P1 des Igf2-Gens gelegene Bereich (Rotwein und Hall, 1990) im methylierungsensitiven Southern-Blot analysiert werden (Abb. 28 und 29). 


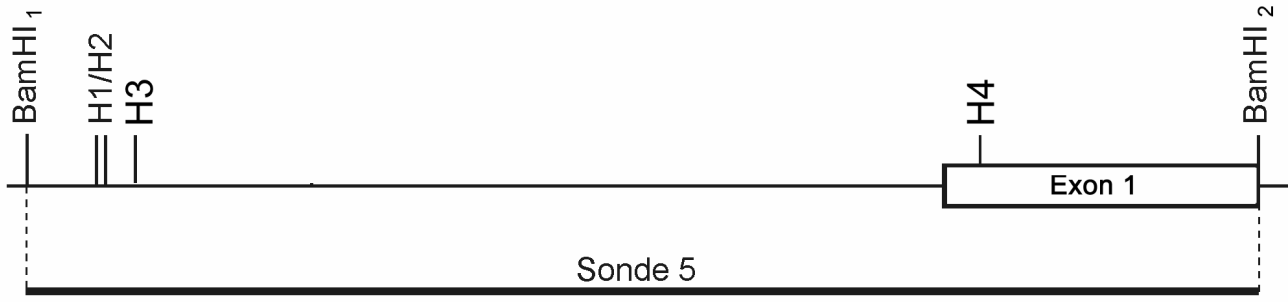

Abb. 28: Schematische Darstellung des Bereiches der DMR1 des Igf2-Gens, der durch die Sonde 5 hybridisiert wird. Die Sonde 5 (2600 bp BamHI) hybridisiert ein 2600 bp BamHI-Fragment, welches fünf methylierungssensitive HpaII-Schnittstellen (H1-H4) umfaßt. Dabei liegt die Schnittstelle H4 im Exon 1 des Igf2-Gens (offenes Rechteck).

Für diesen methylierungssensitiven Southern-Blot wurde genomische DNA aus acht Tumoren (RMS), den entsprechenden Skelettmuskeln (SM) und der Lunge heterozygoter Ptch-Mäuse sowie aus dem Muskelgewebe von CD1 Wildtyp-Mäusen analysiert. Ein Nachweis der eingesetzten DNA-Mengen wurde durch eine weitere Hybridisierung des Blots mit der AtractinSonde 9 erbracht. Ein repräsentativer Southern-Blot ist in der folgenden Abbildung (Abb. 29) gezeigt.

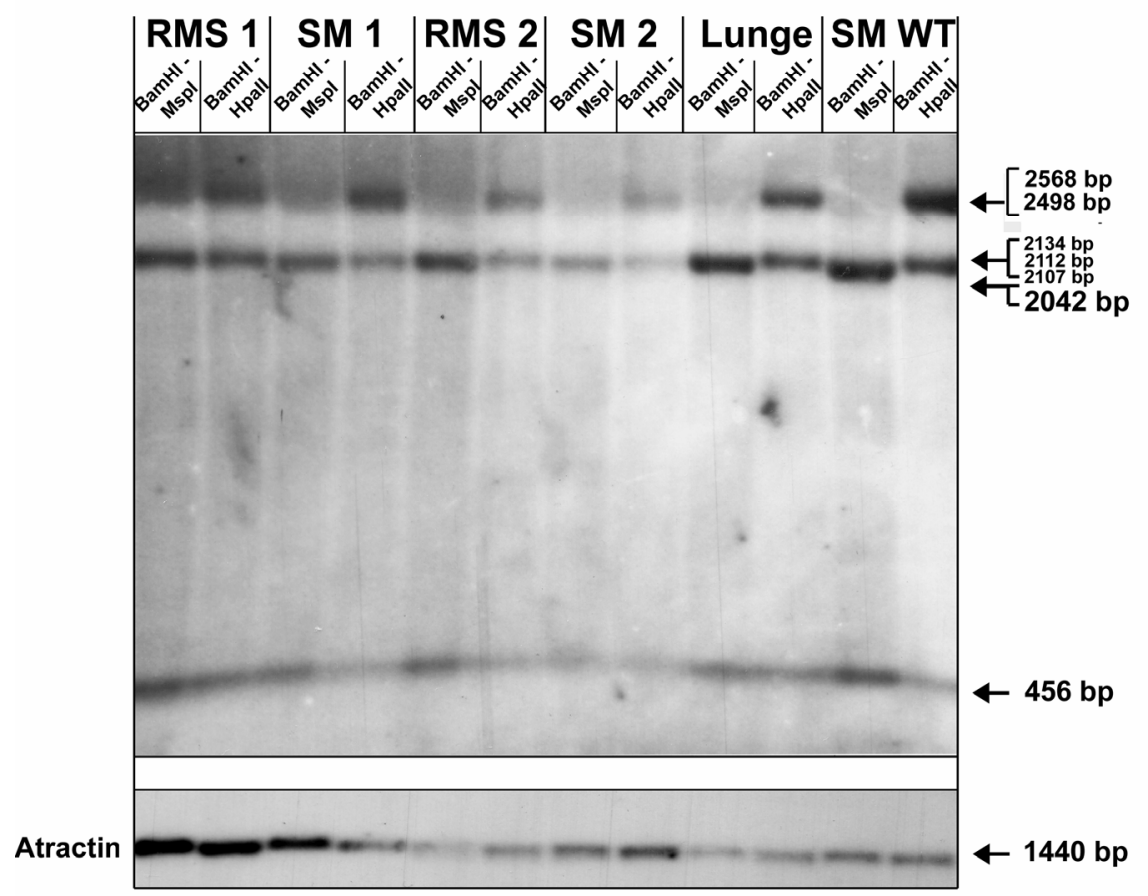

Abb. 29: Untersuchung der Methylierungsunterschiede in der DMR1 zwischen Tumor und normalem Muskelgewebe über die methylierungssensitive Southern-Blot-Technik mittels der Sonde 5: Die DNA aus jedem Gewebe wurde im Doppelverdau EcoRI-MspI und EcoRI-HpaII hydrolytisch gespalten und in einem $0,8 \%$ igen Agarosegel aufgetrennt. Als Ladekontrolle für die eingesetzte DNA-Menge wurde eine Atractin-Sonde verwendet, welche ein BamHI-1440 bp-Fragment hybridisiert. 
In diesem Southern-Blot ist der Kontrollverdau mit dem Enzym BamHI nicht dargestellt. Dabei hybridisiert die Sonde mit einem Fragment bekannter Größe, was zur Kontrolle der Hybridisierung und der Zuordnung der Fragmente des Blots diente. Im Folgenden wurden die im Blot detektierbaren Fragmente ihren Größen zugeordnet. Über die Analyse der Intensitäten der Banden wurde eine Aussage über die Methylierung der involvierten Schnittstellen getroffen (Tab. 31).

Tabelle 31: Auswertung der Intensitäten von BamHI/ HpaII-geschnittenen Fragmente der DMR1, die durch die Sonde 5 detektiert wurden: Die mit einem hochgestellten Buchstaben markierten Fragmente können auf Grund ähnlicher Größen im Blot nicht aufgetrennt werden, wobei jeder Buchstabe verschiedene, eng zusammenliegende Fragmente repräsentiert. Ptch $^{+/}=$heterozygote $P t c h$-Mäuse, H=HpaII-Schnittstellen

\begin{tabular}{|c|c|c|c|c|c|}
\hline \multicolumn{2}{|l|}{ Fragment } & \multicolumn{4}{|c|}{ Intensität } \\
\hline Fragmentgröße & Schnittstellen & $\begin{array}{l}\text { RMS } \\
\text { Ptch }^{+/-}\end{array}$ & $\begin{array}{l}\text { Skelettmuskel } \\
\text { Ptch }^{+/}\end{array}$ & $\begin{array}{l}\text { Lunge } \\
\text { Ptch }^{+/-}\end{array}$ & $\begin{array}{l}\text { Skelettmuske } \\
\text { Wildtyp }\end{array}$ \\
\hline $\begin{array}{l}\text { DMR1-F1 } \\
2134 \mathrm{bp}^{\mathrm{a}}\end{array}$ & $\mathrm{BamH}_{1}-\mathrm{H}_{4}$ & $+++^{a}$ & $++^{\mathrm{a}}$ & $++++^{a}$ & $+++^{a}$ \\
\hline $\begin{array}{l}\text { DMR1-F2 } \\
2112 \mathrm{bp}^{\mathrm{a}}\end{array}$ & $\mathrm{H}_{1}-\mathrm{H}_{4}$ & $+++^{a}$ & $++^{a}$ & $++++^{a}$ & $+++^{a}$ \\
\hline $\begin{array}{l}\text { DMR1-F3 } \\
2568 \mathrm{bp}^{\mathrm{b}}\end{array}$ & $\mathrm{H}_{1}-\mathrm{BamH}_{2}$ & $++++^{b}$ & $++++{ }^{b}$ & $+++{ }^{b}$ & $+++++^{b}$ \\
\hline $\begin{array}{l}\text { DMR1-F4 } \\
2107 \mathrm{bp}^{\mathrm{a}}\end{array}$ & $\mathrm{H}_{2}-\mathrm{H}_{4}$ & $+++^{a}$ & $++^{\mathrm{a}}$ & $++++^{a}$ & $+++^{\mathrm{a}}$ \\
\hline $\begin{array}{l}\text { DMR1-F5 } \\
2563 \mathrm{bp}^{\mathrm{b}}\end{array}$ & $\mathrm{H}_{2}-\mathrm{BamH}_{2}$ & $++++^{b}$ & $++++^{b}$ & $+++{ }^{b}$ & $+++++^{b}$ \\
\hline $\begin{array}{l}\text { DMR1-F6 } \\
2042 \mathrm{bp}^{\mathrm{a}}\end{array}$ & $\mathrm{H}_{3}-\mathrm{H}_{4}$ & $+++^{a}$ & $++^{\mathrm{a}}$ & $++++^{a}$ & $+++^{a}$ \\
\hline $\begin{array}{l}\text { DMR1-F7 } \\
2498 \mathrm{bp}^{\mathrm{b}}\end{array}$ & $\mathrm{H}_{3}-\mathrm{BamH}_{2}$ & $++++^{\mathrm{b}}$ & $+++{ }^{\mathrm{b}}$ & $++++^{\mathrm{b}}$ & $+++++^{\mathrm{b}}$ \\
\hline $\begin{array}{l}\text { DMR1-F8 } \\
456 \mathrm{bp}\end{array}$ & $\mathrm{H}_{4}-\mathrm{BamH}_{2}$ & +++ & ++ & ++ & ++ \\
\hline
\end{tabular}

Durch die enge Lokalisierung der Schnittstellen H1, H2 und H3 (siehe Abb. 28) sind die daraus resultierenden Fragmente im Blot nicht auftrennbar (siehe Tab. 31). Somit kann ein möglich vorliegender Methylierungsunterschied dieser Schnittstellen zwischen RMS und Referenz nicht eindeutig ausgeschlossen werden. Eine klare Aussage über den Methylierungszustand kann nur über die Schnittstelle H4 getroffen werden. Durch den Nachweis des Fragments DMR1-F8 (456 bp), kann von einer nicht- oder partiell-methylierten H4-Schnittstelle sowohl im RMS als auch im Muskel ausgegangen werden.

Da keine auffälligen Veränderungen im Methylierungsmuster in der untersuchten Tumor-DNA und dem entsprechenden Muskel gefunden wurden, wurde diese Region keiner weiteren Analyse unterzogen. 


\subsection{Untersuchungen der Methylierung der H19-DMD-Region}

In der vorliegenden Arbeit wurde die H19-Domäne (H19-DMD) ${ }^{16}$, auf Methylierungsunterschiede in den Tumoren und Kontrollgewebe der Ptch-Mutanten untersucht (Abb. 31). Die H19-DMD ist $2 \mathrm{~kb}$ stromaufwärts vom H19- und $80 \mathrm{~kb}$ stromabwärts vom Igf2Lokus lokalisiert. Die H19-DMD ist eine zwischen Säugetieren hochkonservierte Region und übt die Funktion eines Regulators der reziprok regulierten und geprägten Gene Igf2 und $H 19$ aus (Thorvaldsen et al., 1998; Ishihara et al., 2000). In Abhängigkeit des Methylierungsgrades der H19-DMD wird die Bindung eines Silencerelementes CTCF beeinflußt. Im Fall einer vorliegenden Methylierung der H19-DMD des paternalen Allels wird durch den stromabwärts von $H 19$ liegende Enhancerkomplex über eine große Distanz die paternale Igf2-Expression aktiviert (Kanduri et al., 2000; Szabo et al., 2000).

Im RMS von $P t c h^{\text {neo67/+ }}$-Mäusen wird das paternale $I g f 2$-Allel überexprimiert. Ebenso konnte eine Expression des paternalen Allels des H19-Gens nachgewiesen werden (Hahn et al., 2000), was vermuten ließ, daß die H19-DMD Methylierungsveränderungen im Tumor aufweisen könnte. Daher wurde auch in dieser Region nach Methylierungsunterschieden zwischen Tumor und Muskel gesucht.

Die Sonde 8 (2017 bp) hybridisiert ein 8700 bp umfassendes BamHI-Fragment. Innerhalb dieser Sequenz sind acht HpaII-Schnittstellen lokalisiert (Abb. 230). Durch den Verdau der genomischen DNA mit BamHI und HpaII kann somit eine Aussage über den Methylierungsstatus der HpaII-Schnittstellen getroffen werden.

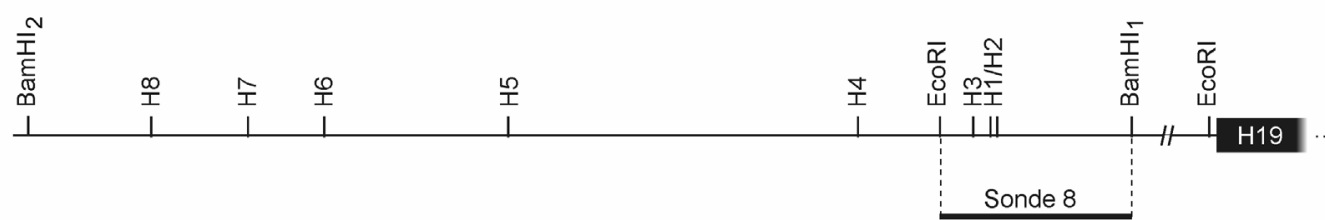

Abb. 30: Schematische Darstellung der hochkonservierten H19-DMD, die durch die Sonde 8 hybridisiert wird: Die H19-DMD befindet sich $2 \mathrm{~kb}$ upstream des H19-Gens. Die Sonde 8 hybridisiert ein 8700 bp-umfassendes BamHI-Fragment, in welchem acht methylierungssensitive HpaII-Schnittstellen (H1-H8) lokalisiert sind.

${ }^{16}$ DMD: differentially methylated domain; engl.: differentiell methylierte Dömäne 
Die H19-DMD wurde in sechs RMS und den entsprechenden normalen Muskeln mittels eines methylierungssensitiven Southern-Blots analysiert (Abb. 31).

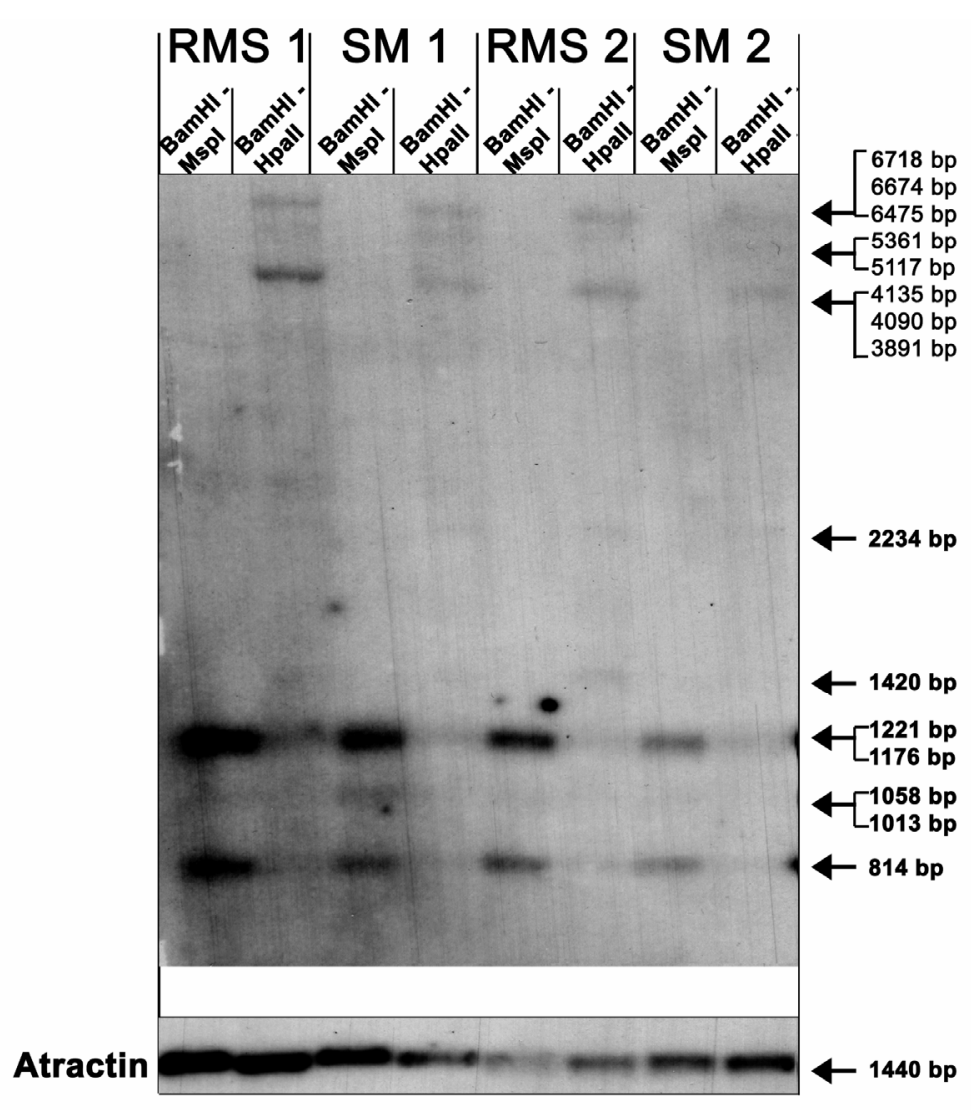

Abb. 31: Untersuchung der Methylierungsunterschiede in der H19-DMD zwischen Tumor und normalem Muskelgewebe über die methylierungssensitive Southern-Blot-Technik mittels der Sonde 8: Die DNA aus jedem Gewebe wurde im Doppelverdau BamHI-MspI und BamHI-HpaII hydrolytisch gespalten und in einem 0,8\% igen Agarosegel aufgetrennt. Als Ladekontrolle für die eingesetzte DNA-Menge wurde eine Atractin-Sonde verwendet, welches ein BamHI-1440 bp-Fragment hybridisiert.

Im Folgenden wurden die Intensitätsunterschiede der Fragmente ausgewertet, die im SouthernBlot durch die Hybridisierung mit der Sonde 8 detektiert wurden (Tab. 32). 
Tabelle 32: Auswertung der Intensitäten von BamHI/ HpaII-geschnittenen Fragmenten der H19-DMD: Die mit einem hochgestellten Buchstaben markierten Fragmente können auf Grund ähnlicher Größen im Blot nicht aufgetrennt werden, wobei jeder Buchstabe verschiedene, eng zusammenliegende Fragmente repräsentiert. Sehr kleine Fragmente, die durch die Sonde nicht detektiert wurden, sind unter „nicht nachweisbar“ aufgeführt, da sie beim Auftrennen der Fragmente bei der Elekrophorese verloren gegangen sind. $(+)$ = Aussage nur begrenzt möglich; Ptch $^{+/-}=$heterozygote Ptch-Mäuse, H=HpaII-Schnittstelle

\begin{tabular}{|c|c|c|c|}
\hline Fragment & & Intensität & \\
\hline Fragmentgröße & Schnittstellen & RMS Ptch ${ }^{+/-}$ & Skelettmuskel Ptch $^{+-}$ \\
\hline $\begin{array}{l}\text { H19-DMD-F1 } \\
8700 \mathrm{bp}\end{array}$ & $\mathrm{BamHI}_{1}-\mathrm{BamHI}_{2}$ & nicht hybrisdisiert & nicht hybrisdisiert \\
\hline $\begin{array}{l}\text { H19-DMD-F2 } \\
1176 \mathrm{bp}^{\mathrm{a}}\end{array}$ & $\mathrm{BamHI}_{2}-\mathrm{H}_{1}$ & $(+)^{\mathrm{a}}$ & $(+)^{\mathrm{a}}$ \\
\hline $\begin{array}{l}\text { H19-DMD-F3 } \\
1221 \mathrm{bp}^{\mathrm{a}}\end{array}$ & $\mathrm{BamHI}_{2}-\mathrm{H}_{2}$ & $(+)^{\mathrm{a}}$ & $(+)^{\mathrm{a}}$ \\
\hline $\begin{array}{l}\text { H19-DMD-F4 } \\
1420 \mathrm{bp}\end{array}$ & $\mathrm{BamHI}_{2}-\mathrm{H}_{3}$ & + & nicht hybrisdisiert \\
\hline $\begin{array}{l}\text { H19-DMD-F5 } \\
2234 \mathrm{bp}\end{array}$ & $\mathrm{BamHI}_{2}-\mathrm{H}_{4}$ & $(+)$ & $(+)$ \\
\hline $\begin{array}{l}\text { H19-DMD-F5 } \\
7099 \mathrm{bp}\end{array}$ & $\mathrm{BamHI}_{2}-\mathrm{H}_{7}$ & nicht hybrisdisiert & nicht hybrisdisiert \\
\hline $\begin{array}{l}\text { H19-DMD-F6 } \\
45 \mathrm{bp}\end{array}$ & $\mathrm{H}_{1}-\mathrm{H}_{2}$ & nicht nachweisbar & nicht nachweisbar \\
\hline $\begin{array}{l}\text { H19-DMD-F7 } \\
199 \mathrm{bp}\end{array}$ & $\mathrm{H}_{1}-\mathrm{H}_{3}$ & nicht nachweisbar & nicht nachweisbar \\
\hline $\begin{array}{l}\text { H19-DMD-F8 } \\
1058 \mathrm{bp}^{\mathrm{b}}\end{array}$ & $\mathrm{H}_{1}-\mathrm{H}_{4}$ & $(+)^{\mathrm{b}}$ & $(+)^{\mathrm{b}}$ \\
\hline $\begin{array}{l}\text { H19-DMD-F9 } \\
4135 \mathrm{bp}^{\mathrm{c}}\end{array}$ & $\mathrm{H}_{1}-\mathrm{H}_{5}$ & $++^{c}$ & $+^{\mathrm{c}}$ \\
\hline $\begin{array}{l}\text { H19-DMD-F10 } \\
5361 \mathrm{bp}^{\mathrm{e}}\end{array}$ & $\mathrm{H}_{1}-\mathrm{H}_{6}$ & $(+)^{\mathrm{e}}$ & $(+)^{\mathrm{e}}$ \\
\hline $\begin{array}{l}\text { H19-DMD-F11 } \\
6718 \mathrm{bp}^{\mathrm{d}}\end{array}$ & $\mathrm{H}_{1}-\mathrm{H}_{8}$ & $+^{d}$ & $+{ }^{d}$ \\
\hline $\begin{array}{l}\text { H19-DMD-F12 } \\
154 \mathrm{bp}\end{array}$ & $\mathrm{H}_{2}-\mathrm{H}_{3}$ & nicht nachweisbar & nicht nachweisbar \\
\hline $\begin{array}{l}\text { H19-DMD-F13 } \\
1013 \mathrm{bp}^{\mathrm{b}}\end{array}$ & $\mathrm{H}_{2}-\mathrm{H}_{4}$ & $(+)^{\mathrm{b}}$ & $(+)^{\mathrm{b}}$ \\
\hline $\begin{array}{l}\text { H19-DMD-F14 } \\
4090 \mathrm{bp}^{\mathrm{c}}\end{array}$ & $\mathrm{H}_{2}-\mathrm{H}_{5}$ & $++^{\mathrm{c}}$ & $+^{\mathrm{c}}$ \\
\hline $\begin{array}{l}\text { H19-DMD-F15 } \\
6674 \mathrm{bp}^{\mathrm{d}}\end{array}$ & $\mathrm{H}_{2}-\mathrm{H}_{8}$ & $+{ }^{d}$ & $+{ }^{d}$ \\
\hline $\begin{array}{l}\text { H19-DMD-F16 } \\
814 \text { bp }\end{array}$ & $\mathrm{H}_{3}-\mathrm{H}_{4}$ & $(+)$ & $(+)$ \\
\hline $\begin{array}{l}\text { H19-DMD-F17 } \\
3891 \mathrm{bp}^{\mathrm{c}}\end{array}$ & $\mathrm{H}_{3}-\mathrm{H}_{5}$ & $++^{c}$ & $+^{c}$ \\
\hline $\begin{array}{l}\text { H19-DMD-F18 } \\
5117 \mathrm{bp}^{\mathrm{e}}\end{array}$ & $\mathrm{H}_{3}-\mathrm{H}_{6}$ & $(+)^{\mathrm{e}}$ & $(+)^{e}$ \\
\hline $\begin{array}{l}\text { H19-DMD-F19 } \\
6475 \mathrm{bp}\end{array}$ & $\mathrm{H}_{3}-\mathrm{H}_{8}$ & $+{ }^{d}$ & $+{ }^{d}$ \\
\hline
\end{tabular}


Nach BamHI-MspI-Verdau wurden das 1176 bp große H19-DMD-F2 Fragment durch Verdau der DNA an den Schnittstellen BamHI $\mathrm{H}_{2} \mathrm{H}_{1}$ und das 814 bp große H19-DMD-F16 durch Verdau an den Schnittstellen H3/ H4 detektiert. Das 45 bp große H19-DMD-F6 (H1/ H2) und das 154 bp große H19-DMD-F12 (H2/ H3) sind bei der Elektrophorese auf Grund ihrer Größe verloren gegangen und daher nicht detektierbar. Das Fragment H19-DMD-F8 (1058 bp) läßt sich nur durch einen partiellen Verdau der DNA erklären.

Da im vorliegenden Southern-Blot nach Spaltung der DNA mit BamHI und HpaII (Abb. 31) weder im RMS noch im SM das BamHI-Fragment H19-DMD-F1 der Größe 8700 bp detektiert werden konnte, ist von einer partiellen Relaxierung der Methylierung auszugehen. Dabei konnte festgestellt werden, daß die H7-Schnittstelle im RMS als auch im SM methyliert vorliegt.

Im RMS, nicht aber im Muskel des Tumortieres, konnte das Fragment H19-DMD-F4 (1420 bp) nachgewiesen werden. Dies bedeutet, daß die H3 Schnittstelle im Tumor weniger methyliert ist als im Muskel. Zudem waren im Tumor eines (oder mehrere) der Fragmente H19-DMD-F9 (4135 bp), H19-DMD-F14 (4090 bp) oder H19-DMD-F17 (3891 bp) verstärkt hybridisiert. Hierbei entsteht das H19-DMD-F9 Fragment durch den Verdau der DNA an den Schnittstellen H1/ H5, das H19-DMD-F14 Fragment durch den Verdau an den Schnittstellen H2/ H5 und das H19-DMD-F17 durch die Spaltung der DNA an den Schnittstellen H3/ H5. Würde davon ausgegangen werden, daß die H3 Schnittstelle im Tumor weniger methyliert ist, könnte das entsprechende Fragment am wahrscheinlichsten dem Fragment H19-DMD-F17 entsprechen.

Durch das Fehlen des 45 bp großen Fragmentes kann keine eindeutige Aussage über den Methylierungszustand der Schnittstellen $\mathrm{H} 1$ und $\mathrm{H} 2$ getroffen werden. Auch die größeren Fragmente, die durch eine der beiden Schnittstellen zustande kommen, konnten auf Grund ihrer ähnlichen Größen nicht eindeutig zugeordnet werden. Hierbei handelt es sich um die Fragmente H19-DMD-F2 (1176 bp) und H19-DMD-F3 (1221 bp) sowie die Fragmente H19-DMD-F8 (1058 bp) und H19-DMD-F13 (1013 bp) (siehe Tabelle 32).

Auf Grund dieser Daten war es schwer, eine eindeutige Aussage über Methylierungsunterschiede zwischen Muskel und Tumor $\mathrm{zu}$ treffen. Daher wurde auf weiterführende Methylierungsanalysen mittels der Bisulfit-Sequenzierung verzichtet. 


\subsection{Untersuchung der Methylierung der Cytosine der DMRs über Bisulfit-Sequenzierung}

In eukaryontischen Zellen wird die Methylierung mit Hilfe von DNA-Methyltransferasen katalysiert. Diese Enzyme sind sequenzspezifisch, so daß die kovalente Anheftung eines Methyl-Restes ausschließlich an der 5' Position von Cytosin-Resten innerhalb der Sequenz 5' -CpG- 3' stattfindet (Wang et al., 1950). Funktionelle Unterschiede in der DNAMethylierung sind meist auf sogenannte CpG-Inseln beschränkt, in denen das Dinukleotid CpG gehäuft vorkommt. Experimentell kann der Nachweis von methylierten Cytosinen in DNABereichen über eine Natrium-Bisulfit-Behandlung erbracht werden.

Die Methode der selektiven Basen-Konversion der Einzelstrang-DNA durch BisulfitBehandlung erlaubt es, eine Methylierung des Cytosins zu detektieren. Genutzt wird dabei die Eigenschaft des Natriumbisulfits, effizient Cytosin-Reste in Uracil zu verwandeln, während das 5-Methyl-Cytosin unverändert bleibt (Hayatsu et al., 1970; Wang et al., 1980). Bei der anschließenden Amplifikation mittels einer Polymerase-Kettenreaktion werden alle UracilReste als Thymine gelesen, während die 5-Methyl-Cytosine weiterhin als Cytosine erkannt werden. Durch eine Sequenzierung der Bisulfit-behandelnden DNA kann somit der Methylierungsstatus jedes einzelnen Cytosins festgestellt werden.

Die Methode der Bisulfit-Sequenzierung wurde in der vorliegenden Arbeit zum Nachweis von Methylierungsveränderungen angewendet. Sequenziert wurden hierbei drei distinkte Bereiche, in denen mit Hilfe der methylierungssensitiven Southern-Blot-Technik Veränderungen des Methylierungsmusters zwischen dem RMS und dem Referenzgewebe beobachtet wurden.

Diese Bereiche wurden nach der Bisulfit-Umwandlung der DNA mittels PCR amplifiziert. Das PCR-Fragment wurde nicht sequenziert, da davon auszugehen war, daß im PCR-Produkt ein Gemisch sowohl von methylierten als auch von unmethylierten Cytosinen vorlag. Dies hätte die Auswertung der Sequenzen erschwert. Die amplifizierten Bisulfit-behandelten DNA-Fragmente von RMS und Muskel wurden daher nach einer Geleluierung in den Vektor pGEM ${ }^{\circledR}$-T Easy subkloniert. Da der Vektor nur jeweils ein DNA-Fragment aufnehmen kann, konnte nach erfolgter Subklonierung und Sequenzierung eine wesentlich bessere Qualität der Elektropherogramme erzielt werden. Um eine statistische Aussage über die Methylierung eines Cytosins treffen zu können, wurden für jede Region sowohl von RMS als auch vom Referenzgewebe 17-20 Subklone sequenziert. Ein weiterer Vorteil, der sich durch eine Subklonierung Bisulfit-behandelter Amplifikate ergibt, ist die Anwendung der Sequenzierprimer des Vektors, wodurch ebenfalls eine wesentlich bessere Qualität der Elektropherogramme erzielt werden konnte. 


\subsubsection{Bestimmung der Effizienz der Bisulfitbehandlung}

Um eine genaue Aussage über den Methylierungszustand der CpGs treffen zu können, mußte zunächst die Effizienz der Bisulfit-Behandlung der DNA untersucht werden. Hierzu wurde, wie zuvor beschrieben, die DNA mit Bisulfit behandelt, mit spezifischen Primern amplifiziert (Tab. 23) und in den Vektor pGEM ${ }^{\circledR}$-T Easy kloniert. In den für jede untersuchte Region gewonnenen Subklonen wurde die Konvertierung aller Cytosine in Thymidine ausgezählt. Nicht in die Analyse einbezogen wurde die Sequenzabfolge Cytosin-Guanosin, da die Cytosine in dieser Abfolge entweder methyliert (und damit nicht zu Thymidin konvertiert) oder unmethyliert (und damit zu Thymidin konvertiert) vorliegen können.

Am Beispiel einer Region der DMR2 H1 (Exon 6) soll demonstriert werden, wie die Fehlerrate der Konvertierung berechnet wurde. Es wurden 17 Klone der Bisulfit-behandelten DNA aus RMS in einer Bisulfit-Sequenzierung analysiert. In dem subklonierten Fragment (795 bp) können insgesamt 144 Konvertierungen von C zu T auftreten. Bei 17 Klonen sind insgesamt 17 Klone x $144=2448$ Konvertierungen möglich. Hierbei traten 32 Fehler auf. Somit ergab sich eine Fehlerrate von $1,3 \%$.

In allen untersuchten Klonen betrug die Fehlerrate der Konvertierung $<2 \%$ (weitere Angaben im Text). Somit kann mit 98 \%iger Sicherheit angenommen werden, daß die als unmethyliert beschriebenen Cytosine auch tatsächlich unmethyliert waren.

\subsubsection{Analyse der Methylierungsveränderungen der DMR2 mittels Bisulfit-Sequenzierung}

Im methylierungssensitiven Southern-Blot (Abb. 18) konnte in zwei Bereichen der DMR2 Methylierungsveränderungen zwischen den Tumoren und der Referenz nachgewiesen werden (Abb. 17 und 18). Mittels Bisulfit-Sequenzierung wurde der Methylierungsgrad der CpGs dieser Regionen ermittelt. Die Ergebnisse wurden in einem zweiten unabhängig durchgeführten Experiment bestätigt.

\subsubsection{Sequenzanalyse der DMR2 im Exon 6}

Ein 795 bp-Fragment wurde aus Bisulfit-behandelter DNA des RMS und des Skelettmuskels mit den Primern DMR2 H1 (siehe Tab. 23) amplifiziert und subkloniert. Der amplifizierte Bereich ist in Abb. 17 gezeigt. Im Anschluß erfolgte die Sequenzierung von 18 Klonen aus SM und 17 Klonen aus RMS. Die Fehlerrate der Konvertierung von $\mathrm{C}$ zu T nach Bisulfitbehandlung betrug für die 17 Klone des RMS 1,3\% und für die 18 Klone des SM 1,4 \%. Die Analyse der DNA-Sequenzen hinsichtlich des Methylierungsgrades ihrer CpGs ist in Abbildung 32 dargestellt. 


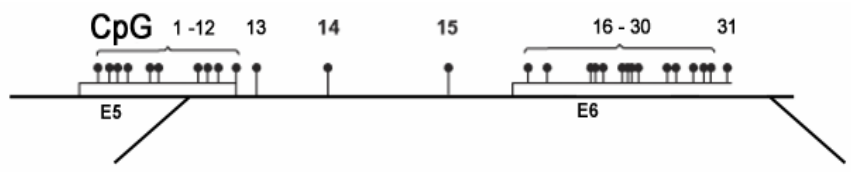

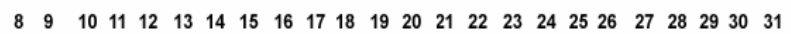

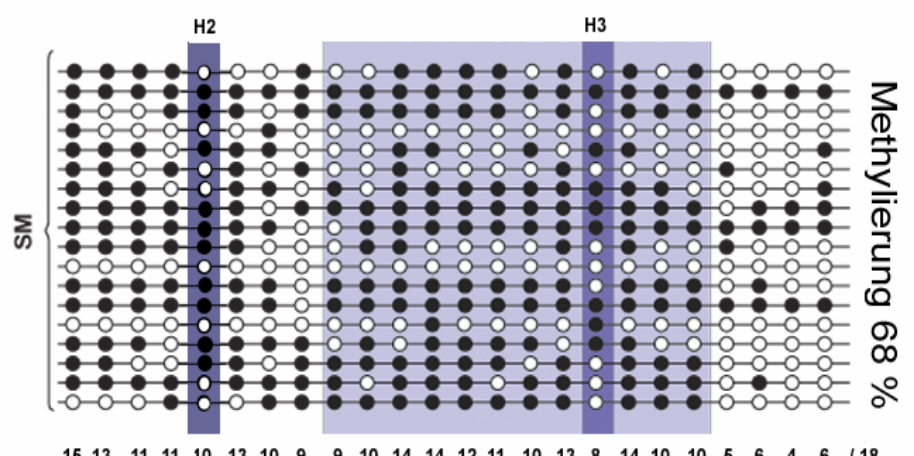

$\begin{array}{lllllllllllllllllllllllll}15 & 13 & 11 & 11 & 10 & 13 & 10 & 9 & 9 & 10 & 14 & 14 & 12 & 11 & 10 & 13 & 8 & 14 & 10 & 10 & 5 & 6 & 4 & 6 & / 18\end{array}$

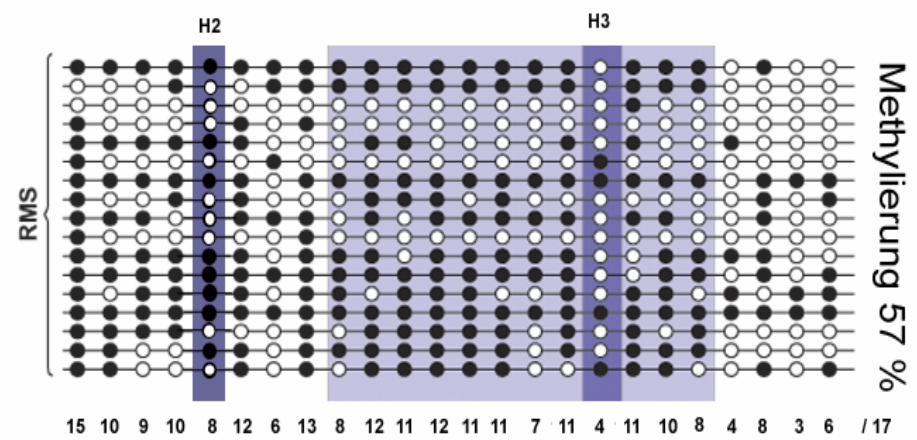

Abb. 32: Sequenzanalyse der bisulfitbehandelten DNA von RMS und SM der Kernregion der DMR2 im Bereich der Exone 5 und 6 des Igf2-Genes: Die Exone 5 und 6 sind im oberen Teil der Abbildung schematisch dargestellt. Die in dieser Region lokalisierten CpGs sind als Balken mit Köpfchen dargestellt. Der sequenzierte Bereich umfaßt 24 CpGs, die von 8-31 durchnummeriert wurden. Dabei sind die CpGs mit den Nummern 24 und 12 Bestandteile der HpaII-Schnittstellen H1 und H2 (blau markiert).

Der Bereich der Kernregion der DMR2 umfaßt die CpGs 16-27 (hellviolett markiert). Methylierte Cytosine sind als schwarze Kreise und unmethylierte Cytosine sind als weiße Kreise schematisch dargestellt. Die sequenzierten 17 Klone aus RMS und 18 Klone aus SM, die repräsentativ für 17 bzw 18 Chromosomen stehen, sind vertikal angeordnet. In jedem Chromosom wurden 24 CpGs der DMR2-Region analysiert. Die Anzahl der methylierten CpGs ist für jedes CpGs als Zahl unter den Einzelschemen für SM und RMS angegeben. Im Falle eines signifikanten Methylierungsunterschiedes zwischen RMS und SM ist dieser mit " ${ }^{*}$ " gekennzeichnet. Die Signifikanz $(\mathrm{p}<0,05)$ wurde mit dem $\mathrm{Chi}^{2}$ Test berechnet.

Das CpG 24 ist Bestandteil der Schnittstelle H1 und das CpG 12 ist Bestandteil der Schnittstelle H2, welche im Southern-Blot (siehe Abb. 18) im RMS - gegenüber SM - auf eine Hypomethylierung schließen ließen.

Aus der Gesamtheit der methylierten und unmethylierten $\mathrm{CpGs}$ wurde die prozentuale Methylierung für den Tumor und den Muskel ermittelt. Dabei konnte für den Tumor eine 57 \%ige und im Muskel eine 68 \%ige Methylierung der DMR2 in dem Bereich der Exone 5 und 6 festgestellt werden. 
Auf Grund der Sequenzanalyse konnte der Methylierungsstatus von $24 \mathrm{CpGs}$, die in den Exonen 5 und 6 lokalisiert sind, ermittelt werden. Dabei war es nicht von Interesse, eine Unterscheidung zwischen der Methylierung der CpGs des paternalen und maternalen Allels zu treffen. Vielmehr sollte der Unterschied des Methylierungsgrades zwischen RMS und Referenzgewebe festgestellt werden.

Aus der Gesamtzahl der methylierten und unmethylierten Cytosine der Chromosomen ergab sich eine Methylierung von $57 \%$ im Tumor und von $68 \%$ im Muskel (Abb. 32). Die Signifikanz für die Methylierungsunterschiede zwischen RMS und SM wurde für jedes einzelne $\mathrm{CpG}$ mittels $\mathrm{Chi}^{2}$-Test (Statistica-Software) bestimmt. Bei keinem der untersuchten CpGs zeigte sich ein signifikanter Methylierungsunterschied. Selbst bei den CpGs 12 und 24 konnte keine signifikante Veränderung in der Methylierung zwischen RMS und Skelettmuskel gezeigt werden. Das CpG 24 ist Bestandteil der HpaII-Schnittstelle H1 und das CpG 12 ist Bestandteil der HpaII-Schnittstelle H2 (siehe Tabelle 26 und Abb. 18), welche durch den Verdau der Tumor DNA mit HpaII zu einem stark hybridisierten DMR2-F7-Fragment von 354 bp im SouthernBlot geführt hatten und daher auf eine mögliche Hypomethylierung der entsprechenden CpGs im Tumor hingewiesen hatten. Durch die Bisulfitsequenzanalyse konnte eine solche Hypomethylierung jedoch nicht bestätigt werden.

\subsubsection{Sequenzanalyse der DMR2 im Exon 4}

Für die Untersuchung der Methylierungsveränderung zwischen Tumor und Referenz der DMR2 im Exon 4 wurde zunächst ein 635 bp-Fragment (vergleiche Tab. 23, DMR2 H4 Primer) aus Bisulfit-behandelter DNA des RMS und des Skelettmuskels amplifiziert und subkloniert. Im Anschluß erfolgte die Sequenzierung von 20 Klonen sowohl für RMS als auch für SM. Die Fehlerrate für die Konvertierung $\mathrm{C}$ zu $\mathrm{T}$ nach Bisulfitbehandlung betrug für die 20 Klone des RMS 1,7 \% und für die 20 Klone des Muskels 1,4\%.

Die Analyse der DNA-Sequenzen hinsichtlich des Methylierungsgrades ihrer CpGs ist in Abbildung 33 dargestellt. 

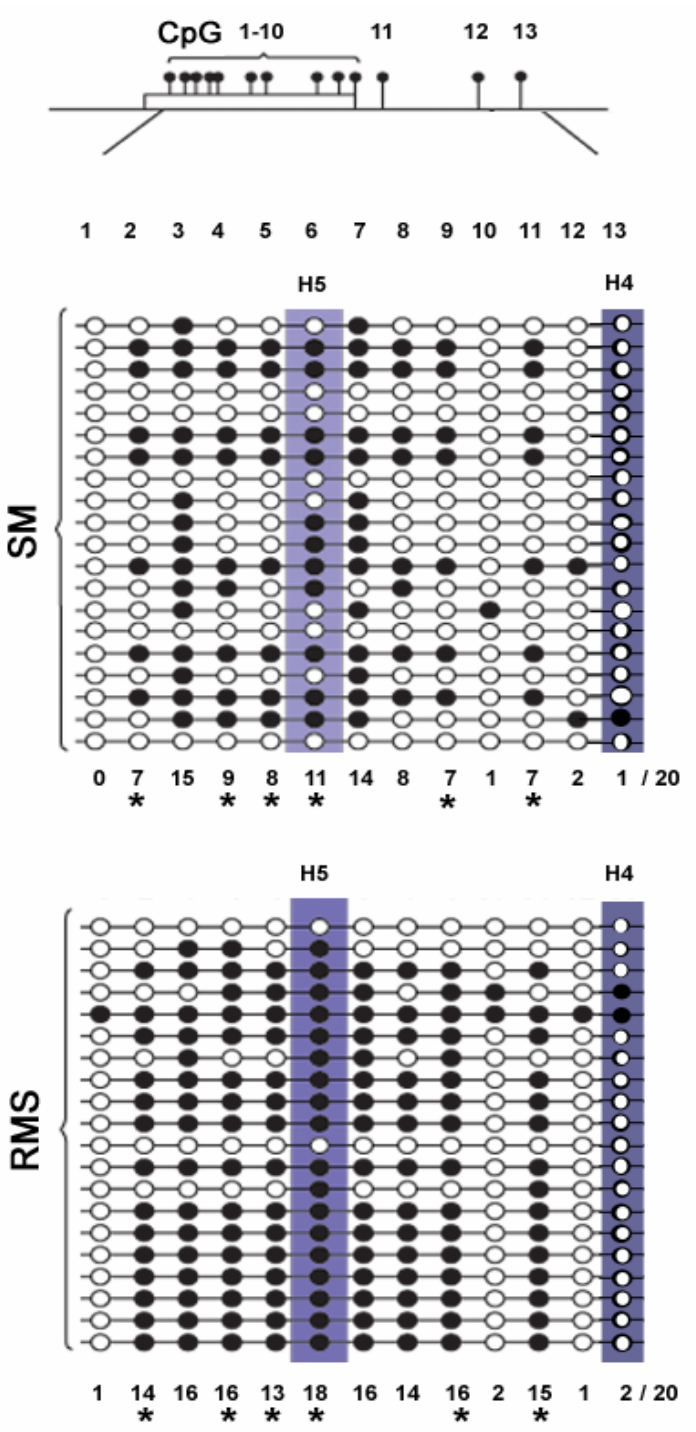

Abb. 33: Sequenzanalyse der Bisulfitbehandelten DNA von RMS und SM der DMR2-Region im Bereich des Exons 4 des Igf-Genes: Das Exon 4 ist im oberen Teil der Abbildung schematisch dargestellt. Die in dieser Region lokalisierten CpGs sind als Balken mit Köpfchen dargestellt. Der sequenzierte Bereich umfaßt 13 CpGs, die von 1-13 nummeriert wurden. Dabei sind die CpGs 6 und 13 Bestandteile der HpaII-Schnittstellen H5 und H4 (violett markiert). Methylierte Cytosine sind als schwarze Kreise und unmethylierte Cytosine sind als weiße Kreise schematisch dargestellt.

Die sequenzierten 20 Klone aus RMS und 20 Klone aus SM, die repräsentativ für 20 Chromosomen stehen, sind vertikal angeordnet. Die Anzahl der methylierten CpGs ist unter dem Einzelschema SM und RMS dargestellt.

Die Methylierung von RMS und SM ist im unteren Teil der Abbildung zusammengefaßt. Aus der Gesamtheit der methylierten und unmethylierten CpGs wurde prozentual die Methylierung für den Tumor und den Muskel ermittelt. Dabei konnte für den Tumor eine 55 \%ige und im Muskel eine 35 \%ige Methylierung der DMR2 im Exon 4 festgestellt werden.

Im Falle eines signifikanten Methylierungsunterschiedes zwischen RMS und SM ist das Dinukleotid CpG mit ,*“ gekennzeichnet. Die Signifikanz $(p<0,05)$ wurde mit dem $\mathrm{Chi}^{2}$ Test berechnet. In den CpGs 2, 4, 5, 6, 9 und 11 sind signifikante Methylierungsunterschiede zwischen Tumor und SM festgestellt worden

Aus der Gesamtzahl der methylierten und unmethylierten Cytosine der 20 Chromosomen ergab sich eine Methylierung von $55 \%$ im Tumor und von $35 \%$ im Muskel. Die Signifikanz für die Methylierungsunterschiede zwischen RMS und SM wurde dann, wie auch schon für die Kernregion der DMR2 (siehe oben) für jedes einzelne CpG mittels Chi ${ }^{2}$-Test (Statistica) bestimmt. In fünf der untersuchten $\mathrm{CpGs}$ konnte ein signifikanter Methylierungsunterschied zwischen RMS und SM festgestellt werden. Hierbei waren diese CpGs im RMS stärker methyliert als im SM. Aus der $\mathrm{Chi}^{2}$-Analyse ergaben sich für die $\mathrm{CpG}$ 2, 4, 6, 9 und 11 folgende P-Werte: CpG 2: 0,0281; CpG 4: 0,0222; CpG 6: 0,0132; $\mathrm{CpG}$ 9: 0,040 und CpG 11: 0,011. Für das CpG 8 betrug der P-Wert 0,0565 und lag somit nur knapp über der Signifikanzgrenze. 
Das CpG 6 ist Bestandteil der HpaII-Schnittstelle H5. Der Southern-Blot ließ in dieser Region zunächst keine Hypermethylierung im RMS vermuten (Abb. 18). Sie konnte aber auch nicht direkt ausgeschlossen werden. Dagegen gab der Southern-Blot Hinweise auf eine vermehrte Methylierung an der HpaII-Schnittstelle $\mathrm{H} 4$ (Abb. 18), für die jedoch der Methylierungsunterschied in der hier durchgeführten Analyse nicht signifikant war.

\subsubsection{Analyse der Methylierungsveränderungen in der DMR1 über Bisulfit-Sequenzierung}

Im methylierungssensitiven Southern-Blot konnte in zwei Bereichen der DMR1 Methylierungsveränderungen zwischen den Tumoren und der Referenz nachgewiesen werden (Abb. 25). Auf Grund der schwierigen Amplifikation von Bisulfit-behandelter DNA in diesem Bereich konnte nur eine kleine Sequenz im Bereich der HpaII-Schnittstelle H1 (siehe SouthernBlot in Abb. 25, Abb. 26, Tab. 29) hinsichtlich des Methylierungsstatus der CpGs über die Bisulfit-Sequenzierung analysiert werden.

\subsubsection{Sequenzanalyse der DMR1}

Für die Untersuchung der Methylierungsveränderung zwischen Tumor und Referenz der DMR1 wurde zunächst ein 596 bp-Fragment (vergleiche Tab. 23, DMR1 H1-Primer) aus Bisulfitbehandelter DNA des RMS und des Skelettmuskels amplifiziert und subkloniert. Im Anschluß erfolgte die Sequenzierung von je 17 Klonen aus RMS und SM. Die Fehlerrate der Konvertierung $\mathrm{C}$ zu T nach Bisulfitbehandlung betrug für die 17 Klone des RMS 1,3\% und für die 17 Klone des SM 1,6\%.

Die Analyse der DNA-Sequenzen hinsichtlich des Methylierungsgrades ihrer CpGs ist in Abb. 34 dargestellt. Aus der Gesamtzahl der methylierten und unmethylierten Cytosine der 17 Chromosomen ergab sich eine Methylierung von $90 \%$ im Tumor und von $100 \%$ im Muskel. Damit konnte insgesamt eine Hypomethylierung für diesen Bereich im Tumor beschrieben werden.

Obwohl nicht eindeutig, ließ der methylierungssensitive Southern-Blot mit der Sonde 3 (Abb. 25; Tab. 29) an den HpaII-Schnittstellen H1 und H2 einen Methylierungsunterschied zwischen RMS und SM vermuten. Mittels der Bisulfit-Sequenzierung konnte nun eine signifikante Relaxierung der Methylierung am CpG 3 im RMS nachgewiesen werden (P-Wert: 0,0332), welches der HpaII-Schnittstelle H1 entspricht. 


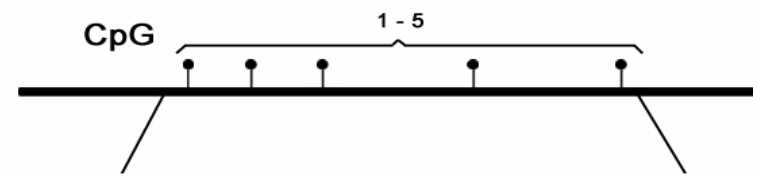

$\begin{array}{lllll}1 & 2 & 3 & 4 & 5\end{array}$

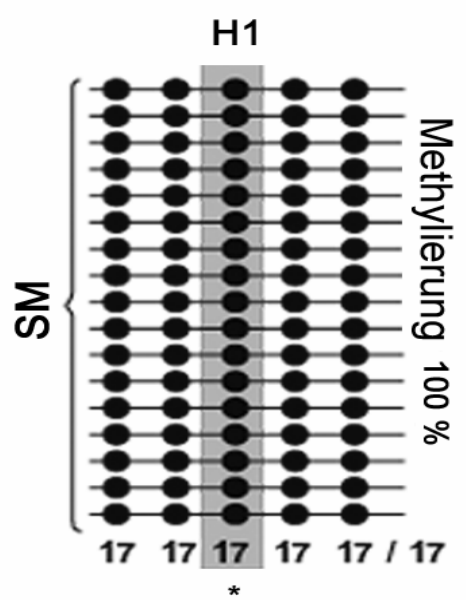

H1

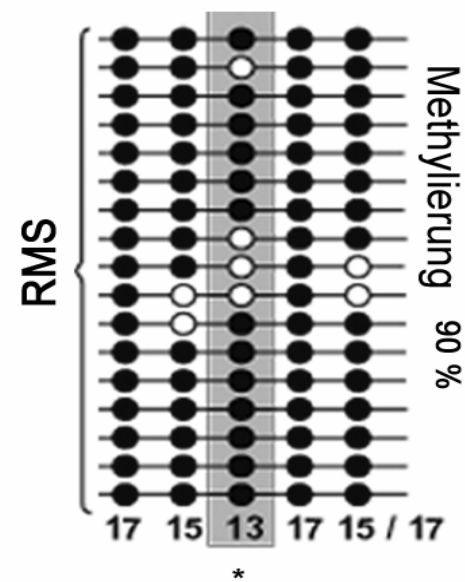

Abb. 34: Sequenzanalyse der Bisulfitbehandelten DNA von RMS und SM der DMR1: Ein Ausschnitt der DMR1 ist im oberen Teil der Abbildung 34 schematisch dargestellt. Die in dieser Region lokalisierten $\mathrm{CpGs}$ sind als Balken mit Köpfchen dargestellt. Der sequenzierte Bereich umfaßt fünf $\mathrm{CpGs}$, die von 1-5 nummeriert wurden. Dabei ist das CpG 1 Bestandteil der HpaIISchnittstelle H1 (violett markiert). Methylierte Cytosine sind als schwarze Kreise und unmethylierte Cytosine sind als weiße Kreise schematisch dargestellt. Die sequenzierten 17 Klone aus SM und 17 Klone aus RMS, die repräsentativ für 17 Chromosome stehen, sind vertikal angeordnet. Insgesamt wurden je Klon fünf CpGs der DMR1 analysiert. Die Anzahl der methylierten $\mathrm{CpGs}$ ist unter den einzelnen $\mathrm{CpGs}$ angegeben.

Im Falle eines signifikanten Methylierungsunterschiedes zwischen RMS und $\mathrm{SM}$ ist das Dinukleotid $\mathrm{CpG}$ mit ,*“ gekennzeichnet. Die Signifikanz $(p<0,05)$ wurde mit dem $\mathrm{Chi}^{2}$ Test berechnet.

In dem $\mathrm{CpG} 3$ ist ein signifikanter Methylierungsunterschied zwischen Tumor und SM festgestellt worden

Aus der Gesamtheit der methylierten und unmethylierten $\mathrm{CpGs}$ wurde prozentual die Methylierung für den Tumor und den Muskel ermittelt. Dabei konnte für den Tumor eine 90 \%ige und im Muskel eine 100 \%ige Methylierung für diesen Bereich der DMR1 festgestellt werden. 


\subsection{Untersuchung des Einflußes von Gli- Transkriptionsfaktoren auf die Igf2-Expression}

Neben den Untersuchungen von epigenetischen Veränderungen am Igf2-Lokus in heterozygoten Ptch-Mäusen stand im weiteren Fokus der vorliegenden Arbeit die Untersuchung des Einflusses der Gli-Transkriptionsfaktoren auf die Igf2-Expression.

Gli Zink-Finger-Transkriptionsfaktoren sind die direkten Übermittler der Aktivierung der Sonic hedgehog-Signalkaskade (Kinzler et al., 1987; Arheden et al., 1989b; Ruppert et al., 1990; Kas et al., 1996; Matsumoto et al., 1996). Die Gli-Familie besteht aus Gli1, Gli2, Gli3; die das Sonic hedgehog-Signal in den Kern transferieren und hier die Expression von Zielgenen der Kaskade aktivieren. Es konnte gezeigt werden, daß diese Faktoren auch bei der pathologischen Aktivierung des Signalwegs, die durch Mutationen in Ptch ausgelöst wird, eine Rolle spielen (Toftgard et al., 2000; Hahn et al., 1998). So überexprimieren alle bisher untersuchten Ptchassoziierten Tumoren wenigsten einen der Gli-Transkriptionsfaktoren. Unter diesem Aspekt stellte sich daher die Frage, ob diese Transkriptionsfaktoren die Expression von Igf2 im Tumor über Aktivierung der Igf2-Promotoren stimulieren. Um diese Frage zu beantworten, mußte zunächst überprüft werden, ob der Igf2-Lokus Bindungsstellen für Gli-Transkriptionsfaktoren enthält. Dann wurde überprüft, welche der drei Gli-Gene im RMS überexprimiert sind und somit einen potentiellen Einfluß auf die Igf2-Expression ausüben könnten.

\subsubsection{Identifikation von Gli-Bindungsstellen im Igf2-Lokus}

Unter der Fragestellung, ob Igf 2 ein mögliches Ziel-Gen der Gli-Onkogene darstellt, wurde eine bioinformatische Suche nach möglichen Gli-Bindungsstellen in der Igf2-Sequenz durchgeführt. Es wurden fünf potentielle Gli-Konsensus-Sequenzen im Igf2-Lokus nachgewiesen (Abb. 35). Hierzu wurde der Igf2-Lokus auf alle bisher in der Literatur beschriebenen Gli-Bindungsstellen durchsucht. Es konnte festgestellt werden, daß die Konsensus-Sequenzen für GliBindungsstellen im Promotorbereich von P0 und in den differentiell methylierten Regionen DMR0, DMR1 und DMR2 lokalisiert sind. Dies läßt die Schlußfolgerung zu, daß die GliTranskriptionsfaktoren an der Kontrolle der Transkription des Igf2-Genes beteiligt sein könnten. 


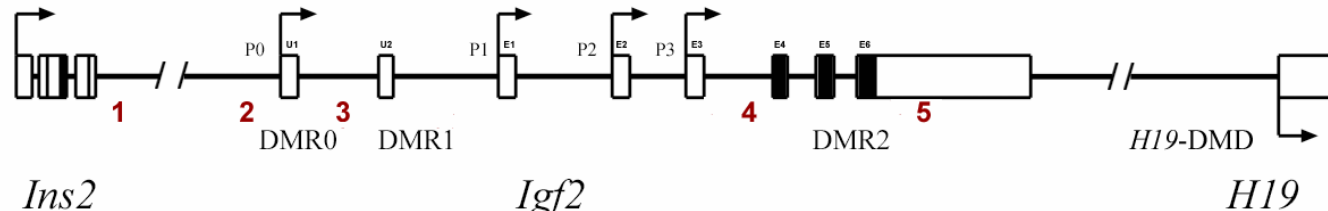

Abb. 35: Nachweis von fünf potentiellen Gli-Bindungsstellen im distalen Bereich des Chromosomes 7 der Maus: Schematische Darstellung der Insulin 2-, Igf2- und H19-Loci: Die Pfeile zeigen die Transkriptionsrichtung der drei Gene an. Die drei Igf2-Promotoren (P0-P3) und alle Igf2-Exone (U1, U1, E1-E6) sind eingezeichnet. Die Igf2kodierenden Bereiche wurden mit gefüllten Rechtecken, die nicht-kodierenden mit offenen dargestellt. Die Positionen der identifizierten Gli-Bindungsstellen sind von 1-5 nummeriert. Differentiell methylierte Regionen: DMR0, DMR1 und DMR2; H19-DMD.

Die Konsensus-Sequenzen der Gli-Bindungsstellen sind in der Tabelle 33 aufgeführt.

Tabelle 33: Gli-Bindungsstellen und ihre Positionen aus der bioinformatischen Analyse. Die im Igf2-Lokus identifizierte Gli-Bindungstelle Nummer 2 zeigt eine von der publizierten Konsensus-Sequenz abweichende Base, die in der Tabelle unterstrichen wurde.

\begin{tabular}{|c|c|c|c|}
\hline $\begin{array}{l}\text { Gli-Bindungsstelle } \\
\text { Nummer }\end{array}$ & Sequenz & Position & Literaturhinweis \\
\hline 1 & GCCCACCCA & stromabwärts des Insulin-Lokus & R. Bigelow et al., 2004 \\
\hline 2 & TGCCACCCA & $\begin{array}{l}\text { stromaufwärts des P0-Promotors des } \\
\text { Igf2-Gens, }-21768 \text { bp vor dem } \\
\text { Translationsstart }\end{array}$ & G. Regl et al., 2004 \\
\hline 3 & CTGGAGGGT & $\begin{array}{l}\text { zwischen den U1- und U2-Exonen in } \\
\text { der DMR0 des Igf2-Gens (in reverser } \\
\text { Orientierung), -13194 bp vor dem } \\
\text { Translationsstart }\end{array}$ & W. Yoon et al., 2002 \\
\hline 4 & TGGGTGGTC & $\begin{array}{l}\text { im Intron } 3 \text { des } \operatorname{Ig} f 2-\text { Gens (in reverser } \\
\text { Orientierung), - } 294 \text { bp vor dem } \\
\text { Translationsstart }\end{array}$ & $\begin{array}{l}\text { Kinzler und } \\
\text { Vogelstein, } 1990\end{array}$ \\
\hline 5 & GCACACCCA & $\begin{array}{l}\text { im untranslatierten Bereich des Exons } 6 \text {, } \\
+2882 \text { bp nach dem Translationsstart }\end{array}$ & R. Bigelow et al., 2004 \\
\hline
\end{tabular}

Kinzler und Vogelstein beschrieben 1990 die erste funktionelle Konsensus-Sequenz der ZinkFinger DNA-Bindungsdomäne von GLI1 im Promotor des humanen Cyclin D2. Diese Konsensus-Sequenz (5`-GACCACCCA- 3’) konnte im Igf2-Lokus im Intron 3294 bp vor dem Translationsstart in reverser Orientierung nachgewiesen werden (Tab. 33, Nummer 4).

In Biglow et al., 2004 wurden die Gli-Bindungsstellen 1 und 5 im bcl-2-Promotor beschrieben. Die Bindungsstelle 1 befindet sich $8 \mathrm{~kb}$ stromaufwärts vom Promotor P0 des Igf2-Gens entfernt. Die Bindungsstelle 5 ist dagegen im 3` -untranslatierten Bereich von Igf2 lokalisiert. 
Eine weitere Gli-Bindungsstelle, die im humanen BCL2-Promotor nachgewiesen wurde, ist die Bindungstelle 2, die sich stromaufwärts vom Promotor P0 des Igf2-Lokus befindet. Im Vergleich zu der in der Literatur angegebenen Konsensus-Sequenz tritt ein Mismatch von G zu $\mathrm{T}$ in der im Igf2-Lokus identifizierten Bindungsstelle auf.

Im Osteopontin-Promotor wurde die Konsensus-Sequenz 3 zum ersten Mal beschrieben und ist im Igf2-Gen zwischen den Exonen U1 und U2 lokalisiert. Diese Analyse zeigte, daß der Igf2Lokus mehrere potentielle Gli-Bindungsstellen beinhaltet. Um nun zu überprüfen, welches der Gli-Gene eine Rolle bei der Aktivierung der endogenen Expression vom Igf2 spielen könnte, wurde zunächst die Expression dieser Gene im RMS, Skelettmuskel und an entsprechenden Zelllinien untersucht.

\subsubsection{Untersuchung der Gli-Expression in RMS von heterozygoten Ptch-Mäusen und Zelllinien}

Für den Nachweis der Gli-Expression in RMS von heterozygoten Ptch-Mäusen wurde eine semi-quantitative PCR durchgeführt. Dafür wurde die RNA aus vier Tumoren isoliert und in cDNA umgeschrieben. Die cDNA der Skelettmuskel der Tumortiere diente als Referenz. Als Kontrolle für den Nachweis der Expression aller Gli-Gene wurde die cDNA vom Embryo (E12,5) mitgeführt (Abb. 36).

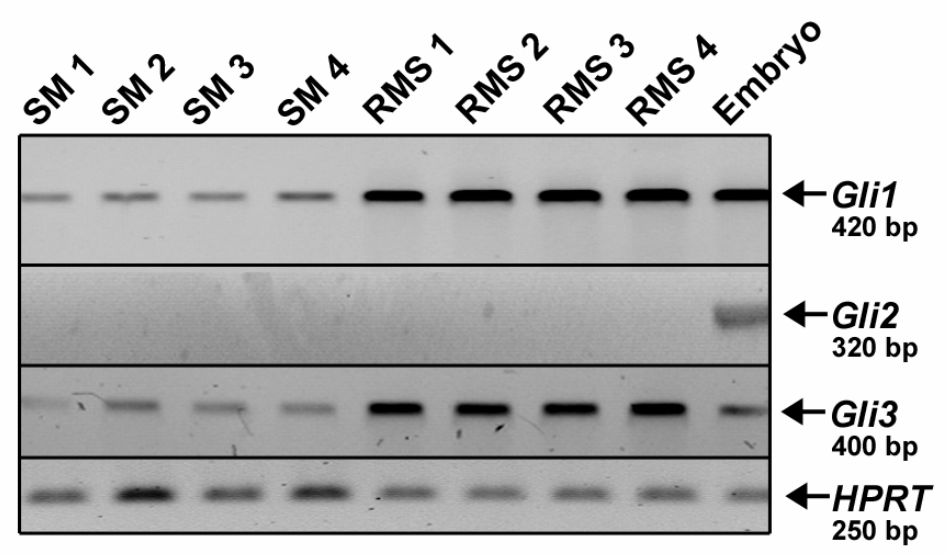

Abb. 36: Untersuchung der Gli-Expression in RMS von $\boldsymbol{P t c h}^{\text {neo67/+ }}$-Mäusen mit Hilfe einer semi-quantitativenPCR. In allen vier Tumoren konnte eine Glilund Gli3-Überexpression (420 bp- bzw. 400 bp-Fragment) festgestellt werden. Eine Gli2-Expression war nicht nachzuweisen. Zur Kontrolle wurde das Haushaltsgen HPRT amplifiziert. SM: normaler Skelettmuskel, RMS: Rhabdomyosarkom.

Die Expressionsanalyse der Gli-Transkriptionsfaktoren zeigte eine starke Überexpression von Gli1 und Gli3 im RMS gegenüber dem normalen Muskel. Eine Expression von Gli2 konnte weder in den Tumoren noch im Muskelgewebe festgestellt werden. Diese Daten zeigen, daß die 
Transkriptionsfaktoren Gli1 und Gli3 (einzeln oder aber zusammen) potentielle Aktivatoren der Igf2-Expression in RMS darstellen könnten.

Zusätzlich zu den nativen RMS wurden zwei RMS Zelllinien TP1588 und TP5014, die aus Tumoren von heterozygoten Ptch-Mäusen gewonnen wurden, sowie C2C12Muskelvorläuferzellen auf die endogene Expression von Gli1, Gli2 und Gli3 sowie Igf2 hin untersucht (Abb. 37).

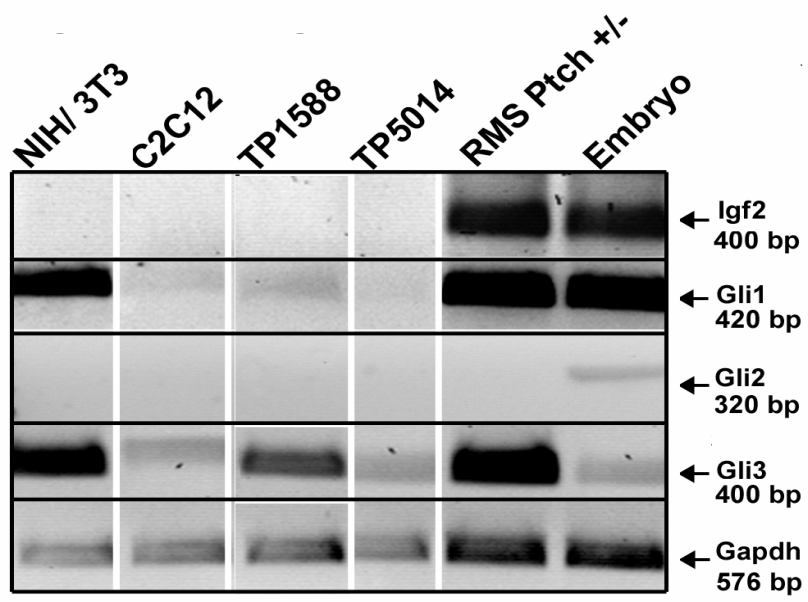

Abb. 37: Untersuchung der endogenen
Expression von Gli1, Gli2, Gli3 und
Igf2 in den Zelllinien NIH/ 3T3
(Fibroblasten-Zellinie), C2C12
(Myoblasten-Zellinie), TP1588 und
TP5018 (RMS-Zelllinien): Als
Positivkontrollen wurden cDNAs aus
einem RMS von Ptch neo67/+-Mäusen
(Ptch $^{+/}$) und aus einem Embryo (WT;
E12,5) herangezogen. Als interne
Kontrolle der semi-quantitativen Analyse
wurde eine PCR für das Haushaltsgen
Gapdh mitgeführt.

Zunächst läßt sich feststellen, daß in keiner der untersuchten Zelllinien Gli2 exprimiert wurde. Auch konnte in keiner der Zelllinien eine endogene Igf2-Expression nachgewiesen werden. Gli1 war, im Gegensatz zu Gli3, in den myogenen Zelllinien (C2C12, TP1588 und TP5018) kaum exprimiert. Es ist jedoch festzuhalten, daß TP1588 die höchste Gli3-Expression der untersuchten myogenen Zelllinien aufzeigte.

Dagegen exprimierte die Fibroblasten-Zelllinie NIH/ 3T3 sowohl Gli1 als auch Gli3.

\subsubsection{Untersuchung des Einflußes der Gli Transkriptionsfaktoren auf die endogene Expression vom Igf2 in Zellkultur mittels QRT-PCR Analyse}

Im Folgenden wurden die Zelllinien C2C12, TP1588, TP5014 und NIH/ 3T3 mit den Expressionsplasmiden von Gli1 und Gli3 als auch in der Kombination Gli1/ Gli3 kotransfiziert. Die cDNAs aus Gli-stimulierten Zellen wurden aus $2 \mu \mathrm{g}$ totaler RNA hergestellt. Der Gesamtansatz von $20 \mu 1$ wurde $1: 5$ verdünnt, wobei $10 \mu 1$ zur Quantifizierung der endogenen Expression des $I g f$-Gens in den TaqMan-Assay eingesetzt wurden (siehe 2.2.7.1.). Aus den Werten der Messungen von Igf2 und 18S rRNA wurde der Quotient gebildet, die Standardabweichung errechnet und grafisch dargestellt. Die relative Quantifizierung der Igf2- 
Expression ermöglichte somit den Vergleich verschiedener cDNA Proben. Alle Messungen wurden in Doubletten durchgeführt und jedes Ergebnis wurde in einem zweiten unabhängig durchgeführten Experiment verifiziert. Eine repräsentative Analyse jeder Zelllinie ist den folgenden Abbildungen graphisch dargestellt (Abb. 38-41).

Als Referenzwert für die Analysen wurde die endogene Igf2-Expression nach Transfektion mit dem Leervektor pCR3.1 verwendet. Dieser Referenzwert unterschied sich teilweise von dem der mit dem Transfektionsgeagenz behandelten Zellen. Hierauf soll aber im Folgenden nicht eingegangen werden.

\subsubsection{QRT-PCR -Analyse der durch Gli1 und/ oder Gli3-induzierten Igf2- Expression in C2C12-Zellen}

Weder durch die alleinige Gli1- noch durch die alleinige Gli3-Transfektion wurde eine Stimulation der Igf2-Expression in den C2C12 Zellen hervorgerufen. Dagegen wurde in Gli1/ Gli3-kotransfizierten Myoblasten-Zellen eine 4,5fache Induktion der Expression des Igf2-Gens gegenüber dem Kontrollwert (nach Transfektion mit dem Leervektor pCR3.1) beobachtet (Abb. $38)$.

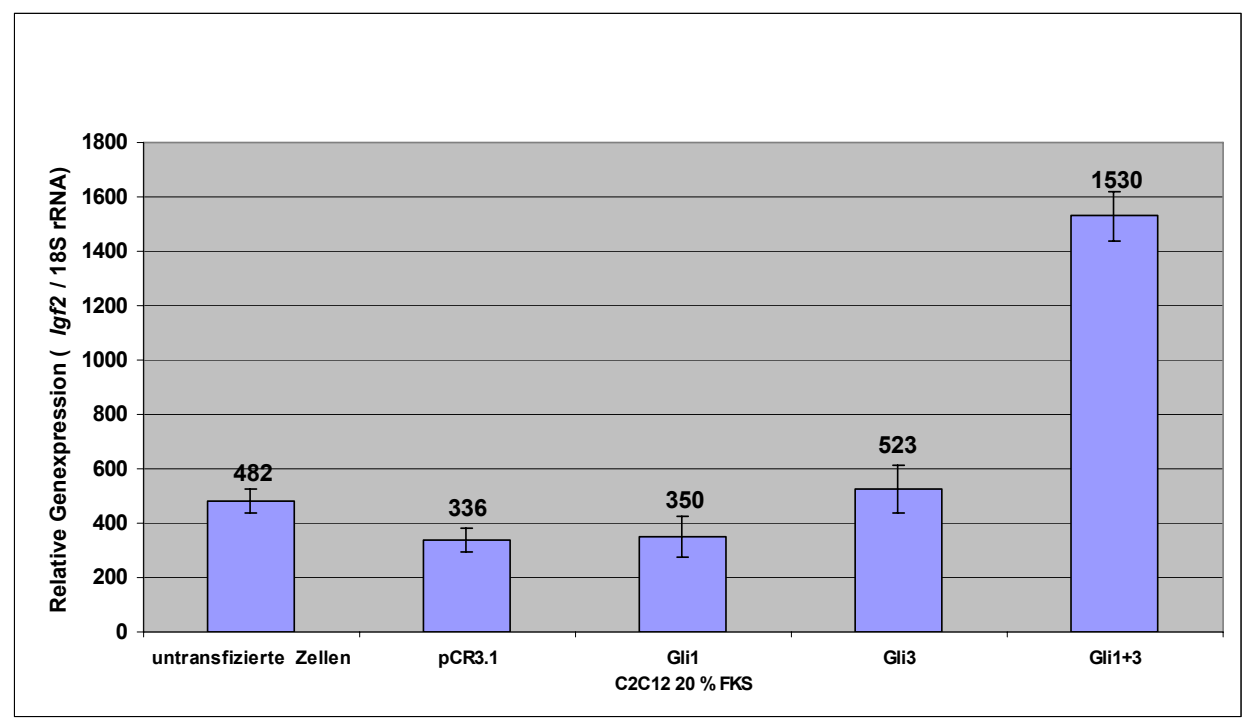

Abb. 38: Quantitative TaqMan-Analyse der Gli-induzierten Igf2-Expression in C2C12-Zellen (20 \% FKS): Grafische Darstellung der relativen Genexpression des Igf2-Gens nach Transfektion mit Glil und/ oder Gli3: Die über jedem Balken angegebene Zahl stellt den Mittelwert der Expression des Igf2-Gens dar. Standardabweichungen sind als Fehlerbalken angegeben. pCR3.1: Leerplasmid. 


\subsubsection{QRT-PCR -Analyse der durch Gli1 und/ oder Gli3-induzierten Igf2- Expression in TP1588 und TP5014-Zellen}

Die Zelllinien TP1588 und TP5014 wurden aus RMS von heterozygoten Ptch-Mäusen etabliert. Obwohl diese Zellen einige der Marker verlieren, die im nativen RMS exprimiert werden (z.B. Gli1, aber auch Igf2; siehe Abb. 37) können sie doch als Tumor-Modellsystem in vitro angesehen werden.

Die Quantifizierung der Igf2-Expression in diesen Zelllinien nach Gli1- und/ oder Gli3Transfektion ist in der Abbildung 39 dargestellt.

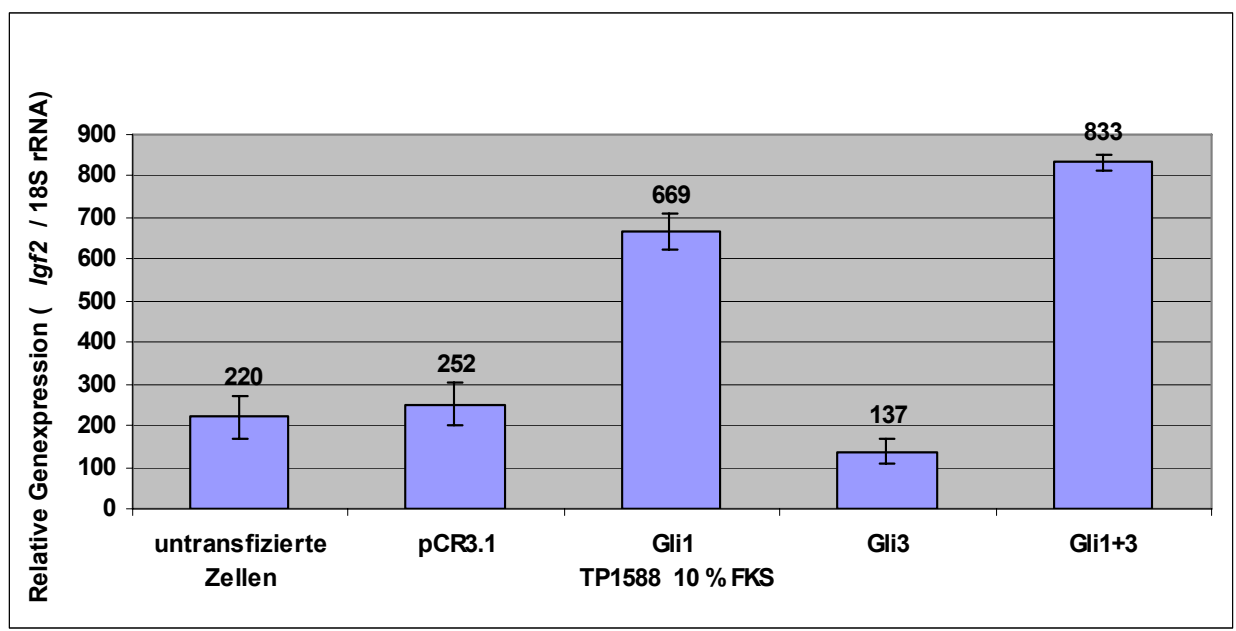

Abb. 39: Quantitative TaqMan-Analyse der Gli-induzierten Igf2-Expression in TP1588 Zellen (10 \% FKS): Grafische Darstellung der relativen Genexpression des Igf2-Gens nach Transfektion mit Glil und/ oder Gli3: Die über jedem Balken angegebene Zahl stellt den Mittelwert der Expression des Igf2-Gens dar. Standardabweichungen sind als Fehlerbalken angegeben. pCR3.1: Leerplasmid.

In der Zelllinie TP1588 wurde durch die einfache Transfektion mit dem Transkriptionsfaktor Gli1 eine 2,6fach stärkere Igf2-Expression hervorgerufen. Die Kombination von Gli1 und Gli3 führte in TP1588 RMS-Zellen zu einer 3,3fachen Induktion der endogenen Igf2-Expression.

Gli3 schien in dieser Zelllinie möglicherweise die Funktion eines negativen Regulators der Igf2Genexpression auszuüben, da die Igf2-Expression um die Hälfte gegenüber der Kontrolle abnahm. 


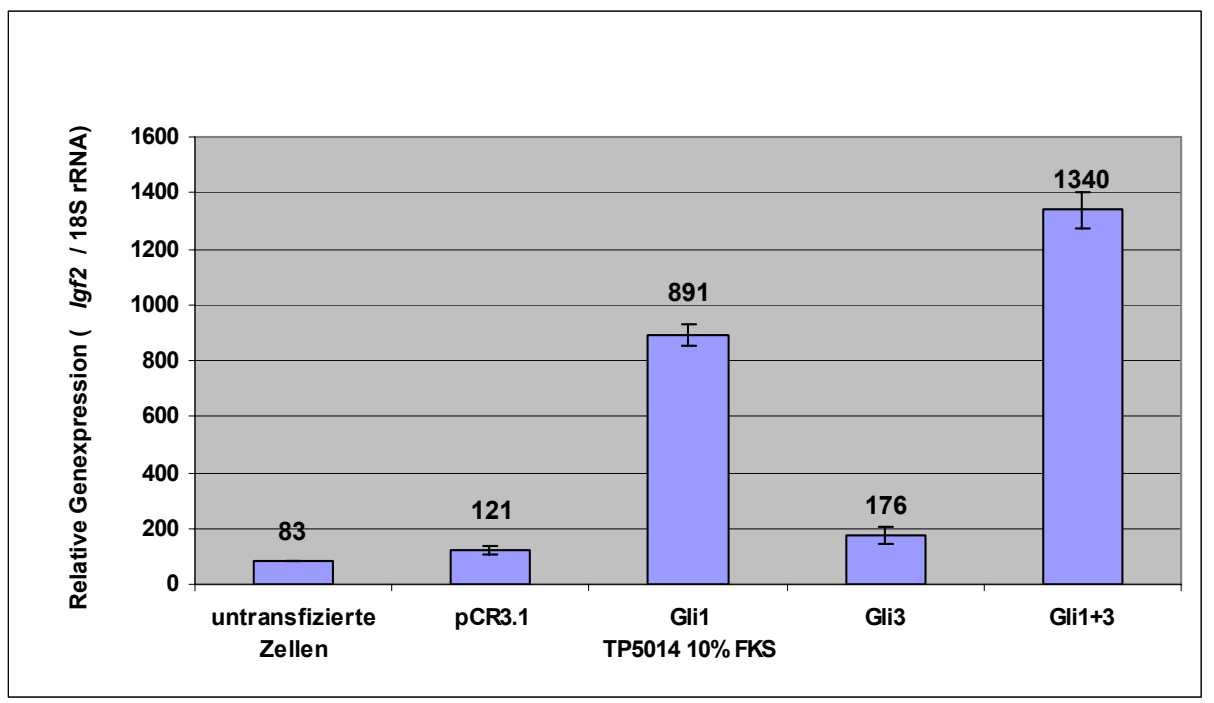

Abb. 40: Quantitative TaqMan-Analyse der Gli-induzierten Igf2-Expression in TP5014 Zellen (10 \% FKS): Grafische Darstellung der relativen Genexpression des Igf2-Gens nach Transfektion mit Glil und/ oder Gli3: Die über jedem Balken angegebene Zahl stellt den Mittelwert der Expression des Igf2-Gens dar. Standardabweichungen sind als Fehlerbalken angegeben. pCR3.1: Leerplasmid.

In der Tumorzelllinie TP5014 konnte durch Gli1-Transfektion die Expression des Igf2-Gens um den Faktor 7,3 gegenüber der Transfektion mit dem Leervektor pCR3.1 gesteigert werden (Abb. 40). Die Kotransfektion von Gli1 und Gli3 führte zu einer weiteren Steigerung der Igf2Expression um das 11 fache gegenüber der mitgeführten Kontrolle (Leervektor pCR3.1). Die Gli3-Transfektion hatte keinen Einfluß auf die Igf2-Expression.

\subsubsection{QRT-PCR -Analyse der durch Gli1 und/ oder Gli3-induzierten Igf2- Expression in NIH/ 3T3-Zellen}

In NIH/ 3 T3 Fibroblasten-Zellen werden im Vergleich zu den drei myogenen Zelllinien Gli1 und Gli3 bereits endogen exprimiert (Abb. 37). Trotzdem konnte in NIH/ 3T3 kein endogenes $\operatorname{Igf2}$ nachgewiesen werden.

Auch in NIH/ $3 \mathrm{~T} 3$ konnte durch eine Gli1- und Gli3-Kotransfektion die endogene Igf2Expression um das 4,5fache gesteigert werden. Die Transfektion jedes einzelnen Transkriptionsfaktors hatte dagegen keinen signifkanten Effekt auf die Igf2-Expression (Abb. 41). 


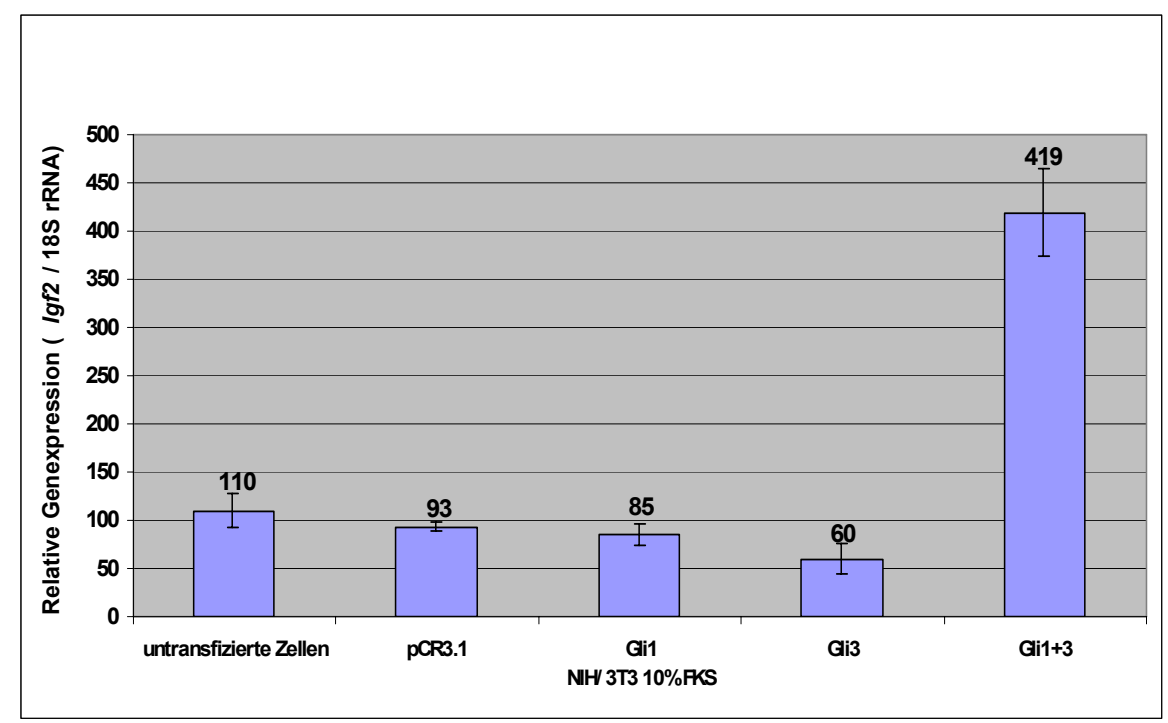

Abb. 41: Quantitative TaqMan-Analyse der Gli-induzierten Igf2-Expression in NIH/ 3T3 Zellen (10 \% FKS): Grafische Darstellung der relativen Genexpression des Igf2-Gens nach Transfektion mit Glil und/ oder Gli3: Die über jedem Balken angegebene Zahl stellt den Mittelwert der Expression des Igf2-Gens dar. Standardabweichungen sind als Fehlerbalken dargestellt. pCR3.1: Leerplasmid.

Zusammengefaßt zeigen die Transfektionsexperimente folgendes:

In allen untersuchten Zelllinien läßt sich die Igf2-Expression am effizientesten durch die KoExpression von Gli1 und Gli3 stimulieren. In den Tumor-Zelllinien führt die Gli1-Transfektion bereits zu einem Anstieg der Igf2-Expression. In den C2C12 und den NIH/ 3T3 Zellen ist die gemeinsame Transfektion beider Faktoren absolut notwendig, um einen Anstieg der Igf2Expression hervorzurufen.

\subsubsection{QRT-PCR -Analyse der durch Gli2-induzierten Igf2-Expression in C2C12, TP-1588, TP-5014 und NIH/ 3T3-Zellen}

In der vorliegenden Arbeit wurde weiterhin der Einfluß des Transkriptionsfaktors Gli2 auf die Igf2-Expression untersucht. Hierfür wurden ebenfalls die Zelllinien C2C12, NIH/ 3T3, TP1588 und TP5014 sowohl mit den Expressionsvektoren von Gli2 als auch mit den Kombinationen Gli2/ Gli1 und Gli2/ Gli3 transfiziert. In Abbildung 42 sind die Ergebnisse der quantitativen Analysen der Gli2-induzierten endogenen Expression vom Igf2 in NIH/ 3T3-und C2C12-Zellen zusammengefaßt und graphisch dargestellt. Wird die endogene Igf2-Expression nach Tranfektion mit dem Leervektor pCR3.1 als Referenzwert festgelegt, kann folgendes festgestellt werden:

Durch Transfektion der Fibroblastenzellen mit Gli2, Gli1/ Gli2 und Gli2/ Gli3 konnte keine Igf2-Expression induziert werden. Vielmehr wurde in den Fibroblasten die endogene Expression von Igf2 durch Transfektion von Gli2 oder durch Kotransfektion von Gli2/ Gli1 unterdrückt. 
Eine Kotransfektion von Gli2/ Gli3 schien keinen großen Einfluß auf die Igf2-Expression zu haben.

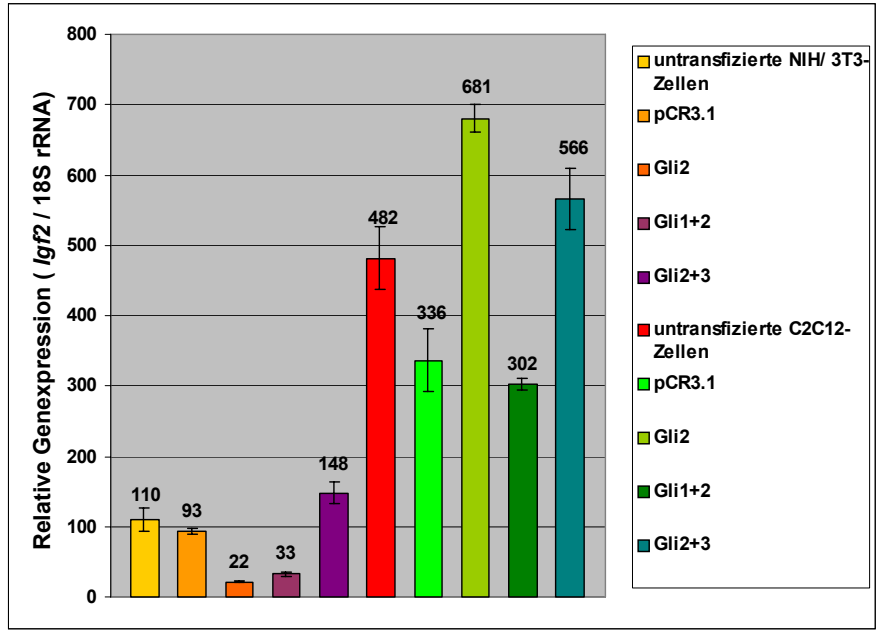

Abb. 42: Quantitative TaqMan-Analyse der Gli-induzierten Igf2-Expression in NIH/ 3T3 Zellen (10 \% FKS) und C2C12-Zellen (20 \% FKS). Grafische Darstellung der relativen Genexpression des Igf2-Gens nach Transfektion mit Gli2 und/ oder Gli1 bzw Gli3. Die über jedem Balken angegebene Zahl stellt den Mittelwert der Expression des Igf2-Gens dar. Standardabweichungen sind als Fehlerbalken angegeben. pCR3.1: Leerplasmid.

In Myoblastenzellen dagegen führte eine alleinige Gli2-Transfektion als auch eine Gli2/ Gli3Kotransfektion zu einer Stimulierung der Igf2-Expression. In dieser Zelllinie zeigte die Kombination Gli1/ Gli2 keinen stimulierenden Effekt auf die endogene Expression vom Igf2.

In Abbildung 43 sind die Ergebnisse der quantitativen Analysen der Gli2-induzierten endogenen Expression von Igf2 in den RMS-Zelllinien TP1588 und TP5014 zusammengefaßt und graphisch dargestellt.

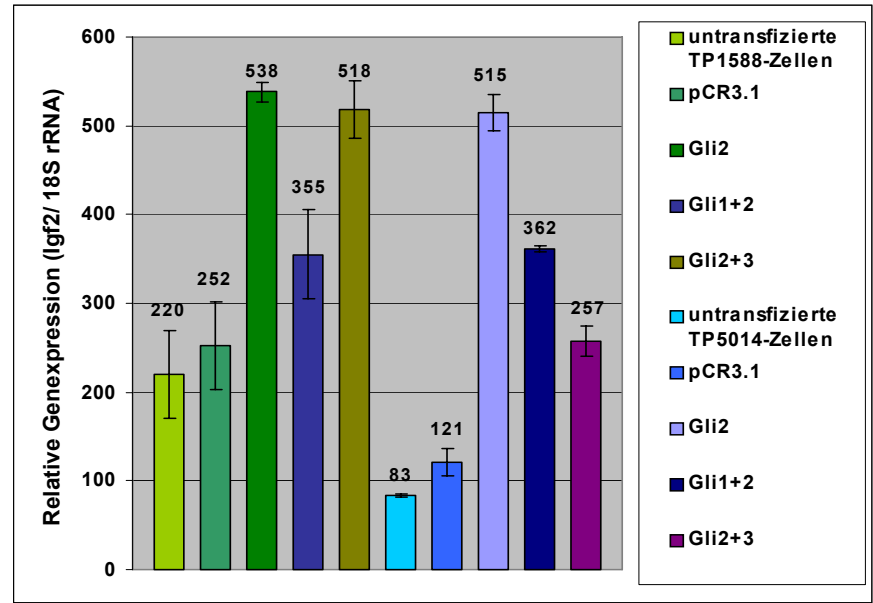

Abb. 43: Quantitative TaqMan-Analyse der Gli-induzierten Igf2-Expression in den RMS-Zellen TP1588 und TP5014 (10 \% FKS). Grafische Darstellung der relativen Genexpression des Igf2-Gens nach Transfektion mit Gli2 und/ oder Gli1 bzw Gli3: Die über jedem Balken angegebene Zahl stellt den Mittelwert der Expression des Igf2-Gens dar. Standardabweichungen sind als Fehlerbalken angegeben. pCR3.1: Leerplasmid. 
Nach Gli2-Transfektion in den TP1588 und TP5014 Zelllinien konnte ebenso wie nach Gli1Transfektion (siehe Abschnitt 3.6.3.2.) die Igf2-Expression stimuliert werden. Ein synergistischer Effekt auf die Igf2-Expression von Gli2 mit einem der beiden anderen GliTranskriptionsfaktoren konnte jedoch nicht beobachtet werden. Vielmehr wurde die Expression von $\operatorname{Ig} f 2$ nach Kotransfektion von Gli2 mit Gli1 in beiden Zelllinien reduziert. Der Effekt der Kombination von Gli2/ Gli3 scheint in den beiden Tumorzelllinien sehr unterschiedlich zu sein. In TP1588-Zellen führte die Kotransfektion von Gli2/ Gli3 zu einer Induktion der Igf2Expression, wogegen in TP5014-Zellen die Expression des Igf2-Gens reprimiert wurde.

\subsubsection{Analyse der Funktionalität der Gli-Bindungsstelle 4 des Igf2- Lokus im $\beta$-Galaktosidase-Reporter-Assay}

Auf Grund der vorherigen Befunde konnte die Schlußfolgerung gezogen werden, daß sich die Igf2-Expression in NIH/ 3T3 Zellen am effizientesten durch die Transkriptionsfaktoren Gli1 und Gli3 stimuliert läßt. Hierbei stellte sich die Frage, ob die von Kinzler und Vogelstein 1990 beschriebene Konsensus-Sequenz (Abb. 35, Tab. 33) eine funktionelle Bindungssequenz für die Transkriptionsfaktoren Gli1 und Gli3 darstellt.

Um dies zu überprüfen, wurden zunächst zwei Cosmide, IgflacZB und H19eIgflacZ, verwendet, bei denen das LacZ-Gen in frame in den offenen Leserahmen des Igf2-Gens eingebracht wurde. (siehe Abb. 44; Pravtcheva und Wise, 1998). Das Konstrukt H19eIgflacZ enthält zusätzlich am 3` -Ende zwei endodermale Verstärker-Elemente. Diese Elemente spielen eine Rolle in der reziproken Prägung von Igf2 und H19 (Zemel et al., 1992). Mit beiden Cosmiden ist somit mittels der $\beta$-Galaktosidase-Färbung eine Aussage über die transkriptionelle Aktivierung von Igf 2 möglich.

Die Transfektionsexperimente wurden in der Fibroblasten-Zelllinie NIH/ 3T3 durchgeführt (siehe 2.2.12.3.2.). Als Positivkontrolle wurde ein pCMV-beta-GAL-Plasmid mitgeführt (mit freundlicher Genehmigung von Dr. P. Burfeind; in Abb. 45 nicht gezeigt), das die $\beta$ Galaktosidase unter dem CMV-Promotor konstitutiv exprimiert. Da bekannt ist, daß der P3 Promotor des Igf2-Gens eine Ap1-Bindungsstelle enthält und sich durch c-Jun und c-Fos stimulieren läßt (Caricasole und Ward, 1993), wurden die Cosmide mit c-Jun- und c-FosExpressionsvektoren als weitere Kontrolle kotransfiziert. Die Ergebnisse wurden in einem zweiten unabhängig durchgeführten Experiment verifiziert (Abb. 45). 

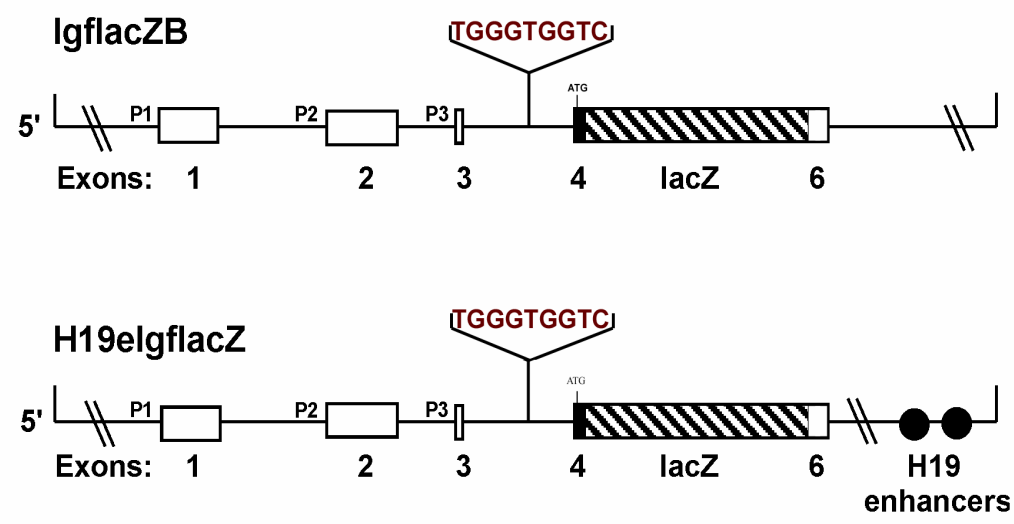

Abb. 44: Struktur der Igf2-Konstrukte: Offene und gefüllte Rechtecke, nummeriert von 1-6, präsentieren die untranslatierten und translatierten Exone. P1, P2 und P3 zeigen die Position der drei Promotoren an. Die KonsensusSequenz für die Bindung von Glil (5’ TGGGTGGTC 3') liegt im Intron 3. Der LacZ-Reporter ersetzt das kodierenden Exon 5 vollständig. Dabei bleiben eine Sequenz des Exons 4 mit dem ersten ATG-Startkodon und ein 3 -untranslatierter Bereich von 433 bp des Exons 6 mit der Polyadenylierungsregion erhalten. Das H19eIgflacZCosmid enthält zusätzlich am 3` -Ende zwei endodermale Verstärker-Elemente.

Die Cosmide enthalten eine 8100 bp umfassende DNA-Sequenz stromaufwärts vom Translationsstart im Exon 4. Die Exone U1 und U2 sind daher in den Cosmiden nicht mehr enthalten. Somit sind auch die ersten drei im Igf2-Lokus identifizierten Gli-Bindungsstellen (Tab. 33) nicht mehr enthalten. Die Gli-Konsensus-Sequenz 5 (Tab. 33) wurde durch die Insertion des LacZ-Gens deletiert.

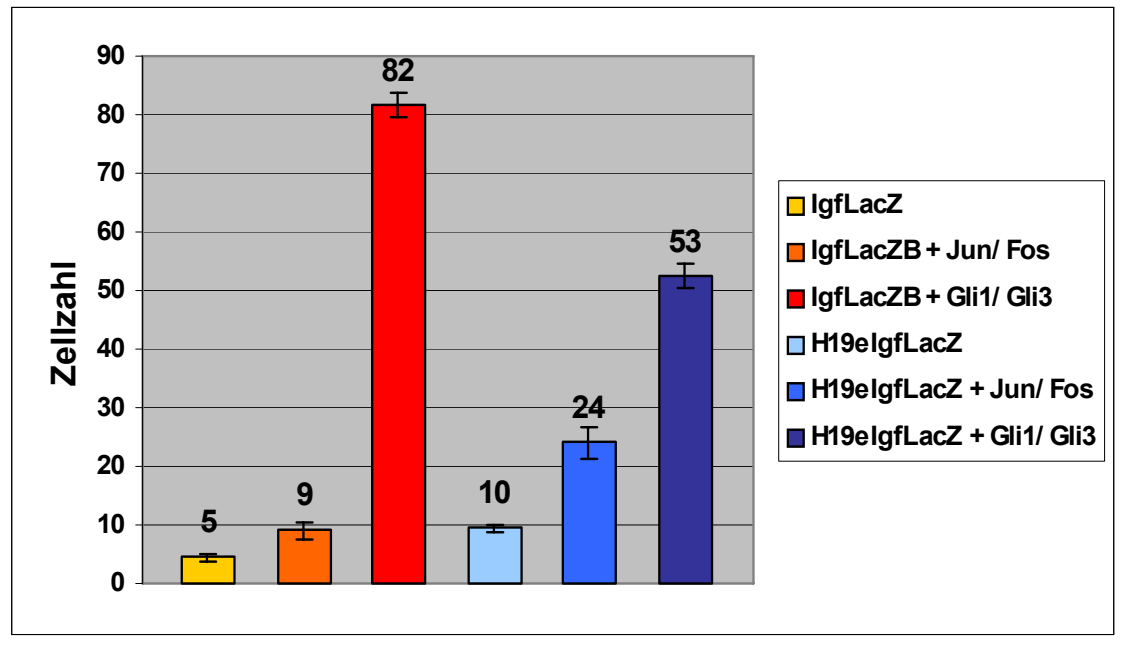

Abb. 45: Nachweis der Reporteraktivität in Gli-stimulierten NIH/ 3T3-Zellen: Die Zellzahl stellte ein Maß für die Stärke der Reporteraktivität nach Stimulierung mit Jun/ Fos und Gli1/ Gli3 dar. 
In beiden Konstrukten IgflacZB und H19eIgfLacZ konnte eine Gli-induzierte Reporteraktivität nachgewiesen werden. Dabei stellt die Anzahl der blau-gefärbten Zellen ein Maß für die Igf2Stimulierung nach der Kotransfektion mit Glil und Gli3 dar. Die Aktivierung war im H19eIgfLacZ-Konstrukt nach Gli-Transfektion geringer als im IgfLacZB-Konstrukt.

Mit Hilfe dieses Experimentes konnte gezeigt werden, daß die im Intron 3 der Cosmide lokalisierte Gli-Bindungsstelle wahrscheinlich eine wichtige Rolle bei der Induktion der Igf2Expression spielt. Da jedoch auch weitere regulatorische Elemente der Promotoren P1, P2 und P3 an der Stimulierung beteiligt sein können, sollte im Folgenden mit Hilfe von PromotorDeletions-Konstrukten versucht werden, diesen regulatorischen Bereich einzugrenzen.

\subsubsection{Analyse der Funktionalität der Gli-Bindungsstelle 4 des $\operatorname{Igf2-}$ Lokus im Luziferase-Reporter-Assay}

Zur Analyse der Gli-Bindungsstelle 4 wurden drei verschieden große Deletionskonstrukte vom Igf-Gen verwendet, die in einen Vektor kloniert wurden, in dem das Luziferase-Gen aus Photinus pyralis (Firefly) als Reportergen fungierte (Abb. 46). Die Quantifizierung der Luziferase-Aktivität, die im Luminometer über eine chemolumineszente Reaktion nachgewiesen werden konnte, ermöglichte es, Rückschlüsse auf die Aktivierung des Promotorkonstruktes zu ziehen (siehe 2.2.13.1.). Alle drei Promotorkonstrukte enthalten den Promotor P3, der die Ap1-Konsensus-Sequenz besitzt. Alle Konstrukte lassen sich somit durch c-Jun und c-Fos aktivieren (Abb. 47). Die Stimulierbarkeit dieser Promotorkonstrukte durch cJun/ c-Fos wurde bereits in Caricasole und Ward, 1993 beschrieben und ein entsprechendes Experiment diente daher als Kontrolle der Transfektionen.

Zwei der Reporterkonstrukte, pP3L und pP3M, enthalten die im Intron 3 beschriebene GliBindungsstelle 4 (siehe Tab. 33). Im Konstrukt pP3MM wurde das Intron 3 und somit die hier enthaltene Gli-Bindungsstelle 4 deletiert (Abb. 46).

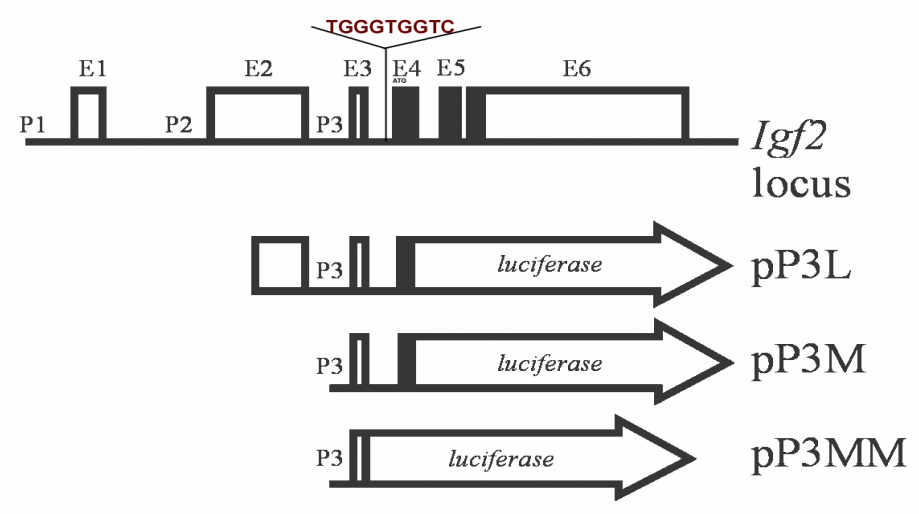

Abb. 46: Struktur der Igf2 Promotor-Luziferase Fusionskonstrukte pP3L, pP3M und pP3MM: Dargestellt ist das jeweilige Igf2-Promotorfragment, das vor die Luziferase (durch Pfeile angegeben) kloniert wurde und die im Intron 3 lokalisierte Gli-Bindungsstelle 4 (5' TGGGTGGTC 3', in rot dargestellt; siehe Tab. 33). Im Konstrukt pP3MM wurde das Intron 3 und somit die GliBindungsstelle deletiert. 


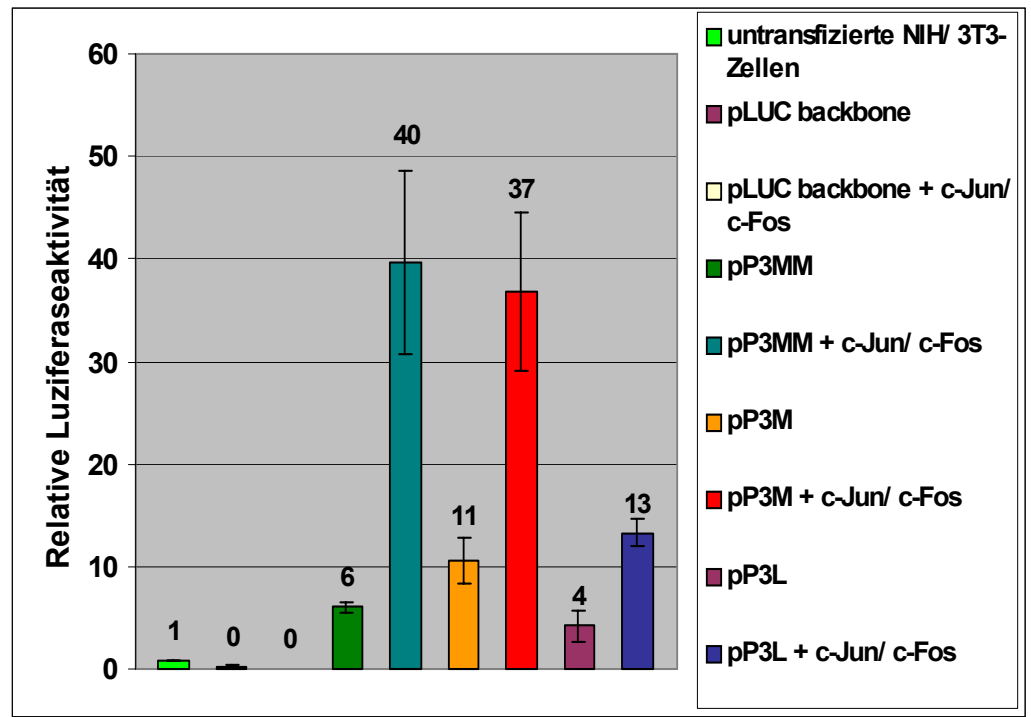

Abb. 47: Stimulation der Reporterkonstrukte pP3L, pP3M und pP3MM mit c-Jun/ c-Fos in 3T3 Zellen: c-Jun und c-Fos-induzieren in drei Konstrukten die Luziferaseaktivität. pLuc-MCS: Luziferase-Leervektor. Die Zahlen über den Balken geben die relative Luziferaseaktivität an. Mittelwertabweichungen sind im Fehlerbalken angegeben

Sowohl die Kontrollexperimente mit c-Jun/ c-Fos als auch die Transfektionen mit Gli1/ Gli3 (Abb. 48) wurden in Doubletten angesetzt, um statistische Schwankungen mitteln zu können. Zur Bestätigung der Ergebnisse wurden die Experimente mindestens zweimal durchgeführt.

Wie erwartet, ließ sich die Luziferaseaktivität in allen drei Promotordeletionskonstrukte pP3L, pP3M und pP3MM durch eine $c-J u-/$ c-Fos-Kotransfektion induzieren. Dieses Vorexperiment diente als Kontrollexperiment für die Stimulierbarkeit der Konstrukte.

Nach der Kotransfektion der Reporterkonstrukte mit Glil/ Gli3 wurde die relative Luziferaseaktivität bestimmt und graphisch ausgewertet (Abb. 48). 


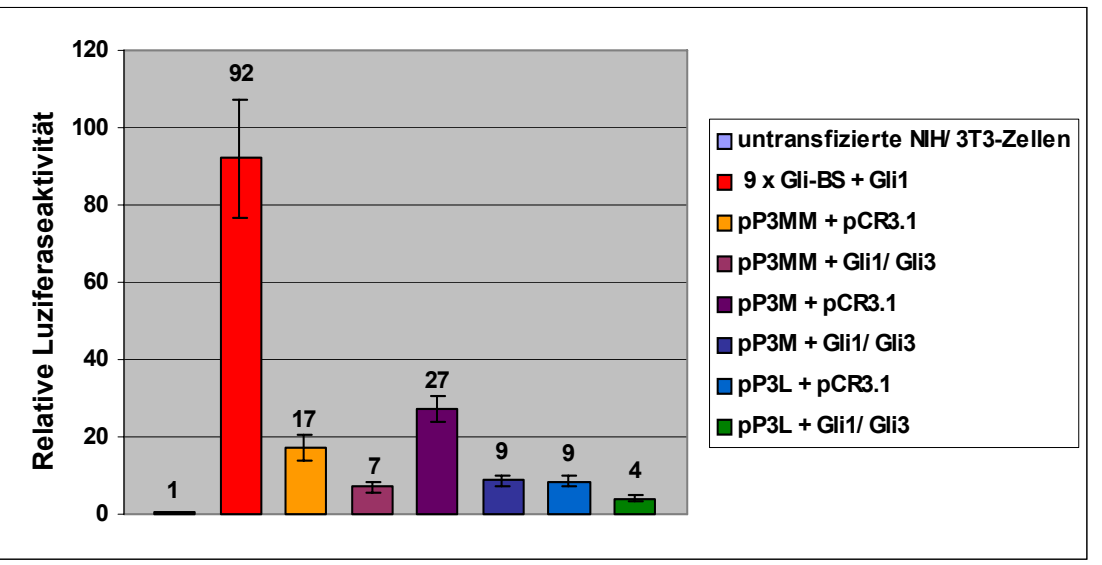

Abb. 48: Stimulation der Reporterkonstrukte pP3L, pP3M und pP3MM mit Gli1/ Gli3 in NIH/ 3 T3 Zellen.

Keines der Reporterkonstrukte pP3L, pP3M oder pP3MM ließ sich durch die Kotransfektion von Gli1 und Gli3 stimulieren und der Anstieg der Luziferaseaktivität war eher geringer als bei der mitgeführten jeweiligen Kontrolltransfektion (Kotransfektion der Reporter-Konstrukte mit dem pCR3.1-Leervektor). Als Positivkontrolle wurde ein Plasmid verwendet, bei dem neun Gli-Bindungsstellen vor das Luziferase-Gen kloniert worden sind (9 x Gli-BS). Durch Gli1-Kotransfektion wird eine Stimulierung der Reporteraktivität dieses Plasmids hervorgerufen.

Im Experiment (Abb. 48) konnte keine Induktion der Luziferase durch Gli1 und Gli3 festgestellt werden. Die Luziferaseaktivität aller drei Konstrukte war nach Gli1-/ Gli3-Kotransfektion sogar geringer als nach Kotransfektion mit dem Leervektor pCR3.1

Die höchste Luziferaseaktivität wurde durch eine Kotransfektion eines 9 x Gli-Bindungsstellen enthaltenden Luziferase-Expressionsvektors mit Glil erzielt (Beer et al, 2003).

Zusammenfassend zeigen diese Experimente, daß die Gli-Bindungsstelle 4 nicht für eine Gliinduzierte Stimulation des Promotors P3 veantwortlich sein kann. 


\section{Diskussion}

\subsection{Ein bisher nicht identifizierter Mechanismus bedingt die Überexpression des paternalen Igf2-Allels in Ptch- assoziierten RMS}

Gene, die für Wachstumsfaktoren und ihre Rezeptoren kodieren, spielen eine essentielle Rolle in Zellwachstums- und Differenzierungsprozessen der frühen Embryonalentwicklung. Ein solch wichtiger Wachstumsfaktor stellt der Insulin like growth factor 2 (IGF2/Igf2) dar, der während der frühen Embryonalentwicklung unter maternaler Prägung und in gewebespezifischer Weise exprimiert wird (Chiariotti et al., 1986; Rotwein und Hall, 1990, Rotwein, 1991).

Die Genexpression von humanem als auch murinem IGF2/Ig/2 unterliegt einer epigenetischen Regulation, die zu einer Allel-spezifischen Aktivierung des paternalen Allels führt (DeChiara et al., 1991; Hu et al., 1995; Jirtle, 2004). Die Prägung wird über ein parental-spezifisches DNAMethylierungsmuster von CpG-reichen Regionen (CpG-Inseln) gesteuert, die Bindungsstellen methylierungssensitiver regulatorischer Elemente aufweisen. IGF2/Igf2 ist ein Gen, das beim Menschen und der Maus nur vom paternalen, nicht aber vom maternalen Allel exprimiert wird (Reik und Maher et al., 1997).

\subsubsection{Aktivierung der $I G F 2 / \operatorname{Ig} 2$ 2-Expression bei der Tumorentstehung} Als Mitogen wirkt das Polypeptid IGF2/ Igf2 auf verschiedene Zelltypen, fördert die Differenzierung und das Wachstum von Muskelgewebe und verhindert die Apoptose (Pedone et al., 1994b; Pavelic et al., 2002). Während in vielen embryonalen Geweben eine hohe IGF2Expression zu verzeichnen ist, nimmt diese im postnatalen und adulten Organismus ab.

Auf Grund seiner anti-apoptotischen und wachstumsfördernden Wirkung wird IGF2 eine wichtige Rolle in der Tumorentstehung und dem Tumorwachstum zugeschrieben (Sussenbach et al., 1992; Zarrilli et al., 1994). Dies ist seit mehr als 20 Jahren bekannt und schon im Jahre 1985 beschrieb A. E. Reeve in Patienten mit Wilms-Tumoren eine erhöhte Transkription des IGF2-Gens.

Ein aberranter Methylierungs-Verlust oder -Zugewinn kann zu einem Verlust des Imprints führen, was wiederum eine biallelische Expression zur Folge hat. Ein LOI des IGF2-Gens 
wurde in verschiedenen Tumortypen, wie Kolon-, Leber-, Lunge - und Ovarial-Tumoren beschrieben und beruht auf einer veränderten Methylierung des maternalen Allels des Imprinting Centers H19-DMD, welches $2 \mathrm{~kb}$ upstream vom H19-Lokus lokalisiert ist (Moulton et al., 1994 und 1996; Steenman et al., 1994; Reik et al.; 2000; Vu und Hoffman, 1996; Moore et al.; 1997).

Auch eine uniparentale Disomie (UDP), bei der das maternale IGF2-Allel verloren geht und durch ein paternales IGF2-Allel ersetzt wird, sowie paternale Trisomie führen zu einer Überexpression von $I G F 2$ und werden zum Beispiel mit der Tumorentstehung bei BeckwithWiedemann-Syndrom in Verbindung gebracht.

Neben diesen beiden bekannten Mechanismen der IGF2 Überexpression in Tumoren werden noch weitere diskutiert. Die IGF2-Expression wird beispielsweise durch verschiedene Transkriptionsfaktoren aktiviert. Ein bekanntes Beispiel ist Prolaktin, das die IGF2-Expression stimulieren kann und bei der Entstehung von Brustkrebs eine wichtige Rolle spielt (Brisken et al., 2002). Ein weiteres Beispiel ist der Transkriptionsfaktor WT1, welcher die IGF2-Expression in Wilms-Tumoren induziert (Nichols et al., 1995).

\subsubsection{Die Rolle von $I G F 2 / I g f 2$ in Ptch-assoziierten Tumoren}

Die wachstumsfördernde Rolle von Igf2 spiegelt sich auch in den MB und RMS heterozygoter Ptch-Mutanten wider. In allen untersuchten heterozygoten Ptch-Mausmutanten konnte eine Überexpression von Igf2 sowohl in RMS als auch in MB nachgewiesen werden. Interessanterweise konnte gezeigt werden, daß Igf2 ein notwendiger Faktor für die Genese und das Wachstum dieser Tumoren darstellt (Hahn et al., 2000). So weisen heterozygote Ptch-Mäuse auf einem $\operatorname{Ig} f 2$-Null-Hintergrund eine signifikant niedrigere Inzidenz dieser Tumoren auf. In nicht-tumorigenem Gewebe homozygoter Ptch-Embryonen wurde eine Überexpression des Igf2-Gens beobachtet. Es konnte somit postuliert werden, daß Igf2 ein Zielgen des ShhSignalweges darstellt (Hahn et al., 2000). Eine essentielle Rolle von IGF2 konnte auch in humanen $P T C H$-assoziierten Tumoren nachgewiesen werden. So überexprimieren alle bisher untersuchten desmoplastischen $\mathrm{MB}$, die durch Mutationen in PTCH hervorgerufen werden, neben GLII auch IGF2 (Pomeroy et al., 2002). 


\subsubsection{Die Überexpression des Igf2-Gens in Ptch-assoziierten Tumoren wird weder durch LOI des maternalen Allels, noch durch uniparentale Disomie, Polyploidie oder Genamplifikation hervorgerufen}

Zahlreiche Mechanismen, die für die Überexpression von Genen in Tumoren verantwortlich gemacht werden können, wurden im Falle der Igf2-Überexpression in Ptch-assoziierten RMS untersucht. Jedoch konnten weder LOI, uniparentale Disomie, Polyploidie noch Genamplifikation als Ursache der Überexpression des Igf2-Gens identifiziert werden. Es konnte demnach die Schlußfolgerung gezogen werden, daß in heterozygoten Ptch-Mutanten das paternale Allel, unabhängig vom Imprinting und der damit assoziierten Methylierungen, aberrant überexprimiert wird (Hahn et al., 2000).

Trotz der genannten Studien konnten andere mögliche Mechanismen für die Igf2Überexpression in RMS nicht ausgeschlossen werden, wie zum Beispiel aktivierte transkriptionelle Mechanismen oder DNA-Modifikationen der DMRs vom Igf2. Ziel der vorliegenden Arbeit war es daher, RMS in heterozygoten Ptch-Mäusen auf solche Veränderungen zu untersuchen und die Ereigniskette, die zur Überexpression führt, besser zu verstehen.

\subsection{Aktivität von drei Promotoren führt zu Igf2- Überexpression in Ptch-assoziierten RMS}

Vom Igf2-Lokus werden zahlreiche Igf2-Transkripte in diversen Spleißvarianten von vier alternativen Promotoren transkribiert (Rotwein und Hall., 1990, Moore et al., 1997). Die Struktur des Igf2-Lokus, die Anzahl der Promotoren und die von ihnen aktivierten Transkripte lassen auf eine hochkomplexe Transkriptionskontrolle schließen (Rietvelt et al., 1997). Es war daher zunächst von Interesse, zu untersuchen, welche dieser Transkripte in Ptch-assoziierten RMS-Tumoren überexprimiert sind und ob sie aberrante $I g f 2$-Spleißvarianten exprimieren. Derartig detaillierte Untersuchungen lagen in der Literatur nicht vor.

In der vorliegenden Arbeit konnte gezeigt werden, daß alle bekannten Igf2-Transkripte (T1, T2, T3) in Ptch-assoziierten RMS-Tumoren überexprimiert sind. Dieses Ergebnis resultiert sowohl aus einer Northern-Blot-Analyse als auch aus semi-quantitativen RT-PCR-Analysen. Insbesondere die PCR-Analysen dienten dabei dem quantitativen Vergleich der Expressionsraten der einzelnen Transkripte. Ferner war es möglich, die Existenz weiterer, bisher nicht beschriebener Spleißvarianten, auszuschließen. Die Analyse des Northern-Blot (Abb. 9) zeigte, daß die alternativen Transkripte T3 (3,6 kb; 2,1 kb; 1,8 kb und 1,3 kb), die durch den Promotor P3 reguliert werden, in den untersuchten RMS stark überexprimiert wurden. Ein viertes vom 
Promotor P3 reguliertes alternatives Trankript von 1,3 kb war dagegen nur schwach exprimiert. Im Skelettmuskel, der das Referenzgewebe des RMS darstellt, wurde keine Expression eines Igf2-Transkriptes beobachtet. Letzteres bestätigt die in der Literatur getroffene Aussage, daß Igf2 in adulten, murinen Geweben nicht exprimiert wird (DeChiara et al., 1991). Eine klare Trennung zwischen den Transkripten T0 und T2, die der Kontrolle der Promotoren P0 und P2 unterliegen, konnte nicht vollzogen werden, da die Transkriptgrößen von 5,0 kb und 4,8 kb im Blot wahrscheinlich nicht aufzutrennen waren. Eine Aussage über die Aktivierung des Promotors P1 konnte ebenfalls nicht getroffen werden, da die Größe des Transkriptes T1 in der Literatur nicht bekannt ist.

Zum Nachweis der Spleißvarianten Exon1/ Exon4, Exon2/ Exon4 und Exon3/ Exon4 wurde eine semi-quantiative RT-PCR durchgeführt (Abb. 10). Alle drei Spleißvarianten, die die Transkripte T1, T2 und T3 repräsentieren, sind im RMS überexprimiert. Somit konnte gezeigt werden, daß auch das Transkript $\mathrm{T} 1$, welches im Northern-Blot keiner Größe zugeordnet werden konnte, in RMS ebenfalls überexprimiert wird. Der Nachweis der Spleißvariante Exon2/ Exon4, die das Transkript T2 repräsentiert, konnte ebenfalls in den untersuchten RMS erbracht werden. Dies läßt zunächst die Schlußfolgerung zu, daß das größte im Northern-Blot detektierbare Fragment dem Transkript T2 (4,8 kb) zuzuordnen war.

In einer zweiten semi-quantitativen RT-PCR wurde die eventuelle Expression des Transkript T0 untersucht (Abb. 13). Dieses Transkript unterliegt einer gewebespezifischen Kontrolle des Promotors P0 und war bisher nur in Trophoblastenzellen der Plazenta nachzuweisen (Constancia et al., 2002). Mittels RT-PCR konnte kein Transkript T0 im RMS detektiert werden.

Zur Analyse aberranter Spleißvarianten wurde eine weitere semi-quantitative PCR durchgeführt. Dabei wurden die Vorwärtsprimer in das Exon 1, 2 oder 3 gelegt und die entsprechenden Rückwärtsprimer in die Exone 5 oder 6 (Abb. 11 und 12). Auf Grund der Größe der entsprechenden Amplifikate hätten so alle eventuell auftretenden Spleißvarianten detektiert werden müssen, die die Exone 2, 3, 4 und 5 umfassen. Durch dieses Vorgehen wurden jedoch keine weiteren Spleißvarianten nachgewiesen, so daß sich feststellen läßt, daß nur die bekannten Igf2-Transkripte T1, T2 und T3 im RMS überexprimiert sind. Demnach müssen alle Igf2Promotoren (P1, P2 und P3) aktiviert sein. Da kein Transkript T0 in den Tumoren detektiert wurde, ist davon auszugehen, daß der P0 Promotor nicht aktiviert wird.

Diesen Befunden können unterschiedliche Mechanismen zugrunde liegen. Einerseits besteht die Möglichkeit, daß ein übergeordneter Transkriptionsfaktor an allen Promotorsequenzen angreift. Andererseits kann ein dem gesamten Igf2-Lokus übergeordneter Mechanismus vorliegen, der die Aktivierung der einzelnen Promotoren initiiert (z. B. epigenetische Modifaktionen: DNA- 
Methylierungen, Histon-Azetylierung/-Deazetylierung). Beide Möglichkeiten wurden im Weiteren in der vorliegenden Arbeit untersucht.

\subsection{Die Igf2-Expression der RMS-Zelllinie TP5014 ist methylierungssensitiv}

Um der Hypothese nachzugehen, daß möglicherweise eine epigenetische Modifikation an der Überexpression des Igf2-Gens in RMS beteiligt ist, wurden Zellkultur-Experimente an der TP5014-Zelllinie mit dem Demethylierungsreagent 5-Aza-Cytidin durchgeführt. Die RMSZelllinie wurde aus RMS heteozygoter Ptch-Mutanten gewonnen und stellt somit ein mit dem Mausmodell korrespondierendes in vitro-System dar. 5-Aza-Cytidin ist ein Cytidinanalogon, welches in der Zelle anstatt des Cytidins in die DNA eingebaut wird. Dadurch werden sowohl die DNA-Synthese als auch die DNA-Methylierung stark gehemmt (Cihak et al., 1974; Jones und Taylor, 1980). Nach Behandlung der Tumorzellen mit dem Cytidinanalogon wurde die endogene Expression des Igf2-Gens mittels real-time-PCR quantifiziert (Abb. 14). Zur Kontrolle wurde eine Fibroblasten-Zelllinie NIH/ 3T3 unter gleichen Konditionen der 5-AzaCytidin-Behandlung unterzogen. In zwei unabhängig durchgeführten Experimenten konnte der Nachweis erbracht werden, daß in den Tumorzellen eine Stimulierung der Expression von Igf2 durch 5-Aza-Cytidin hervorgerufen wird. Unbehandelte und mit 5-Aza-Cytidin behandelte Fibroblastenzellen dagegen zeigen keinen Unterschied in der endogenen Expression des Igf2Gens. Die aus diesen Experimenten gewonnen Daten legen die Vermutung nahe, daß die Expression des $\operatorname{Ig} f 2$-Gens einer Kontrolle methylierungssensitiver Aktivatoren unterliegt. Eine andere mögliche Erklärung wäre der Verlust der DNA-Bindung durch methylierungssensitive Repressoren, der ebenfalls zu einer indirekten Aktivierung der Expression führen könnte. Vor dem Hintergrund der in Fibroblasten aktiven Signalwege scheinen diese Mechanismen nicht zu greifen.

\subsection{Methylierungssensitive Regionen im $\operatorname{Ig} f$-Lokus zeigen aberrante Methylierung in RMS}

Im Fokus der vorliegenden Arbeit stand die Untersuchung von Methylierungsveränderungen zwischen RMS heterozygoter Ptch-Mutanten und dem adulten Skelettmuskel, welches das Referenzgewebe des Tumors repräsentiert. Mit Hilfe der methylierungssensitiven SouthernBlot-Technik und anschließender Bisulfit-Sequenzierungsanalyse wurden sowohl das Imprinting Center (H19-DMD) als auch die im Igf2-Lokus lokalisierten methylierungssensitiven Regionen DMR0, DMR1 und DMR2 untersucht. Die H19-DMD stellt die Kernregion des 
Imprinting Centers von $\operatorname{Ig} 2$ und $H 19$ dar und ist $2 \mathrm{~kb}$ stromaufwärts vom $H 19$ - und $80 \mathrm{~kb}$ stromabwärts vom Igf2-Lokus lokalisiert. Die Region ist zwischen Säugetieren hochkonserviert und übt die Funktion eines Insulators der reziprok geprägten Gene $\operatorname{Ig} 2$ und $H 19$ aus (Thorvaldsen et al., 1998; Ishihara et al., 2000). Die DMR0 und DMR1 liegen in den Promotorbereichen P0 und P1, wogegen die DMR2 im kodierenden Bereich des Igf2-Gens lokalisiert ist.

\subsubsection{Die H19-DMD von Igf2 und H19 weist keine Methylierungs- veränderungen im RMS auf}

In Abhängigkeit des Methylierungsgrades der H19-DMD wird die Bindung eines SilencerElementes CTCF beeinflußt. Im Fall einer vorliegenden Methylierung der H19-DMD des paternalen Allels wird die Bindung von CTCF blockiert. Dadurch kann durch den stromabwärts von $H 19$ liegenden Enhancerkomplex über eine große Distanz die paternale Igf2-Expression aktiviert werden. Die Expression von $\mathrm{H} 19$ wird hierbei geblockt (Kanduri et al., 2000; P. Szabo et al., 2000). Die Hypomethylierung der H19-DMD des maternalen Allels erlaubt dagegen die Bindung des CTCF-Faktors. Dies führt $\mathrm{zu}$ einer Inaktivierung vom $\operatorname{Ig} f 2$ und $\mathrm{zu}$ einer Aktivierung der Expression des H19-Gens (Abb. 49).

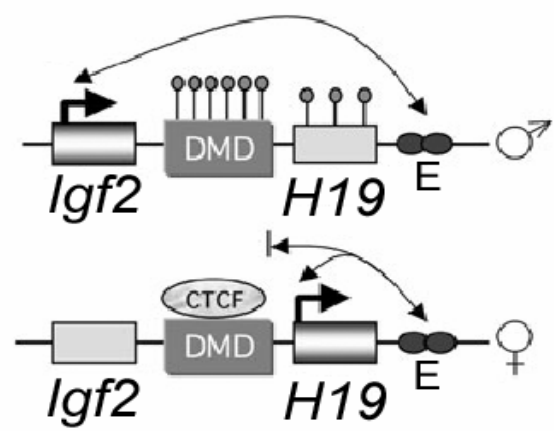

Abb. 49: Schematische Darstellung des reziproken Imrintings des Igf2- und H19-Gens der H19-DMD. Die H19-DMD hat die Funktion eines Chromatin-Insulators. Die unmethylierte H19-DMD des maternalen Allels bindet den Repressor CTCF und erlaubt nur den Zugriff der Enhancer (E) auf die Promotoren des H19. Die Igf2-Expression wird inhibiert. Die Methylierung der H19-DMD des paternalen Allels verhindert die Bindung von CTCF und führt über die Enhancer zu einer Aktivierung der Promotoren des paternalen Allels vom Igf2. (bearbeitet nach Charalambous et al., 2004)

Im RMS von $P t c h^{\text {neo67/+ }}$-Mäusen wird das paternale Igf2-Allel überexprimiert. Eine Überexpression des maternalen Allels konnte dagegen nicht festgestellt werden (Hahn et al., 2000). Diese Untersuchungen zeigten, daß der Mechanismus der in diesen Tumoren die Überexpression von Igf2 bewirkt, höchstwahrscheinlich kein LOI des maternalen Allels umfassen kann. Jedoch konnte in RMS neben der paternal-bedingten Igf2-Expression paradoxerweise auch eine Expression des paternalen H19-Allels nachgewiesen werden (Hahn et al., 2000). Dies ließ vermuten, daß die H19-DMD Methylierungsveränderungen im Tumor aufweisen könnte. Aus diesem Grund wurde in der vorliegenden Arbeit mögliche 
Methylierungsunterschieden der H19-DMD-Region zwischen Tumoren und normalem Muskel untersucht. Wie im Abschnitt 3.4. beschrieben, ergab die Analyse des methylierungssensitiven Southern-Blots keine eindeutigen Veränderungen im Methylierungsmuster zwischen den beiden Geweben in der H19-DMD-Region (Abb. 31). Es konnte keine Aussage über den Methylierungszustand der HpaII-Schnittstellen H1 und H2 getroffen werden, da die kleinen Fragmente (45 bp, $154 \mathrm{bp}$ ), die die H1-/ H2-Fragmente repräsentieren, aus dem Gel herausgelaufen waren. Auch die größeren Fragmente, die durch eine der beiden Schnittstellen zustande kommen, konnten auf Grund ihrer ähnlichen Grössen nicht eindeutig zugeordnet werden. Es war daher problematisch, eine Aussage über Methylierungsunterschiede zwischen Muskel und Tumor in der H19-DMD zu treffen.

Eine erhöhte Methylierung der H19-DMD des paternalen Allels des Igf2-Gens, die zu einer möglichen Aktivierung der Promotoren und somit $\mathrm{zu}$ einer verstärkten Expression des paternalen Allels vom Igf2 führen könnte, hätte sich jedoch auch in einem Verlust von Fragmenten im Southern-Blot widergespiegelt. Eine verstärkte Methylierung des maternalen Igf2-Allels im Tumor wäre ebenfalls durch den Verlust von Fragmenten sichtbar geworden. Dies konnte aber nicht belegt werden, woraus folgt, daß die Überexpression vom Igf2 in RMS nicht von der Methylierung der H19-DMD beeinflußt wird und nicht in einem LOI des maternalen $\operatorname{Ig} f 2$ begründet ist.

\subsubsection{Die DMR0 weist keine Methylierungsveränderungen im RMS auf} In vielen Tumoren (z. B. in Patienten mit Beckwith-Wiedemann-Syndrom und in Wilms Tumoren) konnte im maternalen IGF2 Allel im Bereich der $2 \mathrm{~kb}$ stromaufwärts von Promotor P1 gelegenen DMR0 eine Relaxierung in der Methylierung nachgewiesen werden. Diese Hypomethylierung führt zu einem Verlust der Prägung (LOI), was eine erhöhte IGF2Expression zur Folge hat (Ogawa et al., 1993; Randhawa et al., 1998). Wie bereits mehrmals beschrieben worden ist, liegt im RMS von Ptch $^{\text {neo67/+ }}$-Mäusen eine Überexpression des paternalen Igf2-Allels vor. Eine Überexpression des maternalen Allels konnte dagegen nicht festgestellt werden (Hahn et al., 2000), was auf unveränderte Methylierung des maternalen Allels in diesen Tumoren hinweist. Um dies über eine zweite Methode zu überprüfen, wurde in der vorliegenden Arbeit die DMR0 mittels methylierungssensitiver Southern-Blot-Technik analysiert (Abb. 21). Anhand der Intensitäten der detektierten Fragmente im Southern-Blot wurde versucht, Unterschiede in der Methylierung zwischen Tumor und der Referenz festzustellen. Interessant waren hierbei Unterschiede in den Intensitäten der Fragmente DMR0F4 (568 bp) und DMR0-F17 (960 bp), die in einem der vier untersuchten RMS gegenüber dem entsprechenden SM zu beobachten waren (siehe Abb. 21). Diese Unterschiede könnten auf einer 
Hypomethylierung der H4-Schnittstelle im RMS beruhen und eventuell zu einem LOI des maternalen Igf2 Allels beitragen. Hierzu ist zu bemerken, daß der Methylierungszustand der DMR0 die Aktivität des Promotors P0 beinflusst (Moore et al., 1997). In Sullivan et al., 1999 wurde der Nachweis erbracht, daß ein LOI der DMR0 zu einer gestörten Repression aller Promotoren des maternalen Allels führt. Der Nachweis eines Transkriptes T0 im RMS konnte weder im Northern-Blot (Abb. 9) noch durch die semi-quantiative PCR (Abb. 13) erbracht werden. Es ist daher anzunehmen, daß die Intensitätsunterschiede zwischen RMS und SM, die durch die Analyse des Southern-Blots (Abb.21) festgestellt werden konnten, nicht auf einer veränderten Methylierung des maternalen Allels beruhen.

\subsubsection{Die DMR1 weist signifikante Methylierungsveränderungen im RMS auf}

Die DMR1-Region des aktiven paternalen Igf2-Allels ist methyliert. Es ist bekannt, daß die DNA-Sequenzen Bindungsstellen für methylierungssensitive Repressor-Elemente bereitstellen, die mit Faktoren in trans interagieren. Eine Methylierung dieser Region auf dem paternalen Chromosom inhibiert somit eine Interaktion zwischen der DNA und den Repressor-Elementen und führt zur Expression vom Igf2 (Sasaki et al., 1992; Brandeis et al., 1993; Feil et al., 1995, Eden et al, 2001). Dies konnte auch in Methylase-negativen Embryonen nachgewiesen werden. In diesen Embryonen kommt es zu einer Hemmung der Methylierung der DMR1 (und auch der DMR2; siehe weiter im Text), was zu einer transkriptionellen Inaktivierung sowohl des paternalen als auch des maternalen Igf2-Gens führt (Li et al., 1993). Constancia et al., 2000 generierten transgene Mäuse ( $\triangle \mathrm{DMR} 1-\mathrm{U} 2)$ mit einer $5 \mathrm{~kb}$-umfassenden Deletion der DMR1. Die Analysen zeigten, daß der Effekt der Deletion in Mäusen mit maternaler Transmission zu einer biallelischen Expression des Igf2-Gens in Geweben führt, was nahelegt, daß die DMR1Region einen Einfluß auf die Ig 2 -Expression ausübt.

Da die Überexpression von Igf2 in Ptch-assoziierten RMS durch eine verstärkte Expression des paternalen Igf2-Allels zustande kommt, stellte diese Region eine potentielle Kandidatenregion für Methylierungsunterschiede zwischen RMS und SM dar (Hahn et al., 2000). Es wurde vermutet, daß dieser Bereich im RMS gegenüber dem entsprechenden SM verstärkt methyliert sein könnte.

Die DMR1-Region befindet sich $2 \mathrm{~kb}$ stromaufwärts von der Promoterregion P1 des Igf2-Gens und wurde in der vorliegenden Arbeit mit Hilfe von vier Hybridisierungssonden (Sonden 2-5, Abb. 18, Feil et al, 1994) systematisch auf ihre Methylierung untersucht. Sowohl durch die Hybridisierung mit der Sonde 2 (Abb. 23) als auch mit der Sonde 5 (Abb. 29) konnten im Southern-Blot keine Unterschiede zwischen dem Tumor und der Referenz festgestellt werden. 
Dieser Befund deutet auf das Fehlen von Methylierungsveränderung in diesen Regionen im Tumor im Vergleich zum Normalgewebe hin.

Die Sonden 3 und 4 ließen auf eine Hypomethylierung der methylierungssensitiven Schnittstellen H1, H2, und H7 im RMS rückschließen. In der vorliegenden Arbeit konnte nur die die H1-Schnittstelle umfassende Region einer Methylierungsanalyse mittels BisulfitSequenzierung unterzogen werden, da sich die PCR-Amplifikation an Bisulfit-behandelter DNA als äußerst schwierig erwies. Für diesen Bereich im Tumor konnte eine Hypomethylierung detektiert werden. So zeigte eine statistische Analyse mittels $\mathrm{Chi}^{2}$-Test eine signifikante Relaxierung der Methylierung des CpG-Dinukleotides 3 (P-Wert: 0,0332) im RMS, welches Bestandteil der HpaII-Schnittstelle H1 ist (Abb. 34).

In der Literatur gibt es keine Hinweise auf eine Hypomethylierung der H1-Schnittstelle in Tumoren. Es kann somit davon ausgegangen werden kann, daß in dieser Arbeit eine neue Region innerhalb der DMR1 identifiziert wurde, die, zumindest in Ptch-assoziierten murinen Tumoren, hypomethyliert vorliegt. Dieser Befund kontrastiert zunächst mit der zuvor aufgestellten Hypothese, gemäß derer eigentlich eine Hypermethylierung der DMR1 erwartet wurde. Trotzdem kann diese Beobachtung für die Überexpression des paternalen Igf2-Allels relevant sein.

Hypomethylierungen verschiedener Regionen, die für die Expression von Proto-Onkogenen verantwortlich sind, werden häufig in Tumorzellen angetroffen und führen $\mathrm{zu}$ einer genomischen Instabilität (Yoder et al., 1997). So führt zum Beispiel die Demethylierung des Melanoma-Antigens (MAGE) zu einer erhöhten Expression dieses Antigens in Tumoren des Testis (DeSmet et al., 2004). Eine Demethylierung, die in einem Anstieg der Expression des S100-Kalzium-bindenden Proteins A4 (S100A4-Gen) resultiert, wurde in Tumoren des Kolon beschrieben (Nakamura et al., 1998). In Tumoren der Brust und der Ovarien konnte eine Reaktivierung des Onkogens $\gamma$-Synuclein $(S N C G)$ beobachtet werden, der eine Demethylierung zugrunde lag (Inaba et al., 2005).

All diese Befunde weisen darauf hin, daß die hier beschriebene Hypomethylierung der DMR1Region von Bedeutung für die Expression von Igf2 (auch des paternalen Allel) sein könnte. Die Hypomethylierung liegt dabei in einer Region des Igf2-Gens, welche den Promotoren P1-P3 vorgeschaltet ist. Die hier beobachtete Methylierungsveränderung im Tumor könnte daher tatsächlich dazu führen, daß Igf2 von allen drei aktivierten Promotoren vermehrt exprimiert wird. Ob die Hypomethylierung jedoch von funktioneller Bedeutung für die Igf2-Expression ist, wird in weiterführenden Experimenten überprüft werden.

Im Gegensatz zu den hier beschriebenen Ergebnissen, wurde von Feil et al., 1994 unter Verwendung der Hybridisierungssonde 3 eine verstärkte Methylierung der HpaII-Schnittstellen 
H3, H4 und H5 des paternalen Allels sowohl im embryonalen als auch im adulten Gewebe der Leber beschrieben. Eden et al., 2001 unterzogen diese Region einer detaillierten Methylierungsanalyse und wiesen nach, daß die methylierungssensitive HpaII-Schnittstelle H4 eine Bindungssequenz des Repressor-Elementes GCF2 darstellt. Wie bereits beschrieben wurde, verhindert die Methylierung dieser Bindungsstelle die Bindung von GCF2 am paternalen Allel, was mit einer vermehrten Igf2-Expression einhergeht.

In der vorliegenden Arbeit konnten anhand der methylierungssensitiven Southern-BlotAnalysen keine Methylierungsveränderungen an den HpaII-Schnittstellen H3, H4 und H5 im RMS nachgewiesen werden. Dieser Befund läßt die Schlussfolgerung $z u, d a ß$ die Bindungsstelle des Repressors in Ptch-assoziierten RMS nicht vermehrt methyliert ist und nicht zur erhöhten Igf2-Expression beiträgt.

\subsubsection{Die DMR2-Region weist signifikante Methylierungs- veränderungen im RMS auf}

Die DMR2 liegt innerhalb des kodierenden Bereichs vom Igf2 und umspannt die Exone 4, 5 und 6. Diese Region weist während der Embryonalentwicklung eine im paternalen Allel verstärkte Methylierung auf (Sasaki et al., 1992; Feil et al., 1994). Die DMR2-Region wurde erstmalig von Feil et al., 1994 einer detaillierten Analyse der Methylierung unterzogen. Dabei konnte gezeigt werden, daß die vermehrte Methylierung der drei HpaII-Schnittstellen H1, H2 und H3 (Abb. 16), die im Bereich des Exon 5 und 6 von Igf2 lokalisiert sind, zu einer erhöhten Expression des paternalen Allels in der adulten Leber und in Spermien führt. Murell et al., 2001 deletierten den Bereich, der das Exon 6 umfaßt ( $\triangle \mathrm{DMR} 2)$. Die $\triangle \mathrm{DMR} 2$-knock-out Mäuse waren nach paternaler Transmission der Deletion $17 \%$ kleiner im Vergleich zu den Wildtyp-Mäusen und zeigten eine reduzierte Expression des paternalen Allels des Igf2-Gens. Nach maternaler Transmission der Deletion zeigten die Mäuse dagegen einen normalen Phänotyp. Auf Grund der Befunde wurde die Hypothese formuliert, daß die Methylierung der DMR2 des paternalen Allels die Transkriptionsrate vom Igf2 erhöht und somit die Funktion eines positiven Regulators des paternalen Allels einnimmt. Die 54 bp-umfassende Region der DMR2, welche durch Murrell et al., 2001 deletiert wurde, wird heute daher als Kernregion bzw. als „core region“ der DMR2 bezeichnet.

Auf Grund dieser Daten wurde in der vorliegenden Arbeit die DMR2 auf Methylierungsveränderungen im Tumor untersucht. Die dafür verwendete Hybridisierungssonde 6 wurde in Feil et al., 1994 erstmalig beschrieben und zum Nachweis Methylierung des paternalen Allels im Embryo verwendet (Abb. 15 und Abb. 16).

Ein wichtiger Befund der Untersuchungen (siehe Southern-Blot Abb. 18) stellt der Unterschied in den Bandenintensitäten des Fragmentes DMR2-F7 (354 bp) dar, welcher auf einen 
differentiellen Methylierungsstatus der Schnittstellen H1 und H2 zwischen RMS und Muskel hinwies. Da dieses Fragment im Southern-Blot eindeutig stärker im RMS hybridisiert wurde, kann von einer Hypomethylierung der Schnittstellen H1 und H2 im Tumor ausgegangen werden. Die H1-Schnittstelle liegt zudem in der Kernregion der DMR2 (siehe Abb. 32).

Ein weiterer sehr interessanter Befund betraf den Intensitätsunterschied des Fragmentes DMR2F4 (2193 bp) zwischen RMS und Normalgewebe. Die schwache Intensität dieses Fragmentes wies auf eine Hypermethylierung der Schnittstelle H4 im RMS hin.

Mittels Bisulfit-Sequenzierung wurde der Methylierungsgrad der CpGs dieser beiden DMR2Bereiche ermittelt. Zur Untersuchung des Bereichs, der die H1 und die H2 umfaßt, wurde ein 795 bp-Fragment aus Bisulfit-behandelter DNA des RMS und des Skelettmuskels mit den Primern DMR2 H1 (siehe Tab. 23) amplifiziert und subkloniert. Bei keinem der untersuchten 24 CpGs in diesem Fragment konnte ein signifikanter Methylierungsunterschied gefunden werden. Selbst bei den CpGs 12 und 24, die die Schnittstellen H1 und H2 repräsentieren, war der Methylierungszustand zwischen RMS und Skelettmuskel im $\mathrm{Chi}^{2}$-Test nicht signifikant.

Dieser Befund kontrastiert zunächst mit der Aussage des Southern-Blots, bei dem eine Hypomethylierung der beiden Schnittstellen festgestellt worden war. Werden jedoch die Methylierungsverhältnisse in RMS und normalen Muskel unabhängig von $\mathrm{Chi}^{2}$-Test betrachtet, so kann eine Tendenz zur Hypomethylierung im Tumor an den beiden Schnittstellen festgestellt werden. So waren an der H1 Schnittstelle im normalen Muskel $44 \%$ der Cytosine methyliert, wogegen es im Tumor nur $24 \%$ waren. An der H2-Schnittstelle waren im normalen Muskel $55 \%$ der Cytosine methyliert, im RMS dagegen nur $48 \%$. Dies deutet darauf hin, daß tatsächlich ein leichter Methylierungsunterschied zwischen Muskel und Tumor an diesen beiden Schnittstellen bestehen könnte. Es wäre daher sehr sinnvoll, dieselbe Analyse an weiteren RMS und SM durchzuführen. Im Falle einer tatsächlich vorliegenden Hypomethylierung dieser Region im Tumor stände dieser Befund im Kontrast zu der aufgestellten Hypothese, bei der vielmehr eine Hypermethylierung in dieser Region erwartet worden wäre.

Für die Untersuchung der Methylierungsveränderung zwischen Tumor und Referenz der DMR2 im Bereich des Exons 4 an der Schnittstelle H4 wurde zunächst ein 635 bp-Fragment (Tab. 23; DMR2 H4 Primer) aus Bisulfit-behandelter DNA des RMS und des Skelettmuskels amplifiziert und subkloniert. Dieses Fragment beinhaltet neben der H4-Schnittstelle auch die H5Schnittstelle und weitere 11 CpGs. In fünf der untersuchten CpGs (CpG 2, 4, 6, 9 und 11) wurde ein signifikanter Methylierungsunterschied zwischen RMS und SM festgestellt. Hierbei waren diese CpGs im RMS stärker methyliert als im SM. Für ein weiteres CpG (CpG 8) lag der Methylierungsunterschied knapp unter der Signifikanzgrenze (siehe Abb. 33). 
Eines der methylierten CpGs (CpG 6) ist Bestandteil der H5-Schnittstelle, an der der SouthernBlot zunächst keine Hypermethylierung im RMS vermuten ließ (Abb. 18). Dagegen gab der Southern-Blot Hinweise auf eine vermehrte Methylierung an der H4-Schnittstelle, für die jedoch der Methylierungsunterschied bei der Analyse im $\mathrm{Chi}^{2}$ Test nicht signifikant war (siehe Abb. 33; CpG 13). Jedoch ist auch hier wiederum festzustellen, daß bei einer vom $\mathrm{Chi}^{2}$ Test unabhängigen Betrachtung der Methylierungsergebnisse eine Tendenz zur Hypermethylierung des CpG 13 im RMS festgestellt werden kann. So waren 5 \% der Cytosine im normalen Muskel methyliert, im RMS dagegen $10 \%$.

Das Ergebnis der Bisulfit-Sequenzierung konnte in der Analyse des Tumors und des Muskels einer weiteren Maus bestätig werden. Da die Bisulfit-Sequenzierung im Gegensatz zur Southern-Blotanalyse die exaktere und direktere Methode zur Bestimmung von Methylierungsunterschieden darstellt, kann somit die Aussage getroffen werden, daß im RMS von heterozygoten Ptch-Mäusen eine Hypermethylierung im Bereich der kodierenden Region des Igf2-Gens im Exon 4 vorliegt

Über den Einfluss dieser Region auf die Expression des $I g f 2$-Gens sowie über Methylierungsgrad bei der Tumorigenese liegen keine Hinweise in der Literatur vor. Es kann somit davon ausgegangen werden, daß eine neue Region im Exon 4 des Igf2-Gens identifiziert worden ist, die auf Grund der verstärkten Methylierung distinkter CpGs an der Überexpression des paternalen Allels in RMS heterozygoter Ptch-Mutanten beteiligt sein kann. Interessanterweise ist die DMR 2 im Bereich des Exons 4-6 zwischen Mensch und Maus hochkonserviert. Daher sollte diese Region auch in humanen $P T C H$-assoziierten RMS untersucht werden. Im Rahmen dieser vorliegenden Arbeit war eine solche Analyse jedoch nicht durchzuführen. Weitere Untersuchungen könnten Aufschluß darüber geben, ob die beobachtete de novo-Methylierung (im Bereich des Exons 4) ein allgemeines Merkmal von PTCH/ Ptchassoziierten Tumoren ist. 


\subsection{Konsensus-Sequenzen im Igf2-Lokus weisen auf eine Gli- vermittelte Transkription hin}

Neben den Untersuchungen von epigenetischen Veränderungen am Igf2-Lokus in heterozygoten Ptch-Mäusen stand im Fokus der vorliegenden Arbeit die Untersuchung des Einflusses der GliTranskriptionsfaktoren auf die Igf2-Expression.

\subsubsection{Gli-Transkriptionsfaktoren und ihre Rolle als Mediatoren des Shh- Signalweges in der Tumorigenese}

Wie bereits in der Einleitung beschrieben, sind Gli Zink-Finger-Transkriptionsfaktoren die direkten Übermittler der Aktivierung der Shh-Signalkaskade (Kinzler et al., 1987; Arheden et al., 1989a; Ruppert et al., 1990; Kas et al., 1996; Matsumoto et al., 1996). Dies trifft sowohl auf die physiologische Aktivierung durch Bindung von Shh and Ptch zu als auch auf die pathologische Aktivierung des Shh-Signalweges im Falle einer Ptch-Mutation.

Die Aktivität der multifunktionalen Proto-Onkogene Gli ist gewebespezifisch reguliert. Dabei können sie sowohl als Aktivatoren als auch als Repressoren ihrer Zielgene wirken (Ruiz it Altaba et al., 1999b; Ohlmeyer et al., 1999; Sasaki et al., 1999; Bai et al., 2002). In der Maus scheinen Gli2 und Gli3 frühe Mediatoren des Shh-Signals darzustellen, wogegen Gli1 eine Verstärkung der Antwort auslöst (Sasaki et al., 1999c; Bai et al, 2002). Aufgrund ihrer redundanten Wirkung wird vermutet, daß die Gli-Faktoren in Kombination gewebespezifisch miteinander interagieren (Ruiz i Altaba et al., 2002a). Humanes GLI1 wurde erstmalig als amplifiziertes Gen in Glioblastomen beschrieben (Kinzler et al., 1987) und führt zu einer malignen Transformation von Zellen in vitro (Louro et al., 2002). GLI1 konnte ebenfalls als amplifiziertes Gen in Basaliomen, Osteosarkomen, Rhabdomyosarkomen und B-ZellLymphomen nachgewiesen werden (Dahmane et al., 1997; Ghali et al., 1999; Roberts et al., 1989; Werner et al., 1997). Eine erhöhte Expression des GLI2-Gens wurde in humanen Basalzellkarzinomen beschrieben (Tojo et al., 2003). Eine Überexpression von GLI3 konnte bisher weder in humanen noch in murinen Tumoren nachgewiesen werden.

In der Arbeit von Kimura et al., 2005 ließen sich Fibroblasten durch eine Tranfektion mit Gli1 transformieren, wogegen durch Gli2-Transfektion eine schwächere Transformation induziert wurde. Eine Gli3-Transfektion führte zu keiner pathologischen Veränderung der Fibroblasten. Diese Experimente führten zu der Schlussfolgerung, daß Glil den stärksten Aktivator der induzierten Transformation in Fibroblasten darstellt.

Eine große Anzahl an Zielgenen des Shh-Signalweges konnten identifiziert werden, die durch die Gli-Transkriptionsfaktoren reguliert werden. Als direkte Zielgene des Shh-Signals wurden die Gene Wnt, Bmp, Pdgfa, Igf2 und Ptch identifiziert (Dai et al., 2001; Polakis et al., 2000; 
200; Hahn et al., 2000). Auf Grund von DNA-Gli-Interaktionen wurden auch HNF-3B, Cyclin D2, IGFBP-6, Osteopontin und Plakoglobin als Gli-Zielgene postuliert (Yoon et al., 2002; Sasaki et al., 1997).

\subsubsection{Der Igf2-Lokus enthält Gli-Konsensus-Sequenzen}

Wie im Ergebnisteil dargestellt ist, konnten fünf potentielle Gli-Konsensus-Sequenzen im Igf2Lokus detektiert werden (Abb. 35). Hierzu wurde der Igf2-Lokus auf alle bisher in der Literatur beschriebenen Gli-Bindungsstellen durchsucht. Die erste der fünf Bindungsstellen liegt stromabwärts des Insulin-Lokus, der 15 kb vom Igf2-Lokus entfernt ist. Auf Grund der Distanz zum Igf2-Gen ist anzunehmen, daß diese Bindungsstelle höchstwahrscheinlich keinen Einfluß auf die Igf2-Expression ausübt. Eine weitere Gli-Bindungsstelle, die jedoch in einem Basenpaar einen Mismatch zu der von Regl et al., 2004 publizierten Sequenz zeigte, konnte im Promotor P0 identifiziert werden. Eine weitere Bindungsstelle ist in der DMR1 und zwei weitere in der DMR2 lokalisiert. Gli-Transkriptionsfaktoren könnten daher an der Kontrolle der Igf2Expression beteiligt sein.

\subsection{Ptch-assoziierte RMS zeigen eine Überexpression von Gli1 und Gli3}

Falls die identifizierten Gli-Bindungsstellen tatsächlich über die Bindung von GliTranskriptionsfaktoren zur vermehrten Expression des Igf2-Gens im RMS beitragen sollten, dann müßte einer oder mehrere dieser Transkriptionsfaktoren in diesen Tumoren nachweisbar sein. Für den Nachweis der Gli-Transkriptionsfaktoren im RMS wurde eine semi-quantitative PCR durchgeführt (Abb. 36). Die Expressionsanalyse der Gli Transkriptionsfaktoren zeigte neben einer bereits bekannten Überexpression von Glil (Hahn 1998) eine starke Überexpression von Gli3 im RMS gegenüber dem normalen Muskel. Eine Überexpression von Gli3 konnte bisher weder in humanen noch in murinen Tumoren nachgewiesen werden. Diese Daten zeigen, daß die Transkriptionsfaktoren Gli1 und Gli3 (einzeln oder aber zusammen) potentielle Aktivatoren der Igf2-Expression in RMS darstellen könnten. Eine Expression von Gli2 konnte weder in den Tumoren noch im Muskelgewebe festgestellt werden. 


\subsection{Gli1/ Gli3-Kombination führt zu einem Anstieg der Expression des Igf2-Gens in vitro}

In Fokus des zweiten Teils der vorliegenden Arbeit stand die Untersuchung des Einflusses der Gli-Transkriptionsfaktoren auf die endogene Expression des Igf2-Gens. Unter diesem Aspekt wurden Zellkulturexperimente durchgeführt, bei denen der Einfluß der GliTranskriptionsfaktoren auf die Expression des Igf2-Gens mittels quantitativer real-time PCR, sowie Luziferase- und $\beta$-Galaktosidase-Reporter Assays untersucht wurde.

\subsubsection{Igf2-Expression kann durch Ko-Expression von Gli1 und Gli3 in den Zelllinien C2C12, TP1588, TP5014 und NIH/ 3 T3 stimuliert werden}

Zum Nachweis der Gli-induzierten endogenen Expression des Igf2-Gens wurden vier Zelllinien ausgewählt: die myogene Zelllinie $\mathrm{C} 2 \mathrm{C} 12$ und zwei immortalisierte myogene RMS-Zelllinien TP1588 und TP5014, die aus Tumoren heterozygoter Ptch-Mäusen gewonnen wurden, sowie die Fibroblasten-Zelllinie NIH/ 3 T3.

In den myogenen Zelllinien konnte keine endogene Igf2-Expression festgestellt werden. Auch wurde Gli2 weder in den untersuchten Zelllinien noch im nativen RMS exprimiert. Im Gegensatz zum nativen RMS wurde Glil nicht in den myogenen Zelllinien exprimiert. Endogenes Gli3 dagegen konnte in allen myogenen Zelllinien detektiert werden. Hierbei ist zu betonen, daß die $\mathrm{C} 2 \mathrm{C} 12$ Zelllinie kaum Gli3 exprimiert, die Zelllinie TP1588 dagegen etwas stärker.

In Fibroblastenzellen, die nicht myogenen Ursprungs sind, liegt eine verstärkte Expression sowohl von Gli1 als auch von Gli3 vor. Gli2 wurde nicht exprimiert, ebensowenig Igf2.

Die Transfektion der Zelllinien C2C12, TP1588, TP5014 und NIH/ 3T3 erfolgte mit den Expressionsplasmiden von Gli1 und Gli3 als auch in der Kombination Gli1/ Gli3. Nach $48 \mathrm{~h}$ wurde eine relative Quantifizierung der endogenen Igf2-Expression mittels quantitativer realtime PCR durchgeführt. Es zeigte sich schon nach einfacher Gli1-Transfektion ein Anstieg der Igf2-Expression in den Zelllinien TP1588 und TP5014, die bereits endogenes Gli3 exprimieren. Ein solcher Anstieg vom Igf2 wurde dagegen in $\mathrm{C} 2 \mathrm{C} 12$ als auch in NIH/ 3T3-Zellen nur durch eine Kotransfektion von Glil und Gli3 hervorgerufen.

Zusammenfassend lassen die Untersuchungen folgende Schlussfolgerung zu:

Die Induktion der Igf2-Expression scheint in allen vier untersuchten Zelllinien durch die gemeinsamen Expression der Transkriptionsfaktoren Glil und Gli3 beeinflußt zu werden. Da die RMS-Zelllinien endogen Gli3 exprimieren, bewirkt schon die alleinige Transfektion von Gli1 einen Anstieg der endogenen Expression von Igf2. Durch eine Kotransfektion von Gli1 
und Gli3 wird die Igf2-Expression zusätzlich noch gesteigert, was durch einen Dosiseffekt zu erklären ist. In $\mathrm{C} 2 \mathrm{C} 12$ Zellen, die nur sehr wenig endogenes Gli3 exprimieren, reicht die Transfektion von Gli1 nicht aus, um die Igf2-Expression zu stimulieren. Erst die Kotransfektion von Glil und Gli3 führt zu einer erhöhten endogenen Expression des Igf2-Gens.

Ähnliches trifft auf die Fibroblastenzelllinie NIH/ 3T3 zu: Erst nach Transfektion dieser Zellen mit beiden Transkriptionsfaktoren wird die Igf2-Expression stimuliert. Unklar ist dabei, warum NIH/ 3T3-Zellen per se kein Igf2 exprimieren, obwohl eine sehr hohe endogene Expression von Gli1 und Gli3 vorliegt: Dies kann möglicherweise durch die nicht-myogene Herkunft der Zelllinie zu erklären sein. So könnten notwendige Ko-Faktoren fehlen. Andererseits ist denkbar, daß die in NIH/ 3T3-Zellen exprimierten Gli-Faktoren nicht funktionell sind.

Durch Transfektion der Fibroblastenzellen mit Gli2, Gli1/ Gli2 und Gli2/ Gli3 konnte keine Igf2-Expression induziert werden. In myogenen $\mathrm{C} 2 \mathrm{C} 12$ und Tumorzellinien dagegen führte die Transfektion von Gli2 zu einer Stimulierung der Igf2-Expression So scheint der Gli2Transkriptionsfaktor, abhängig vom zellulären Kontext, ebenfalls zu einer Stimulierung der Igf2-Expression zu führen. Gli2 scheint jedoch in RMS auf Grund seiner fehlenden Expression keine Rolle bei der Entstehung dieser Tumoren in vivo $\mathrm{zu}$ spielen. Daher wurde auf Folgeexperimente verzichtet.

\subsubsection{Ein 8.1 kb Fragment stromaufwärts des Igf2-Translationsstarts ist notwendig für die Gli1 und Gli3 induzierte Igf2-Expression}

Die dargestellten Ergebnisse zeigten, daß sich die endogene Igf2-Expression in NIH/ 3T3 Zellen am effizientesten durch die Transkriptionsfaktoren Gli1 und Gli3 stimuliert lässt. Um eine Aussage über die mögliche Funktionalität der im Igf2-Lokus identifizierten Gli-KonsensusSequenzen zu treffen, wurden in Transfektionsexperimenten zwei Cosmide IgflacZB und H19eIgflacZ verwendet, wobei das LacZ-Gen in frame in den offenen Leserahmen des Igf2 Gens eingebracht wurde (siehe Abb. 44; Pravtcheva und Wise, 1998). Mit beiden Cosmiden konnte über die $\beta$-Galaktosidase-Färbung eine Aussage über die transkriptionelle Aktivierung von Igf2 getroffen werden. Die Cosmide enthalten eine 8100 bp umfassende DNA-Sequenz stromaufwärts vom Translationsstart des Igf2-Gens. Die Exone U1 und U2 sind daher in den Cosmiden nicht mehr enthalten. Somit entfallen auch die ersten drei im Igf2-Lokus identifizierten Gli-Bindungsstellen (Tab. 33). Die Gli-Konsensus-Sequenz 5, die im 3 ' - untranslatierten Bereich des Igf2-Gens lokalisiert ist, wurde durch die Insertion des LacZGens deletiert. Somit kann durch den $\beta$-Galaktosidase-Reporter-Assay nur die Funktionalität der Gli-Bindungsstelle, die im Intron 3 von $\operatorname{Ig} / 2$ lokalisiert ist, untersucht werden. Die Transfektionsexperimente mit Gli1/ Gli3 wurden in der Fibroblasten-Zelllinie NIH/ 3T3 durchgeführt. Im Kontrollexperiment wurden die Cosmide zunächst mit Jun- und Fos- 
Expressionsvektoren kotransfiziert, da über eine Ap1-Konsensus-Sequenz im Promotor P3 des Igf2-Gens die Igf2-Expression stimuliert wird (Abb. 45; Caricasole und Ward, 1993). Nach Gli1-/Gli3-Kotransfektion konnte mit dem IgflacZB-Konstrukt eine neunfach höhere Reporteraktivität als nach Jun-/ Fos-Kotransfektion hervorgerufen werden. Eine zweifach höhere Reporteraktvität gegenüber der Stimulierung mit Jun/ Fos wurde im H19eIgfLacZKonstrukt beobachtet (Abb. 45). Das H19eIgfLacZ-Konstrukt enthält am 3` -Ende zusätzlich zwei endodermale Enhancer-Elemente, die eine Rolle bei der Igf2-Expression spielen (siehe Abb. 44). Das Einfügen dieser Elemente führt dabei zu einer Vergrößerung des Cosmids um $7 \mathrm{~kb}$. In H19eIgfLacZ transgenen Mäusen führen die Enhancer-Elemente hierbei zu einer Hypomethylierung im gesamten Bereich zwischen Exon 1 und Exon 6 des Igf-Gens (Prachteva und Wise, 1998). Der Unterschied der Reporteraktivität der Cosmide nach Gli1-/ Gli3Kotransfektion kann daher durch drei Mechanismen bedingt sein: a) es ist möglich, daß die Größe des Cosmids einen Einfluß auf die Transfektionseffizienz hat b) es ist möglich, daß NIH/ 3T3-Zellen den Repressor CTCF exprimieren, der vermehrt an das - höchstwahrscheinlich nicht methylierte H19eIgfLacZ-Konstrukt bindet und dadurch die Expression vom Igf2 hemmt. c) Die letzte Möglichkeit ist diejenige, daß die Bindung von Gli-Transkriptionsfaktoren an die potentielle Gli-Bindungsstelle im Igf2-Lokus bei verminderter Methylierung (wie sie im Cosmid H19eIgfLacZ möglich ist) nicht effizient ist. Um letzteres zu bestätigen, müßte zunächst überprüft werden, ob das Cosmid H19eIgfLacZ im Vergleich zu IgflacZB tatsächlich nach der Transfektion hypomethyliert ist.

Trotz dieser offenen Fragen konnte mit Hilfe dieses Experimentes gezeigt werden, daß die im Intron 3 der Cosmide lokalisierte Gli-Bindungsstelle wahrscheinlich einen Einfluß auf die Induktion der Igf2-Expression ausübt.

\subsubsection{Induktion von $\operatorname{Ig} / 2$ durch Gli1 und Gli3 wird nicht nur über die Gli-Bindungsstelle im Intron 3 vermittelt}

Zur weiteren Analyse der Gli-Bindungsstelle im Intron 3 des Igf2-Gens wurde der regulatorische Bereich eingegrenzt und mit Hilfe von drei verschieden großen Promotordeletionskonstrukte vom Igf2-Gen untersucht. Über die Quantifizierung der Luziferase-Aktivität war es möglich, Rückschlüsse auf die Aktivierung de Promotorkonstrukte zu ziehen. Alle drei Promotorkonstrukte enthalten den Promotor P3. Zwei der Reporterkonstrukte, $\mathrm{pP} 3 \mathrm{~L}$ und $\mathrm{pP} 3 \mathrm{M}$, enthalten die im Intron 3 beschriebene GliBindungsstelle. Im Konstrukt pP3MM wurde das Intron 3 und somit die hier enthaltene GliBindungsstelle deletiert. Nach der Kotransfektion der Reporterkonstrukte mit Gli1/ Gli3 konnte mit keinem der drei Konstrukte eine Induktion der Luziferase festgestellt werden (Abb. 48). 
Dieses Experiment zeigt, daß die Gli-Bindungsstelle im Intron 3 vom Igf2 für eine Gliinduzierte Stimulation des Promotors P3 nicht ausreicht. Eine mögliche Erklärung liegt im Fehlen der Promotoren P1 und P2, die im Gegensatz zu den Cosmiden in den Reporterkonstrukten nicht enthalten sind. Vorstellbar ist die Beteiligung weiterer regulatorischer Elemente, die durch Interaktionen mit Gli1 und Gli3 eine mögliche Stimulierung der Igf2-Expression induzieren. Eine weitere Erklärung besteht in der Existenz von anderen, bisher unbekannten Gli-Konsensus-Sequenzen, die ebenfalls im Igf2-Lokus lokalisiert sein können und die in den Luziferasekonstrukten, im Gegensatz zu den Cosmiden, nicht mehr vorhanden sind. Ein Hinweis auf die Existenz solcher Bindungsstellen wurde in Hallikas et al. 2006 gegeben.

\subsection{Verschiedene Mechanismen verdichten sich zu einem Modell der Igf2-Überexpression in RMS}

Die aberrante Aktivierung von Signalwegen führt oft zu veränderter Genexpression in den betroffenen Zellen. Dafür kann einerseits die veränderte Aktivität von Transkriptionsfaktoren verantwortlich sein. Oft kommt es aber auch zu epigenetischen Modifikationen in der Chromatinstruktur bestimmter Genomabschnitte (Reik und Dean, 2001). Sowohl die veränderte Aktivität von Transkriptionsfaktoren, als auch epigenetische Veränderungen können in tumorigene Prozesse involviert sein. Im RMS liegt eine Aktivierung der Igf2-Promotoren P1, P2 und P3 vor, nicht jedoch des Promotors P0. Die Aktivierung der drei Promotoren führt zu einer Überexpression aller bekannten Igf2-Transkripte, die durch diese Promotoren reguliert werden können. Eine Aktivierung aller Igf2-Promotoren weist auf einen regulatorischen Mechanismus hin, der sowohl am Promotor P1 als auch an P2 und P3 angreift.

Die Analyse der Methylierungsveränderungen der DMR0, DMR1, DMR2 und der H19-DMD, deren Methylierungsstatus eine wesentliche Rolle in der Expression des paternalen Allels des Igf2-Gens spielen, zeigte im RMS in zwei Regionen eine signifikante Methylierungsveränderung im Vergleich zum Normalgewebe. Ein Bereich der DMR1 liegt im RMS hypomethyliert vor. Es ist bekannt, daß Hypomethylierungen von Genen in einer Anzahl von Tumoren zu einer Reaktivierung von Onkogenen führt (DeSmet et al., 1999; Gupta et al., 2003). Dies könnte auch als Ursache der Überexpression von Igf2 in Ptch-assoziierten RMS angesehen werden und würde die durch das Demethylierungsagens 5-Aza-Cytidin induzierte Igf2-Überexpression in der RMS-Zelllinie TP5014 erklären. Auf der anderen Seite wurde in der DMR2 eine signifikante Hypermethylierung im RMS nachgewiesen. Für diesen Bereich konnte beim Menschen gezeigt werden, daß eine Hypermethylierung bei der Aktivierung des 
paternalen IGF2-Allels gewebsspezifisch eine Rolle spielt (Schneid et al., 1993). Ähnliche Studien in der Maus lagen in der Literatur nicht vor. Da Hypermethylierungen von CpG-Inseln zu Histonmodifikationen (Antequera et al., 1990) und Veränderungen der Chromatinstruktur führen (Song et al., 2005; Strichman-Almashanu et al., 2002) und bei der Tumorentstehung eine wichtige Rolle spielen (Issa; 2004), ist es möglich, daß die Hypermethylierung der DMR2 in den hier untersuchten Tumoren zu einer erhöhten Expression des paternalen Igf2-Allels beiträgt. Die Tatsache, daß im Igf2-Lokus eine Region hypomethyliert, die andere hypermethyliert vorliegt, ist in keiner Weise widersprüchlich. Kluster von hypomethylierten Regionen, die von hypermethylierten Regionen gefolgt werden (und vice versa), wurde in sporadischen kolorektalen Tumoren beschrieben (Herman und Baylin, 2003; Jones und Baylin, 2002).

In vitro Untersuchungen der transkriptionellen Mechanismen der Überexpression des Igf2-Gens zeigten, daß die Kombination der Transkriptionsfaktoren Gli1 und Gli3 für die Expression von Igf2 notwendig ist. Auch im nativen RMS liegt eine Überexpression beider Transkriptionsfaktoren vor, was zu der Schlußfolgerung führt, daß beide Proto-Onkogene an der Transformation zum RMS beteiligt sein können. Im Igf2-Lokus konnten durch bioinformatische Analyse fünf potentielle Gli-Konsensus-Sequenzen identifiziert werden. Eine im Intron 3 lokalisierte Gli-Bindungsstelle wurde auf ihre Funktionalität untersucht. In Reporterkonstrukten, die ein 8100 bp großes Fragment mit allen drei Promotoren P1 - P3 von Igf 2 beinhalteten, konnte eine Stimulierung der endogenen Expression des Genes Ig 2 durch die Transkriptionsfaktoren Gli1 und Gli3 bestätigt werden. Dagegen zeigten die ReporterKonstrukte, welche nur die Gli-Bindungsstelle und den Promotor P3 beinhalteten, nach Kotransfektion von Gli1 und Gli3 keine Aktivität. Eine mögliche Erklärung liegt in dem Fehlen der Promotoren P1 und P2 in diesen Deletionskonstrukten, die Bindungsstellen weiterer regulatorischer Elemente, die an der Aktivierung vom Igf 2 beteiligt sind, enthalten. Eine andere Möglichkeit liegt in der Existenz weiterer unbekannter Gli-Konsensus-Sequenzen im Igf2Lokus, die ebenfalls nicht in den Promotordeletionskonstrukten, dafür aber in den LacZKonstrukten enthalten sind.

Ein direkter Zusammenhang zwischen modifizierter DNA und der damit verbundenen Veränderung der Chromatinstruktur und der transkriptionellen Regulierung des Igf2-Gens durch die Gli-Transkriptionsfaktoren konnte durch die durchgeführten Experimente nicht gezeigt werden. Dennoch ist vorstellbar, daß die Funktion von Gli1 und Gli3 vom Methylierungszustand des Igf2-Lokus beeinflusst werden. Es ist möglich, daß die identifizierte Hypermethylierung der DMR2 und/ oder Hypomethylierung der DMR1 zu einer effektiveren Funktion der Gli Transkriptionsfaktoren beitragen. 


\subsection{Zusammenfassung der Arbeit}

$\mathrm{Zu}$ den zahlreichen Fragen, die sich zum Verständnis der Tumorentstehung und der Progression von RMS aus Ptch-Mutanten stellen, gehörte die Analyse der Mechanismen, die zu einer paternalen Überexpression des mitogenen Wachstumsfaktors $\operatorname{Ig} 2$ führen.

Die Untersuchungen der Promotoraktivität vom Igf2 mittels semi-quantitativer RT-PCRs zeigten eine Überexpression der Transkripte T1, T2 und T3, die durch die Promotoren P1, P2 und P3 reguliert werden. Es konnte ausgeschlossen werden, daß unbekannte Spleißvarianten exprimiert werden. Dies ließ die Schlussfolgerung zu, daß regulatorische Mechanismen wie DNA-Modifikationen oder Transkriptionsfaktoren in die Überexpression vom Igf2 in RMS involviert sein müssen.

Zunächst konnte in dieser Arbeit verifiziert werden, daß die Überexpression von $\operatorname{Ig} f 2$ in RMS nicht durch den Verlust der Prägung des maternalen Igf2 Allels zustande kommt. In zwei Regionen des Igf2-Lokus konnten im RMS signifikante Methylierungsveränderungen gefunden werden. Ein Bereich umfaßt einen Teil der DMR1, welche im Tumor im Vergleich zum Normalgewebe hypomethyliert ist. Der zweite Bereich umfaßt das Exon 4 in der DMR2, welcher im RMS im Vergleich zum Normalgewebe hypermethyliert vorliegt. Die Methylierungsveränderungen betreffen hierbei Bereiche, von denen nicht bekannt ist, daß sie in die Regulation der Igf2-Gen Expression involviert sind.

Ein weiterer Fokus der Arbeit stellte die Untersuchung von transkriptionellen Mechanismen dar, die an einer Überexpression des Igf2-Gens in Ptch-assoziierten Tumoren beteiligt sein können. Igf2 stellt ein Zielgen des in RMS abnormal aktivierten Shh-Signalweges dar. Mediatoren dieses Signals sind die Proto-Onkogene der Gli-Familie, die entscheidend als Aktivatoren auf die Expression von Zielgene des Shh-Signalweges einwirken. Im Rahmen der vorliegenden Arbeit konnten durch bioinformatische Recherchen fünf Gli-Konsensussequenzen im Igf2-Lokus nachgewiesen werden, die auf ihre Funktionalität hin überprüft wurden. In Zellkulturexperimenten mittels quantitativer real-time PCR konnte der Nachweis erbracht werden, daß Gli1 in der Kombination mit Gli3 zu einer bis zu elffachen Aktivierung der endogenen Expression vom Igf2 führt. Um die Funktionalität der im Igf2-Lokus identifizierten Gli-Konsensus-Sequenzen zu überprüfen, wurden im $\beta$-Galaktosidase-Reporter-Assay zwei LacZ-Konstrukte verwendet, in denen nach Stimulierung mit Gli1/ Gli3 eine bis zu neunfache Reporteraktivität $\mathrm{zu}$ verzeichnen war. Promotordeletionskonstrukte dagegen wiesen im Luziferase-Reporter-Assay nach Kotransfektion mit Gli1/ Gli3 keine Luziferaseaktivität auf. 


\subsection{Ausblick}

Ein direkter Zusammenhang zwischen modifizierter DNA und der damit verbundenen Veränderung der Chromatinstruktur sowie der transkriptionellen Regulierung des Igf2-Gens durch die Gli-Transkriptionsfaktoren konnte durch die hier durchgeführten Experimente nicht nachgewiesen werden. Ziel weiterer und an diese Arbeit anküpfender Studien sollte es sein, einen solchen Zusammenhang herzustellen. Dabei wäre es unter anderem interessant, mit stabil transfizierte IgfLacZB und H19eIgfLacZ Zelllinien, oder aber Zelllinien aus IgfLacZB- oder H19eIgfLacZ-transgenen Mäusen zu arbeiten. Die Enhancer-Elemente im Konstrukt H19eIgfLacZ führen zu einer Hypomethylierung im gesamten Bereich zwischen Exon 1 und Exon 6 des Igf2-Gens (Prachteva und Wise, 1998). Würde sich nun bestätigen, daß die Kotransfektion von Gli1/ Gli3 in den IgfLacZB-exprimierenden Zellen tatsächlich zu einer vermehrten Igf2-Stimulation im Vergleich zu H19eIgfLacZ-exprimierenden Zellen führt, wäre dies ein direkter Nachweis dafür, daß die Aktivität der Gli-Transkritionsfaktoren am Igf2-Lokus von einer vermehrten Methylierung abhängt. Ein weiteres Experiment, welches den Nachweis erbringen würde, daß die DNA-Hypermethylierung der DMR2 mit den GliTranskriptionsfaktoren interagiert und zu einer Überexpression des $I g / 2-G e n s$ führt, bestünde beispielsweise in der Herstellung eines Reporterkonstruktes, welches den Promotor 3, das Intron 3 mit der Gli-Bindungsstelle und das Exon 4 enthält und in frame in den offenen Leserahmen des Luziferasegenes gebracht wird. Nach einer in vitro-Methylierung des Konstruktes und Kotransfektion mit Gli1/ Gli3 könnte nicht nur eine Aussage über den Einfluß der Methylierung der DMR2, sondern auch ihre Interaktion mit Gli-Transkriptionsfaktoren hinsichtlich der Igf2Expression getroffen werden.

Eine weitere bioinformatische Suche zum Nachweis substituierter Gli-Konsensus-Sequenzen in den Promotoren P1 - P3 würde sich als sinnvoll erweisen, da eine im Januar 2006 erschienene Publikation auf die Existenz solcher Bindungsstellen hindeutet (Hallikas et al, 2006). Mit Hilfe von Reporterkonstrukten müßte die Funktionalität dieser Bindungstellen untersucht werden. Falls nachweislich funktionelle Gli-Bindungsstellen im Igf2-Lokus identifiziert werden sollten, müßten sich CHIP- oder EMSA-Assays anschließen, um die direkte Interaktion der GliTranskriptionsfaktoren mit der DNA nachzuweisen.

Schließlich sollten weitere bioinformatische Recherchen anschlossen werden, mit Hilfe derer nach weiteren Regulatoren der Igf2-Expression gesucht werden. Diese Regulatoren können beispielsweise durch Gli1/ Gli3 regulierte Transkriptionsfaktoren sein, die dann wiederum, abhängig vom Methylierungsgrad des $I g f 2$-Lokus, die paternale $I g f 2$-Expression stimulieren. 


\section{Anhang}

\subsection{Nomenklatur und Abkürzungen}

Kursiv geschrieben sind Gennamen, die Namen zugehöriger mRNAs sowie wissenschaftliche Bezeichnungen für Begriffe, die aus dem Lateinischen entlehnt sind. Für Gennamen wurden die international standardisierten Abkürzungen verwendet.

Neben den konventionellen physikalischen Einheiten und chemischen Symbolen fanden folgende Abkürzungen Anwendung (einige sind dabei auch im Text erklärt):

$\begin{array}{ll}\text { Abb. } & \text { Abbildung } \\ \text { ATP } & \text { Adenosintriphosphat } \\ \text { bp } & \text { Basenpaar } \\ \text { BSA } & \text { bovine serum albumin (Rinderserumalbumin) } \\ \text { bzw. } & \text { beziehungsweise } \\ { }^{\circ} \text { C } & \text { Grad Celsius } \\ \text { ca. } & \text { circa } \\ \text { CIAP } & \text { calfintestinal phosphatase (alkaline Phosphatase aus dem Kälberdarm) } \\ \text { cDNA } & \text { complementary DNA (komplementäre DNA) } \\ \text { CI } & \text { Chloroform/ Isoamylalkohol (24 . 1) } \\ \text { CMV } & \text { Cytomegalovirus } \\ \text { cpm } & \text { counts per minute (radioaktive Zerfälle pro Minute) } \\ \text { CTP } & \text { Cytidintriphosphat } \\ \text { dCTP } & \text { desoxy- Cytidintriphosphat } \\ \text { DEPC } & \text { Diethylpyrocarbonat } \\ \text { dest. } & \text { destilliert } \\ \text { DMEM } & \text { Dulbeccos Modified Eagle Medium } \\ \text { DMSO } & \text { Dimethylsulfoxid } \\ \text { DNA } & \text { desoxy ribonucleic acid (Desoxyribonukleinsäure) } \\ \text { DNAase } & \text { Desoxyribonuklease } \\ \text { dNTPs } & \text { Desoxynukleotriphosphate } \\ \text { DTT } & \text { Dithiothreitol }\end{array}$


E. coli

EDTA

EGFP

engl.

et al.

FKS

fwd.

$x \mathrm{~g}$

GAPDH

Hadhsc

HPRT

IPTG

$\mathrm{kb}$

LacZ

LB

M

MB

MGB

MOPS

mRNA

nt

OD

PBS

PCI

PCR

$\mathrm{pH}$

rev.

RMS

RNA

RNase

RPMI

RT

SDS

SSC
Escherichia coli

Etylendiamintetraacetat

enhanced green fluorescent protein (verstärkt grün fluoreszierendes Protein)

englisch

et alteri

Fetales Kälberserum

forward (Design des Oligonukleotid am Vorwärtsstrang der DNA)

Erdbeschleunigung $\left(9,81 \mathrm{~m} / \mathrm{s}^{2}\right)$

Glycerinaldehyd-3- phosphat-Dehydrogenase

L-3-hydroxyacyl-Coenzym

Hypoxanthin-guanin-phosphoribosyl-Transferase

Isopropyl- $\beta$-thiogalaktopyranosid

Kilobasenpaare

$\beta$-Galaktosidase

Luria-Bertani Medium

Molarität

Medulloblastom

minor groove binder

3-(N-morpholino)-Propansulfonsäure

messenger Ribonukleinsäure

Nukleotide

optische Dichte

Phosphatgepufferte Salzlösung

Phenol/ Chloroform/ Isoamylalkohol (25: $24: 1)$

polymerase chain reaction

$\mathrm{pH}-\mathrm{Wert}$

reversed (Design des Oligonukleotid am Rückwärtsstrang der DNA)

Rhabdomyosarkom

ribonucleic acid (Ribonukleinsäure)

Ribonuklease

Roswell Park Memorial Institute Medium 1640

Raumtemperatur

sodiumdedocylsulfate (Natriumdedodecylsulfat)

standard saline citrate buffer (Standard-NaCl/ $\mathrm{NaCitrat-Lösung)}$ 


$\begin{array}{ll}\text { Tab. } & \text { Tabelle } \\ \text { Taq } & \text { Thermophilus aquaticus } \\ \text { TBE } & \text { Tris-Borat-EDTA-Puffer } \\ \text { TE } & \text { Tris-EDTA-Puffer } \\ \text { U } & \text { unit (Einheit der Enzymaktivität) } \\ \text { UTR } & \text { untranslatierte Region } \\ \text { UV } & \text { ultraviolettes Licht } \\ \text { vol } & \text { Volumenanteile } \\ \text { vol/ vol } & \text { Volumen pro Volumen } \\ \text { w/ vol } & \text { Gewicht pro Volumen } \\ \text { X-Gal } & \text { 5-Bromo-4-chloro-3-indolyl- } \beta \text {-Galaktosid } \\ \text { z. B. } & \text { zum Beispiel }\end{array}$

\subsection{Code der Nukleinsäuren}

$\begin{array}{cc}\text { A } & \text { Adenin } \\ \text { C } & \text { Cytosin } \\ \text { G } & \text { Guanin } \\ T & \text { Thymin } \\ \text { U } & \text { Uracil }\end{array}$




\section{Literaturverzeichnis}

Alberts B, Johnson A, Leweis J, Raff M, Roberts K, Walter P.

Molekular Biology of the Cell: Signaling Pathways that depend on regulated proteolysis.

New York Garland Publishing. IV International Organization of the Cell, 4. Auflage, 2002

Alcedo J, Ayzenzon M, Von Ohlen T, Noll M, Hooper JE.

The Drosophila smoothened gene encodes a seven-pass membrane protein, a putative receptor for the hedgehog signal.

Cell. 1996 Jul 26;86(2):221-32.

Antequera F, Boyes J, Bird A.

High levels of de novo methylation and altered chromatin structure at $C p G$ islands in cell lines.

Cell. 1990 Aug 10;62(3):503-14.

Arheden K, Nilbert M, Heim S, Mandahl N, Mitelman F.

No amplification or rearrangement of INT1, GLI, or COL2A1 in uterine leiomyomas with t(12;14)(q14-15; q23-24).

Cancer Genet Cytogenet. 1989a Jun;39(2):195-201

Arheden K, Ronne M, Mandahl N, Heim S, Kinzler KW, Vogelstein B, Mitelman F.

In situ hybridization localizes the human putative oncogene GLI to chromosome subbands

12q13.3-14.1.

Hum Genet. 1989b Apr;82(1):1-2.

Armitage P, Doll R.

The age distribution of cancer and a multi-stage theory of carcinogenesis. 1954.

Int J Epidemiol. 2004 Dec;33(6):1174-9. Epub 2004 Aug 19.

Aszterbaum M, Beech J, Epstein EH Jr.

Ultraviolet radiation mutagenesis of hedgehog pathway genes in basal cell carcinomas.

J Investig Dermatol Symp Proc. 1999a Sep;4(1):41-5.

Aszterbaum M, Epstein J, Oro A, Douglas V, LeBoit PE, Scott MP, Epstein EH Jr.

Ultraviolet and ionizing radiation enhance the growth of BCCs and trichoblastomas in patched heterozygous knockout mice.

Nat Med. 1999b Nov;5(11):1285-91.

Bai CB, Auerbach W, Lee JS, Stephen D, Joyner AL.

Gli2, but not Gli1, is required for initial Shh signaling and ectopic activation of the Shh pathway.

Development. 2002 Oct;129(20):4753-61.

Beer C, Buhr P, Hahn H, Laubner D, Wirth M.

Gene expression analysis of murine cells producing amphotropic mouse leukaemia virus at a cultivation temperature of 32 and 37 degrees $C$.

J Gen Virol. 2003 Jul;84(Pt 7):1677-86. 
Bell AC, Felsenfeld G.

Methylation of a CTCF-dependent boundary controls imprinted expression of the Igf2 gene.

Nature. 2000 May 25;405(6785):482-5.

Bigelow RL, Chari NS, Unden AB, Spurgers KB, Lee S, Roop DR, Toftgard R, McDonnell TJ.

Transcriptional regulation of bcl-2 mediated by the sonic hedgehog signaling pathway through gli-1.

J Biol Chem. 2004 Jan 9;279(2):1197-205. Epub 2003 Oct 10.

Birnboim HC, Doly J.

A rapid alkaline extraction procedure for screening recombinant plasmid DNA.

Nucleic Acids Res. 1979 Nov 24;7(6):1513-23.

Brandeis M, Kafri T, Ariel M, Chaillet JR, McCarrey J, Razin A, Cedar H.

The ontogeny of allele-specific methylation associated with imprinted genes in the mouse.

EMBO J. 1993 Sep;12(9):3669-77.

Briscoe J, Chen Y, Jessell TM, Struhl G.

A hedgehog-insensitive form of patched provides evidence for direct long-range morphogen activity of sonic hedgehog in the neural tube.

Mol Cell. 2001 Jun;7(6):1279-91.

Brisken C, Ayyannan A, Nguyen C, Heineman A, Reinhardt F, Tan J, Dey SK, Dotto GP, Weinberg RA.

IGF-2 is a mediator of prolactin-induced morphogenesis in the breast.

Dev Cell. 2002 Dec;3(6):877-87. Erratum in: Dev Cell. 2003 Feb;4(2):283.

Caricasole A, Ward A.

Transactivation of mouse insulin-like growth factor II (IGF-II) gene promoters by the AP-1 complex.

Nucleic Acids Res. 1993 Apr 25;21(8):1873-9.

Cavenee WK, Dryja TP, Phillips RA, Benedict WF, Godbout R, Gallie BL, Murphree AL, Strong LC, White RL.

Expression of recessive alleles by chromosomal mechanisms in retinoblastoma.

Nature. 1983 Oct 27-Nov 2;305(5937):779-84.

Charalambous M, Menheniott TR, Bennett WR, Kelly SM, Dell G, Dandolo L, Ward A. An enhancer element at the Igf2/H19 locus drives gene expression in both imprinted and nonimprinted tissues.

Dev Biol. 2004 Jul 15;271(2):488-97.

Chen Y, Struhl G.

Dual roles for patched in sequestering and transducing Hedgehog.

Cell. 1996 Nov 1;87(3):553-63.

Chiariotti L, Brown AL, Frunzio R, Clemmons DR, Rechler MM, Bruni CB.

Structure of the rat insulin-like growth factor II transcriptional unit: heterogeneous transcripts are generated from two promoters by use of multiple polyadenylation sites and differential ribonucleic acid splicing.

Mol Endocrinol. 1988 Nov;2(11):1115-26. 
Chuang PT, McMahon AP.

Vertebrate Hedgehog signalling modulated by induction of a Hedgehog-binding protein.

Nature. 1999 Feb 18;397(6720):617-21.

Cihak A.

Biological effects of 5-azacytidine in eukaryotes.

Oncology. 1974 30(5):405-22.

Cohen MM Jr.

Nevoid basal cell carcinoma syndrome: molecular biology and new hypotheses.

Int J Oral Maxillofac Surg. 1999 Jun;28(3):216-23.

Cohen MM Jr.

The hedgehog signaling network.

Am J Med Genet A. 2003 Nov 15;123(1):5-28. Erratum in: Am J Med Genet. 2004

Feb;124A(4):439-40.

Constancia M, Dean W, Lopes S, Moore T, Kelsey G, Reik W.

Deletion of a silencer element in Igf2 results in loss of imprinting independent of H19.

Nat Genet. 2000 Oct;26(2):203-6.

Constancia M, Hemberger M, Hughes J, Dean W, Ferguson-Smith A, Fundele R, Stewart F,

Kelsey G, Fowden A, Sibley C, Reik W.

Placental-specific IGF-II is a major modulator of placental and fetal growth.

Nature. 2002 Jun 27;417(6892):945-8.

Cui H, Horon IL, Ohlsson R, Hamilton SR, Feinberg AP.

Loss of imprinting in normal tissue of colorectal cancer patients with microsatellite instability.

Nat Med. 1998 Nov;4(11):1276-80.

Cui H, Niemitz EL, Ravenel JD, Onyango P, Brandenburg SA, Lobanenkov VV, Feinberg AP. Loss of imprinting of insulin-like growth factor-II in Wilms' tumor commonly involves altered methylation but not mutations of CTCF or its binding site.

Cancer Res. 2001 Jul 1;61(13):4947-50.

Dagher R, Helman L.

Rhabdomyosarcoma: an overview.

Oncologist. 1999;4(1):34-44.

Dahmane N, Lee J, Robins P, Heller P, Ruiz i Altaba A.

Activation of the transcription factor Glil and the Sonic hedgehog signalling pathway in skin tumours.

Nature. 1997 Oct 23;389(6653):876-81. Erratum in: Nature 1997 Dec 4;390(6659):536.

Dai P, Akimaru H, Tanaka Y, Maekawa T, Nakafuku M, Ishii S.

Sonic Hedgehog-induced activation of the Glil promoter is mediated by GLI3.

J Biol Chem. 1999 Mar 19;274(12):8143-52.

De Smet C, Loriot A, Boon T.

Promoter-dependent mechanism leading to selective hypomethylation within the 5' region of gene MAGE-Al in tumor cells.

Mol Cell Biol. 2004 Jun;24(11):4781-90. 
DeChiara TM, Efstratiadis A, Robertson EJ.

A growth-deficiency phenotype in heterozygous mice carrying an insulin-like growth factor II gene disrupted by targeting.

Nature. 1990 May 3;345(6270):78-80.

DeChiara TM, Robertson EJ, Efstratiadis A.

Parental imprinting of the mouse insulin-like growth factor II gene.

Cell. 1991 Feb 22;64(4):849-59.

Eden S, Constancia M, Hashimshony T, Dean W, Goldstein B, Johnson AC, Keshet I, Reik W, Cedar $\mathrm{H}$.

An upstream repressor element plays a role in Igf2 imprinting.

EMBO J. 2001 Jul 2;20(13):3518-25.

Eggenschwiler JT, Espinoza E, Anderson KV.

Rab23 is an essential negative regulator of the mouse Sonic hedgehog signalling pathway.

Nature. 2001 Jul 12;412(6843):194-8.

Falls JG, Pulford DJ, Wylie AA, Jirtle RL.

Genomic imprinting: implications for human disease.

Am J Pathol. 1999 Mar;154(3):635-47.

Feil R, Walter J, Allen ND, Reik W.

Developmental control of allelic methylation in the imprinted mouse Igf2 and H19 genes.

Development. 1994 Oct;120(10):2933-43.

Feinberg AP, Oshimura M, Barrett JC.

Epigenetic mechanisms in human disease.

Cancer Res. 2002 Nov 15;62(22):6784-7.

Gailani MR, Stahle-Backdahl M, Leffell DJ, Glynn M, Zaphiropoulos PG, Pressman C, Unden AB, Dean M, Brash DE, Bale AE, Toftgard R.

The role of the human homologue of Drosophila patched in sporadic basal cell carcinomas. Nat Genet. 1996 Sep;14(1):78-81.

Ghali L, Wong ST, Green J, Tidman N, Quinn AG.

Gli1 protein is expressed in basal cell carcinomas, outer root sheath keratinocytes and a subpopulation of mesenchymal cells in normal human skin.

J Invest Dermatol. 1999 Oct;113(4):595-9.

Gorlin RJ.

Nevoid basal cell carcinoma syndrome.

Dermatol Clin. 1995 Jan;13(1):113-25. .

Gupta D, Middleton LP, Whitaker MJ, Abrams J.

Comparison of fluorescence and chromogenic in situ hybridization for detection of HER-2/neu oncogene in breast cancer.

Am J Clin Pathol. 2003 Mar;119(3):381-7. 
Hahn H, Wicking C, Zaphiropoulous PG, Gailani MR, Shanley S, Chidambaram A, Vorechovsky I, Holmberg E, Unden AB, Gillies S, Negus K, Smyth I, Pressman C, Leffell DJ, Gerrard B, Goldstein AM, Dean M, Toftgard R, Chenevix-Trench G, Wainwright B, Bale AE. Mutations of the human homolog of Drosophila patched in the nevoid basal cell carcinoma syndrome.

Cell. 1996a Jun 14;85(6):841-51.

Hahn H, Christiansen J, Wicking C, Zaphiropoulos PG, Chidambaram A, Gerrard B, Vorechovsky I, Bale AE, Toftgard R, Dean M, Wainwright B.

A mammalian patched homolog is expressed in target tissues of sonic hedgehog and maps to a region associated with developmental abnormalities.

J Biol Chem. 1996b May 24;271(21):12125-8.

Hahn H, Wojnowski L, Zimmer AM, Hall J, Miller G, Zimmer A.

Rhabdomyosarcomas and radiation hypersensitivity in a mouse model of Gorlin syndrome.

Nat Med. 1998 May;4(5):619-22.

Hahn H, Wojnowski L, Miller G, Zimmer A.

The patched signaling pathway in tumorigenesis and development: lessons from animal models.

J Mol Med. 1999 Jun;77(6):459-68.

Hahn H, Wojnowski L, Specht K, Kappler R, Calzada-Wack J, Potter D, Zimmer A, Muller U, Samson E, Quintanilla-Martinez L, Zimmer A.

Patched target Igf 2 is indispensable for the formation of medulloblastoma and rhabdomyosarcoma.

J Biol Chem. 2000 Sep 15;275(37):28341-4.

Hahn H, Nitzki F, Schorban T, Hemmerlein B, Threadgill D, Rosemann M.

Genetic mapping of a Ptch1-associated rhabdomyosarcoma susceptibility locus on mouse chromosome 2.

Genomics. 2004 Nov;84(5):853-8.

Hallikas O, Palin K, Sinjushina N, Rautiainen R, Partanen J, Ukkonen E, Taipale J.

Genome-wide prediction of mammalian enhancers based on analysis of transcription-factor binding affinity.

Cell. 2006 Jan 13;124(1):47-59.

Hanahan D, Weinberg RA.

The hallmarks of cancer.

Cell. 2000 Jan 7;100(1):57-70.

Hanahan D.

Studies on transformation of Escherichia coli with plasmids.

J Mol Biol. 1983 Jun 5;166(4):557-80.

Hayatsu H, Wataya Y, Kai K, Iida S.

Reaction of sodium bisulfite with uracil, cytosine, and their derivatives.

Biochemistry. $1970 \mathrm{Jul}$ 7;9(14):2858-65.

Herman JG, Baylin SB.

Gene silencing in cancer in association with promoter hypermethylation.

N Engl J Med. 2003 Nov 20;349(21):2042-54. 
Ho KS, Scott MP.

Sonic hedgehog in the nervous system: functions, modifications and mechanisms.

Curr Opin Neurobiol. 2002 Feb;12(1):57-63.

Holland PM, Abramson RD, Watson R, Gelfand DH.

Detection of Specific Polymerase Chain Reaction Product by Utilizing the 5' $\rightarrow 3{ }^{`}$ Exonuclease Activity of Thermus aquaticus DNA polymerase.

PNAS. 1991; 88: 7276-7280

Hooper JE, Scott MP.

The Drosophila patched gene encodes a putative membrane protein required for segmental patterning.

Cell. 1989 Nov 17;59(4):751-65.

$\mathrm{Hu} \mathrm{JF}, \mathrm{Vu} \mathrm{TH}$, Hoffman AR.

Differential biallelic activation of three insulin-like growth factor II promoters in the mouse central nervous system.

Mol Endocrinol. 1995 May;9(5):628-36.

$\mathrm{Hu}$ JF, Vu TH, Hoffman AR.

Promoter-specific modulation of insulin-like growth factor II genomic imprinting by inhibitors of DNA methylation.

J Biol Chem. 1996 Jul 26;271(30):18253-62.

Hu JF, Nguyen PH, Pham NV, Vu TH, Hoffman AR.

Modulation of Igf2 genomic imprinting in mice induced by 5-azacytidine, an inhibitor of DNA methylation.

Mol Endocrinol. 1997aDec;11(13):1891-8.

$\mathrm{Hu} \mathrm{JF}, \mathrm{Vu} \mathrm{TH}$, Hoffman AR.

Genomic deletion of an imprint maintenance element abolishes imprinting of both insulin-like growth factor II and H19.

J Biol Chem. 1997bAug 15;272(33):20715-20.

Inaba S, Li C, Shi YE, Song DQ, Jiang JD, Liu J.

Synuclein gamma inhibits the mitotic checkpoint function and promotes chromosomal instability of breast cancer cells.

Breast Cancer Res Treat. 2005 Nov;94(1):25-35.

Ishihara K, Hatano N, Furuumi H, Kato R, Iwaki T, Miura K, Jinno Y, Sasaki H.

Comparative genomic sequencing identifies novel tissue-specific enhancers and sequence elements for methylation-sensitive factors implicated in Igf2/H19 imprinting.

Genome Res. 2000 May;10(5):664-71.

Issa JP.

CpG island methylator phenotype in cancer.

Nat Rev Cancer. 2004 Dec;4(12):988-93.

Jaenisch R.

DNA methylation and imprinting: why bother?

Trends Genet. 1997 Aug;13(8):323-9. 
Jirtle RL.

IGF2 loss of imprinting: a potential heritable risk factor for colorectal cancer.

Gastroenterology. 2004 Apr;126(4):1190-3.

Johnson RL, Rothman AL, Xie J, Goodrich LV, Bare JW, Bonifas JM, Quinn AG, Myers RM, Cox DR, Epstein EH Jr, Scott MP.

Human homolog of patched, a candidate gene for the basal cell nevus syndrome.

Science. 1996 Jun 14;272(5268):1668-71.

Johnson RL, Milenkovic L, Scott MP.

In vivo functions of the patched protein: requirement of the $C$ terminus for target gene inactivation but not Hedgehog sequestration.

Mol Cell. 2000 Aug;6(2):467-78.

Jones PA, Taylor SM.

Cellular differentiation, cytidine analogs and DNA methylation.

Cell. 1980 May;20(1):85-93.

Jones PA, Baylin SB.

The fundamental role of epigenetic events in cancer.

Nat Rev Genet. 2002 Jun;3(6):415-28.

Kanduri C, Holmgren C, Pilartz M, Franklin G, Kanduri M, Liu L, Ginjala V, Ulleras E, Mattsson R, Ohlsson R.

The 5'flank of mouse H19 in an unusual chromatin conformation unidirectionally blocks enhancer-promoter communication.

Curr Biol. 2000a Apr 20;10(8):449-57.

Kanduri C, Pant V, Loukinov D, Pugacheva E, Qi CF, Wolffe A, Ohlsson R, Lobanenkov VV. Functional association of CTCF with the insulator upstream of the $\mathrm{H} 19$ gene is parent of origin-specific and methylation-sensitive.

Curr Biol. 2000b Jul 13;10(14):853-6.

Kappler R, Bauer R, Calzada-Wack J, Rosemann M, Hemmerlein B, Hahn H.

Profiling the molecular difference between Patched-and p53-dependent rhabdomyosarcoma.

Oncogene. 2004 Nov 18;23(54):8785-95.

Kappler R, Calzada-Wack J, Schnitzbauer U, Koleva M, Herwig A, Piontek G, Graedler F, Adamski J, Heinzmann U, Schlegel J, Hemmerlein B, Quintanilla-Martinez L, Hahn H.

Molecular characterization of Patched-associated rhabdomyosarcoma.

J Pathol. 2003 Jul;200(3):348-56.

Kas K, Wlodarska I, Meyen E, Van den Berghe H, Van de Ven WJ.

Assignment of the gene encoding human Kruppel-related zinc finger protein 4 (GLI4) to 8q24.3 by fluorescent in situ hybridization.

Cytogenet Cell Genet. 1996;72(4):297-8.

Kimura H, Stephen D, Joyner A, Curran T

Gli1 is important for medulloblastoma formation in Ptc1+/- mice.

Oncogene. 2005 Jun 9;24(25):4026-36. 
Kinzler KW, Bigner SH, Bigner DD, Trent JM, Law ML, O'Brien SJ, Wong AJ, Vogelstein B. Identification of an amplified, highly expressed gene in a human glioma.

Science. 1987 Apr 3;236(4797):70-3.

Kinzler KW, Vogelstein B.

The GLI gene encodes a nuclear protein which binds specific sequences in the human genome. Mol Cell Biol. 1990 Feb;10(2):634-42.

Knudson AG Jr.

Mutation and cancer: statistical study of retinoblastoma.

Proc Natl Acad Sci U S A. 1971 Apr;68(4):820-3.

Ko HW, Jiang J, Edery I.

Role for Slimb in the degradation of Drosophila Period protein phosphorylated by Doubletime. Nature. 2002 Dec 12;420(6916):673-8. Epub 2002 Nov 20.

Lamonerie T, Lavialle C, de Galle B, Binoux M, Brison O.

Constitutive or inducible overexpression of the IGF-2 gene in cells of a human colon carcinoma cell line.

Exp Cell Res. 1995 Feb;216(2):342-51.

Lee JJ, von Kessler DP, Parks S, Beachy PA.

Secretion and localized transcription suggest a role in positional signaling for products of the segmentation gene hedgehog.

Cell. 1992 Oct 2;71(1):33-50.

Lewis A, Murrell A.

Genomic imprinting: CTCF protects the boundaries.

Curr Biol. 2004 Apr 6;14(7):R284-6.

Li E, Beard C, Forster AC, Bestor TH, Jaenisch R.

DNA methylation, genomic imprinting, and mammalian development.

Cold Spring Harb Symp Quant Biol. 1993a58:297-305.

Li E, Beard C, Jaenisch R.

Role for DNA methylation in genomic imprinting.

Nature. 1993bNov 25;366(6453):362-5.

Li J, Saunders JC, Gilmour RS, Silver M, Fowden AL.

Insulin-like growth factor-II messenger ribonucleic acid expression in fetal tissues of the sheep during late gestation: effects of cortisol.

Endocrinology. 1993 May;132(5):2083-9.

Livak KJ, Flood SJ, Marmaro J, Giusti W, Deetz K.

Oligonucleotides with fluorescent dyes at opposite ends provide a quenched probe system useful for detecting PCR product and nucleic acid hybridization.

PCR Methods Appl. 1995 Jun;4(6):357-62. 
Louro ID, Bailey EC, Li X, South LS, McKie-Bell PR, Yoder BK, Huang CC, Johnson MR, Hill AE, Johnson RL, Ruppert JM.

Comparative gene expression profile analysis of GLI and c-MYC in an epithelial model of malignant transformation.

Cancer Res. 2002 Oct 15;62(20):5867-73.

Macaluso M, Montanari M, Cinti C, Giordano A.

Modulation of cell cycle components by epigenetic and genetic events.

Semin Oncol. 2005 Oct;32(5):452-7.

Marigo V, Davey RA, Zuo Y, Cunningham JM, Tabin CJ.

Biochemical evidence that patched is the Hedgehog receptor.

Nature. 1996a Nov 14;384(6605):176-9.

Marigo V, Johnson RL, Vortkamp A, Tabin CJ.

Sonic hedgehog differentially regulates expression of GLI and GLI3 during limb development.

Dev Biol. 1996b Nov 25;180(1):273-83.

Marigo V, Scott MP, Johnson RL, Goodrich LV, Tabin CJ.

Conservation in hedgehog signaling: induction of a chicken patched homolog by Sonic hedgehog in the developing limb.

Development. 1996c Apr;122(4):1225-33.

Marigo V, Tabin CJ.

Regulation of patched by sonic hedgehog in the developing neural tube.

Proc Natl Acad Sci U S A. 1996d Sep 3;93(18):9346-51.

Matsumoto H, Hayashi S, Shioura H, Ohtsubo T, Ohnishi T, Kano E.

Suppression of heat-induced hsp72 accumulation by cisplatin in human glioblastoma cells.

Cancer Lett. 1996 Dec 20;110(1-2):253-7.

Merlino G, Helman LJ.

Rhabdomyosarcoma--working out the pathways.

Oncogene. 1999 Sep 20;18(38):5340-8.

Ming JE, Kaupas ME, Roessler E, Brunner HG, Golabi M, Tekin M, Stratton RF, Sujansky E, Bale SJ, Muenke M.

Mutations in PATCHED-1, the receptor for SONIC HEDGEHOG, are associated with holoprosencephaly.

Hum Genet. 2002 Apr;110(4):297-301. Epub 2002 Mar 2. Erratum in: Hum Genet 2002

Oct;111(4-5):464.

Mohler J, Vani K.

Molecular organization and embryonic expression of the hedgehog gene involved in cell-cell communication in segmental patterning of Drosophila.

Development. 1992 Aug;115(4):957-71.

Momparler RL, Bovenzi V.

DNA methylation and cancer.

J Cell Physiol. 2000 May;183(2):145-54. 
Moore T, Constancia M, Zubair M, Bailleul B, Feil R, Sasaki H, Reik W.

Multiple imprinted sense and antisense transcripts, differential methylation and tandem repeats in a putative imprinting control region upstream of mouse Igf2.

Proc Natl Acad Sci U S A. 1997 Nov 11;94(23):12509-14.

Moulton T, Crenshaw T, Hao Y, Moosikasuwan J, Lin N, Dembitzer F, Hensle T, Weiss L, McMorrow L, Loew T, et al.

Epigenetic lesions at the H19 locus in Wilms' tumour patients.

Nat Genet. 1994 Jul;7(3):440-7.

Moulton T, Chung WY, Yuan L, Hensle T, Waber P, Nisen P, Tycko B.

Genomic imprinting and Wilms' tumor.

Med Pediatr Oncol. 1996 Nov;27(5):476-83.

Murrell A, Heeson S, Bowden L, Constancia M, Dean W, Kelsey G, Reik W.

An intragenic methylated region in the imprinted Igf 2 gene augments transcription.

EMBO Rep. 2001 Dec;2(12):1101-6. Epub 2001 Nov 21.

Nakagawa H, Chadwick RB, Peltomaki P, Plass C, Nakamura Y, de La Chapelle A.

Loss of imprinting of the insulin-like growth factor II gene occurs by biallelic methylation in a core region of H19-associated CTCF-binding sites in colorectal cancer.

Proc Natl Acad Sci U S A. 2001 Jan 16;98(2):591-6. Epub 2000 Dec 19.

Nakamura N, Takenaga K.

Hypomethylation of the metastasis-associated S100A4 gene correlates with gene activation in human colon adenocarcinoma cell lines.

Clin Exp Metastasis. 1998 Jul;16(5):471-9.

Nanni L, Ming JE, Bocian M, Steinhaus K, Bianchi DW, Die-Smulders C, Giannotti A, Imaizumi K, Jones KL, Campo MD, Martin RA, Meinecke P, Pierpont ME, Robin NH, Young ID, Roessler E, Muenke M.

The mutational spectrum of the sonic hedgehog gene in holoprosencephaly: SHH mutations cause a significant proportion of autosomal dominant holoprosencephaly.

Hum Mol Genet. 1999 Dec;8(13):2479-88.

Nichols KE, Re GG, Yan YX, Garvin AJ, Haber DA.

WT1 induces expression of insulin-like growth factor 2 in Wilms' tumor cells.

Cancer Res. 1995 Oct 15;55(20):4540-3.

Nüsslein-Volhard C, Wieschaus E.

Mutations affecting segment number and polarity in Drosophila.

Nature. 1980 Oct 30;287(5785):795-801.

Nybakken K, Perrimon N.

Hedgehog signal transduction: recent findings.

Curr Opin Genet Dev. 2002 Oct;12(5):503-11.

Oden ZM, Selvitelli DM, Bouxsein ML.

Effect of local density changes on the failure load of the proximal femur.

J Orthop Res. 1999 Sep;17(5):661-7. 
Ogawa O, Becroft DM, Morison IM, Eccles MR, Skeen JE, Mauger DC, Reeve AE.

Constitutional relaxation of insulin-like growth factor II gene imprinting associated with

Wilms' tumour and gigantism.

Nat Genet. 1993 Dec;5(4):408-12.

Ohlmeyer JT, Kalderon D.

Hedgehog stimulates maturation of Cubitus interruptus into a labile transcriptional activator.

Nature. 1998 Dec 24-31;396(6713):749-53.

Pavelic K, Bukovic D, Pavelic J.

The role of insulin-like growth factor 2 and its receptors in human tumors.

Mol Med. 2002 Dec;8(12):771-80.

Pedone PV, Cosma MP, Ungaro P, Colantuoni V, Bruni CB, Zarrilli R, Riccio A.

Parental imprinting of rat insulin-like growth factor II gene promoters is coordinately

regulated.

J Biol Chem. 1994a Sep 30;269(39):23970-5.

Pedone PV, Tirabosco R, Cavazzana AO, Ungaro P, Basso G, Luksch R, Carli M, Bruni CB, Frunzio R, Riccio A.

Mono- and bi-allelic expression of insulin-like growth factor II gene in human muscle tumors. Hum Mol Genet. 1994b Jul;3(7):1117-21.

Pietsch T, Koch A, Wiestler OD.

Molecular genetic studies in medulloblastomas: evidence for tumor suppressor genes at the chromosomal regions 1q31-32 and 17p13.

Klin Padiatr. 1997a Jul-Aug;209(4):150-5.

Pietsch T, Waha A, Koch A, Kraus J, Albrecht S, Tonn J, Sorensen N, Berthold F, Henk B, Schmandt N, Wolf HK, von Deimling A, Wainwright B, Chenevix-Trench G, Wiestler OD, Wicking C.

Medulloblastomas of the desmoplastic variant carry mutations of the human homologue of Drosophila patched.

Cancer Res. 1997b Jun 1;57(11):2085-8.

Polakis P.

Wnt signaling and cancer.

Genes Dev. 2000 Aug 1;14(15):1837-51.

Pomeroy SL, Tamayo P, Gaasenbeek M, Sturla LM, Angelo M, McLaughlin ME, Kim JY, Goumnerova LC, Black PM, Lau C, Allen JC, Zagzag D, Olson JM, Curran T, Wetmore C, Biegel JA, Poggio T, Mukherjee S, Rifkin R, Califano A, Stolovitzky G, Louis DN, Mesirov JP, Lander ES, Golub TR.

Prediction of central nervous system embryonal tumour outcome based on gene expression. Nature. 2002 Jan 24;415(6870):436-42.

Pravtcheva DD, Wise TL.

Metastasizing mammary carcinomas in $H 19$ enhancers-Igf2 transgenic mice.

J Exp Zool. 1998 May 1;281(1):43-57. 
Randhawa GS, Cui H, Barletta JA, Strichman-Almashanu LZ, Talpaz M, Kantarjian H, Deisseroth AB, Champlin RC, Feinberg AP.

Loss of imprinting in disease progression in chronic myelogenous leukemia.

Blood. 1998 May 1;91(9):3144-7.

Reeve AE, Eccles MR, Wilkins RJ, Bell GI, Millow LJ.

Expression of insulin-like growth factor-II transcripts in Wilms' tumour.

Nature. 1985 Sep 19-25;317(6034):258-60.

Regl G, Kasper M, Schnidar H, Eichberger T, Neill GW, Philpott MP, Esterbauer H, HauserKronberger C, Frischauf AM, Aberger F.

Activation of the BCL2 promoter in response to Hedgehog/GLI signal transduction is predominantly mediated by GLI2.

Cancer Res. 2004 Nov 1;64(21):7724-31.

Reik W, Maher ER.

Imprinting in clusters: lessons from Beckwith-Wiedemann syndrome.

Trends Genet. 1997 Aug;13(8):330-4.

Reik W, Constancia M, Dean W, Davies K, Bowden L, Murrell A, Feil R, Walter J, Kelsey G. Igf 2 imprinting in development and disease.

Int J Dev Biol. 2000;44(1):145-50.

Reik W, Dean W, Walter J.

Epigenetic reprogramming in mammalian development.

Science. 2001a Aug 10;293(5532):1089-93.

Reik W, Dean W.

DNA methylation and mammalian epigenetics.

Electrophoresis. 2001b Aug;22(14):2838-43.

Rietveld LE, Holthuizen PE, Sussenbach JS.

Identification of a key regulatory element for the basal activity of the human insulin-like growth factor II gene promoter P3.

Biochem J. 1997 Nov 1;327 ( Pt 3):689-97.

Roberts WM, Douglass EC, Peiper SC, Houghton PJ, Look AT.

Amplification of the gli gene in childhood sarcomas.

Cancer Res. 1989 Oct 1;49(19):5407-13.

Robertson KD, Wolffe AP.

DNA methylation in health and disease.

Nat Rev Genet. 2000 Oct;1(1):11-9.

Robertson KD.

DNA methylation, methyltransferases, and cancer.

Oncogene. 2001 May 28;20(24):3139-55.

Roessler E, Belloni E, Gaudenz K, Jay P, Berta P, Scherer SW, Tsui LC, Muenke M.

Mutations in the human Sonic Hedgehog gene cause holoprosencephaly.

Nat Genet. 1996 Nov;14(3):357-60. 
Rotwein P, Hall LJ.

Evolution of insulin-like growth factor II: characterization of the mouse IGF-II gene and identification of two pseudo-exons.

DNA Cell Biol. 1990 Dec;9(10):725-35.

Rotwein P.

Structure, evolution, expression and regulation of insulin-like growth factors I and II.

Growth Factors. 1991;5(1):3-18.

Ruiz i Altaba A.

Gli proteins and Hedgehog signaling: development and cancer.

Trends Genet. 1999a Oct;15(10):418-25.

Ruiz i Altaba A.

Gli proteins encode context-dependent positive and negative functions: implications for development and disease.

Development. 1999b Jun;126(14):3205-16.

Ruiz i Altaba A.

The works of GLI and the power of hedgehog.

Nat Cell Biol. 1999c Oct;1(6):E147-8.

Ruiz i Altaba A, Palma V, Dahmane N.

Hedgehog-Gli signalling and the growth of the brain.

Nat Rev Neurosci. 2002a Jan;3(1):24-33.

Ruiz i Altaba A, Sanchez P, Dahmane N.

Gli and hedgehog in cancer: tumours, embryos and stem cells.

Nat Rev Cancer. 2002b May;2(5):361-72.

Ruppert JM, Vogelstein B, Arheden K, Kinzler KW.

GLI3 encodes a 190-kilodalton protein with multiple regions of GLI similarity.

Mol Cell Biol. 1990 Oct;10(10):5408-15.

Sambrook F, Fritsch EF, Maniatis T.

Molecular Cloning. A Laborytory Manual.

Cold Spring Harbor Laborytory. 1989; Cold Spring Harbor 2.

Sanger F, Nicklen S, Coulson AR.

DNA sequencing with chain-terminating inhibitors.

Proc Natl Acad Sci U S A. 1977 Dec;74(12):5463-7.

Sasaki H, Jones PA, Chaillet JR, Ferguson-Smith AC, Barton SC, Reik W, Surani MA.

Parental imprinting: potentially active chromatin of the repressed maternal allele of the mouse insulin-like growth factor II (Igf2) gene.

Genes Dev. 1992 Oct;6(10):1843-56.

Sasaki H, Shimozaki K, Zubair M, Aoki N, Ohta K, Hatano N, Moore T, Feil R, Constancia M, Reik W, Rotwein P.

Nucleotide sequence of a $28-\mathrm{kb}$ mouse genomic region comprising the imprinted Igf 2 gene.

DNA Res. 1996 Oct 31;3(5):331-5. 
Sasaki H, Nishizaki Y, Hui C, Nakafuku M, Kondoh H.

Regulation of Gli2 and Gli3 activities by an amino-terminal repression domain: implication of Gli2 and Gli3 as primary mediators of Shh signaling.

Development. 1999 Sep;126(17):3915-24.

Schneid H, Holthuizen PE, Sussenbach JS.

Differential promoter activation in two human insulin-like growth factor-II-producing tumor cell lines.

Endocrinology. 1993 Mar;132(3):1145-50.

Schneid H, Seurin D, Noguiez P, Le Bouc Y.

Abnormalities of insulin-like growth factor (IGF-I and IGF-II) genes in human tumor tissue.

Growth Regul. 1992 Mar;2(1):45-54.

Schneid H, Seurin D, Vazquez MP, Gourmelen M, Cabrol S, Le Bouc Y.

Parental allele specific methylation of the human insulin-like growth factor II gene and

Beckwith-Wiedemann syndrome.

J Med Genet. 1993 May;30(5):353-62.

Shapiro R, Braverman B, Louis JB, Servis RE.

Nucleic acid reactivity and conformation. II. Reaction of cytosine and uracil with sodium bisulfite.

J Biol Chem. 1973 Jun 10;248(11):4060-4.

Shapiro R, Braverman B, Louis JB, Servis RE.

Nucleic acid reactivity and conformation. II. Reaction of cytosine and uracil with sodium bisulfite.

J Biol Chem. 1973 Jun 10;248(11):4060-4.

Singal R, Grimes SR.

Microsoft Word macro for analysis of cytosine methylation by the bisulfite deamination reaction.

Biotechniques. $2001 \mathrm{Jan} ; 30(1): 116-20$.

Slatter RE, Elliott M, Welham K, Carrera M, Schofield PN, Barton DE, Maher ER.

Mosaic uniparental disomy in Beckwith-Wiedemann syndrome.

J Med Genet. 1994 Oct;31(10):749-53.

Song S, Byrd JC, Mazurek N, Liu K, Koo JS, Bresalier RS.

Galectin-3 modulates MUC2 mucin expression in human colon cancer cells at the level of transcription via AP-1 activation.

Gastroenterology. 2005 Nov;129(5):1581-91.

Southern EM.

Detection of specific sequences among DNA fragments separated by gel electrophoresis. J Mol Biol. 1975 Nov 5;98(3):503-17.

Stanbridge EJ.

Human tumor suppressor genes.

Annu Rev Genet. 1990a24:615-57. 
Stanbridge EJ.

Identifying tumor suppressor genes in human colorectal cancer.

Science. 1990bJan 5;247(4938):12-3.

Steenman MJ, Rainier S, Dobry CJ, Grundy P, Horon IL, Feinberg AP.

Loss of imprinting of IGF2 is linked to reduced expression and abnormal methylation of H19 in Wilms' tumour.

Nat Genet. 1994 Jul;7(3):433-9. Erratum in: Nat Genet 1994 Oct;8(2):203.

Strachan T, Read AP.

Molekulare Humangenetik.

Spektrum Akademischer Verlag Heidelberg. 1996

Strichman-Almashanu LZ, Lee RS, Onyango PO, Perlman E, Flam F, Frieman MB, Feinberg AP.

A genome-wide screen for normally methylated human $C p G$ islands that can identify novel imprinted genes.

Genome Res. 2002 Apr;12(4):543-54.

Sullivan MJ, Taniguchi T, Jhee A, Kerr N, Reeve AE.

Relaxation of IGF2 imprinting in Wilms tumours associated with specific changes in IGF2 methylation.

Oncogene. 1999 Dec 9;18(52):7527-34.

Sussenbach JS, Steenbergh PH, Jansen E, Holthuizen P, Meinsma D, van Dijk MA, Gloudemans T.

Structural and regulatory aspects of the human genes encoding IGF-I and-II.

Adv Exp Med Biol. 1991;293:1-14.

Sussenbach JS, Steenbergh PH, Holthuizen P.

Structure and expression of the human insulin-like growth factor genes.

Growth Regul. 1992 Mar;2(1):1-9.

Sutcliffe JS, Nakao M, Christian S, Orstavik KH, Tommerup N, Ledbetter DH, Beaudet AL. Deletions of a differentially methylated $C p G$ island at the SNRPN gene define a putative imprinting control region.

Nat Genet. 1994 Sep;8(1):52-8.

Szabo PE, Mann JR.

Biallelic expression of imprinted genes in the mouse germ line: implications for erasure, establishment, and mechanisms of genomic imprinting.

Genes Dev. 1995aAug 1;9(15):1857-68.

Szabo PE, Mann JR.

Allele-specific expression and total expression levels of imprinted genes during early mouse development: implications for imprinting mechanisms.

Genes Dev. 1995bDec 15;9(24):3097-108.

Szabo P, Tang SH, Rentsendorj A, Pfeifer GP, Mann JR.

Maternal-specific footprints at putative CTCF sites in the $H 19$ imprinting control region give evidence for insulator function.

Curr Biol. 2000 May 18;10(10):607-10. 
Tabata T, Sakaguchi K, Tajima T, Suzuki AS.

Comparative study of sequential expression of the organizer-related genes in normal Cynops pyrrhogaster embryos and mesodermalized ectoderm.

Dev Growth Differ. 2001 Aug;43(4):351-9.

Taipale J, Chen JK, Cooper MK, Wang B, Mann RK, Milenkovic L, Scott MP, Beachy PA. Effects of oncogenic mutations in Smoothened and Patched can be reversed by cyclopamine. Nature. 2000 Aug 31;406(6799):1005-9.

Thorvaldsen JL, Duran KL, Bartolomei MS.

Deletion of the $H 19$ differentially methylated domain results in loss of imprinted expression of H19 and Igf2.

Genes Dev. 1998 Dec 1;12(23):3693-702.

Toftgard R.

Hedgehog signalling in cancer.

Cell Mol Life Sci. 2000 Nov;57(12):1720-31.

Tojo M, Kiyosawa H, Iwatsuki K, Nakamura K, Kaneko F.

Expression of the GLI2 oncogene and its isoforms in human basal cell carcinoma.

Br J Dermatol. 2003 May;148(5):892-7.

Tostar U, Malm CJ, Meis-Kindblom JM, Kindblom LG, Toftgard R, Unden AB.

Deregulation of the hedgehog signalling pathway: a possible role for the PTCH and SUFU genes in human rhabdomyoma and rhabdomyosarcoma development.

J Pathol. 2006 Jan;208(1):17-25.

Uhmann A, Ferch U, Bauer R, Tauber S, Arziman Z, Chen C, Hemmerlein B, Wojnowski L, Hahn $\mathrm{H}$.

A model for PTCH1/Ptch1-associated tumors comprising mutational inactivation and gene silencing.

Int J Oncol. 2005 Dec;27(6):1567-75.

van den Heuvel M, Ingham PW.

Smoothening' the path for hedgehogs.

Trends Cell Biol. 1996 Dec;6(12):451-3.

van Dijk MA, van Schaik FM, Bootsma HJ, Holthuizen P, Sussenbach JS.

Initial characterization of the four promoters of the human insulin-like growth factor II gene.

Mol Cell Endocrinol. 1991 Oct;81(1-3):81-94.

$\mathrm{Vu} \mathrm{TH}$, Hoffman A.

Alterations in the promoter-specific imprinting of the insulin-like growth factor-II gene in

Wilms' tumor.

J Biol Chem. 1996 Apr 12;271(15):9014-23.

Wang TP, Sable HZ, Lampen JO.

Enzymatic deamination of cytosine nucleosides.

J Biol Chem. 1950 May;184(1):17-28. 
Wang RY, Gehrke CW, Ehrlich M.

Comparison of bisulfite modification of 5-methyldeoxycytidine and deoxycytidine residues.

Nucleic Acids Res. 1980 Oct 24;8(20):4777-90.

Wang ZY, Baker TL, Keith IM, Mitchell GS, Bisgard GE.

Continuous, but not episodic hypoxia, induces CREB phosphorylation in rat carotid body type I cells.

Adv Exp Med Biol. 2000;475:631-5.

Ward A, Fisher R, Richardson L, Pooler JA, Squire S, Bates P, Shaposhnikov R, Hayward N, Thurston M, Graham CF.

Genomic regions regulating imprinting and insulin-like growth factor-II promoter 3 activity in transgenics: novel enhancer and silencer elements.

Genes Funct. 1997 Feb;1(1):25-36.

Weinberg RA.

Tumor suppressor genes.

Science. 1991 Nov 22;254(5035):1138-46.

Werner CA, Dohner H, Joos S, Trumper LH, Baudis M, Barth TF, Ott G, Moller P, Lichter P, Bentz M.

High-level DNA amplifications are common genetic aberrations in B-cell neoplasms.

Am J Pathol. 1997 Aug;151(2):335-42.

Wetmore C, Eberhart DE, Curran T.

The normal patched allele is expressed in medulloblastomas from mice with heterozygous germ-line mutation of patched.

Cancer Res. 2000 Apr 15;60(8):2239-46.

Wexler LH, Garvin JH Jr.

Pediatric nonrhabdomyosarcoma soft tissue sarcomas: progress on clinical and biologic fronts.

J Pediatr. 1997 Oct;131(4):508-9.

Yoder JA, Walsh CP, Bestor TH.

Cytosine methylation and the ecology of intragenomic parasites.

Trends Genet. 1997 Aug;13(8):335-40.

Yoon JW, Kita Y, Frank DJ, Majewski RR, Konicek BA, Nobrega MA, Jacob H, Walterhouse $\mathrm{D}$, Iannaccone P.

Gene expression profiling leads to identification of GLI1-binding elements in target genes and a role for multiple downstream pathways in GLI1-induced cell transformation.

J Biol Chem. 2002 Feb 15;277(7):5548-55. Epub 2001 Nov 21.

Young MM, Kinsella TJ, Miser JS, Triche TJ, Glaubiger DL, Steinberg SM, Glatstein E.

Treatment of sarcomas of the chest wall using intensive combined modality therapy.

Int J Radiat Oncol Biol Phys. 1989 Jan;16(1):49-57.

Zarrilli R, Bruni CB, Riccio A.

Multiple levels of control of insulin-like growth factor gene expression.

Mol Cell Endocrinol. 1994 May;101(1-2):R1-14. 
Zatkova A, Rouillard JM, Hartmann W, Lamb BJ, Kuick R, Eckart M, von Schweinitz D, Koch A, Fonatsch C, Pietsch T, Hanash SM, Wimmer K.

Amplification and overexpression of the IGF 2 regulator PLAG1 in hepatoblastoma.

Genes Chromosomes Cancer. 2004 Feb;39(2):126-37.

Zeller R

It takes time to make a pinky: unexpected insights into how SHH patterns vertebrate digits. Sci STKE. 2004 Nov 16;2004(259):pe53.

Zemel S, Bartolomei MS, Tilghman SM.

Physical linkage of two mammalian imprinted genes, H19 and insulin-like growth factor 2. Nat Genet. 1992 Sep;2(1):61-5. 


\section{Danksagung}

Herrn Prof. Dr. Wolfgang Engel danke ich für die Übernahme des Referates und für die Möglichkeit, im Institut für Humangenetik meine Doktorarbeit anfertigen zu können.

Besonderer Dank gilt Frau PD Dr. Sigrid Hoyer-Fender für die Übernahme des Korreferates, für viele freundliche Gespräche und hilfreiche Ratschläge in Bezug auf Transfektionsexperimente.

Meinen ganz besonderen Dank möchte ich Frau Prof. Dr. Heidi Hahn aussprechen, die es mir ermöglichte, in ihrer Arbeitsgruppe in diesem interessanten und komplexen Thema arbeiten zu können. Ihr stetes Interesse an den Ergebnissen und dem Fortgang des Projektes haben mich begeistert und motiviert.

Großer Dank gilt Astrid Herwig für die angenehme Zusammenarbeit während der letzten Phase der praktischen Arbeit und für die Hilfe in zahlreichen technischen Fragen. Ich danke Dr. Frauke Petry für die freundliche Zusammenarbeit und für die hilfreichen Korrekturvorschläge in einer schwierigen Phase der Arbeit. Herrn PD. Dr. Roland Kappler und Frau Dr. Milena Koleva danke ich für viele fruchtbare Diskussionen und wissenschaftliche Ideen. Ebenfalls großer Dank gilt Alexandra Pahl, die mich mit Fachkompetenz und viel Gefühl in das Leben der Mäuse einweihte.

Des Weiteren möchte ich mich bei Dr. Arne Zibat, Ines Ecke, Frauke Nitzki und Ina Hess für die nette und kollegiale Atmosphäre im Labor bedanken. Anja Uhmann danke ich für die Unterstützung bei der Durchführung der TaqMan-Assays.

Cornelia Meineke und Dr. Mladen Tzvetkov aus der Abteilung Klinische Pharmakologie des Universitäts-Klinikums danke ich für die Unterstützung bei der Etablierung der BisulfitSequenzierung.

Dem Graduiertekolleg „Genetik der Entwicklung“ der Universität Göttingen danke ich für die Gewährung eines Promotionsstipendiums und für die Möglichkeit, durch zahlreiche Vorträge und Praktika wissenschaftliche Horizonte erweitern zu können.

Für die freundliche Aufnahme und zahlreiche Hilfestellungen danke ich den Mitarbeitern und Mitarbeiterinnen des Institutes für Humangenetik. 


\section{Lebenslauf und Publikationen}

\section{Persönliche Daten}

Regine Bauer

geboren am 28.11.1974 in Meerane (Sachsen)

\section{Schulbildung}

$1981-1990$

1990 - 1991

1991-1993

07/ 1993

\section{Freiwilliges soziales Jahr}

1993 - 1994

\section{Hochschulbildung \\ $1994-2001$}

$09 / 2001$

\section{Promotion}

\section{Stipendium}

$2002-2005$

\section{Publikationen}

$11 / 2004$

$12 / 2005$

\footnotetext{
2006 (in Vorbereitung) Bauer R., Hahn H.

Aberrant DNA methylation causes Gli dependen overexpression of Igf2 in Patched-associated tumors

2006 (in Vorbereitung) $\quad$ Bauer R., Pravtcheva D., Hahn H.

Optimized transfection of NIH/3T3 cells with cosmids using the

TransFectin ${ }^{\mathrm{TM}}$ lipid reagent

[invited technical note, Bio-Rad]
}

Schiller", Jena

Diplomarbeit, Thema:

„Etablierung eines real-time PCR-Systemes zur Quantifizierung der beiden Telomerease-Untereinheiten hTERT und hTR “

AG Prof. U. Claussen, Institut für Humangenetik und Anthropologie Diplom, Note ,sehr gut“"

Promotion, Thema:

Untersuchung des transkriptionellen Mechanismus der Igf2-

AG Prof. H. Hahn, Institut für Humangenetik an der Universität

Förderung im Rahmen des Graduiertenkollegs "Genetik der Entwicklung“ der Universität Göttingen

Kappler R., Bauer R., Calzada-Wrack J., Rosemann M., Hemmerlein B., Hahn H.

Profiling the molecular difference between Patched-and p53-

ent rhabdomyosarcoma.

Uhmann A., Ferch U., Bauer R., Tauber S., Arziman Z., Chen C., .emmerlein B., Wojnowski L., Hahn H.

inactivation and gene silencing.

Int J Oncol. 2005 Dec;27(6):1567-75 